DONALD MCGOVERN SALTER

Submitted for the degree of Doctor of Medicine Edinburgh University 1990

i

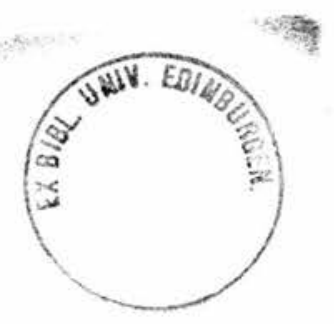




\section{DECLARATION}

I declare that the experiments described in this work were performed by me or carried out under my supervision and that this thesis was composed by myself. 


\section{ACKNOWLEDGEMENTS}

I wish to thank all of the staff of the Pathology Department, University of Edinburgh. In particular I wish to acknowledge the help, advice and encouragement of Dr Andrew Krajewski throughout this project and Dr Edna Dewar in the formative years.

I am extremely grateful to Liz Ramage, Eric Miller, Dave Cossar and scott Cunningham for technical assistance.

Both Professor Sir Alastair Currie and Professor Colin Bird have encouraged the undertaking and completion of this work.

I am grateful to the consultant haematologists and oncologists of Lothian, Borders and Fife Health Boards for access to clinical information on the patients included in this study. I am pleased to acknowledge the assistance of Dr's Tommy Sheehan, Gillian Turner and Robert Cuthbert for their help in obtaining the clinical data from patient's notes.

The advice and assistance of Dr Alec McLean and Miss Celia McIntyre was invaluable for statistical analyses.

This study was supported by a grant from the Melville Trust. 


\section{PUBLICATIONS}

Part of this work has already been published in a scientific journal:-

1) Salter DM, Krajewski AS, Cunningham S. (1988). Activation and differentiation antigen expression by B-cell non-Hodgkin's lymphoma. J Pathol 154:209-222.

2) Salter DM, Krajewski AS, Sheehan T, Turner G, Cuthbert RJG, Mclean A. (1989). Prognostic significance of activation and differentiation antigen expression in B-cell non-Hodgkin's lymphoma. J Pathol. 159: 211-220. 


\author{
Title Page \\ Declaration \\ Acknowledgements \\ Publications \\ Contents \\ Abstract
}

$i{ }^{i}$
$i i j$
$i v$
viii

1

CHAPTER 1: INTRODUCTION

1.1 ORGANISATION OF B CELLS IN PERIPHERAL LYMPHOID TISSUE

1.1.1 Lymph Nodes

1.1.2 Spleen

1.1.3 Mucosa Associated Lymphoid Tissue (MALT)

1.2 B CELL DEVELOPMENT AND MATURATION

1.2.1 Antigen-Independent Bone Marrow Maturation 5

1.2.2. Antigen-Dependent Peripheral B-cell Maturation

1.2.2.1 Primary Follicles and the Germinal Centre Reaction

1.2.2.2. Marginal Zone Cells and Centrocyte-like Cells 9

1.2.2.3 CD5 Positive Lymphocytes 10

1.2.3 Terminal Differentiation 10

1.3 THE RELATIONSHIP OF B-CELL PHENOTYPE TO ACTIVATION, GROWTH AND DIFFERENTIATION

1.4 STRUCTURE, FUNCTION AND DISTRIBUTION OF B-CELL SURFACE ANTIGENS

1.4.1 Pan B-Cell antigens

1.4.2 Restricted B-cell markers

1.4.3 Activation Associated antigens 21

$\begin{array}{ll}1.4 .4 \text { MHC Class II Molecules } & 26\end{array}$

1.5 NON-HODGKINS LYMPHOMA $\quad 27$

1.5.1 Historical Overview 27

1.5.2 Newer Classifications 28

1.5.3 Prognostic Factors 29

\section{CHAPTER 2 MATERIALS AND METHODS}

\subsection{CASES}

2.2 TISSUE COLLECTION AND HANDLING 34

2.3 IMMUNOHISTOCHEMICAL STAINING 34

2.3.1 Indirect Immunoperoxidase 35

2.3.2 Direct Immunofluorescence 36 
2.5 ASSESSMENT OF STAINING

2.6 PARAFFIN SECTION HISTOLOGY AND LYMPHOMA CLASSIFICATION

CHAPTER 3 PHENOTYPES OF NORMAL PERIPHERAL B-CELLS

\section{CHAPTER 4 ANTIGEN EXPRESSION BY B CELL NON-HODGKINS LYMPHOMA}

4.1 INTRODUCTION 68

4.2 MATERIALS AND METHODS $\quad 69$

4.2.1 Cases 69

4.2.2 Immunohistology 69

4.2.3 Antibodies $\quad 69$

4.3 RESULTS $\quad 69$

4.3.1 Lymphocytic lymphoma 69

4.3.2 Lymphoplasmacytic lymphoma 70

4.3.3 Prolymphocytic lymphoma 70

4.3.4 Hairy cell leukaemia 71

4.3.5 Centrocytic lymphoma 71

4.3.5 Follicular centroblastic/centrocytic 72

lymphomas

4.3.6 Diffuse centroblastic/centrocytic lymphoma 73

4.3.7 Centroblastic lymphoma 73

4.3.8 Immunoblastic lymphoma 74

4.3.9 Plasmacytic/Plasmablastic lymphoma 75

4.3.10 Lymphoblastic lymphoma 76

4.4 DIscussION 110 


\section{NON-HODGKIN'S LYMPHOMA}

5.2 MATERIALS AND METHODS

5.2.1 Cases and Clinical Data

5.2.2 Histology and Phenotyping

5.2.3 statistical Analyses

5.3.1 Histology and Clinical Features

5.3.2 Immunophenotype Analysis and Clinical

Correlation

5.3.3 Survival Analyses

5.3.3.1 Clinical Data

5.3.3.2 Histology

5.3.3.3 Immunophenotype

5.3.3.4 Multivariate Analysis 


\section{ABSTRACT}

Over the last few years there has been an explosion of the knowledge of normal B-cell physiology particularly in the area of control of B-cell activation, proliferation and differentiation. This has been augmented by the availability of a large number of monoclonal antibodies which recognise a wide range of molecules expressed at the cell surface by B-cells at different stages of activation and differentiation. Non-Hodgkin's lymphomas are believed to result from the uncontrolled proliferation and accumulation of B-cells arrested at different stages of differentiation. Currently used classifications of non-Hodgkin's lymphoma are based on this idea and morphologically equivalent normal and neoplastic cells may be identified. Monoclonal antibodies which detect surface antigens on B-cells may be used by immunohistological techniques to accurately phenotype both neoplastic and equivalent normal cells. Detailed phenotyping using a panel of antibodies against surface antigens may allow more accurate classification of non-Hodgkin's lymphoma and comparison with presumed normal equivalents. As many of the surface markers expressed by B-cells have been shown recently to be important in cell activation it is possible that their expression may be important in uncontrolled growth and have prognostic significance.

This investigation was undertaken in an attempt to evaluate the usefulness of such detailed phenotyping in the pathological diagnosis and classification of non-Hodgkin's lymphoma and to evaluate the prognostic significance of antigens whose expression was associated with cell proliferation and differentiation. 
The results show that there is extensive immunophenotypic heterogeneity in B-cell lymphomas. Differences in antigen expression are seen between cells of individual cases and between morphologically similar groups of tumours but certain patterns of antigen expression were present. CD antigens 5, 10, and 23 were expressed significantly more often by low grade lymphomas, CD5 expression being almost exclusive to lymphocytic and centrocytic groups. CD38, 4 F2 antigen and CD71 were more often expressed by high grade lymphoma.

The phenotypic heterogeneity exposed by detailed phenotyping creates difficulty for comparison with normal equivalents and mitigates against its use for diagnostic purposes. Nevertheless a limited panel of antibodies has been identified which would be suitable and useful for routine use. Although many of the antigens studied were known to be involved with the control of normal B-cell proliferation the expression of only two were shown to be of prognostic value. There was a significant correlation with survival and expression of $4 \mathrm{~F} 2$ antigen and CD71 (transferrin receptor). $4 \mathrm{~F} 2$ antigen and CD71 may identify a poor prognostic group of cases in low grade lymphoma but phenotyping B-cell non-Hodgkin's lymphoma for many of the antigens expressed at various stages of B-cell differentiation and activation does not provide clinically useful information in addition to that obtained from standard histological classifications. 


\section{CHAPTER 1: INTRODUCTION}

over the last few years there has been an increase in the understanding of normal B-cell physiology. This has been assisted by the production of monoclonal antibodies (MCA) against novel antigens expressed at different stages of $\mathrm{B}-\mathrm{cell}$ activation and maturation (Bernard et al 1984, Reinherz et al 1986, McMichael et al 1987). The morphology and distribution of distinct B-cell subsets in lymphoid tissue has been elucidated and correlated with antigen expression (stein et al 1982, Campana et al 1985, Nadler 1986, Ling et al 1987). In-vitro studies of activation and differentiation of B-cells have shown sequential changes of antigen expression by these cells as they transit the cell cycle or undergo terminal differentiation (Boyd et al 1985a, 1986, Smeland et al 1985, Walker and Gordon 1987). It is becoming clear that such antigens may be important receptors for soluble mediators involved in the control of B-cell growth and differentiation (Clark and Einfield 1986, Frade et al 1985b, Muraguchi et al 1985b, Clark and Ledbetter 1989). As many of these antigens appear to be involved with cell proliferation it is possible that their expression by neoplastic cells may be related to uncontrolled proliferation and clinical prognosis.

Non-Hodgkin's lymphomas (NHL) are a group of neoplasms which are believed to arise as a result of uncontrolled proliferation and accumulation of lymphoid cells arrested at a set maturation stage (Lukes and collins 1974). They show cytomorphological and some phenotypic similarities to cells in normal lymphoid tissues. Presently used classifications of NHL such as 
the Kiel classification (Lennert 1978, Stansfeld et al 1988) are based on these features. Detailed phenotyping with a panel of activation and differentiation antigens should allow more accurate comparison between normal and neoplastic B-cells and may lead to more accurate classification of lymphoma.

This study was undertaken to investigate these possibilities.

In the remainder of chapter 1 I shall review what is known of normal B-cell distribution and maturation in human lymphoid tissue and the factors controlling Bcell activation and differentiation including the function and distribution of the antigens studied in this work. I shall also discuss briefly the classification of NHL and factors which may have clinical prognostic relevance. In chapter 2 I will describe the materials and methods used in this study. Chapter 3 includes the results and discussion of antigen expression in reactive lymphoid tissue whereas in chapter 4 the results of analyses of antigen expression by NHL will be shown and their significance discussed. Finally in Chapter 5 the relationship of antigen expression to clinical parameters including survival will be presented and discussed.

1.1 ORGANISATION OF B CELLS IN PERIPHERAL LYMPHOID TISSUE

B lymphocytes are present circulating in blood, in lymphoid tissue of spleen, lymph nodes and mucosa associated lymphoid tissue. Smaller numbers of mature lymphocytes are present in bone marrow. 


\subsubsection{Lymph Nodes}

The architecture of lymph nodes is generally separated into cortex, paracortex, medulla and sinuses (stein et al 1982, Van der Valk and Meijer 1988). The cortex is the predominant $\mathrm{B}-\mathrm{cell}$ rich area with both primary and secondary lymphoid follicles. Primary follicles are collections of mature small lymphocytes. Secondary follicles comprise a mantle of small lymphocytes which surrounds a germinal centre consisting of a population of proliferating and maturing B-cells, centroblasts and centrocytes, as well as a number of accessory cells including dendritic cells tingible body macrophages and T-cells (Stein et al 1982). Small numbers of Bcells may also be identified in the paracortex a predominantly $\mathrm{T}$-cell rich area. The medullary cords contain large numbers of plasma cells, small lymphocytes, lymphoplasmacytoid cells and smaller numbers of immunoblasts. A population of B lymphocytes, monocytoid B-cells, are present in sinuses in certain conditions such as toxoplasmosis and AIDS (Sheibani et al 1985). A marginal zone of B-cells (vide infra) is only seen infrequently in lymph nodes (Van der Valk and Meijer 1988).

\subsection{2 spleen}

The B lymphocyte population in the spleen is predominantly in the Malpighian follicles that constitute the white pulp. B lymphocytes are collected as primary and secondary follicles as in the lymph node but in addition a further anatomically distinct group of marginal zone lymphocytes can be identified around the mantle of the B-cell follicle, at the edge of the white pulp (Van Krieken and te Velde 1988). 


\subsubsection{Mucosa Associated Lymphoid Tissue (MALT)}

Diffuse aggregates of non-encapsulated lymphoid tissue are present in the lamina propria and submucosa of a number of organs including the respiratory and gastrointestinal tracts and have been termed MALT. Lymphoid cells recirculate and home specifically to these mucosal tissues (Parrot 1976). MALT has both B-cell and Tcell areas (Spencer et al 1985, 1986, Isaacson and spencer 1987). The B-cell compartment includes follicles and, in a zone between follicles and the overlying epithelium, small lymphoid cells with irregular nuclei resembling centrocytes and some plasma cells (Spencer et al 1985, 1986). These small lymphoid cells which have been termed centrocyte-like cells resemble spleen marginal zone cells phenotypically (Spencer et al 1985, 1986).

\subsection{B CELL DEVELOPMENT AND MATURATION}

The B lymphocyte lineage is characterised by the synthesis of Immunoglobulin ( Ig). The major product of adult marrow lymphopoiesis is a virgin, small B lymphocyte. These cells migrate to peripheral lymphoid tissue where they may encounter antigen and differentiate into immunoglobulin secreting cells - plasma cells. Normal B-cell development can conveniently be separated into three stages :- an antigen-independant maturation in bone marrow, antigen-dependant clonal expansion and maturation in peripheral lymphoid tissue, where a number of distinct subsets of B-cells probably exist, and terminal differentiation to immunoglobulin secreting plasma cells.

Most understanding of in-vivo B lymphocyte maturation 
has come from analysis of the cellular component of primary follicles as they appear in the fetus and the features of germinal centres developing in secondary lymphoid follicles. Additional information has been obtained by extrapolation from comparisons between lymphomas, leukaemias, cell lines and postulated normal equivalent cells. In-vitro work has added information on which factors may be necessary for control of B-cell activation, growth and differentiation and which alterations occur at the cell surface as a result of changes in activated state and differentiation. Figure 1.1 (page 12) summarises the current thoughts on expression of surface antigens at different stages of B-cell development.

\subsubsection{Antigen-Independent Bone Marrow Maturation}

Purification of lymphoid progenitor cells from fetal bone marrow shows a population of immature lymphoid cells expressing HLA DR and TdT (Hokland et al 1983). Ig heavy chain gene rearrangement occurs in these cells (Cooper 1987). Stimulation of HLA DR, TdT positive cells with $\mathrm{PMA}-$ conditioned medium results in sequential acquisition of CD19, CD22, CD10, CD20 and cytoplasmic Ig without surface Ig (Hokland et al 1985, Campana et al 1985, Ling et al 1987). Other markers which have been identified on pre-B-cells (characterised by the expression of cytoplasmic mu heavy chain (Raff et al 1976)) include CD9, CD22, CD38 and CD45 (Zola et al 1983, Tedder et al 1984, Campana et al 1985, Kincade 1987). These cells do not express light chains or surface Ig. They appear in human fetal liver at about 8 weeks (Gathings et al 1977) and are present in the bone marrow from around the fifteenth to sixteenth week 
of gestation (Bodger et al 1983, Bofill et al 1985, Hokland et al 1985). Surface Ig positive B-cells are seen about a week later. Transition to a surface Ig positive cell is closely associated with light chain Ig gene rearrangement and with light chain synthesis (Siden et al 1981). These surface Ig positive cells do not express CD10 or TdT (Hokland et al 1985). The transition of a pre-B-cell to a surface Ig positive Bcell also involves loss of $\mathrm{CD} 38$ and acquisition of $\mathrm{CD} 21$ (Tedder et al 1984).

\subsubsection{Antigen-Dependent Peripheral B-cell Maturation}

Mature peripheral B-cells are heterogeneous in respect of tissue distribution and phenotypic expression and it is probable that several subsets exist. B-cells are produced in large numbers from the bone marrow - in the adult mouse the number produced daily represents approximately $20 \%$ of the total peripheral lymphoid tissue (Opstelten and osmond 1985) - but most of these die. A small number are selected for long term survival (MacLennen and Gray 1986). These may either be long lived virgin cells or newly produced memory B-cell clones resulting from activation by antigen in peripheral lymphoid tissue. This phase of activation is believed to occur in extrafollicular areas predominantly in lymphatic sinusoids and at the cortico-medullary junction (Lortan et al 1987) and results in the production of a population of circulating memory B-cells. Germinal centres may also give rise to memory cells (vide infra).

Peripheral blood B lymphocytes are believed to be predominantly memory cells which are recirculating from thoracic duct via blood, through high endothelial venules to migrate and repopulate primary and secondary 
Different populations of B-cells are recognised in the primary follicles, mantle zone and germinal centres of secondary follicles of lymph nodes (Stein et al 1982). Populations with phenotypic and morphologic differences are seen in the marginal zone of the spleen and lymph nodes and adjacent to Peyers patches in the gut (Gray et al 1982, spencer et al 1985,1986, Van-der Valk and Meijer 1988). In fetal primary follicles at least two subsets of B-cells (CD5 positive and negative) can be identified (Bofill et al 1985).

\subsubsection{Primary Follicles and the Germinal centre Reaction}

Primary follicle B-cells in the fetus and adult show different phenotypic profiles. In the adult the primary follicle comprises a collection of mature small lymphocytes which express surface IgM and IgD (Stein et al 1982) whereas in the fetus two populations can be identified (Bofill et al 1985). The majority (60\%) population has a phenotype similar to that of adult primary follicles, surface IgM and IgD positive, whereas the smaller population in addition express CD5.

The phenotype of cells in primary follicles and mantle zone cells around germinal centres is similar to mature B cells which emerge from the bone marrow (i IgM, IgD, CD19, CD20, CD21, CD22, CD24 positive) (Campana et al 1985). This supports the idea that these are either long lived virgin cells, newly produced memory cells or both. 
The development of lymph follicles has been studied during embryogenesis, in neonates and in adults. Only primary follicles are present in embryos. Germinal centres arise only after antigenic stimulation following birth. Primary follicles comprise tight clusters of small lymphocytes. Secondary follicles consist of a germinal centre and a cuff of mature small lymphocytes :- the mantle zone. Following antigen stimulation secondary follicles develop from primary follicles and undergo sequential changes in morphology (stein et al 1980, 1982). Activated lymphoid cells, which appear to be memory cells (Jelinek and Lipsky 1987, Gray et al 1986), migrate from the mantle zones towards the developing germinal centres. Initially in the germinal centres proliferating centroblasts are predominant. Subsequently centrocytes appear and the germinal centre can be morphologically separated into light and dark zones, the centroblast derived centrocytes residing predominantly in the light zone (Stein et al 1980, 1982). Centroblasts later disappear. Germinal centre cells show phenotypic differences from mantle zone and primary follicle cells. They do not or only weakly express IgD and CD21 and have acquired CD10 and CD38 (Hsu and Jaffe 1984).

As well as B-cells germinal centres contain follicular dendritic reticulum cells (DRCs) (Stein et al 1980, 1982) which probably function as long term antigen presenting cells. Germinal centres are believed to be the major source of memory cells in a secondary response (Klaus et al 1980, Coico et al 1983). Memory cells in turn enrich the mantle zones of B-cell follicles (Klaus and Kunkl 1981).

In vitro studies suggest that activation of peripheral blood, lymph node and tonsillar derived lymphocytes results in blast transformation and differentiation to 
Ig secreting cells. It appears that the microenvironment within germinal centres is such that differentiation is promoted along the line for production of memory cells rather than for Ig secretory cells. DRCs may be the important cell in the control of this directed differentiation (Heinen and Tsunoda 1987).

\subsubsection{Marginal zone cells and centrocyte-like cells}

A number of experimental and immunohistological investigations have led to the belief that a population of $B$ lymphocytes exists in the marginal zone of the spleen and lymph nodes which are different from the recirculating and mantle zone lymphocytes. This population which is CD5 negative is surface IgM positive but surface IgD negative. Surface IgD negative follicular germinal centre B-cells develop in animals lacking marginal zone cells (Gray et al 1986, MacLennan et al 1985) whereas marginal zone cells can develop in rats treated from birth with anti-IgD but surface IgD negative follicular cells fail to develop (Bazin et al 1982). The marginal zone lymphocyte may be important in the response to thymus independent antigens (MacLennan et al 1982, Gray et al 1985).

Phenotypically the centrocyte-like cell, marginal zone cell and monocytoid $B-c e l l$ are similar expressing surface IgM, $C D 22$ and CD21 but not CD5, CD23 or IgD (Gray et al 1982, Sheibani et al 1985, spencer et al 1985,1986). They therefore may be a related subpopulation of B-cells perhaps committed in a differentiation pathway outwith germinal centres. 


\subsubsection{CD5 Positive Lymphocyte}

A CD5 positive small lymphocyte makes up a significant population of fetal primary follicle calls (Bofill et al 1985). In adults, however, this population is much reduced and only about 5\% of lymph node B-cells are CD5 positive, most being confined to the edge of germinal centres (Caligaris-Cappio 1982). This pool of CD5 positive lymphocytes is polyclonally expanded in several autoimmune disorders including rheumatoid arthritis and CD5 positive B-cells may be important in the production of autoantibodies (Casali et al 1987, Hardy et al 1987).

\subsubsection{Terminal Differentiation}

Plasma cells are the end stage of B-cell differentiation and are the predominant cells involved in Ig secretion. Plasma cells are present infrequently in germinal centres (Isaacson et al 1980) but are present in large numbers in medullary cords of lymph nodes, in mucosa associated lymphoid tissue and in smaller numbers in the bone marrow.

In vitro experiments show that following activation with mitogens including anti-Ig and $\mathrm{T}$ cell derived factors B-cells differentiate into immunoglobulin secreting cells via large blast cells. This process of differentiation is associated with alterations in surface phenotype including loss of surface Ig, Class II antigens and pan-B-cell markers and the gain of CD38 (Bhan 1981, Stashenko et al 1981, Boyd et al 1985a, 1986).

It has been postulated that there are at least two 
routes available in vivo for plasma cell production (Lennert 1978, Weissman et al 1978):- one, that leads to IgM production, is linked to the primary humoral immune response whereas that of the secondary immune response involves clonal expansion by germinal centres and immunoglobulin isotype class switching which involves further immunoglobulin heavy chain gene rearrangement (Cooper 1987). Differentiation to plasma cells occurs in the medullary cords (Nieuwenhius and Keuning 1974) and in marginal zones to $\mathrm{T}$ independent antigens or in tissues after circulating (MacLennan and Gray 1986).

In vivo a number of morphologically different forms of "plasma cells" are seen including lymphoplasmacytoid cells, with morphology between small lymphocytes and plasma cells, plasmablasts and immunoblasts (Lennert 1978, Weismann et al 1978, Harris and Bahn 1985). 


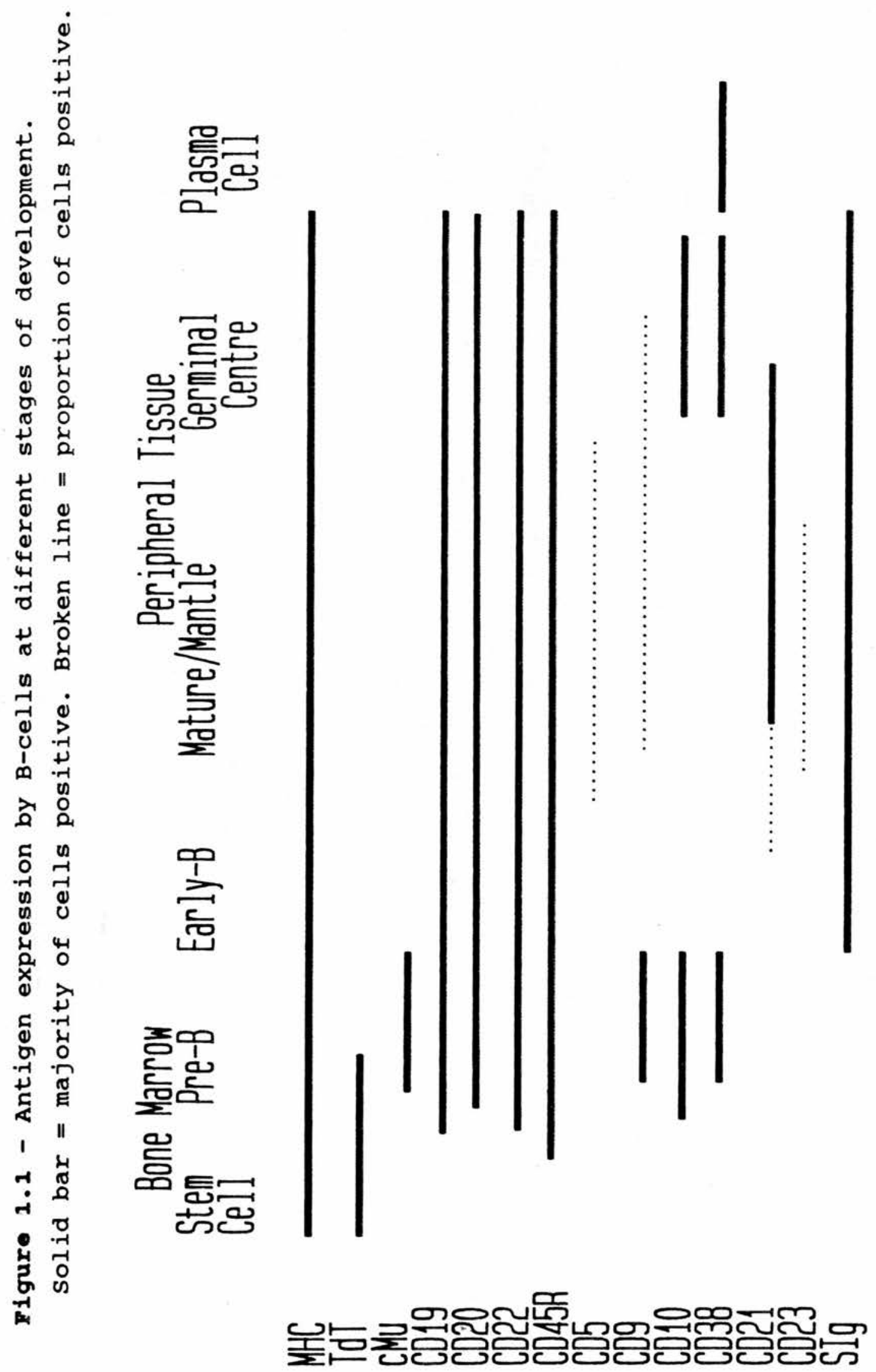



GROWTH AND DIFFERENTIATION

The clonal expansion and differentiation of B-cells appears to be distinct and depends upon the presence of differing cytokines in the microenvironment (Muraguchi et al 1985a). Following antigen stimulation B-cell proliferation will also result in the expansion of antigen specific memory cells. B-cells may be activated to divide without maturing to Ig secretion (Marujama et al 1983, Isakson and Simpson 1984) and can mature without dividing (Neckers et al 1985). Therefore, following activation, B-cells have a choice of either becoming memory cells or differentiating to plasma cells. Helper T-cells have an obligatory role in antibody responses against most antigens with current concepts being those of a two step theory of lymphocyte activation. The first step requires cross-linking of surface Ig on resting B-cells which results in entry of into the cell cycle (Cambier and Ransom 1987) and the expression of new surface molecules, many of which are functional receptors (Jelenik and Lipsky, 1987). The second step is provided by helper T-cells which secrete a number of lymphokines including interleukin (IL) 2, IL4, IL5, IL6, gamma interferon and other B cell growth and differentiation factors (Kishimoto 1985, Lee et al 1986, Yokata et al 1986, O'Garra et al 1988).

Resting B-cells can be activated in vitro by a number of means eg. specific antigen, cross-linking of surface Ig and phorbol ester (Cambier et al 1982, Kuritani and Cooper 1983, Suzuki et al 1985). Activation can be measured by a number of ways, including alterations in cytoplasmic calcium, RNA synthesis and increase in cellular 
DNA (Munroe and Cambier 1983, Cambier et al 1985, Kehrl et al 1985). Such techniques have identified a number of surface antigen changes which occur as B-cells are activated and enter the cell cycle (Figure 1.2, page 16). Three distinct activation stages are available to human B-cells before they enter the cell cycle (Gordon and Guy 1987, 1988). The first stage is defined by the acquisition of $\mathrm{CD} 23$ and the antigen recognised by the MCA BK19.9. This is termed GOA. The second stage GOB is recognised by increased binding of acridine orange to DNA. Truly resting, deeply quiescent lymphocytes devoid of activation antigens are in a stage termed G0Q. The progression from GO - Gl is associated with cellular enlargement RNA synthesis and new protein expression with increased expression of DP, DQ and DR antigens (Kehrl et al 1985). B-cells in early G1 express $4 \mathrm{~F} 2$ but not CD71 and have lost IgD (Kehrl et al 1984a,b). As cells progress through G1, 24-36 hours after stimulation, CD71 appears and CD21 decreases (Smeland et al 1985, Boyd et al 1985a,1986). CD25 is expressed early in G1 and maintained throughout the cell cycle whereas CD30 is not expressed until G2 (Walker and Gordon 1987).

There are a number of points in the cell cycle at which activated cells may be arrested and these appear in GO, G1 and G2 (Gordon and Guy 1988, Melchers and Anderson 1986). The presence or absence of surface membrane molecules which interact with cytokines and ligands at these points would be likely candidates for the control of B-cell proliferation and differentiation.

Many of the molecules on resting $B$ lymphocytes such as CD20, CD21 and CD22 have activity in promoting B-cell proliferation (Frade et al 1985b, Nemerow et al 1985, Golay et al 1985, Pezzutto et al 1987c, vide infra). Activation results in expression of surface receptors for B-cell growth factors e.g. IL4 (Cambier and Ranson 
1987). CD23 is a receptor for low mol wt BCGF (Swendeman and Thorley-Lawson 1987). Anti CD23 MCA and low mol wt BCGF both down-regulate CD23 expression and it is possible that loss of $\mathrm{CD} 23$ by activated cells may facilitate differentiation rather than proliferation (Kikutani et al 1986b). IL2 promotes growth and differentiation of Bcells (Muraguchi et al 1985a, Nakagawa et al 1985). Progression of $B-c e l l s$ through the cell cycle requires IL2 (Gordon et al 1986a). A number of other factors including IL4, IL5 and IL6 induce proliferation and terminal differentiation of B-cells to Ig secreting cells (Kishimoto 1985, Lee et al 1986, Yokata et al 1986, o'Garra et al 1988) however the natural receptors for these and other factors involved in control of B-cell growth and differentiation have not yet been identified.

Proliferation is important for B-cell differentiation to Ig secreting cells over and above that necessary to expand the number of antigen-reactive cells (Jelenik and Lipsky 1987). It has been shown however that in some circumstances small lymphocytes may mature into Ig secreting cells without proliferation (Anderson and Melchers 1974, Neckers et al 1985). Ig secretion can also occur in an actively proliferating cell population (Jelinek and Lipsky 1983). Phenotypically recognised subpopulations of $\mathrm{B}$ cells (eg. $\mathrm{CD} 21+$ and $\mathrm{CD} 21-$ ) respond differently to activation and differentiation factors (Anderson et al 1985, Boyd et al 1985a) suggesting different requirements are necessary for proliferation or differentiation at certain stages of B-cell maturity.

The phenotypic changes which occur following terminal Bcell differentiation in-vivo and in-vitro are loss of pan-B-cell and MHC Class II antigens and gain of CD38 as previously described. 
Figure 1.2 - Changes of antigen expression by B-cells as they enter and transit the cell cycle.

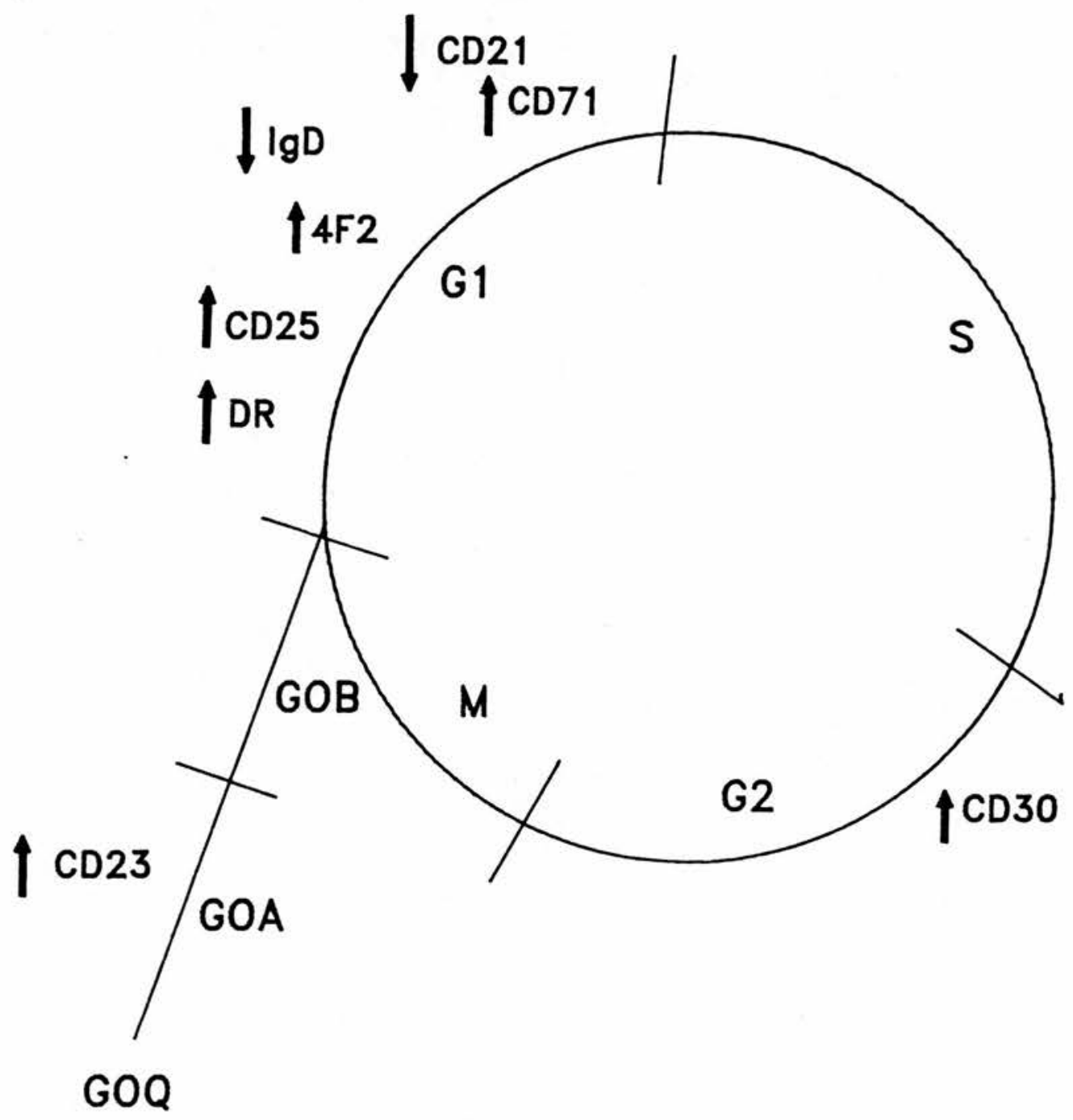


Leucocytes express a large number of molecules on their surface membranes which are important for cell-cell interactions, responses to molecules such as antigen and various cytokines which may induce activation, proliferation or differentiation.

The identification of two distinct lymphocyte populations: the antibody producing B-cell lineage and T-cells allowed the production of allo-antisera which recognised further antigens expressed differentially by the two populations (Raff et al 1969, 1970), however it was not until the late seventies that the use of monoclonal antibody technology developed by Milstein and Kohler (1975) resulted in an explosion of the number of antigens which could be recognised on human lymphocytes. Initially the focus was on T-cells (Reinherz et al 1979, Reinherz and Schlossman 1980) but a number of groups also worked on the production of antibodies which would define B-cells (Ritz et al 1980, stashenko et al 1980). Since those early days a large number of MCA have been produced against leucocyte antigens. International workshops have been held regularly since 1982 to standardise the characterisation and classification of these leucocyte markers (Bernard et al 1984, Reinerz et al 1986, McMichael et al 1987). By the summer of 1989 the fourth International Workshop on Human Leucocyte Differentiation Antigens had been held, adding a further 35 new cluster determinants (CDs) and subclusters to those previously defined (Knapp et al 1989). A total of 78 clusters and subclusters are now recognised. Many of the antigens have been defined biochemically and genetically. The function of some and their natural ligands are also being discovered. of the defined leucocyte antigens seven (CD19, CD20, CD21, CD22, CD40, CD72 and CD77) are specific for B-cells while some 
antigens are shared between B-cells and other leucocytes (eg CD23, $\mathrm{CD} 24, \mathrm{CD} 25, \mathrm{CD} 37, \mathrm{CD} 39, \mathrm{CD} 73, \mathrm{CD} 76$, and $\mathrm{CD} 78$ ) (Knapp et al 1989). The Leucocyte Differentiation Antigen nomenclature includes the transferrin receptor (CD71) but does not include immunoglobulin nor MHC Class II antigens.

The antigens studied during the project reported in this thesis were limited by the availability of antibodies against B-cell markers during the course of the project. only those antigens which were studied will be discussed further (see Table 2.3, page 46). They have been seperated into five groups taking into account the available published data on their expression by normal B-cells. Immunoglobulin and MHC Class II antigens while being recognised as pan-B-cell antigens have been grouped seperately from antigens assigned $C D$ numbers at the recent workshops on Human Leukocyte antigens. 'Pan-B'cell antigens (CD19, CD20, CD22 and CD45R) are those antigens expressed early in B-cell ontogeny continuously until a pre-plasma cell stage of differentiation. The 'restricted' group (CD5, CD9, CD10 and CD38) are those antigens which are believed to be expressed only at certain points of $\mathrm{B}$ cell maturation or are expressed by subsets of cells. Included in the 'activation-associated' group (CD21, CD23, CD25, CD30, CD71 and 4F2) were antigens whose expression could be modified by in-vitro activation.

\subsubsection{Pan-B-Cell antigens}

\section{CD19}

The CD19 antigen is a glycoprotein of approximately 95 $\mathrm{kDa}$ with three extracellular Ig-like domains having strong homologies to human Ig $\mathrm{C}$ or $\mathrm{V}$ regions (Stamenkovic and seed 1988b). The antigen internalises rapidly after 
being bound by MCA (Uckun et al 1988b) and appears to act as a receptor which regulates cytoplasmic calcium concentrations (Pezzutto et al $1987 \mathrm{a}, \mathrm{b}$ ). It may function via regulation of intracytoplasmic calcium concentration to control B-cell proliferation (Clark and Ledbetter 1989).

CD19 is a very early marker of B-cell differentiation being expressed by pre-B-cells in fetal liver (Uckun et al 1988a). It is expressed by mature B-cells (Nadler et al 1983, Meeker et al 1984) and is present on resting and both in-vivo and in-vitro activated B-cells (Boyd et al 1986, Freedman et al 1986, Schwartz et al 1986). It is lost during terminal differentiation to plasma cells (Nadler 1986).

\section{$\underline{\text { CD20 }}$}

The CD20 antigen consists of major $35 \mathrm{kDa}$ and minor 37 kDa non-glycosylated phosphoproteins (Valentine et al 1987a, Moldenhauer et al 1987). Following activation by phorbol ester CD2O is hyperphosphorylated and internalised (Valentine et al 1987b). Interaction of MCA with CD20 does not cause alterations in intercellular calcium concentrations (Tedder et al 1986a, Smeland et al 1987). Anti-CD20 MCA have been produced which are either inhibitory to or promote B-cell activation. The anti-CD20 MCA Bl inhibits proliferation and differentiation of B-cells stimulated with either anti-Ig or EBV (Tedder et al 1985b, Golay et al 1985). Stimulatory anti-CD20 MCA cause dense tonsillar B-cells to proliferate and are costimulatory with either anti-Ig and low-molecular weight BCGF (Clark et al 1985, Clark and Ledbetter 1986) increasing expression of C3d receptors (CD21), MHC Class II molecules and c-myc proto-oncogene (Clark et al 1985, clark and Ledbetter 1986, Smeland et al 1985). The inhibitory action of anti-CD20 MCA prevents DNA synthesis but not the development of a number of activation associated changes such as increase in IL2 receptors, cell enlarge- 
ment or RNA synthesis (Tedder et al 1986a).

CD20 is expressed by most B-cells from blood and lymphoid tissue (Stashenko et al 1980) but many pre-B-cells which are cytoplasmic mu, CD19 and CD22 positive are CD20 negative (Nadler 1986). It is present on both resting and activated B-cells but is lost prior to terminal differentiation to plasma cells (Stashenko et al 1980, Boyd et al 1986).

\section{CD22}

CD22 is a phosphorylated heterodimer with noncovalently linked chains of about 130 and $140 \mathrm{kDa}$ (Schwartz et al 1986, Boue and Lebien 1988).

MCA to CD22 augment entry into the cell cycle as measured by RNA synthesis and proliferation of B-cells (Pezzutto et al 1987c, 1988). CD22 negative cells are incapable of mobilising calcium following treatment with anti-Ig (Pezzutto et al 1988).

CD22 is expressed early in B-cell ontogeny being found in the cytoplasm of TdT positive and pre-B-cells at approximately the same time as CD19 (Campana et al 1985, Ling et al 1987) and is expressed by mature B-cells in lymphoid tissues (Mason et al 1987). Following activation of lymphocytes in-vitro there is a transient increase of CD22 expression and subsequent loss with differentiation (Pezzutto et al 1988).

\section{CD45R}

CD45 is the leucocyte common family, a group of high molecular weight glycoproteins expressed at the surface of leucocytes and precursors (Thomas 1989). The gene for the leucocyte common antigen (LCA) is present on chromosome 1 and the different forms are believed to be produced by differential splicing of three exons to poten- 
tially generate eight mRNAs (Thomas 1989). LCA has exterior, transmembrane and cytoplasmic domains. Four major species are recognised with molecular weights of about $220,205,190$ and $180 \mathrm{kDa}$. These differ in protein sequence and carbohydrate structures of the external domain. MCA which react with LCA may recognise common epitopes (CD45) or restricted epitopes (CD45R) (Cobbold et al 1987). Restricted epitopes have been further separated into CD45RA, expressed by the high molecular weight form and CD45RO, expressed by the low molecular (180 kDa) form. F8-11-13 the MCA used in this study recognises CD45RA (Norton and Isaacson 1989).

Antibodies to both the common and restricted epitopes of CD45 inhibit B-cell proliferation induced by anti-IgM and $\mathrm{T}$-cell replacing factors (Mittler et al 1987). Inhibition is maximal on small resting cells and appears to interfere with an early stage of activation. CD45 may also regulate progression and maturation signals to lymphocytes (Clark and Ledbetter 1989).

All B-cells express the $220 \mathrm{kDa}$ form of CD45, CD45RA, (Thomas 1989). It appears very early in B-cell development probably preceeding immunoglobulin gene rearrangement (Kincade 1987) and is present on all peripheral Bcells but is lost with differentiation to plasma cells (Dalchau and Fabre 1981, Salter et al 1985, Kincade 1987).

\subsubsection{Restricted B-cell markers}

\section{CD5}

CD5 is a $67 \mathrm{kDa}$ glycoprotein (Ledbetter et al 1981, Jones et al 1986). The function of CD5 has not been fully evaluated. Anti-CD5 antibodies enhance IL2 production and proliferation responses by T-cells in mixed lympho- 
cyte cultures (Hollander et al 1981, stanton et al 1986). They act by mobilising cytoplasmic calcium and up-regulating signalling through the $\mathrm{CD} 3$ receptor (June et al 1987).

CD5 is recognised as a pan-T-cell marker but is also expressed by surface Ig positive B chronic lymphocytic leukaemia (CLL) cells (Martin et al 1980, Royston et al 1980) and a population of fetal and adult normal B-cells (Caligaris-cappio 1982, Gobbi 1983). CD5 positive normal B-cells are primarily responsible for autoantibody production (Casali et al 1987, Hardy et al 1987). It is possible that CD5 positive $B$ cells represent a distinct subpopulation although it has been suggested that CD5 expression may be induced on B-cells by phorbol esters (Miller and Gralow 1984).

CD9

CD9 was assigned to an antigen of mol wt $24 \mathrm{kDa}$ at the first workshop on leukocyte antigens (Bernard et al 1984). It has subsequently been shown to have protein and serine kinase activity (Seehafer et al 1984, Zipf et al 1986). Antibodies to CD9 augment the response of $B-C L L$ cells to phytohaemagluttinin (PHA) (Briggs et al 1987).

It is expressed by a number of non-haemopoietic and haemopoietic cells including subsets of B-cells, common acute lymphoblastic leukaemia antigen (CALLA) positive lymphoblastic leukaemia cells and tonsil follicle cells (Ling et al 1987).

\section{CD10}

CD10 is a glycoprotein of approximately $100 \mathrm{kDa}$. Alteration of the carbohydrate component produces a number of variants (Braun et al 1983, Pesando et al 1980, McCormack et al 1986). The antigen was initially defined by Greaves et al in 1975 as the common acute lymphoblastic leukaemia 
antigen (CALLA). The function of this marker is unknown. CD10 is expressed by pre-B-cells in foetal liver (Hokland et al 1983). In peripheral lymphoid tissues it is expressed by germinal centre cells but is absent from mantle zone cells (Hsu and Jaffe 1984).

\section{CD38}

CD38 was assigned to a $45 \mathrm{kDa}$ glycoprotein at the second workshop on leukocyte antigens (Reinherz et al 1986). The function is unknown.

It is not expressed by resting B cells but is expressed by progenitor $\mathrm{T}$ and $\mathrm{B}$ cells (Bhan et al 1981), germinal centre cells and plasma cells (Hsu and Jaffe 1984).

\subsubsection{Activation Associated Antigens}

\section{CD21}

The CD21 antigen is a non-phosphorylated $140 \mathrm{kDa}$ glycoprotein (Oettengen et al 1983) which has been identified as the CR2, C3d receptor (Iida et al 1983, Weis et al 1984). It is also the receptor for EBV (Fingeroth et al 1984, Frade et al 1985a). The CD21 antigen internalises when bound to MCA or EBV (Tedder et al 1986b). Anti-CD21 MCA stimulate proliferation of normal resting B-cells (Frade et al 1985b, Wilson et al 1985, Nemerow et al 1985) and may act by causing both membrane depolarisation and increasing cytoplasmic calcium levels (Rabinovich et al 1987).

CD21 is absent or present in very low amounts on immature B-cells (Campana et al 1985, Tedder et al 1984). Only 60 per cent of peripheral blood and bone marrow B-cells express CD21 and the antigen is present in highest amounts on mature B-cells in lymphoid tissue, predominantly mantle-zone cells (Clark and Einfield 1986, Mason 
et al 1986, Ling et al 1987). After activation in-vitro by anti-Ig or phorbol ester, B-cells loose CD21 simultaneously with IgD (Boyd et al 1985a, 1986, Freedman et al 1986). CD21 is absent from terminally differentiated Bcells (Ling et al 1987).

\section{CD23}

CD23 is a glycoprotein which exists in two forms. The membrane bound form has a molecular weight of approximately $45 \mathrm{kDa}$ (Thorley-Lawson et al 1986). The soluble form comprises a $33 \mathrm{kDa}$ glycoprotein which is probably released from the larger molecule by a protease dependent pathway (Kikutani et al $1986 \mathrm{a}, \mathrm{b}$ ) . CD23 is a low affinity receptor for IgE (Kikutani et al 1986a, Bonnefoy et al 1987). The soluble CD23 molecule binds to IgE and has been found to have B-cell growth factor activity (Swendemen and Thorley-Lawson 1987,1988). Anti-CD23 MCA have BCGF-like activity and are costimulatory with phorbol ester in inducing $B-c e l l$ proliferation (Gordon et al 1986b, 1987). The CD23 antigen appears to be closely associated with MHC Class II DR (but not DP or DQ) on the surface membrane (Bonnefoy et al 1988).

CD23 is either absent or present in very small amounts on resting $\mathrm{B}-\mathrm{cell}$ s but appears rapidly after activation and precedes entry into the cell-cycle by Go B-cells (Walker et al 1986). In-vivo $\mathrm{CD} 23$ is expressed by mantle zone cells but not by germinal centre B-cells in peripheral lymphoid tissue (Ling et al 1987).

\section{$\underline{\mathrm{CD} 25}$}

The CD25 antigen consists of two non-covalently linked 55 and $75 \mathrm{kDa}$ polypeptides (Smith 1987, 1989) and is the receptor for IL2 (Leonard et al 1982). Both polypeptides are capable of binding IL2 but with low affinity and it is only when both proteins are associated that a high affinity receptor is formed (Smith 1989). Anti-Tac MCA 
recognise the low molecular weight protein (Leonard et al 1982 ) .

IL2 promotes T-cell growth and functions to enhance Bcell growth and differentiation (Muraguchi et al 1985b, Nakagawa et al 1985). It appears to function late in the cell cycle probably in S, G2 or M (Mingari et al 1985) acting as a progression signal.

\section{$\underline{\mathrm{CD} 30}$}

CD30 is an $105 / 120 \mathrm{kDa}$ glycoprotein which was initially defined as an antigen expressed by Hodgkin and Reedsternberg cells (Schwab et al 1982). It is absent from resting but present on activated lymphocytes (stein et al 1985). Expression by B-cells occurs following stimulation by phorbol ester but not until G2, late in the cycle (Walker and Gordon 1987). Although expression appears to be related to activation the function is unknown.

In normal lymphoid tissue expression is limited to a population of large blasts in the interfollicular area (Palleson and Hager 1987) and a population of blasts localised around B cell follicles, in some instances at the rim of germinal centres (Schwab et al 1982).

\section{CD71}

The transferrin receptor was assigned CD71 at the fourth International Workshop on Leukocyte Differentiation Antigens. It is a transmembrane glycoprotein with a molecular weight of $180 \mathrm{kDa}$, being comprised of two disulphide bonded $90 \mathrm{kDa}$ subunits (Newman et al 1982). Its expression is associated with cell activation and proliferation (Trowbridge and Omary 1981). Anti CD71 MCA inhibit lymphocyte proliferation (Mendolsohn et al 1983).

In normal lymphoid tissue $\mathrm{CD} 71$ is expressed by germinal centre cells, macrophages and variable numbers of cells 
in the paracortex (Hsu and Jaffe 1984).

4F2

The monoclonal antibody $4 \mathrm{~F} 2$ (Haynes et al 1981) recognises the heavy subunit of a heterodimeric polypeptide complex comprising a glycoprotein of approximately $80 \mathrm{kDa}$ and a disulphide linked light subunit of approximately 40 $\mathrm{kDa}$ (Hemler and strominger 1982). The function of the antigen is unknown. It is expressed early in Gl by proliferating lymphocytes but is not expressed by resting lymphoid cells (Kehrl et al $1984 \mathrm{a}, \mathrm{b}$ ). 4 F2 partially inhibits lymphocyte proliferation induced by mitogens (Haynes et al 1981).

\subsubsection{MHC class II Molecules}

MHC Class II molecules are a group of heterodimers consisting of alpha and beta chains of mol wt $34 \mathrm{kDa}$ and 29 kDa respectively (reviewed by Giles and Capra 1985). They are encoded by genes in the MHC region on the short arm of chromosome 6 . These genes are organised in three loci - DR, DP and DQ, each locus comprising several genes. The beta chains are highly polymorphic. Class II antigen expression is important for cellular interactions in the immune response.

MHC Class II molecules are expressed by cells of the lympho-reticular system and also by other tissues (Daar et al 1984, Guy et al 1986). Expression may be induced by gamma interferon (Shaw et al 1985). In normal lymphoid tissue B-cells, macrophages and a proportion of paracortical T-cells express DR, DP and DQ (Krajewski et al 1985). 


\subsection{NON-HODGKINS LYMPHOMA}

\subsubsection{Historical overview}

Since Thomas Hodgkin published his treatise on primary lymphoid malignancy in 1832 understanding and classification of malignant lymphoma has changed markedly (reviewed by Banks and Berard 1977, Nathwani and Winberg 1983). Virchow distinguished lymphoma from leukaemia and in 1871 Billroth used the term malignant lymphoma. In 1865 Wilks divided lymphoma into two groups, separating Hodgkin's Disease from non-Hodgkin's Lymphoma. Classifications of non-Hodgkin's Lymphoma developed initially on a few fundamental concepts, e.g. neoplasms composed of small non-replicating lymphocytes were recognised as a favourable group, whereas those with atypical lymphocytes with mitoses were less favourable. Cases composed of large cells were considered non-lymphoid, i.e. stem cell or histiocytic in origin. Sequential classification systems of NHL such as those of Robb-Smith, Gall and Mallory, Rappaport and Gall and that of Rappaport's in 1966 (Rappaport 1966) were clinically valuable in that morphologically recognisable categories were shown to have prognostic significance and were of great benefit to clinicians in their management of patients. Nevertheless since their publication there have been great strides in the understanding of lymphocyte physiology, the organisation of lymphoid tissue and its division into $T$ and $B-$ cell compartments which highlighted a number of inaccuracies in the Rappaport system which had become widely used. Newer classifications have been introduced in an attempt to correct these inaccuracies and introduce the new knowledge available. 


\subsubsection{Newer classifications}

Immunological and morphological analyses have led to a variety of new schemes for pathologic classification of non-Hodgkin's lymphoma. Such classifications were based in part on the belief that NHL are monoclonal proliferations of lymphoid cells which were blocked at a particular stage of differentiation or are due to cells being activated (Lukes and collins 1974) with resultant increased and uncontrolled proliferation. Lymphomas would therefore be expected to show similarities to cells of the normal immune system. In the early seventies stein and Lennert showed that the majority of non-Hodgkin's lymphomas were derived from B-cells including the large cell types - reticulum cell sarcoma and histiocytic lymphoma (Stein et al 1972,1974). Lymphomas of nodular or follicular pattern were shown to be neoplastic counterparts of germinal centre cells (Jaffe et al 1974). Numerous other studies have shown morphological and immunological similarities between groups of lymphomas and normal nodal and extra-nodal lymphoid cells (stuart and Habeshaw 1976, Habeshaw et al 1977, 1979, Lennert 1978, Weissman et al 1978, Stein et al 1980).

Some of the new classifications such as those of the World Health Organisation (Mathe et al 1976), the British Lymphoma Group (Bennett et al 1974) and Dorfman (Dorfman 1974) were based mostly on morphological features and comparison with normal counterparts. However both the Kiel (Lennert 1978, Stansfeld et al 1988) and the Lukes and Collins (1974) classifications emphasised immunologic cell type in addition to morphology. The Kiel classification (Table 1.1) has the additional advantage of accepting that tumours of similar histological type could be either of $\mathrm{T}$ or $\mathrm{B}$-cell lineage, the classification of Lukes and collins asserting that phenotypic diversity could be identified by cytomorphometry alone. Neverthe- 
less the importance of different histological groups with clinical relevance was appreciated in these new classifications and low and high grade categories with better and poorer clinical outcomes respectively were recognised.

In an effort to resolve the controversy over classification of non-Hodgkin's lymphoma the National Cancer Institute sponsored a large multi-institutional, international comparison study (Rosenberg 1982). Over 1000 cases with long term clinical follow-up were reviewed by a panel of pathologists and the value and reproducibility of six major classifications Rappaport, Lukes and collins, Dorfman, British Lymphoma Group, Kiel and WHO, were assessed. Analysis showed all the classifications to be of value and comparable but none was clearly superior. The panel believed however that a common terminology was required to allow comparisons of results of clinical trials throughout the world and proposed a Working Formulation of NHL for clinical usage (Table 1.2) based upon simple morphological criteria. Being based purely upon morphology the Working Formulation has been criticised in that it lumps together some entities which are biologically distinct and takes no consideration of the cell of origin.

\subsubsection{Prognostic Factors}

Classification of NHL by morphology allows separation into different groupings which have clinical relevance (Rosenberg 1982). However within these groupings differences in clinical outcome are apparent. Most low grade tumours are indolent but incurable and will lead to death after a number of years (Portlock 1983) whereas patients with high-grade tumours given aggressive chemotherapy approximately half will obtain long-term ( $>2$ years) disease-free remission, the remainder not surviving for 
much over 1 year (De Vita et al 1988).

A number of clinical and biological parameters have been studied in an attempt to more accurately predict the behaviour of these lesions. Of the various clinical parameters studied systemic symptoms (such as fever, weight loss and night sweats) and bone marrow involvement (Bloomfield et al 1974), sex and stage (Leonard et al 1983), tumour bulk (Cabanillas et al 1979) and age (Horwich and Peckham 1983) have been shown to be of prognostic value. In high-grade NHL the presence of $B$ symptoms (Fisher et al 1980, Horwich and Peckham 1983), and disseminated disease (Bloomfield et al 1979) are associated with poorer survival.

The biological parameters studied include assessment of proliferation rates by a number of techniques. Thymidine labelling of NHL by a number of groups has been shown to provide data of prognostic significance, high labelling indices being associated with poor survival (Costa et al 1981, Kvaloy et al 1985, Holte et al 1987). The numbers of cells in s-phase of the cell-cycle as measured by flow cytometry may be associated with survival (Roos et al 1985) although this is not a consistent finding (Morgan et al 1986). The relatively simple method of assessing proliferative activity by counting mitotic fingers has been shown by some workers to be of prognostic significance (Evans et al 1978) although this is not a consistently reported observation (Warnke et al 1982, Ellison et al 1987). The MCA Ki67 which recognises a proliferation associated nuclear antigen (Gerdes et al 1984) may predict a poor prognostic group of low-grade NHL (Hall et al 1988). Immunophenotypic studies have been included in some studies but have shown conflicting results. A "null" cell phenotype appears associated with poor survival (Bloomfield et al 1979). In a number of series $\mathrm{T}$-cell NHL are more aggressive than their B-cell counterparts 
(Lindemalm et al 1983, Brown et al 1989) whereas similar clinical behaviour is seen in other series (Cossman et al 1984, Horning et al 1986). The non-lineage specific markers CD71 (transferrin recepter) and 4F2 both of which are associated with lymphoid activation and proliferation have been reported to be associated with prognosis (Habeshaw et al 1983, Pileri et al 1984, Holte et al 1987). Analysis of chromosomal abnormalities may also provide clinically useful information, certain deletions and duplications being associated with poor survival in high-grade NHL (Yunis et al 1989). 
Table 1.1 Kiel Classification of Non-Hodgkin's Lymphoma (B-cell type).

\section{Low Grade}

Lymphocytic - Chronic lymphocytic and prolymphocytic; hairy cell leukaemia.

Lymphoplasmacytic/lymphoplasmacytoid (LP immunocytoma) . Plasmacytic

Centroblastic/centrocytic - follicular +/- diffuse - diffuse

Centrocytic

\section{High Grade}

Centroblastic

Immunoblastic

Large cell anaplastic ( $\mathrm{Ki}-1$ +ve).

Burkitt lymphoma

Lymphoblastic

\section{Rare Types}


Table 1.2 Working Formulation of Non-Hodgkin's Lymphoma.

\section{Low Grade}

A. Malignant lymphoma, small lymphocytic:- consistent with CLL, plasmacytoid.

B. Malignant lymphoma, follicular:- predominantly small cleaved cell, diffuse areas, sclerosis.

c. Malignant lymphoma, follicular:- mixed small cleaved and large cell, diffuse areas, sclerosis.

\section{Intermediate Grade}

D. Malignant lymphoma, follicular:- predominantly large cells, diffuse areas, sclerosis.

E. Malignant lymphoma, diffuse:- small cleaved cell, sclerosis.

F. Malignant lymphoma, diffuse:- mixed small and large cell, sclerosis, epithelioid cell component.

G. Malignant lymphoma diffuse:- large cell-cleaved cell, non-cleaved cell, sclerosis.

\section{High Grade}

H. Malignant lymphoma, large cell, immunoblastic:plasmacytoid, clear cell, polymorphous, epithelioid cell component.

I. Malignant lymphoma lymphoblastic:- convoluted cell, non-convoluted cell.

J. Malignant lymphoma small cleaved cell:- Burkitt's, follicular areas.

Miscellaneous including extramedullary plasmacytoma. 


\subsection{CASES}

Cases included in this study were sequential cases of Bcell NHL diagnosed in the immunopathology laboratory Edinburgh University Pathology Department, during the period August 1984 to January 1987 inclusive and all cases of B-cell NHL diagnosed in the department during the period July 1982 to July 1984 in which tissue had been snap frozen in liquid nitrogen and stored at $-70^{\circ} \mathrm{C}$. Cases were diagnosed as B-cell lymphomas if they expressed one or more pan-B cell antigens and/or expressed monotypic immunoglobulin light chain. T-cell lymphomas, identified by expression of $\mathrm{T}$-lineage specific antigens (CD2, CD3 and CD7) were excluded (Krajewski et al 1988).

\subsection{TISSUE COLLECTION AND HANDLING}

Tissue was received fresh from the operating theatre. Representative portions were taken for cryostat sections and for fixation in $4 \%$ buffered formaldehyde and paraffin sectioning. In all cases where sufficient tissue was available material was taken for snap-freezing in liquid nitrogen and storage at $-70^{\circ} \mathrm{C}$.

\subsection{IMMUNOHISTOCHEMICAL STAINING}

Cryostat sections were cut at 3-4 microns from either freshly frozen material or from tissue stored at $-70^{\circ} \mathrm{C}$, allowed to air dry at room temperature for $30 \mathrm{~min}$ before fixing in 100 per cent acetone for $20 \mathrm{~min}$. 
The procedure is summarised in Table 2.1. Sections were washed in Tris buffered saline (TBS) (0.5M tris, 1M HCL, pH7.6) followed by TBS containing $20 \%$ normal rabbit serum (NRS) for $10 \mathrm{~min}$. Excess fluid was then tipped off and 50 ul of the primary antibody diluted in TBS/NRS was added and incubated in a wet box for $30 \mathrm{~min}$. The slides were then washed twice in TBS for $10 \mathrm{~min}$, the area around the sections wiped with a paper tissue and $50 \mu l$ of rabbit anti-mouse Ig conjugated to peroxidase (Dako P-260) diluted 1:20 in TBS/NRS added. Following $30 \mathrm{~min}$. incubation at room temperature in a wet box sections were washed twice in TBS for $5 \mathrm{~min}$. The area around the sections was wiped dry with a tissue and the slide flooded with freshly made substrate $(1 \mathrm{mg} / \mathrm{ml}$ diaminobenzidine in $0.02 \mathrm{M}$ tris HCL with $0.01 \mathrm{M}$ imidazole pH7.6). $1004 \mathrm{l}$ of $1 \%$ $\mathrm{H}_{2} \mathrm{O}_{2}$ was added to the substrate immediately before use and the reaction stopped after $5 \mathrm{~min}$ by immersion in tap water for $2 \mathrm{~min}$. The slides were then counterstained in haematoxylin, washed in water, briefly dipped in lithium carbonate, before washing again. The slides were then dehydrated through alcohol to xylene before being mounted in Histomount.

Negative controls were included by omitting the primary antibody. In the majority of cases small numbers of immunoreactive neoplastic or residual normal lymphoid cells were present which acted as intrinsic positive controls. In the small number of cases where sections were completely negative when stained with an antibody the proceedure was repeated with the inclusion of a positive control section of reactive lymph node or known positive lymphoma. 


\subsubsection{Direct Immunofluorescence}

The proceedure is summarised in Table 2.2. $F(a b)_{2}$ antibodies at the appropriate dilution, conjugated to fluorescein isothiocyanate (FITC) or tetraethylrhodamine urothiocyanate (TRIC) were added directly to the sections and incubated at room temperature for $20 \mathrm{~min}$. slides were then washed twice in TBS for $5 \mathrm{~min}$ before being mounted in glycerol-saline and viewed under ultra violet light using a Leitz laborlux 12 microscope. Incident light was provided by a HBO 50 watt mercury short arc lamp. For FITC 450-490 nm exciting and $515 \mathrm{~nm}$ suppression filters were used. 530-560 $\mathrm{nm}$ and $580 \mathrm{~nm}$ exciting and suppression filters were used for visualising TRIC.

\subsection{ANTIBODIES}

The antibodies used, their source, specificity and dilution used are shown in Table 2.3. At the outset of the study HD37, SRFB6, MHM6 and Dako-Kil were not available but were included at a later date. The antibodies used were selected because of postulated reactivity with antigens expressed by B-cells at different stages of in vivo and in vitro activation and differentiation. They were used at dilutions ascertained following titration against normal lymph nodes to give optimal staining in tissue sections of lymphoid cells in a manner consistent with their previously documented reactivity and manufacturers data sheets and with minimal background staining.

\section{Anti-Ig}

Anti-kappa, anti-lambda and anti-IgM antibodies were used by immunoperoxidase on cryostat sections in all cases. In addition in a number of other cases further staining for Ig was carried out by immunofluorescence with TRIC conjugated anti-kappa and anti-lambda and FITC conjugated 
antibody to kappa or lambda or mu, gamma, delta and alpha heavy chains.

\section{HD37}

HD37 is an IgG1 MCA which reacts with CD19 (Pezzutto et al 1986, Nadler 1986). It detects primary and secondary follicular and extrafollicular B-cells in tissue sections.

$\underline{B 1}$

B1 is an IgG2 MCA which recognises CD2O (Nadler et al 1981, Nadler 1986). It reacts with greater than 95\% of peripheral blood and lymphoid tissue B cells (Stashenko et al 1981).

\section{Dako-B}

Dako-B is an IgG2b MCA. It recognises CD22 (Nadler 1986) and labels primary and secondary follicle cells and isolated extrafollicular B-cells in cryostat sections of lymphoid tissue (Mason et al 1987).

\section{F8-11-13}

F8-11-13 is an IgG1 MCA which reacts with CD45R, the high molecular weight restricted form of the leucocyte common antigen (Dalchau and Fabre 1981, McMichael et al 1987). It is expressed by primary and secondary follicular Bcells and also by a subpopulation of T-cells (Dalchau and Fabre 1981, Salter et al 1985).

\section{$\underline{\text { Leul }}$}

Leul is an IgG2 MCA which recognises CD5 (Royston et al 1980, Bernard et al 1984). In normal lymphoid tissue it reacts predominately with $\mathrm{T}$-cells but a minor population of mantle zone lymphocytes may also be positive (Caligaris-Cappio et al 1982). 


\section{FMC8}

FMC8 is an IgG MCA which recognises CD9 (Bernard et al 1984, Zola 1987). It reacts with a proportion of pre-Bcells and $45 \%$ of circulating B cells (Brooks et al 1982).

\section{Dako-CALLA}

Dako-CALLA is an IgG1 MCA which reacts with the human acute Lymphoblastic Leukaemia Antigen (Newman et al 1981) designated CD10 (Bernard et al 1984). CD10 has been shown to be expressed by germinal centre cells in reactive lymphoid tissue (Hsu and Jaffe 1984).

\section{OKT10}

OKT10 is an IgG1 MCA which recognises CD38 (Bhan et al 1981, McMichael et al 1987). In tissue sections it stains plasma cells (Bhan et al 1981) and germinal centre cells but not mantle zone cells (Gobbi et al 1983, Hsu and Jaffe 1984).

\section{S/RFB6}

S/RFB6 is an IgG1 MCA which recognises CD21 (Campana et al 1985). It stains the majority of B-cells in mantle zones and shows strong reactivity in germinal centres (Campana et al 1985).

\section{MHM6}

MHM6 is an IgG MCA which recognises CD23 (Ling et al 1987). It reacts weakly with a variable portion of mantle zone cells and a subpopulation of DRCs in germinal centres (Pallenson and Hager 1987, Mason et al 1986).

\section{Dako-IL2R}

Dako-IL2R is an IgG1 MCA which reacts with CD25 the lowmolecular weight, $55 \mathrm{kDa}$ polypeptide component of the IL2 recepter (Leonard et al 1982, Reinherz et al 1986). In peripheral lymphoid tissue Dako-IL2R labels a varying proportion of lymphoid cells in T-cell zones and light 
zones of the germinal centre (Dakopatts data sheet).

\section{Dako Kil}

Dako Kil is an IgG3 MCA which reacts with the 105/120 KDa glycoprotein designated CD30 (McMichael et al 1987). In normal lymphoid tissue Dako-kil reacts with a small population of large cells preferentially located around B-cell follicles (Schwab et al 1982).

\section{OKT9}

OKT9 is an IgG1 MCA which reacts with the transferrin receptor, CD71 (Reinherz et al 1980, Knapp et al 1989). In normal lymphoid tissue it reacts with germinal centre cells and scattered cells outside follicles (Hsu and Jaffe 1984). Most mantle zone cells are negative (Murray et al 1984).

\section{$\underline{4 \mathrm{~F} 2}$}

$4 \mathrm{~F} 2$ is an IgG2a MCA which recognises a disulphide linked glycoprotein of unknown function expressed by macrophages and proliferating lymphoid cells (Haynes et al 1981. Kehrl et al $1984 a, b)$.

\section{$\underline{\mathrm{L} 243}$}

L243 is an IgG2 MCA which recognises a non-polymorphic determinant of MHC Class II HLA DR (Lampour and Levy 1980, Brodsky 1984). In lymph nodes L243 reacts with primary and secondary follicular B-cells and a variable number of paracortical cells (Hsu and Jaffe 1984).

\section{B7/21}

$\mathrm{B} 7 / 21$ is an IgG3 MCA which recognises MHC Class II DP and reacts in tissue sections with follicular $B$ cells and a minority of cells in the paracortex (Krajewski et al 1985). 


\section{Leu 10}

Leu10 is an IgG1 MCA which recognises a determinant on most but not all HLA Class II DQ molecules (Brodsky 1984). In lymph nodes it reacts with scattered cells of the paracortex and all primary and secondary follicular B-cells (Krajewski et al 1985).

\section{$\underline{\mathrm{Tu} 22}$}

Tu22 is an IgG MCA which reacts with MHC Class II DQ (Brodsky 1984). In lymph nodes it reacts with scattered cells of the paracortex and all primary and secondary follicular B-cells (Krajewski et al 1985).

\section{Leu 4}

Leu 4 is an IgG1 MCA which reacts with CD3 (Ledbetter et al 1981). It is a pan-T-cell marker and does not react with B-cells.

\subsection{ASSESSMENT OF STAINING}

Cells were scored as being positive if they showed cytoplasmic or surface membrane staining. The pattern of immunoglobulin staining and pan-B-cell staining was used in conjuction with toluidine blue and $\mathrm{H}$ and $\mathrm{E}$ stained sections to show the distribution of neoplastic and reactive $\mathrm{B}-\mathrm{cell}$ s in the tissues studied. Those areas were identified in serial sections and the cells assessed for immunoreactivity with the other markers. Counterstaining immunoperoxidase stained sections with haematoxylin allowed additional information on the distribution and type of cells staining. The number of cells staining was assessed in a semi-quantitative manner using a four point scale. The estimated population of malignant cells were scored as $>70 \%=3+$ (figure 2.1 ), approximately $30-70 \%$ $=2+$ (figure 2.2), approximately $5-30 \%=1+$ (figure 2.3 ), approximately $<5 \%=0$ (figure 2.4 ). 
Figure 2.1

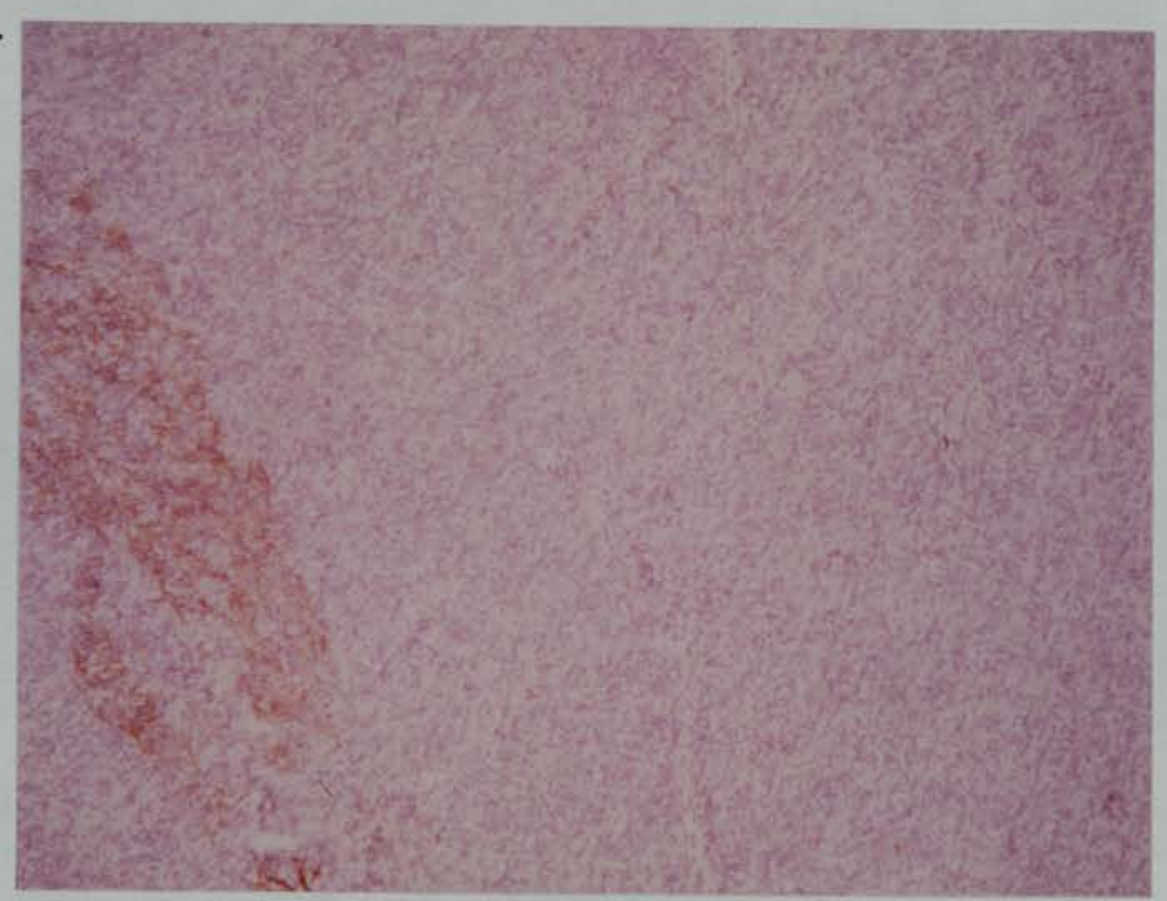

Centroblastic lymphoma (LG no.1051) reacted with S/RFB6 (anti-CD21) showing no staining of tumour cells but residual DRCs are positive. Scored as 0 .

\section{Figure 2.2}

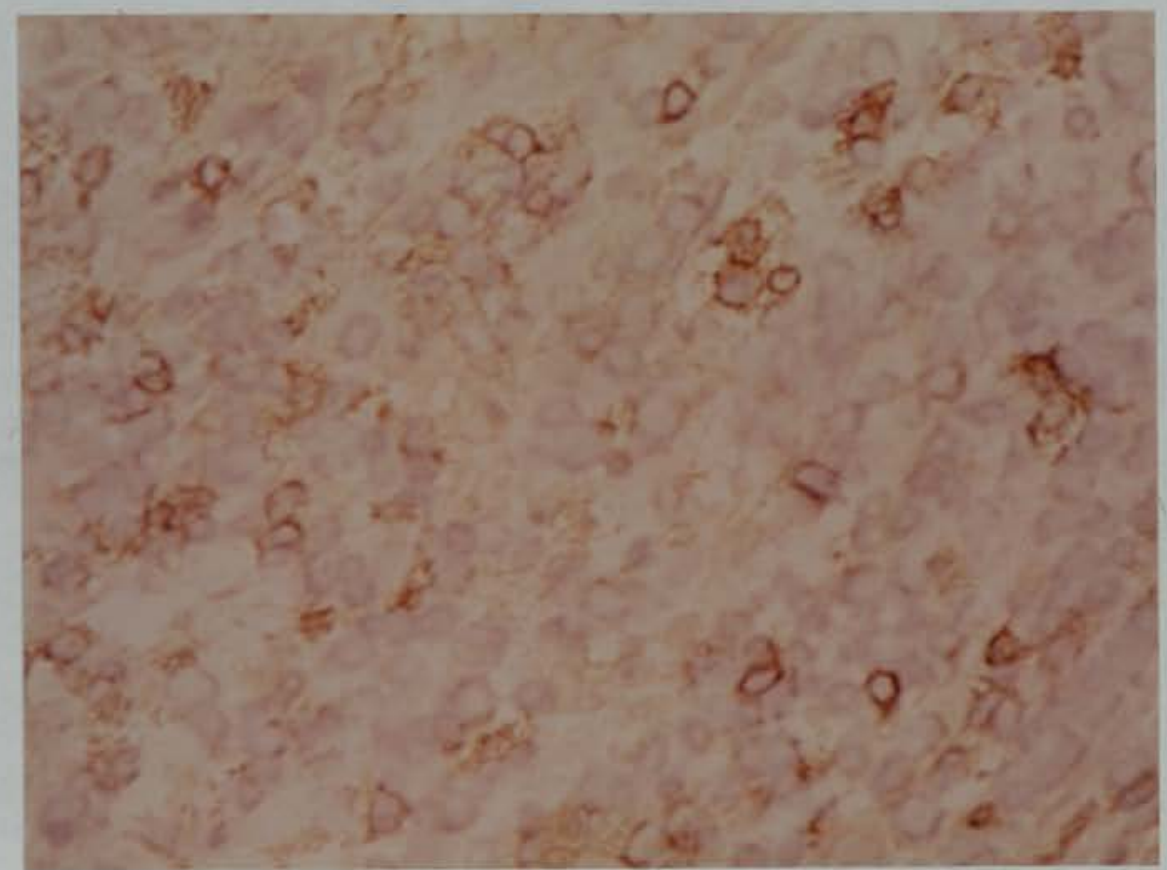

Immunoblastic lymphoma (LG no 620) stained with OKT10 (anti-CD38) showing a minor proportion of positive cells. scored as + . 


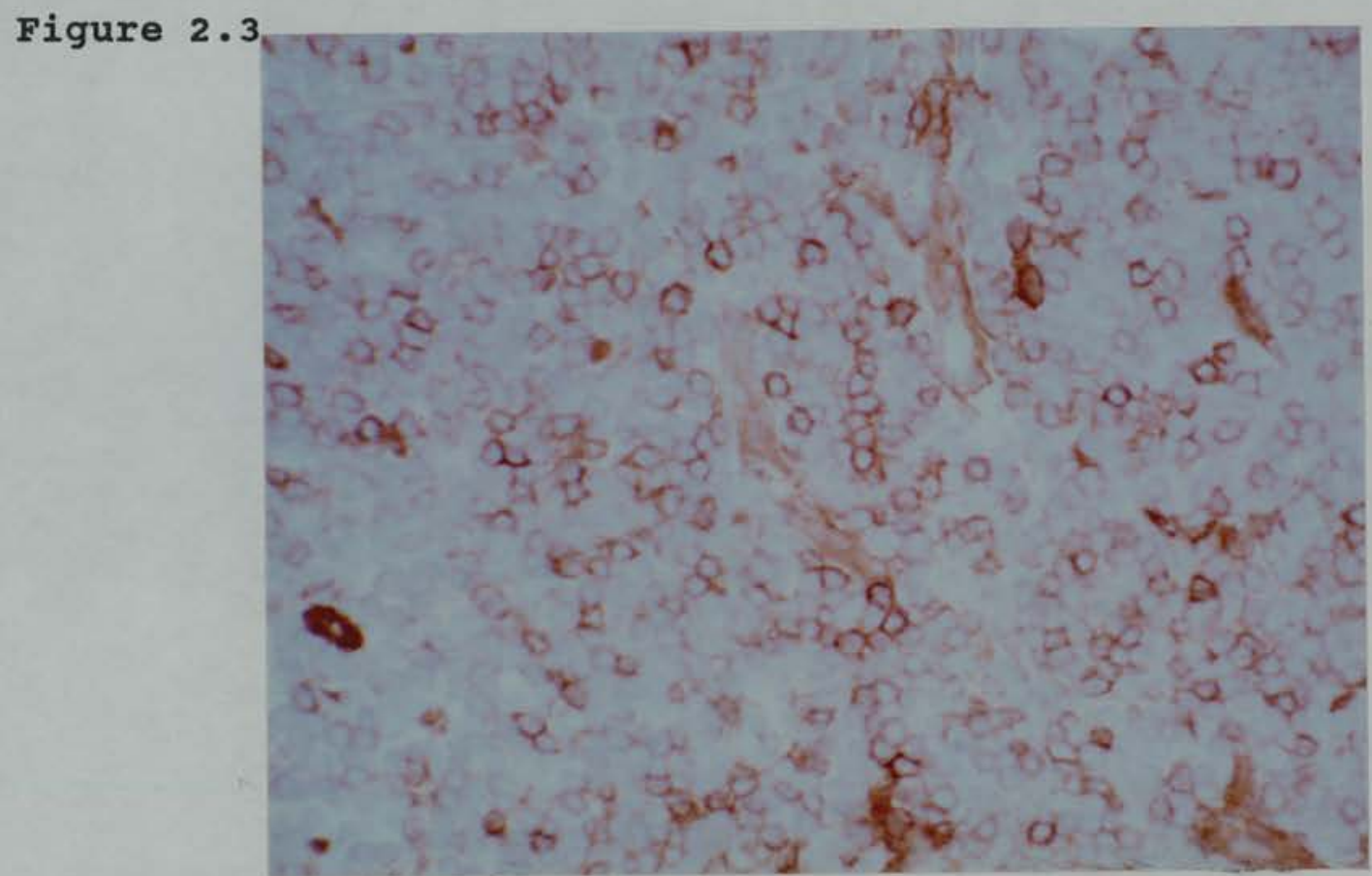

Lymphocytic lymphoma (LG no 919) reacted with OKT9 (antiCD71) showing a proportion of the cells staining. Scored as ++ .

\section{Figure 2.4}

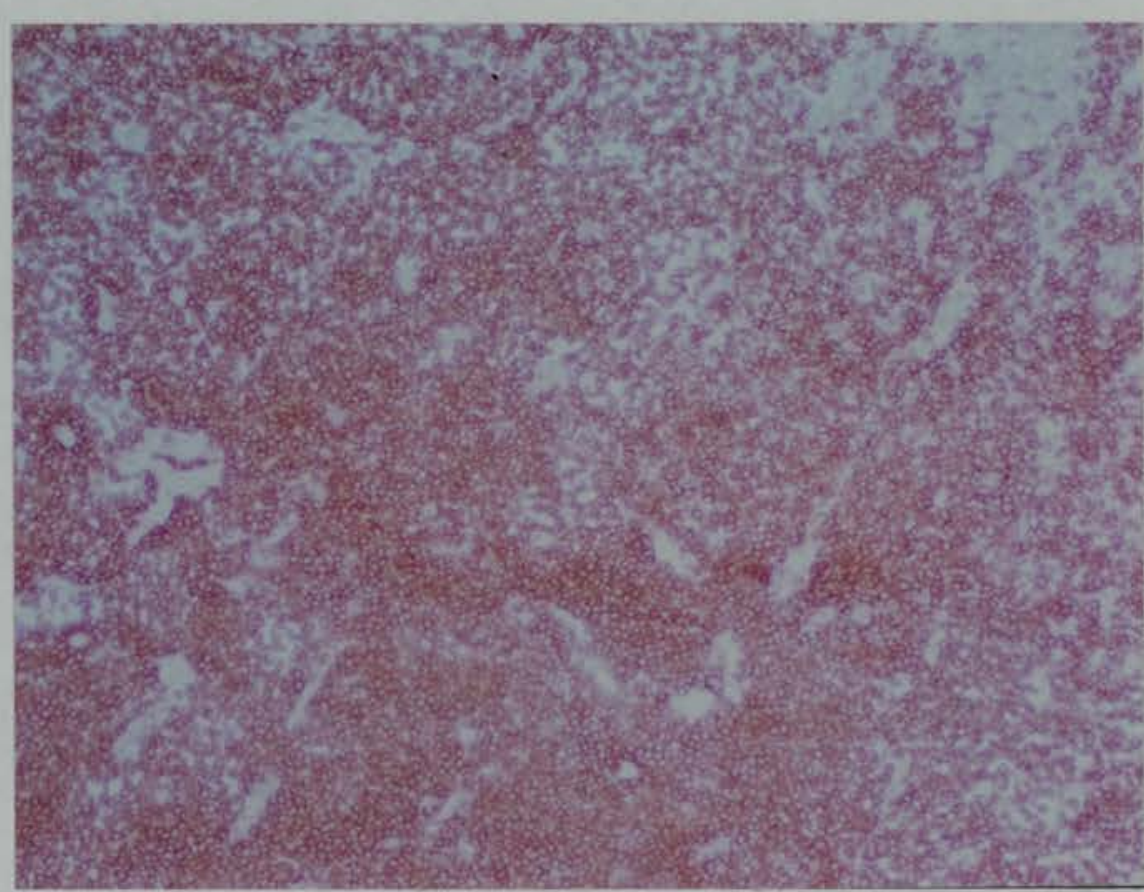

Diffuse Centroblastic/centrocytic lymphoma (Case LG no 85) stained with F8-11-13 (anti-CD45R). The vast majority of cells are positive. Scored as +++ . 

TION

$\mathrm{H}$ and $\mathrm{E}$ stained sections of formalin fixed paraffin embedded tissues were diagnosed by myself and Dr A $S$ Krajewski as part of the routine diagnostic service provided by Edinburgh University Department of Pathology. Cases were classified by consensus using the Kiel classification (Lennert 1978, Stansfeld et al 1988) and the Working Formulation (Rosenberg 1982) (see Tables 1.1 and 1.2). It is becoming evident that malignant lymphomas of MALT have distinctive clinical and biological features (Isaacson and Wright 1984, Isaacson and spencer 1987). classifications of this group of tumours are beginning to be developed (Isaacson et al 1988) but were not in general use during the period of this study. Lymphomas of MALT were therefore included with other NHL and classified by Kiel and Working Formulation.

\subsection{CLINICAL DATA}

Clinical information was obtained from the clinical notes of patients. Notes were obtained from 110 of the 148 cases phenotyped, but were not traced for the remainder. Data was collected for age, sex, stage according to the Ann Arbor classification (Carbonne et al 1971), bone marrow involvement, therapy induction of remission and survival.

Treatment was separated into two groups :- a) low grade therapy included treatments which were given for palliative purposes and included surgery, radiotherapy, cyclophosphamide, vincristine and prednisolone, b) high grade therapy were those treatments which were potentially 
curative or able to induce long term remission and included CHOP $+/-$ bleomycin, BACOD, MOPP, MVPP, CHIVPP, MPEEC, MCHOP+/-bleomycin.

Complete remission was defined as disappearance of all disease present at the start of the therapy . Partial remission was defined as a reduction in tumour bulk to less than $50 \%$ whereas no reduction or reduction of less than $50 \%$ were grouped as showing no remission.

Survival was calculated from the date of diagnosis to the date of death or last follow-up. All patients on which clinical data were available were included in the survival analysis regardless of the type of treatment or cause of death.

\subsection{STATISTICAL ANALYSIS}

Comparisons between groups $i$ those positive or negative for an antigen, were made by the Chi-square test. Survival curves were estimated by the Algorithm of Lee and Desu (Lee and Desu 1972) using SSPX software. Cox's proportional hazards regression model (Cox 1972) was used to adjust the simultaneous effect of different prognostic factors on survival. 
Table 2.1. Indirect Immunoperoxidase Method

1. Cut cryostat sections at 3-4 microns. Air dry for 30 min at room temperature.

2. Fix in 100 per cent acetone for $20 \mathrm{~min}$.

3. Wash in TBS (10 $\mathrm{min})$.

4. Wash in TBS $/ 20 \%$ normal rabbit serum(NRS).

5. Add $50 \mu l$ primary antibody diluted in TBS/NRS, incubate in a wet box for $30 \mathrm{~min}$ at room temperature.

6. Wash twice in TBS (10 min).

7. Add rabbit anti-mouse Ig conjugated to peroxidase, incubate in a wet box for $30 \mathrm{~min}$ at room temperature.

8. Wash twice in TBS ( $5 \mathrm{~min})$.

9. Add lmg per $\mathrm{ml}$ diaminobenzidine $/ 0.02 \mathrm{M}$ tris $\mathrm{HCL} / 0.01 \mathrm{M}$ imidazole $(\mathrm{pH} 7.6)+100 \mu \mathrm{l} 1 \% \mathrm{H}_{2} \mathrm{O}_{2}$ for $2 \mathrm{~min}$.

10. Wash in tap water.

11. Stain with haematoxylin.

Table 2.2. Direct Immunofluorescence Method

1. Cut cryostat sections at 3-4 microns. Air dry for 30 min at room temperature.

2. Fix in 100 per cent acetone for $20 \mathrm{~min}$.

3. Wash in TBS $(10 \mathrm{~min})$.

4. Add $50 \mu 1$ of antibody conjugate (IgH-FITC, K-FITC/LTRIC, or K-TRIC/L-FITC), incubate in a wet box for $20 \mathrm{~min}$ at room temperature.

5. Wash twice in TBS $(5 \mathrm{~min})$.

6. Mount in glycerol-saline and view under UV light. 
Table 2.3 Antibodies used in this study

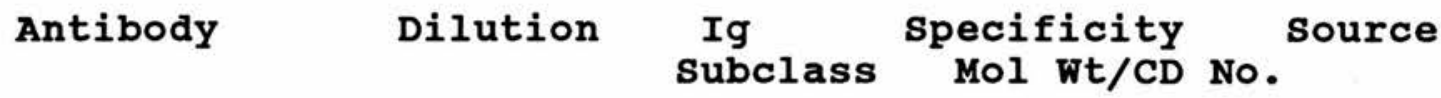

\begin{tabular}{|c|c|c|c|c|}
\hline \\
\hline anti kappa & \multicolumn{4}{|c|}{ Anti-Immunoglobulin } \\
\hline anti kappa-FITC & $1: 20$ & G & kappa & Kallestad \\
\hline anti kappa-TRIC & $1: 20$ & G & kappa & Kallestad \\
\hline anti lambda & $1: 5$ & G1 & lambda & Dakopatts \\
\hline anti lambda-FITC & $1: 20$ & G & lambda & Kallestad \\
\hline anti lambda-TRIC & $1: 20$ & G & lambda & Kallestad \\
\hline anti IgM & $1: 2000$ & G1 & IgM & Dakopatts \\
\hline DA6127 & $1: 20$ & G2 & IgM & K Guy \\
\hline anti IgM-FITC & $1: 20$ & G & IgM & Kallestad \\
\hline anti IgD & $1: 50$ & G1 & IgD & Dakopatts \\
\hline anti IgD-FITC & $1: 20$ & G & IgD & Kallestad \\
\hline anti IgG & $1: 5000$ & G1 & IgG & Dakopatts \\
\hline anti IgG-FITC & $1: 20$ & G & IgG & Kallestad \\
\hline anti IgA & $1: 2000$ & G1 & IgA & Dakopatts \\
\hline \multicolumn{5}{|l|}{ "Pan" B-cell } \\
\hline HD37 & $1: 200$ & G1 & $40 / C D 19$ & Dakopatts \\
\hline B1 & $1: 10$ & G2 & $35 / C D 20$ & Coulter \\
\hline Dako-B & $1: 10$ & $\mathrm{G} 2 \mathrm{~b}$ & $135 / C D 22$ & Dakopatts \\
\hline $\begin{array}{l}\text { F8-11-13 } \\
\text { "Restricted" B-Ce }\end{array}$ & $1: 1000$ & G1 & $220 / C D 45 R A$ & J Fabre \\
\hline Leu 1 & $1: 100$ & G2 & $65 / C D 5$ & BD \\
\hline FMC8 & $1: 20$ & G & $24 / C D 9$ & H Zola \\
\hline Dako Calla & $1: 5$ & G1 & $100 / C D 10$ & Dakopatts \\
\hline OKT10 & $1: 40$ & G1 & $45 / \mathrm{CD} 38$ & Ortho \\
\hline \multicolumn{5}{|c|}{ "Activation-associated" } \\
\hline S/RFB6 & $1: 10$ & G1 & $140 / C D 21$ & SAPU \\
\hline MHM6 & $1: 20$ & G & $45 / \mathrm{CD} 23$ & $\mathrm{~J}$ Gordon \\
\hline Dako-IL2-R & $1: 200$ & G1 & $55 / C D 25$ & Dakopatts \\
\hline Dako-Kil & $1: 5$ & G3 & $116,126 / C D 30$ & Dakopatts \\
\hline OKT9 & $1: 10$ & G1 & $90 / C D 71$ & ortho \\
\hline $4 \mathrm{~F} 2$ & $1: 20$ & G2a & $40,80 / \mathrm{NA}$ & ATCC \\
\hline \multicolumn{5}{|l|}{ MHC Class II } \\
\hline L243 & $1: 20$ & G2a & DR & ATCC \\
\hline B7/21 & $1: 10$ & G3 & DP & IS Trowbrid \\
\hline \multicolumn{5}{|l|}{ "Pan" T-Cell } \\
\hline Leu 4 & $1: 100$ & G1 & $22,28 / C D 3$ & $\mathrm{BD}$ \\
\hline
\end{tabular}

$\mathrm{BD}=$ Becton Dickenson, $\mathrm{NA}=$ not allocated, SAPU = Scottish Antibody Production Unit, ATCC=American Tissue Culture Collection 


\section{LYMPHOID TISSUE}

\subsection{INTRODUCTION}

As discussed in Chapter 1 lymph nodes may be separated anatomically into three main areas:- cortex, paracortex and medulla (Van der Valk and Meijer 1988). B-cells are present in primary and secondary follicles. Mantle zone cells are believed to be resting cells while germinal centre cells are thought to be actively proliferating (Stein et al 1982). A population of migrating B-cells are also present in the paracortex admixed with T-cells. The medulla contains B-cells which are terminally differentiating and differentiated plasma cells (Lennert 1978, Harris and Bahn 1985). Other B-cell areas such as the marginal zone although readily identified in the spleen (Van Krieken and te Velde 1988) are less well demonstrated in lymph nodes and tonsils. The use of immunohistochemical techniques allows accurate assessment of the stage of activation, proliferation and differentiation of these morphologically defined subsets. The purpose of this component of the study was therefore to stain a group of reactive lymph nodes and tonsils with a panel of MCA against $\mathrm{B}-\mathrm{cell}$ antigens to define antigen expression in different B-cell populations. The results would also be available for subsequent comparison with the phenotypes of the "equivalent" cells in cases of non-Hodgkin's lymphoma. 


\subsection{MATERIALS AND METHODS}

Tissue:- Reactive lymph nodes and tonsils

Immunohistochemical techniques:- Indirect immunoperoxidase

Antibodies:- Table 2.3.

\subsection{RESULTS}

Three tonsils and 8 reactive lymph nodes were studied with the panel of MCA. Reactive lymph nodes were also used for the titration of individual MCA during the period of the study. The results from these individual titrations are not presented but were similar to the results of the detailed analyses.

A summary of the staining pattern seen in the lymph nodes and tonsils is shown in Table 3 with more detailed analysis of individual staining patterns below. 
Table 3 Antigen expression by normal B-cells in tonsilsand reactive lymph nodes.

\section{Antigen Mantle Germinal Centre Paracortex Plasma Cell}

"Pan-B" cell

CD19

CD20

CD22

CD45R

$\begin{array}{ll}+++/ \mathrm{DRC} & +++ \\ +++ & +++ \\ +++ & +++ \\ +++ & +++\end{array}$

$\begin{array}{ll}+ & - \\ + & - \\ + & - \\ +/++ & -\end{array}$

"Restricted-B" cell

\section{CD5}

CD9

CD10

CD38

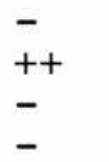

"Activation-Associated"

CD21
CD23
CD25
CD30
CD71
4 F2

$+++$

$+/++$

-

-

$+/++$

$+/++$

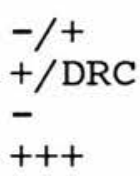

+++
+
+

-

-

$+++$

MHC Class II

HLA DR

HLA DQ

HLA DP
$+/$ DRC

$-/$ DRC

$-/+$

$-$

$+++$

$+++$
$+$

$-1+$

$+/++$

$-1+$

$+/++$

$+/++$
-
-
-
-

"Pan-T" cell

Leu 4

$$
\begin{aligned}
& +++ \\
& +++ \\
& +++
\end{aligned}
$$$$
-1+
$$

++
++
++

$+++$

$+++=>70 \%,++=30-70 \%,+=5-30 \%, 0=<5 \%$ positive cells. DRC = Follicular dendritic network positive. 


\section{$\underline{\mathrm{CD} 19}$}

CD19 was expressed strongly by mantle zone lymphocytes and by germinal centre cells (fig 3.1). A weak dendritic pattern of staining was also present in germinal centres. Variable numbers of lymphoid cells in the paracortex were positive. Plasma cells were negative.

\section{$\underline{\mathrm{CD} 20}$}

CD20 was expressed strongly by germinal centre cells, mantle zone cells and small numbers of cells in the paracortex (fig 3.2). Plasma cells were negative.

\section{$\underline{\mathrm{CD} 22}$}

CD22 was strongly expressed by mantle zone and germinal centre B-cells (fig 3.3). A variable number, usually less than $30 \%$, of paracortical cells were also positive. Plasma cells were negative.

\section{$\underline{\mathrm{CD} 45 \mathrm{R}}$}

CD45R was expressed strongly by germinal centre cells and mantle zone cells (fig 3.4). Variable numbers, 10-50\%, of paracortical lymphocytes also expressed CD45R. Plasma cells were negative.

\section{CD5 and $\mathrm{CD} 3$}

CD5 was expressed strongly by the majority of cells in the paracortex with small numbers of lymphoid cells in mantle zones, germinal centres and in the medulla staining (fig 3.5). Plasma cells were negative. The staining pattern was indistinguishable from that of a pan-T-cell MCA Leu-4 used to show the distribution of T-cells in the cases studied.

\section{$\underline{\mathrm{CD} 9}$}

FMC8 showed strong diffuse dendritic staining in germinal centres (fig 3.6 ) but a population of germinal centre B- 
cells showing cytoplasmic positivity could be identified in areas where the dendritic network was less prominent. A variable proportion of lymphocytes usually less than $30 \%$, were positive in the mantle zone. Occasional positive dendritic processes could also be identified in the mantle zone. Variable numbers of cells were also positive in the paracortex and medulla. Vascular endothelial cells and tonsillar epithelium were also positive.

CD10

only very few cells in the paracortex and mantle zone were CDlo positive (fig 3.7 ). No staining was seen in germinal centres or by plasma cells.

\section{CD38}

CD38 was expressed by a few cells in the mantle zone. Germinal centre cells were positive (fig 3.8) but a small population showed very strong expression similar to that of plasma cells in the medulla.

\section{$\underline{\mathrm{CD} 21}$}

CD21 was expressed by mantle zone cells (fig 3.9). There was diffuse staining of the dendritic network in the germinal centres which made interpretation of reactivity of B-cells difficult. In some areas where dendritic staining was less marked membrane staining of lymphoid cells could be seen. Small numbers of cells in the paracortex expressed CD21. Plasma cells were negative.

\section{$\underline{\mathrm{CD} 23}$}

CD23 was expressed by a proportion, 30-70\%, of mantle zone cells. Germinal centre cells were negative except for a population of dendritic cells in the light zone (fig 3.10). Only small numbers of cells were positive in the paracortex. Plasma cells were negative.

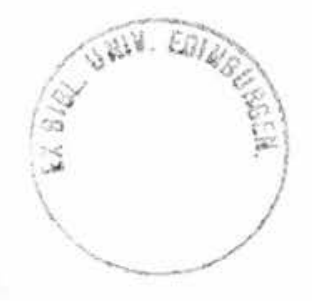




\section{CD25}

CD25 was expressed by cells in the paracortex. In most instances mantle zone and germinal centre cells were negative but in a few cases a population of cells, mostly large blasts in germinal centres were positive (fig 3.11). Plasma cells were negative.

\section{CD30}

CD30 was expressed by occasional cells in the paracortex and in mantle zones (fig 3.12). The majority of mantle zone cells, and germinal centre cells and plasma cells were negative.

\section{CD71}

CD71, the transferrin receptor, was strongly expressed by germinal centre cells and a proportion of mantle zone cells (fig 3.13). A minority of paracortical lymphocytes were positive. Plasma cells were negative.

\section{$\underline{4 \mathrm{~F} 2}$}

4 F2 was expressed by germinal centre cells and by approximately $50 \%$ of mantle zone cells (fig 3.14). A variable proportion of paracortical lymphoid cells, 20-50\%, also expressed 4F2. Plasma cells were negative.

\section{HLA DR, DP, and DQ}

Immunoreactivity for all three antigens were essentially similar. There was strong staining of germinal centre cells and mantle zone cells (fig 3.15). In the paracortex the majority of cells were negative but scattered lymphocytes, interdigitating dendritic reticulum cells and macrophages were positive. 
Figure 3.1

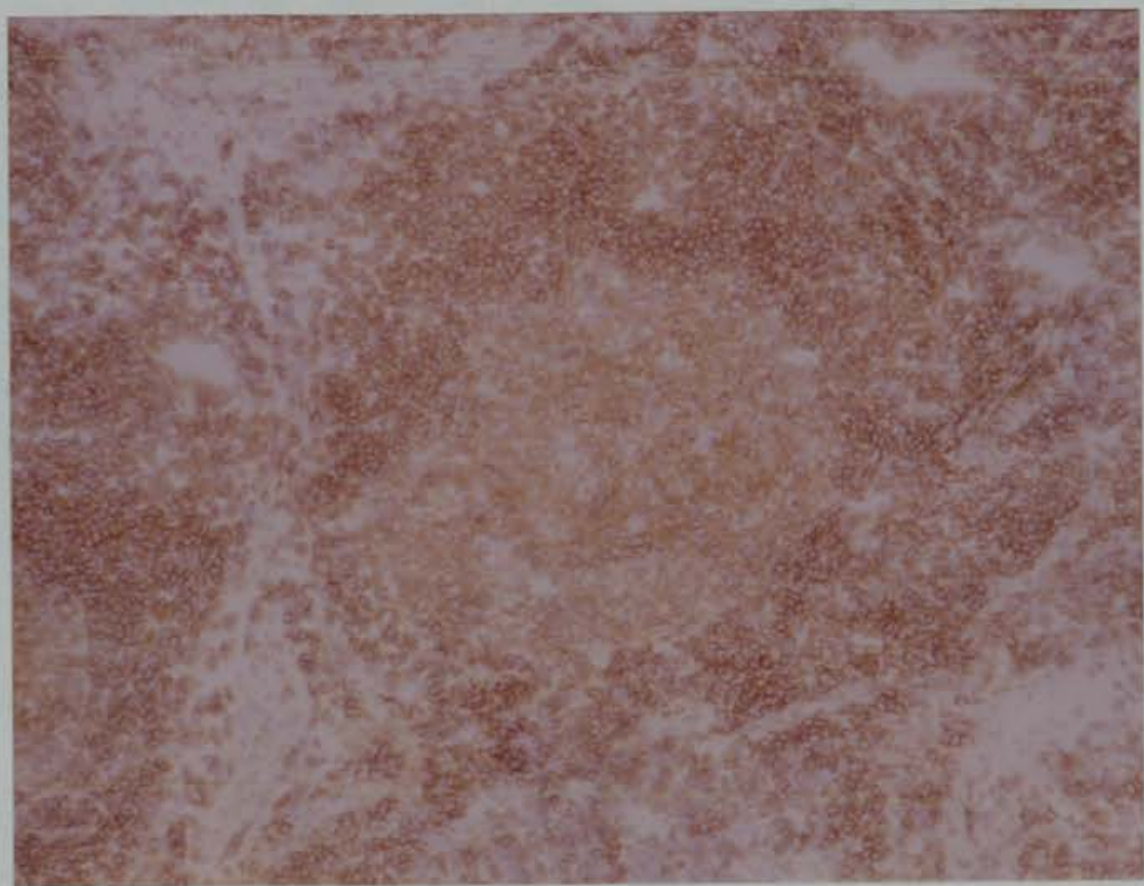

CD19 expression in a reactive lymph node. Germinal centre and mantle zone cells are strongly positive.

Figure $3 \cdot 2$

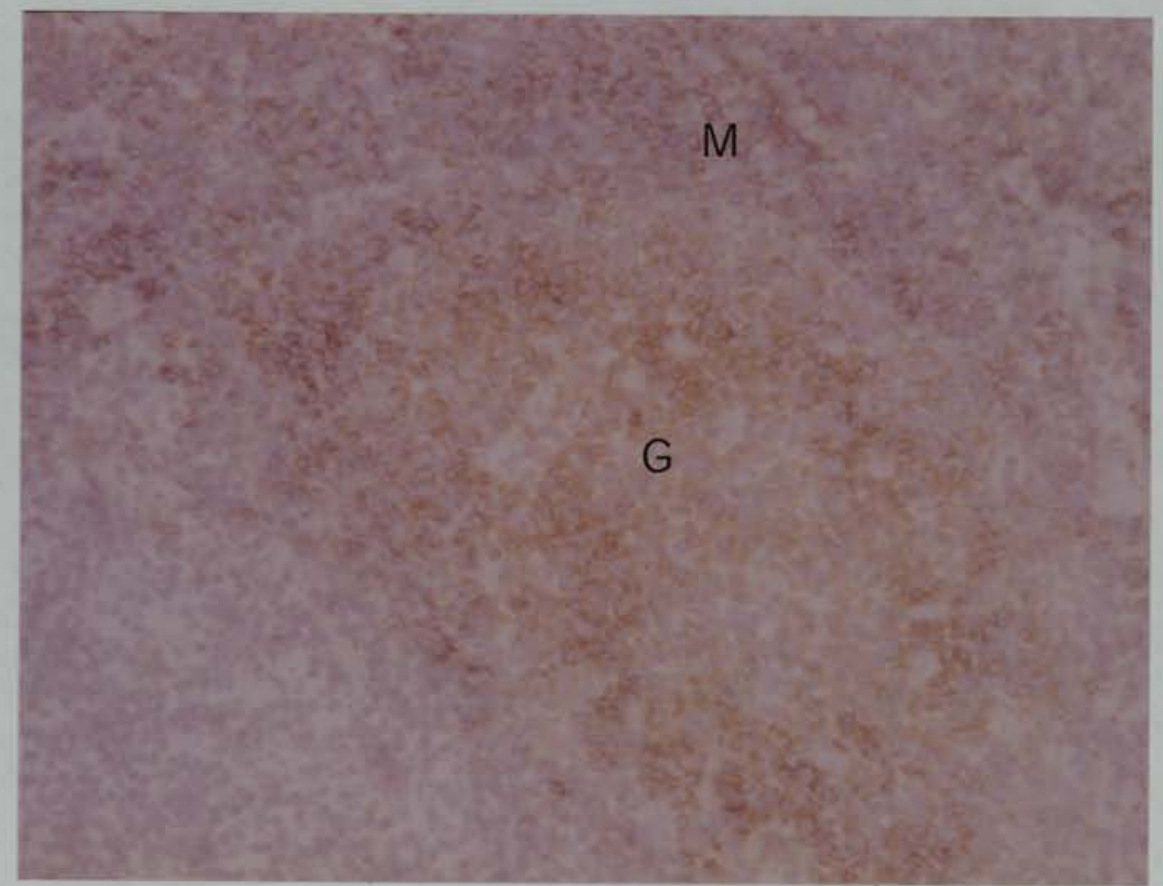

CD20 expression in a reactive lymph node. Germinal centre (G) and mantle zones (M) are positive. 
Figure 3.3

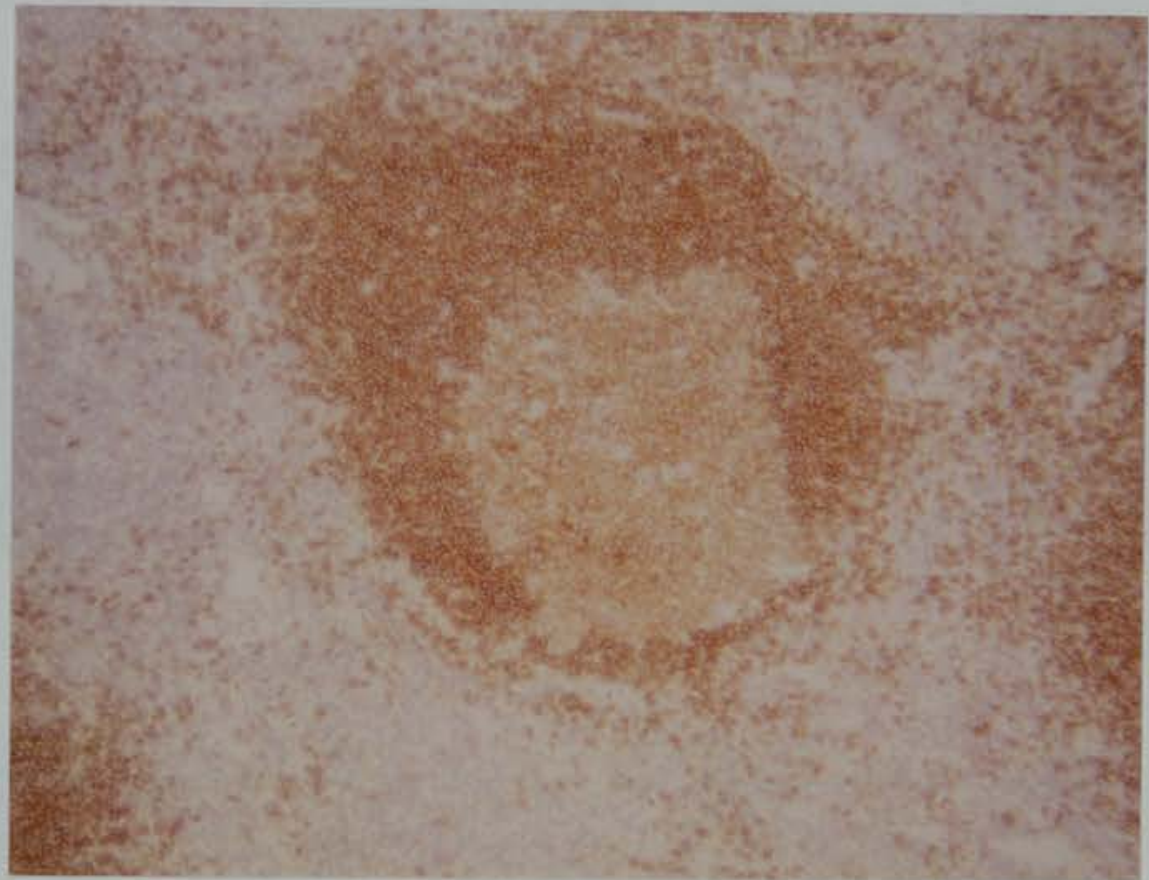

CD22 expression in a reactive lymph node. There is strong expression by both mantle zone and germinal centre cells.

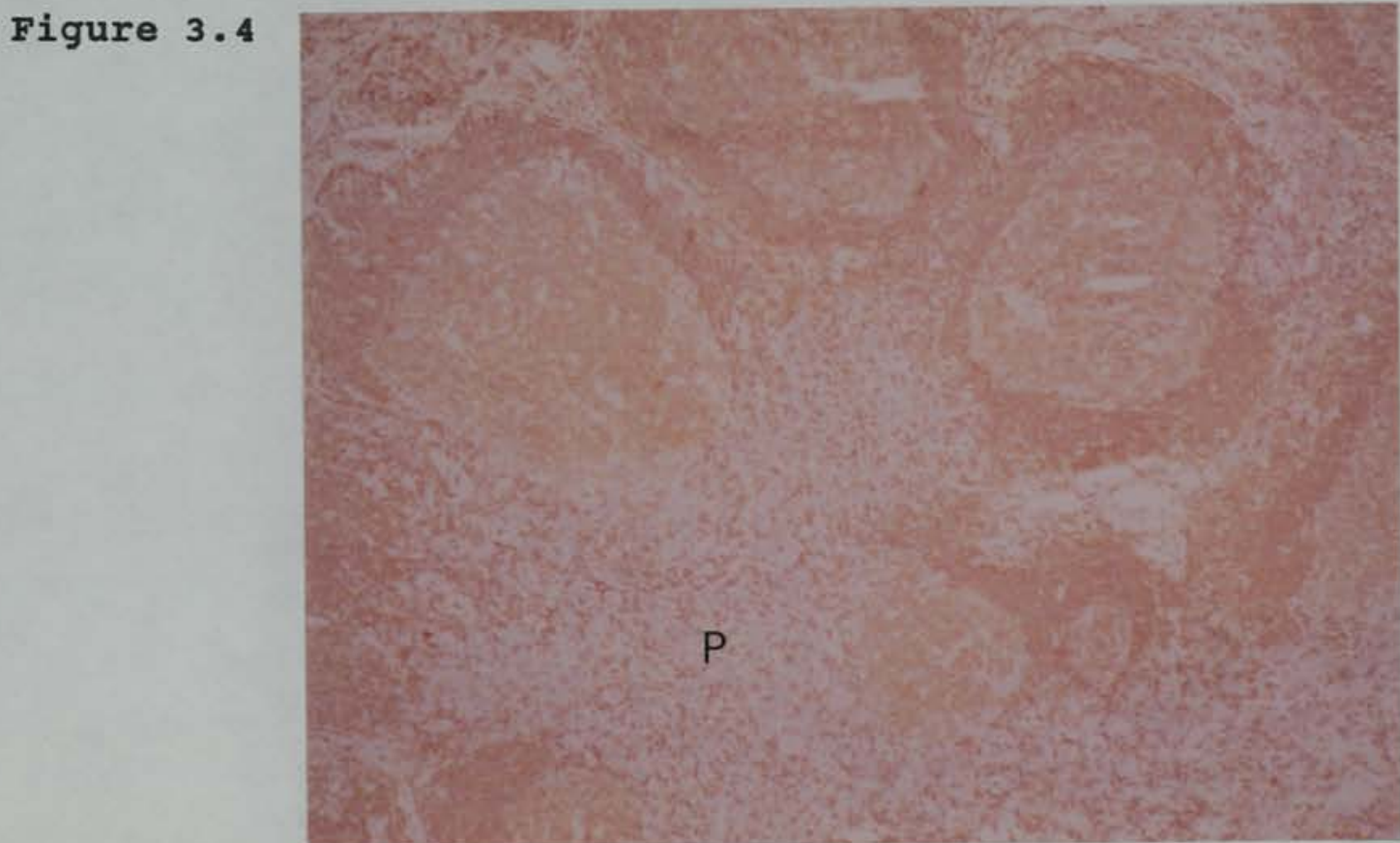

CD45R expression in a reactive lymph node. Mantle zone, germinal centre and a proportion of cells in the paracortex (P) are positive. 
Figure 3.5

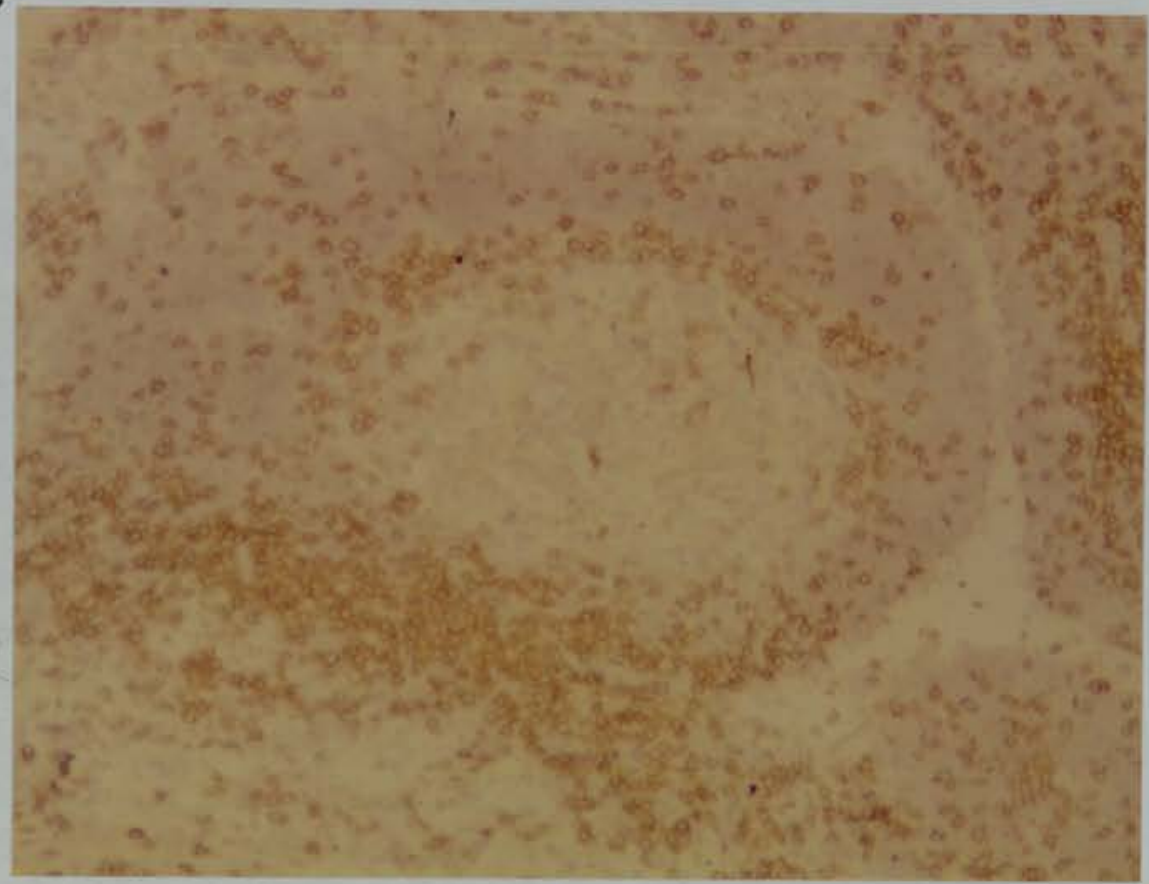

CD5 expression in a reactive lymph node. B-cell rich areas contain only small numbers of positive cells.

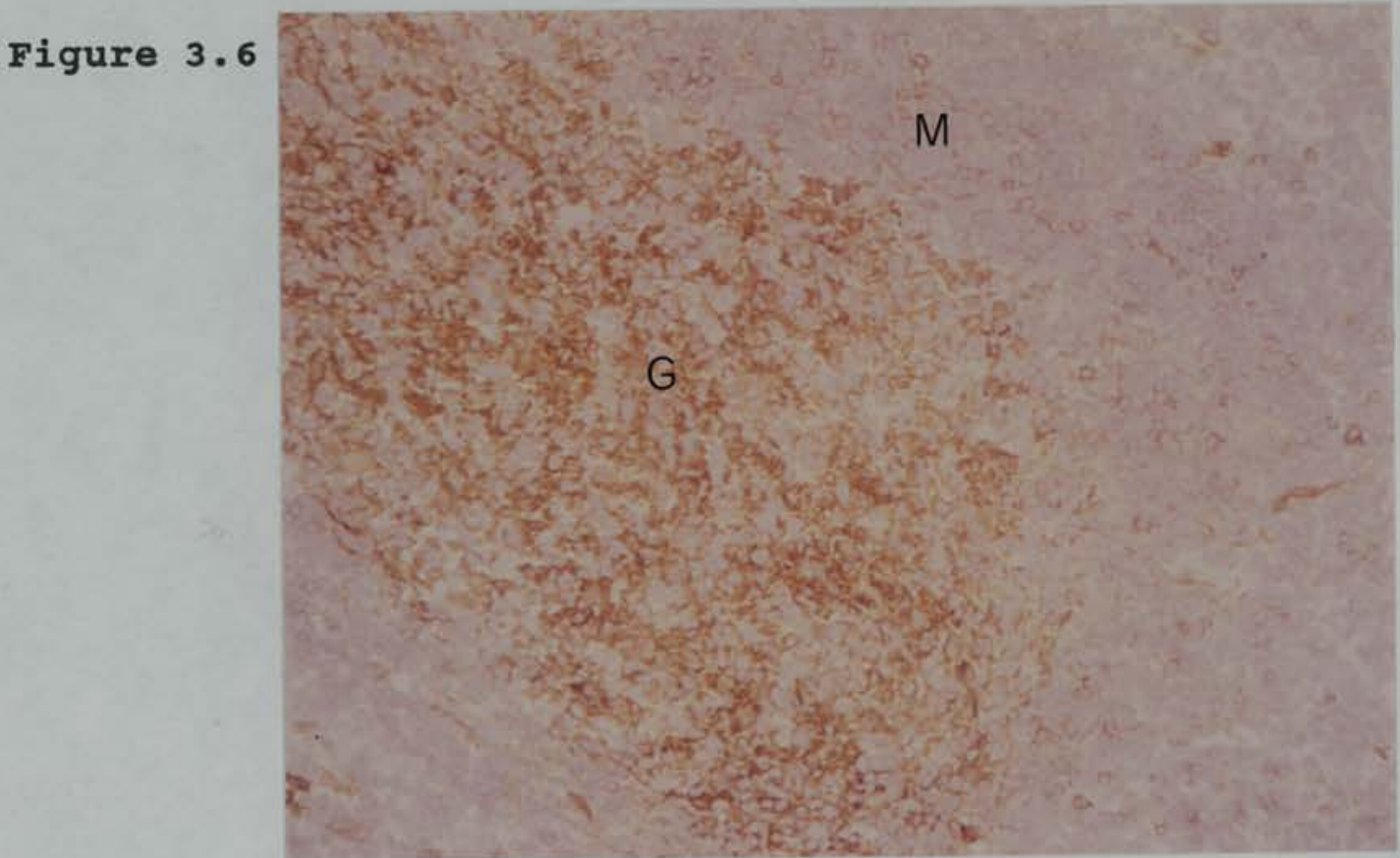

CD9 expression in a reactive lymph node. A proportion of mantle zone (M) and germinal centre cells (G) are positive. DRCs and endothelial cells are also positive. 
Figure 3.7

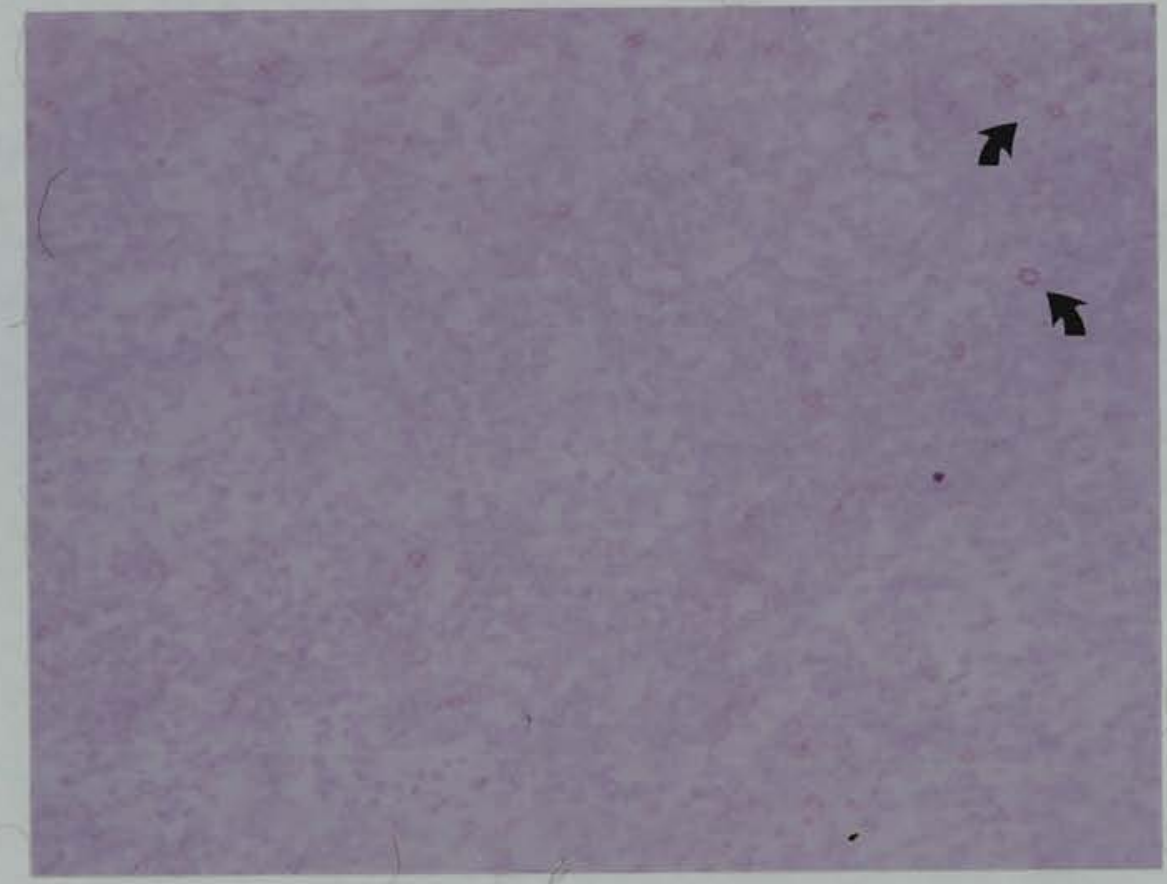

CD10 expression in a reactive lymph node. A few scattered cells are positive. Germinal centre and the majority of mantle cells are negative.

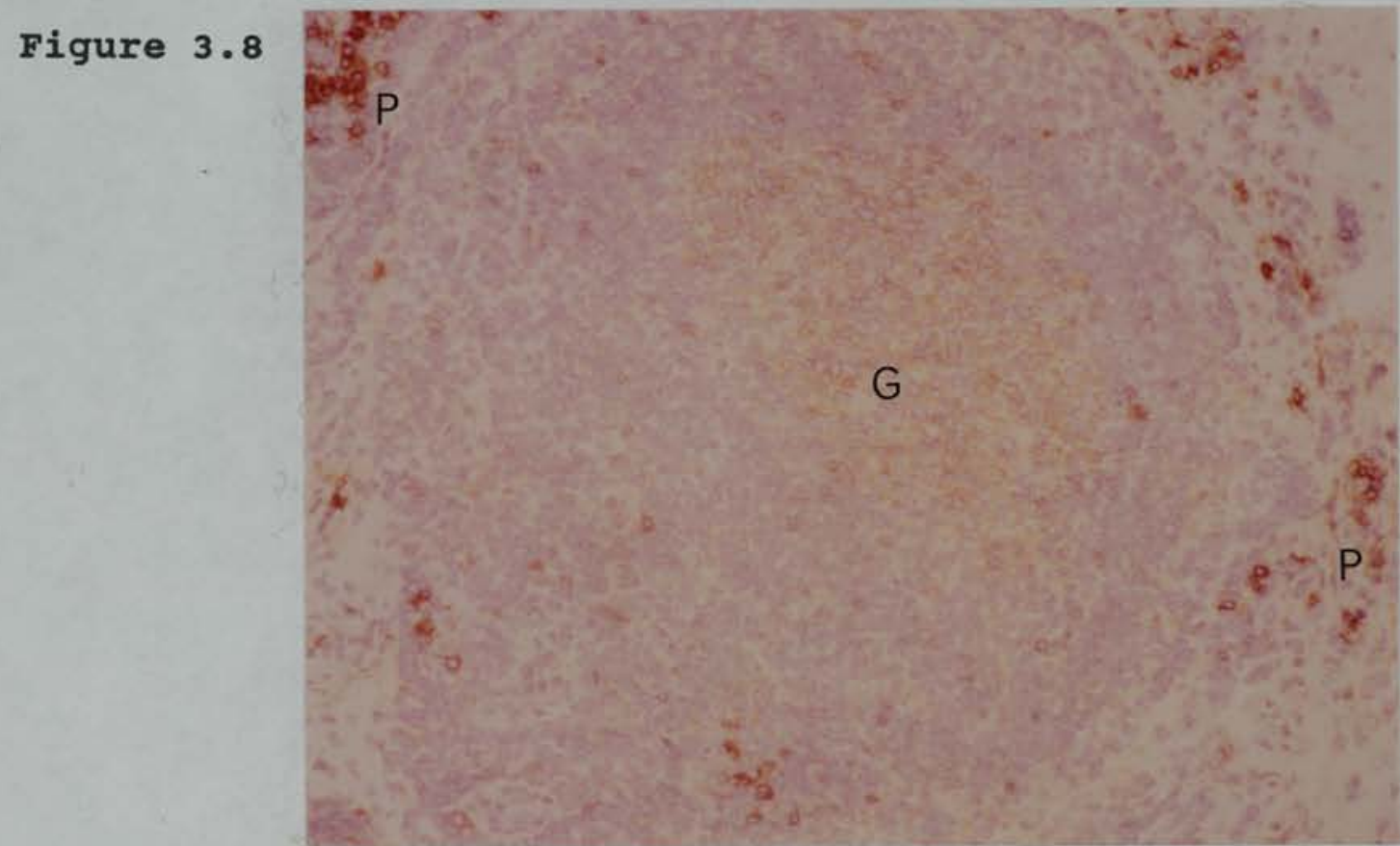

CD38 expression in a reactive lymph node. Germinal centre cells (G) and plasma cells (P) in the medulla are positive. 
Figure 3.9

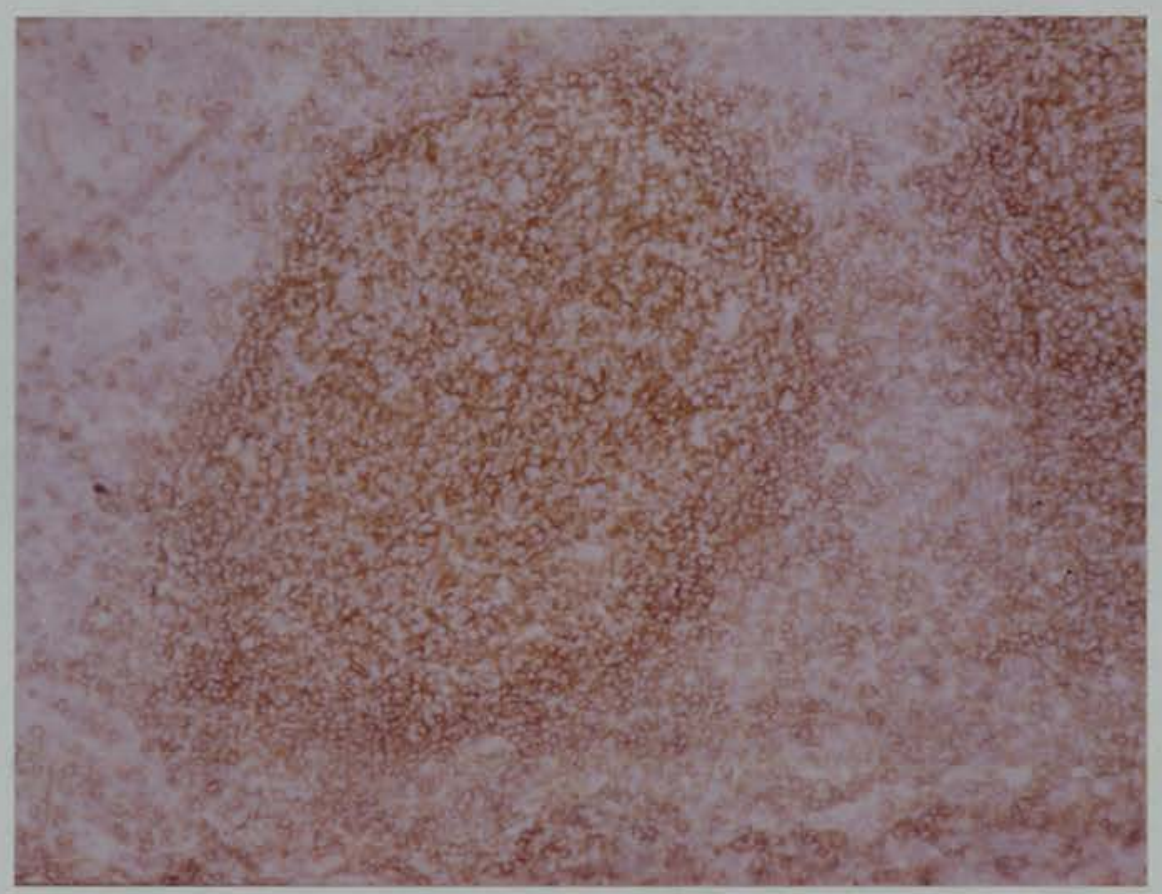

CD21 expression by a reactive lymph node. Mantle zone cells are positive. There is strong dendritic staining in germinal centres.

Figure 3.10

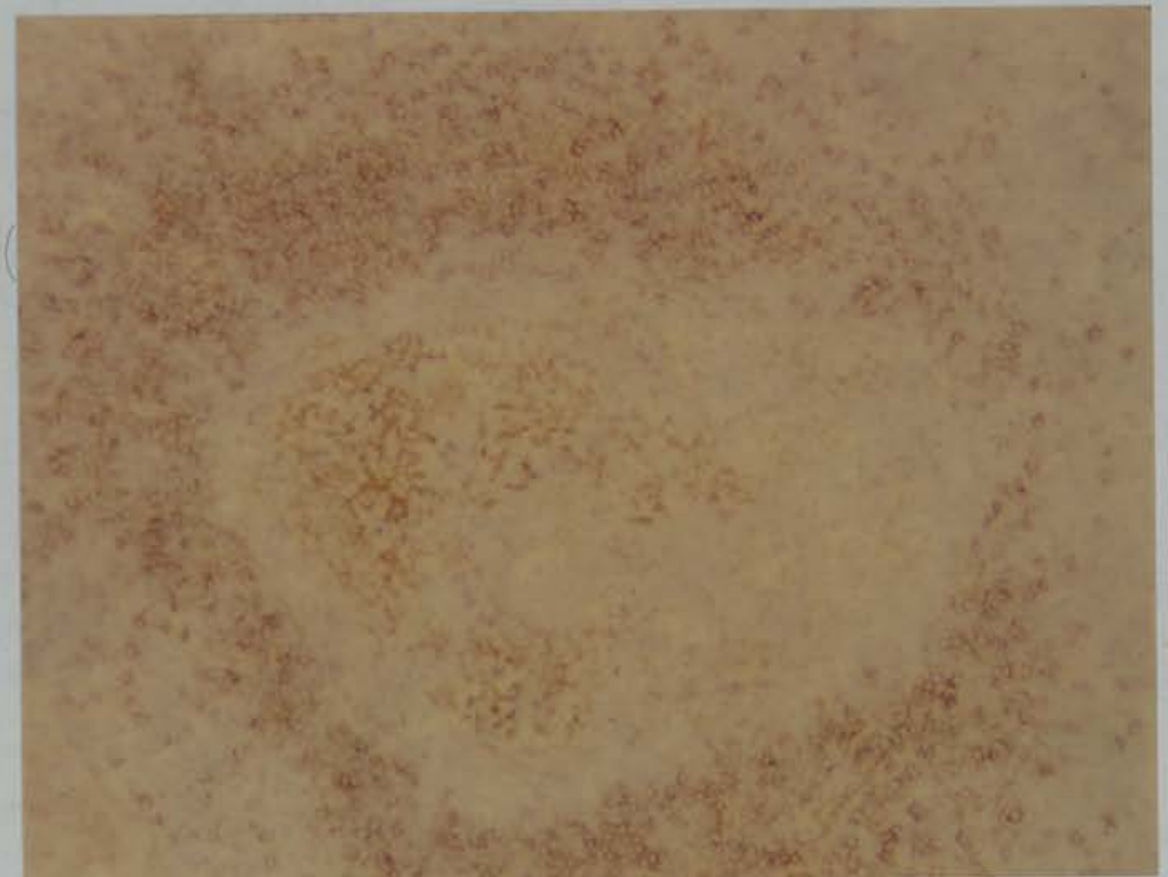

CD23 expression in a reactive lymph node. A proportion of mantle zone cells are positive. Only a sub-population of. germinal centre DRCs are positive. Centroblasts and centrocytes are negative. 
Figure 3.11

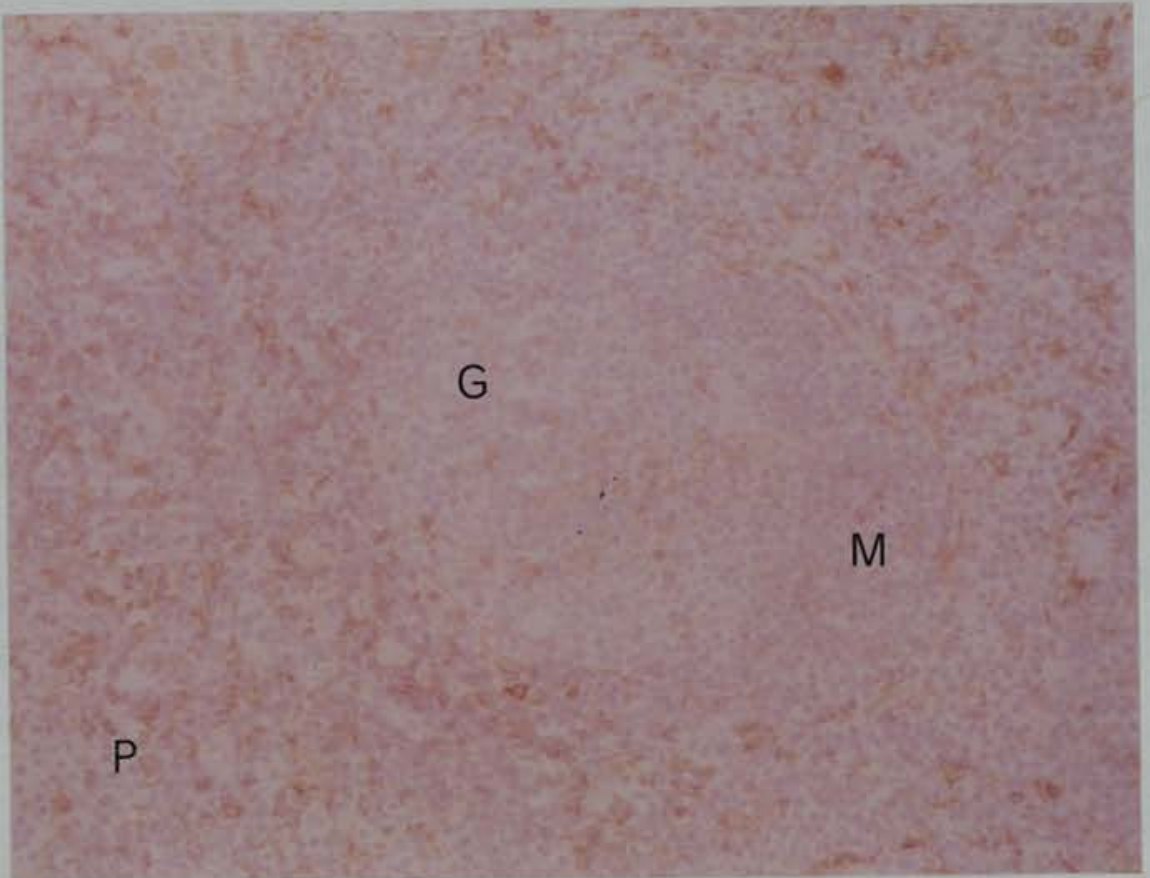

CD25 expression in a reactive lymph node. A proportion of cells in the paracortex (P) are positive with fewer and more weakly positive cells in the mantle zone (M) and germinal centre (G).

Figure 3.12

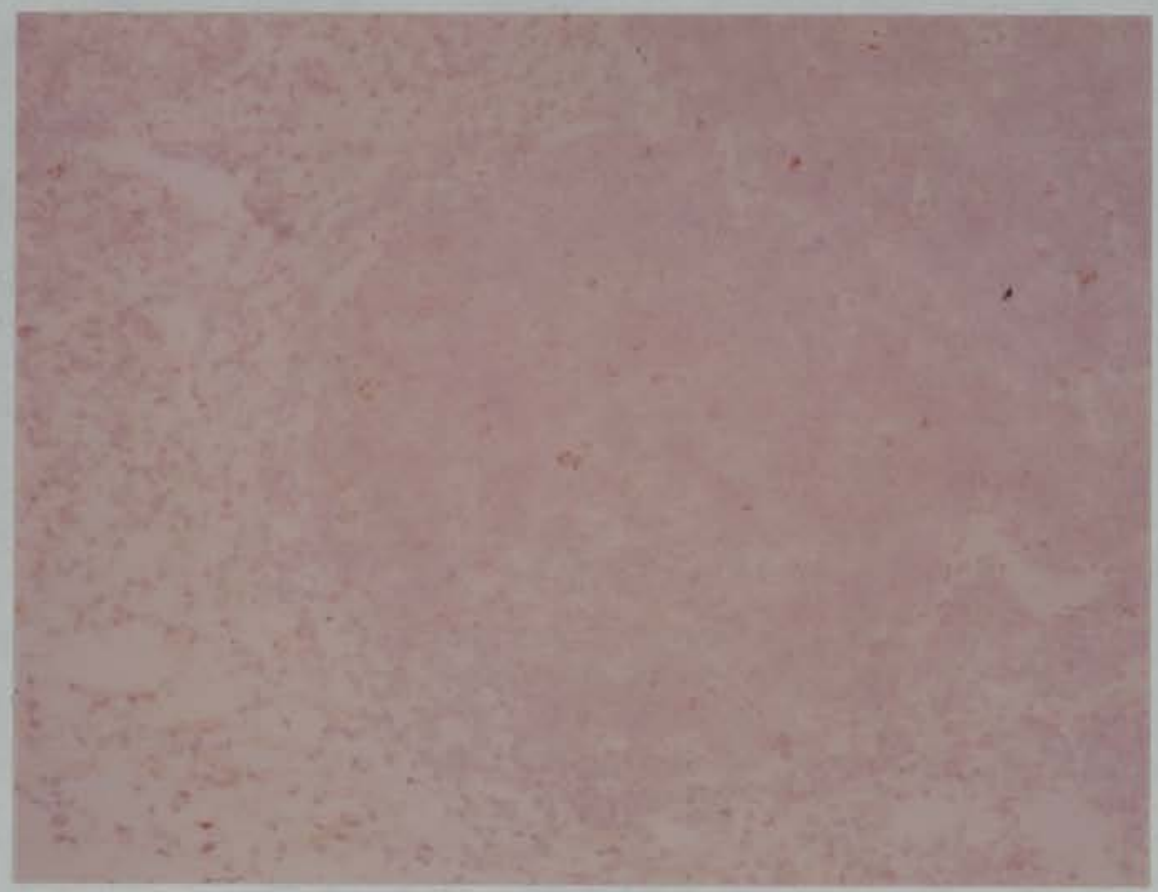

CD30 expression in a reactive lymph node. Only a few cells are positive. 
Figure 3.13

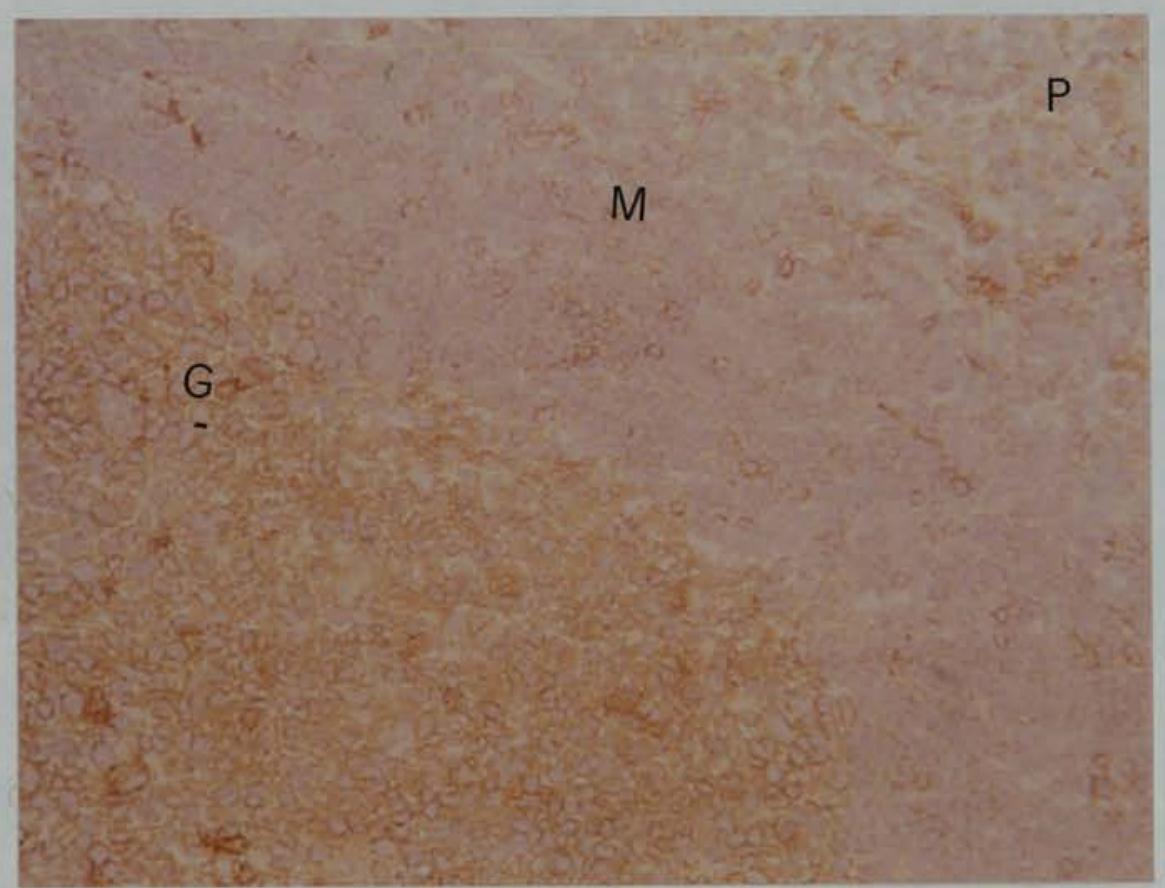

CD71 expression in a reactive lymph node. Germinal centre cells (G) are positive. A proportion of cells in the mantle zone (M) and paracortex (P) are also positive.

Figure 3.14

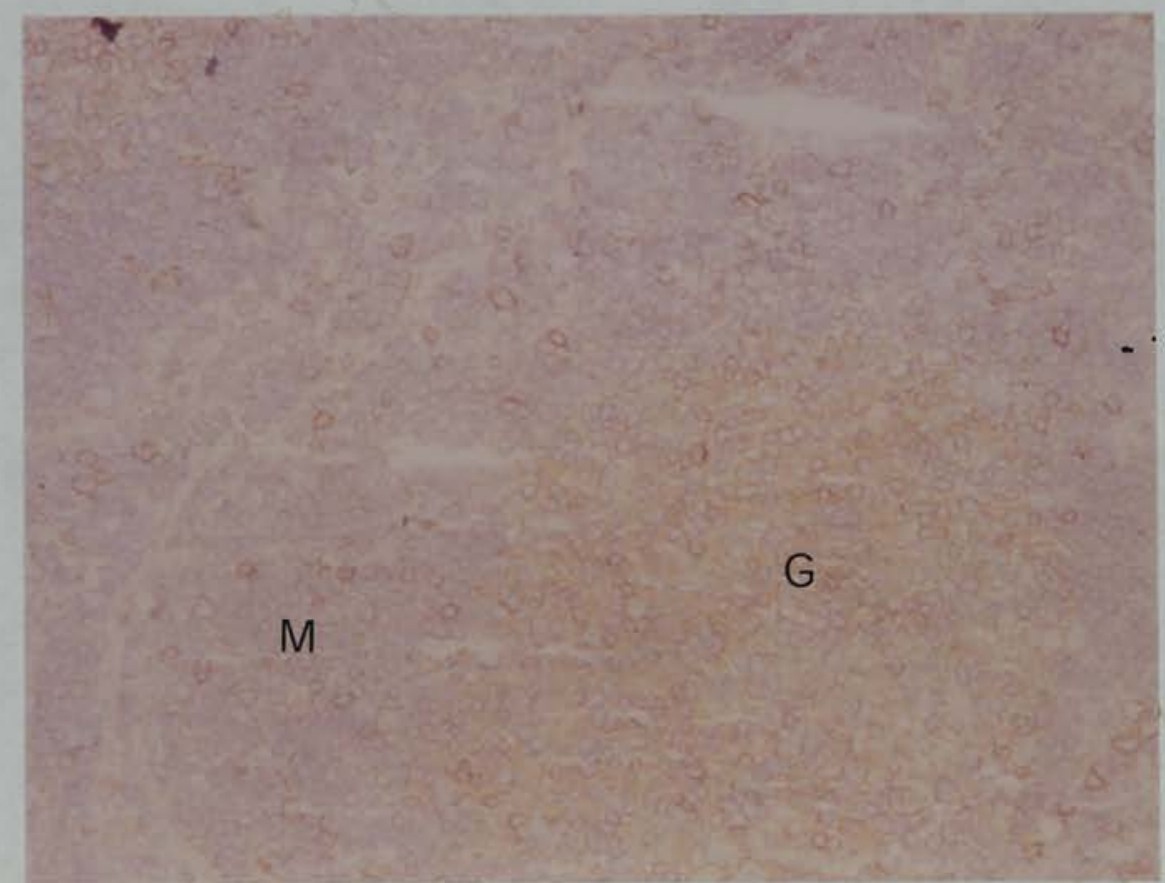

4F2 expression in a reactive lymph node. A proportion of mantle zone cells and the majority of germinal centre cells are positive. 
Figure 3.15

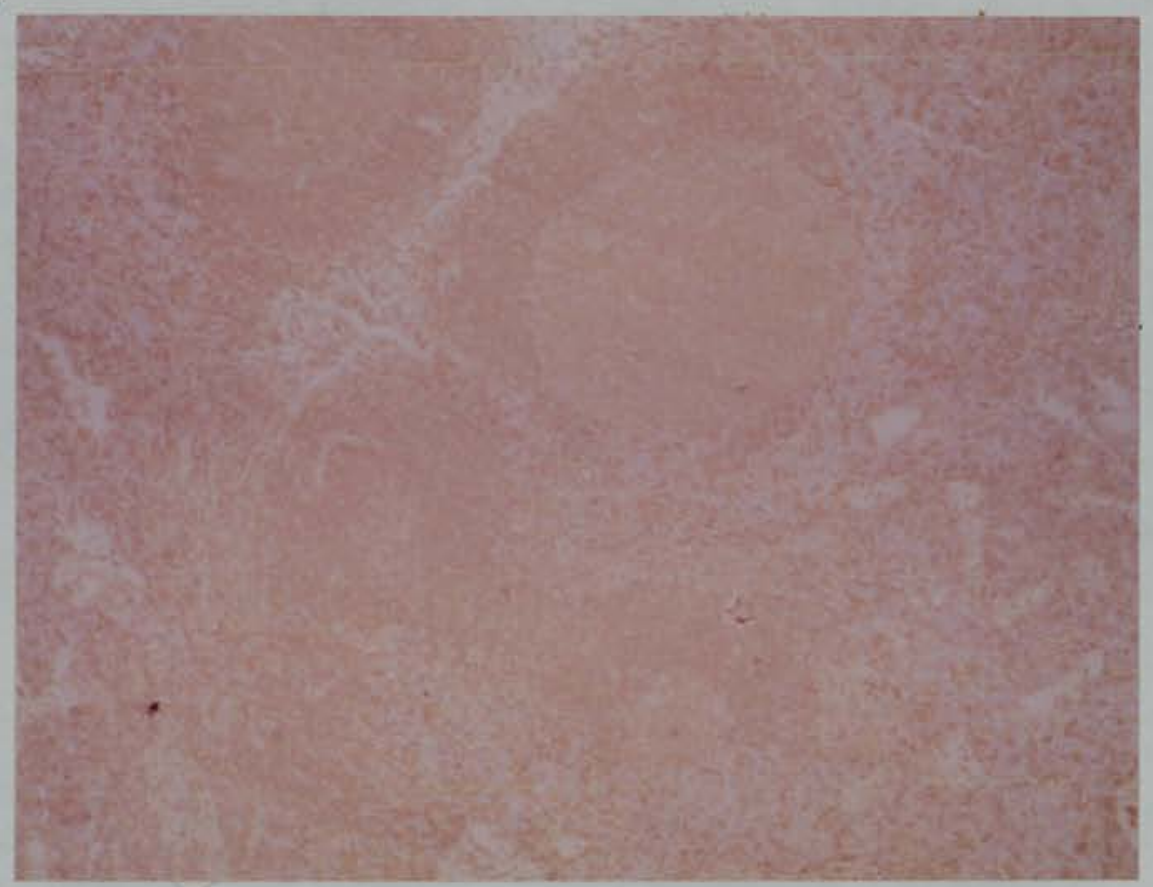

HLA DR expression in a reactive lymph node. Mantle zone and germinal centre cells are strongly positive. A proportion of paracortical cells are positive. 


\subsection{DISCUSSION}

Marginal zones and monocytoid B-cells were not readily identifiable in the tissue studied and so analyses of normal B-cell phenotypes was therefore limited to mantle zone cells, germinal centre cells and plasma cells. These cells showed phenotypic differences. Mantle zone cells and germinal centre cells expressed "pan-B" cell antigens such as CD19, CD2O and CD22 but differed in expression of "activation" and "differentiation" associated antigens including $\operatorname{CD} 2123,38,71,4 \mathrm{~F} 2$. Mantle zone B-cells were positive for CD21, did not express CD38 and only a proportion expressed CD9, CD23, CD38, CD71 and 4F2. Germinal centre cells expressed CD38, CD71, and 4F2. A proportion appeared to express CD9 and CD21 but evaluation of staining was hindered by intense dendritic network staining presumably of DRCs. Germinal centre Bcells did not express CD23. Plasma cells showed a unique phenotype expressing $\mathrm{CD} 38$ strongly and not expressing any of the other antigens studied.

The expression of CD19, CD20, CD22, CD45R and MHC Class II antigens by the majority of B-cells in follicles is consistent with the known expression of these antigens within the B-cell lineage. CD19 is expressed from an early pre-B-cell stage and is lost only by terminally differentiating cells (Nadler 1986). CD20 similarly has broad specificity but is expressed at a slightly later stage by immature B-cells (Nadler 1986). CD22 has been reported to be lost by $\mathrm{B}$-cells following activation (Nadler 1986, Freedman et al 1986,1987) and to be only weakly expressed or not expressed by germinal centre cells (Nadler 1986). The strong reactivity of germinal centre cells in tissue sections seen in this study with an anti-CD22 MCA has been reported by other workers (Mason et al 1986, 1987). The differences in reported expression are a result of using different techniques. 
CD22 is internalised following activation and is subsequently expressed in the cytoplasm (Mason et al 1987). Cytoplasmic expression by germinal centre cells would be identified by immunohistology but would not be detected by the standard flow cytometric techniques used in a number of laboratories. CD45R, the restricted high molecular weight form of the leucocyte common, is expressed by B-cells over much of their development but is lost following terminal differentiation to plasma cells (Dalchau and Fabre 1981, Salter et al 1985). It has been classed as a "pan-B" cell marker in this study although it does not show complete lineage fidelity being expressed by a proportion of $\mathrm{T}$ cells (Dalchau and Fabre 1981, Salter et al 1985). MHC Class II antigens are expressed at the earliest stage of $\mathrm{B}-\mathrm{cell}$ development and are expressed by all B-cells except plasma cells. They are not restricted to the B-lineage being expressed by other lymphoid cells including antigen presenting cells and activated T-cells (Guy et al 1986).

A number of markers associated with B-cell activation and differentiation in-vitro showed differential staining in tissue sections. Mantle zone cells were heterogeneous. The majority expressed CD21 but only a proportion expressed CD9, CD23, CD71 and 4F2. They were consistently CD38 negative. On the other hand germinal centre cells showed a more consistent phenotype. As expected by activated cells CD71 and 4F2 were expressed strongly. CD38 was also expressed by the majority of germinal centre cells whereas only a minor population appeared to be expressing CD21. CD23 was not identified on germinal centre centroblasts or centrocytes. These phenotypes are similar to those reported in other studies (Hsu and Jaffe 1984, Nadler 1986, McMichael et al 1987).

CD5, CD10, and CD30 which have been previously shown to be expressed by normal in-vitro activated B-cells or by 
subpopulations of B-cells in normal lymphoid tissue (Caligaris-Cappio 1982, Bofill et al 1985, Hsu and Jaffe 1984, Waldmann et al 1984, Stein et al 1985) could not be convincingly demonstrated on the B-cells in the tissues studied.

CD5 is expressed by fetal primary follicle cells (Bofill et al 1985) and there appears to be an expansion of CD5 positive B-cells in certain autoimmune conditions (Taniguchi et al 1987). Expression of CD5 by mantle zone cells has been reported (Caligaris-Cappio 1982) but we have been unable to reproduce these results in this study although subsequently we have very occasionally seen weak expression by mantle zone B-cells in reactive lymph nodes.

CD10 has been reported to be expressed by germinal centre cells (Hsu and Jaffe 1984, Murray et al 1984) when the MCA J5 is used. At least two epitopes recognised by different MCA are present on the CD10 molecule (Clark and Einfield 1986). Germinal centre cells may not express the epitope recognised by the MCA (Dako-CALLA) used in this study. Failure of detection may also have been a sensitivity problem but this is felt unlikely as titration experiments showed failure of reactivity when the antibody was used undiluted. Studies of CD10 expression were therefore carried out at the manufacturers suggested dilution which showed reactivity with a known positive lymphoma. A number reactive lymph nodes, tonsils and cases of NHL studied in this series were also assessed with the anti-CD10 MCA J5. Non-specific staining of the majority of cells and tissues in sections was a recurrent problem with a number of batches of the antibody we used and the results were felt to be unreliable.

CD30 is expressed by both in-vitro activated B- and Tcells (Stein et al 1985) but our findings are in agree- 
ment with other reported studies of CD30 expression in tissue sections of normal lymphoid tissue with only scattered cells, predominantly in the T-cell rich paracortex being positive (Schwab et al 1982).

CD25 is expressed by in vitro activated B-cells (Tsudo et al 1984, Waldmann et al 1984, Jung et al 1984) and appears to be important for B-cell growth and differentiation (Muraguchi et al 1985b, Jung et al 1984). CD25 does not appear to be detectable on most B-cells in normal lymphoid tissue (Miyawaki et al 1984, Sheibani et al 1987b) but our results show that a population of positive germinal centre cells can be identified. In contrast flow cytometric analyses of cell suspensions made from tonsils and lymph nodes shows that $>60 \%$ of B-cells express this antigen (Anderson et al 1985) suggesting that a sensitivity problem may be the basis of apparent low expression seen by tissue section immunophenotyping.

In-vitro experiments of $\mathrm{B}-\mathrm{cell}$ stimulation have shown constant and sequential changes in antigen expression by normal B-cells at different stages of activation, transit through the cell-cycle and with differentiation (Kehrl et al 1984a,b, Boyd et al 1985a,1986, Gordon and Guy 1988). As discussed in chapter 1 Gordon and his colleaques have put forward the idea that B-cells in GO have three distinct levels of activation available to them before entry into the cell cycle and these may also be asociated with alterations in antigen expression. Truely quiescent Bcells which do not express markers of activation are in a subcompartment termed GOQ. Stimulation of these cells by mitogens causes progression into the next compartment termed GOA and induces the expression of CD23 (Walker et al 1986, Gordon et al 1986a, Gordon and Guy 1987). Cells in early G1 express $4 \mathrm{~F} 2$ but loss of IgD and expression of other activation associated antigens. Following differentiation there is loss of activation markers, reduction 
in "Pan-B" cell markers such as CD19, CD20 and CD22 with an increase of $\mathrm{CD} 38$ (Boyd et al 1985a, 1986). Equivalent populations may be demonstrated by immunohistology and flow cytometric analyses of cell suspensions of B-cells isolated from lymph nodes and tonsils (Anderson et al 1985, Walker et al 1986, Gordon et al 1986a). Lymph node and tonsil derived B-cells show differences in buoyancy in percoll gradients. High buoyancy B-cells are heterogeneous with respect to activation-antigens (Aman et al 1985) It is possible to identify a population of ultrahigh density $\mathrm{B}$-cells which appear to be in a true resting state (Walker et al 1986, Gordon et al 1986a). These cells do not express markers of activation. Low-buoyancy cells are CD21 negative and IgD negative. Similar phenotypes are expressed by mantle zone cells and germinal centre cells respectively in tissue sections.

Secondary follicles are complicated structures comprising mantle zone B-cells surrounding a germinal centre with centroblasts, centrocytes and DRCs (stein et al 1982). Cytoplasmic processes from DRCs extend into the mantle zones (Stein et al 1982). Mantle zone cells are part of the recirculating B-cell population (Gray et al 1982) and when activated migrate into the germinal centres where they are transformed into proliferating centroblasts (Stein et al 1982). Centroblasts subsequently differentiate into the second germinal centre B-cell population, the centrocyte. Thus in the tissue sections the lymphoid secondary follicle allows a putative linear pathway of activation and differentiation from mantle zone cell to centroblast and centrocyte to be compared with in-vitro recognised changes.

Mantle zone cells express IgD, IgM and CD21 and have been believed to be resting cells (Stein et al 1980, 1982, stashenko et al 1981, Hsu and Jaffe 1984). The results presented here show that a significant proportion of 
mantle zone cells are expressing activation markers including $\mathrm{CD} 23, \mathrm{CD} 71$ and $4 \mathrm{~F} 2$ suggesting that they are actively cycling or at arrest points in the cell cycle. Cytoplasmic processes extending from germinal centre DRCs may be involved in the activation of antigen specific Bcells by presenting antigen to cells in the mantle. These activated mantle zone cells may migrate into the germinal centres and undergo further morphological and phenotypic changes to be recognised as centroblasts. Centroblasts are proliferating cells and their phenotype reflects their stage of activation. They have lost IgD and probably also CD21. Some centroblasts appear to express CD21 consistent with transient increase of expression following activation. $\mathrm{CD} 71$ and $4 \mathrm{~F} 2$ are strongly expressed however other markers associated with B-cell activation and proliferation such as CD23 and CD25 are not detected or are seen on only a minor population of germinal centre cells by immunohistology. CD23 is shed by proliferating B-cells in-vitro (Gordon and Guy 1987) and a similar phenomenon may be occurring in germinal centres with centroblasts shedding the antigen which is then absorbed by a subpopulation of DRCs from where it may function as a B-cell growth factor. Centroblasts differentiate into the centrocytes, which are believed to be a non-proliferating cells. Both germinal centre cell types express CD71 and $4 \mathrm{~F} 2$. Expression of both these antigens is enhanced by activation of B-cells but expression does not appear to be tightly associated with proliferation (Hemler and strominger 1982, Pileri et al 1987). Centroblasts and centrocytes express $\mathrm{CD} 38$ with a minority of germinal centre cells, probably plasma cells, showing strong expression. In-vitro, CD38 expression is usually associated with differentiation to immunoglobulin secreting cells (Boyd et al 1985a). The ultimate fate of germinal centre derived cells is not clearly known but as they are the prime source of memory cells and contribute to the recirculating $\mathrm{B}-\mathrm{cell}$ memory pool (Klaus and Kunkl 1981) 
it is likely that centrocytes migrate and become morphologically identifiable lymphocytes which recirculate in the blood to lymphoid and other tissues. As recirculating cells do not express CD38 it would appear that CD38 expression is only a transient phenomenon in the development of B-cells whose expansion is via the germinal centre.

The medulla is rich in plasma cells and the phenotypes of these cells is similar to B-cells which have been stimulated in-vitro to Ig secreting cells in that they express CD38 strongly and have lost "pan-B"-cell markers, MHC Class II and markers of activation.

In conclusion detailed analyses of antigen expression in reactive lymph nodes and tonsils show differences between the major identifiable groups of B-cells :- mantle zone cells, germinal centre cells and plasma cells. Mantle zone cells are phenotypically heterogeneous containing a population of cells expressing the activation associated antigens CD23, CD71 and 4F2. Germinal centre cells show increased expression of activation associated antigens but have lost $\mathrm{CD} 23$ and CD21. Plasma cells have lost all B-cell specific markers and markers of activation but express CD38 strongly. These phenotypic differences are similar to those demonstrated in vitro following mitogen induced B-cell activation, proliferation and differentiation. 


\subsection{INTRODUCTION}

Non-Hodgkin's lymphomas are believed to result from proliferation and accumulation of lymphoid cells at different stages of differentiation. Currently used classifications of NHL, such as the Kiel classification (Lennert 1978, Stansfeld et al 1988), are based upon the belief that the morphology and immunophenotypes of NHL correspond to normal cells at varying stages of differentiation and activation ranging from lymphoid precursor cells to terminally differentiated $T$ or B-cells e.g. lymphoblastic NHL - immature pre B/thymic T cells; centroblastic/centrocytic NHL - follicle centre cells; immunoblastic NHL and plasmacytoma - terminally differentiated cells. Previous studies have shown some correlation between antigen expression and certain morphological features of B-cell NHL (Habeshaw et al 1983, Anderson et al 1984, stein et al 1984, Nash 1986) but only a relatively limited number of anti-B-cell MCA were used. It is possible differential expression of activation and differentiation antigens by NHL may assist pathological diagnosis and allow more accurate definition of subtypes of NHL within morphologically similar groups. The second part of this study was undertaken to investigate these possibilities. 


\subsection{MATERIALS AND METHODS}

4.2.1 Cases:- 148 cases of B-cell NHL

4.4.2 Immunohistology:- Direct immunofluorescence Indirect immunoperoxidase

4.2.3 Antibodies:-Table 2.3.

\subsection{RESULTS}

A total of $148 \mathrm{~B}-\mathrm{cell}$ NHL were studied. The numbers in each histological group and anatomical site of biopsy are shown in Table 4.1 . Detailed results of antigen expression of cases in each histological group are given in Tables 4.2 - 4.11 (pages 78-87). Results for lymphocytic, centrocytic, follicular centroblastic/centrocytic, diffuse centroblastic/ centrocytic, centroblastic, immunoblastic and plasmacytic/blastic are summarised and presented as histograms in Histograms $4.1-4.7$ (pages 88$94)$.

\subsubsection{Lymphocytic lymphoma}

Eighteen cases of lymphocytic lymphoma (figure 4.1) were studied (Table 4.2, Histogram 4.1) derived from lymph nodes (16), spleen (1) and breast (1). All cases expressed monotypic immunoglobulin: 16 cases expressed kappa and 2 cases expressed lambda; 16 expressed IgM with co-expression of IgD in 7; 1 case expressed IgG alone and 1 monotypic kappa light chain without heavy chains. The pan-B-cell markers CD19, CD22 and CD45R were strongly expressed by all cases. The CD20 marker Bl showed variable and often weak staining between and within cases. All cases tested expressed the CD5 antigen (figure 4.2). CD9 was expressed on a proportion 
of cells in 11 cases. Staining was strongest outwith proliferation centres. There was no staining for CD10 or CD38. CD21 (C3d receptor) was expressed by the majority of cells in all cases (figure 4.3), including one case (573) which did not express sIgD, although lymphomas which expressed IgMD tended to show stronger reactivity than those expressing IgM alone. CD23 was expressed by the majority of cells in 7 cases (figure 4.4) and by a minority in 1. CD25, the interleukin 2 receptor, was expressed weakly by the majority of cells in 6 cases. There was no expression of CD30 in the 3 cases tested. CD71 and 4F2 were variably expressed: in some cases both antigens were expressed by the majority of cells whilst in others only a proportion of cells stained (figure 4.5) . Expression of both antigens was enhanced in proliferation centres (figure 4.6). All cases expressed HLA DR and DP antigens with absent or low DQ expression in a proportion of cases. MHC Class II expression was enhanced in proliferation centres.

\subsubsection{Lymphoplasmacytic lymphoma (immunocytoma)}

Two cases (figure 4.7) - one lymph node and one soft tissue mass - were studied (Table 4.3). The nodal case was IgM positive with a phenotype similar to that of small lymphocytic lymphomas expressing CD22, CD45R and MHC Class II antigens but not CD5. The other case was IgGK positive and showed loss of pan-B-cell antigens with decreased MHC class II antigen expression and absence of CD5. CD38 was not expressed by either tumour.

\subsubsection{Prolymphocytic lymphoma}

Four cases (figure 4.8) were available for study (Table 4.4), these being from spleen (2), lymph node (1) and orbit (1). All cases expressed IgM together with IgD or IgG in two cases. All cases expressed pan B cell antigens although expression of CD20 was weak in one. Two cases expressed CD5 strongly, one weakly and one was 
negative. None expressed CD9, $\mathrm{CD} 10$ ( 3 cases) or $\mathrm{CD} 38$. CD21 was expressed strongly by one case and by a minority of cells in the other studied. Neither of the 2 cases studied expressed CD23 and only $1 / 4$ cases expressed CD25 weakly. The one case tested did not express CD30. Both CD71 and 4F2 were strongly expressed by all four cases. DR and DP were strongly expressed by all 4 cases, but DQ was expressed by only a proportion of cells in 3 cases.

\subsubsection{Hairy cell leukaemia}

All 3 cases of hairy cell leukaemia (figure 4.9) studied were resected spleens (Table 4.5). All were kappa positive with one IgMA, one IgMD and one IgG positive. They expressed the pan-B antigens CD19, CD20, CD22 and CD45R but not $\mathrm{CD} 5$. One was $\mathrm{CD} 9$ positive. Two expressed CD10 weakly in the cytoplasm. None of the cases expressed CD38 but one was positive for CD23. All expressed the CD25 antigen (figure 4.10). Neither of the two cases tested expressed CD30. CD71 and 4F2 expression were weak or absent in $2 / 3$ cases. $D R$ and DP were strongly expressed by all 3 cases whereas only two showed DQ expression.

\subsubsection{Centrocytic lymphoma}

12 cases of centrocytic lymphoma (figure 4.11) were studied from lymph nodes (8), tonsil (1), spleen (2) and small intestine (1) (Table 4.6, Histogram 4.2). All expressed monotypic IgM, and 5/10 tested coexpressed IgD. 5 cases expressed lambda and 7 kappa light chains. All cases tested stained strongly for pan-B-cell antigens and CD5 (figure 4.12). CD9 was expressed by a proportion of cells in 7 cases but was expressed strongly by only 3 cases. None expressed CDIO and only a proportion of cells in 2 cases expressed CD38. All 5 cases tested were CD21 positive and CD23 negative (figure 4.13). 2 cases expressed CD25. In one the majority of cells stained weakly whereas in the other only a minority of cells were 
staining. CD30 was not expressed by either of the two cases tested. Numbers of cell staining with $4 \mathrm{~F} 2$ and CD71 varied between cases. In most cases staining was weak or restricted to a minority of cells. Although DR and DP were expressed strongly in all cases DQ was often absent or weak.

\subsubsection{Follicular centroblastic/centrocytic lymphomas}

A total of 39 cases (figure 4.14) were studied (Table 4.7, Histogram 4.3) from lymph nodes (36), spleen (1), thyroid (1) and breast (1). Twenty three cases expressed kappa, 14 lambda light chains and in 2 cases immunoglobulin staining was negative or equivocal. Thirty cases expressed IgM with coexpression of IgD (4), IgG (1) and IgA (1): 6 cases expressed IgG alone and one lacked heavy chains but expressed lambda light chain. The majority of cases expressed pan-B-cell antigens strongly and were CD5 negative. CD10 (24/36) (figure 4.15), and CD38 (13/38) were variably expressed. CD9, CD21 and CD23 were also variably expressed. Assessment of their expression was complicated by strong DRC staining (figure $4.16)$ but in a number of cases the dendritic network was less intense and definite staining of lymphocytes could be demonstrated (figure 4.17). Four cases (723, 732, 760, and 855) showed strong CD21 expression by the neoplastic follicle cells. These cases did not show CD23 staining and showed strong CD9 expression. CD25 was expressed by neoplastic cells in only $2 / 36$ cases. None of the cases tested expressed $\mathrm{CD} 30.4 \mathrm{~F} 2$ and $\mathrm{CD} 71$ showed similar but variable expression between cases although in some cases there was differential expression e.g. strong expression of $4 \mathrm{~F} 2$ and weak CD71 or vice versa. The majority of the cases expressed $D R, D P$ and $D Q$, although $D Q$ expression was often reduced or absent.

It was not possible to correlate variation in cellular content of follicles (i.e. proportion of centroblasts to 
centrocytes) with any particular phenotype. Three cases $(449,760$ and 879) contained a predominant proportion of centroblasts. All three expressed monotypic IgM kappa and CD9 strongly but showed variable expression of CD10 and CD21. All cases were CD23 negative and expressed CD71 and $4 \mathrm{~F} 2$ strongly.

\subsubsection{Diffuse centroblastic/centrocytic lymphoma}

Thirteen cases of diffuse centroblastic/centrocytic lymphoma (figure 4.18) were studied (Table 4.8, Histogram 4.4 ) derived from lymph nodes ( 9 ; two of which had extranodal spread), small intestine (2) testis (1) and omentum (1). Eight cases expressed kappa and three cases lambda. The testicular tumour and an intestinal lesion did not express light chains. Ten cases expressed IgM together with IgD in two instances. Three cases expressed IgG, one without light chain. The majority of cases expressed CD19, CD22 and CD45R whereas in a few cases CD20 expression was weak or absent. None of the cases were $\mathrm{CD} 5$ or $\mathrm{CD} 38$ positive. Two cases expressed CD9 and a further two CD10. CD21 was expressed by the majority of lymphoid cells in only 3 cases. DRCs in $5 / 6$ cases stained for CD21. CD23 was expressed by the majority of cells in $3 / 7$ cases but CD25 staining was observed in only two cases. Neither of the 2 cases tested expressed CD30. 4F2 was expressed strongly in all cases whereas CD71 staining was seen on only a minority of cells in 4 cases the remainder staining strongly. The MHC class II antigens DR, DP and DQ were strongly expressed in all cases.

\subsubsection{Centroblastic lymphoma}

Thirty four cases of centroblastic lymphoma (figure 4.19) from lymph nodes (24), stomach (2), testis (2), omentum (1), mediastinum (1), tonsil (1), retroperitoneum (1) breast (1) and scalp (1) were studied (Table 4.9, Histo- 
gram 4.5). Seventeen cases expressed kappa, 9 lambda light chains and 1 case gave equivocal results. 16 cases expressed IgM, one with IgD, 9 IgG and 3 IgA; 3 cases expressed heavy chains without light chains. 4 cases did not express immunoglobulin. Whilst the majority of cases expressed pan-B-cell antigens strongly, a few cases showed loss of one or more of these antigens (figure 4.20). CD5 expression was seen in only one case. There was variable expression of CD9, CD10 and CD38 antigens. No relationship was observed between the expression of these antigens with all possible permutations being seen within the series. Twelve of 19 cases tested expressed CD21 although the intensity of staining was often weak in comparison with other lymphomas. In only one of 20 cases was there more than a very minor population of cells or DRCs expressing CD23. CD25 and CD30 were expressed by a minority of cases only whereas $4 F 2$ and CD71 were strongly expressed by the majority (figure 4.21). DR, DP and $D Q$ were expressed strongly by most of cases, although a few showed loss of one or more antigens.

Five cases (no.s 676, 785, 913, 923, and 935) contained a large proportion of multilobated cells. Despite their morphological differences from the remainder of the group they did not show distinct phenotypes. These cases expressed pan-B-cell antigens and $\mathrm{CD} 38$; in 2 cases tested these cells were CD21 positive and CD23 negative. None expressed CD9. Two of these cases (913 and 923) expressed CD30.

\subsubsection{Immunoblastic lymphoma}

Fourteen cases of immunoblastic lymphoma (figure 4.22) were studied (Table 4.10, Histogram 4.6). In this group we included two cases of polymorphic immunocytoma (592 and 653) containing an admixture of plasma cells and plasmablasts with a predominance of immunoblasts. Ten 
cases were lymph nodes and 4 extranodal (1 retroperitoneum, 1 chest wall mass, 1 knee and 1 spleen). Eleven cases expressed kappa and 3 lambda light chains. Eight expressed IgM together with IgD and with IgA in another. Five cases expressed IgA alone and in 1 case IgA and IgG were coexpressed. There was variable expression of pan-B-cell antigens. CD22 and CD45R were most commonly expressed, however, these and other pan-B-cell antigens were often lost or only expressed by a minority of tumour cells (figure 4.23). CD5 and CD9 were not expressed. CD10 staining was observed in only one case (299). This tumour, although showing a vast majority of immunoblasts, in addition contained a population of large centrocytes and centroblasts suggesting derivation from a diffuse centroblastic/centrocytic lymphoma. Almost half of the cases expressed CD38. This was strongest in the cases of polymorphic immunocytoma and in cases showing plasmablastic differentiation. However, two cases showing plasmacytoid differentiation morphologically (nos 478 and 616) did not express CD38. CD21 was expressed by a minority of cases and CD23 was expressed weakly by the majority of cells in only one case tested. Staining for CD25 was inconsistent, whereas both $4 \mathrm{~F} 2$ and $\mathrm{CD} 71$ were strongly expressed by all cases (figure 4.24). In one case the majority of cells expressed CD3O and in two others a minority of large blast cells were positive. The MHC class II antigens DR, DP and DQ were strongly expressed in all cases.

\subsubsection{Plasmacytic/Plasmablastic lymphoma (Plasmacytoma)}

Seven cases (figure 4.25) were studied (Table 4.11) from lymph nodes (4) and extranodal tissues ( 1 sacral tumour, 1 epidural tumour and 1 testicular tumour). These cases included tumours which were composed either wholly by plasma cells or cases in which the majority of cells appeared plasmablastic that is showed cytological appearances of plasma cells but with vesicular nuclei with one 
or more prominent nucleoli. Both case nos 856 and 901 were recurrences from previously diagnosed myelomas, in which the predominant cell types were now plasmablasts.

Six cases expressed kappa and 1 lambda light chain. All 7 expressed IgG, one in association with IgA. All of the cases tested had lost CD19 and CD20 whilst CD22 was expressed by a proportion of cells in 2 cases only (figure 4.26). CD45R expression was observed by a majority of cells in 4 cases. All cases expressed CD38 (figure 4.27 ) and $4 / 7$ expressed CD9. None of the cases tested expressed CD5, CD10, CD21, CD23 or CD30 and only one showed weak expression of CD25. The MHC class II antigens were lost by $6 / 7$ cases (figure 4.28) although one did contain a minor population of class II positive plasma cells.

\subsubsection{Lymphoblastic lymphomas}

only 2 cases morphologically diagnosed as lymphoblastic lymphomas (figure 4.29) were available for study (Table 4.12). One was an epidural tumour and the other a spleen. Both were terminal deoxynucleotidyl transferase positive. one case did not express immunoglobulin and the other expressed monotypic IgM lambda. The immunoglobulin negative case expressed CD19, CD22, CD9 and CD10 (figure 4.30 ) but none of the other pan-B-cell or B-cell differentiation associated antigens including MHC class II. The other case expressed all four pan-B-cell antigens, CD9, $\mathrm{CD} 10, \mathrm{CD} 38$ and MHC Class II antigens but did not express CD21 or CD23. Both cases were strongly $4 \mathrm{~F} 2$ and CD71 positive. 


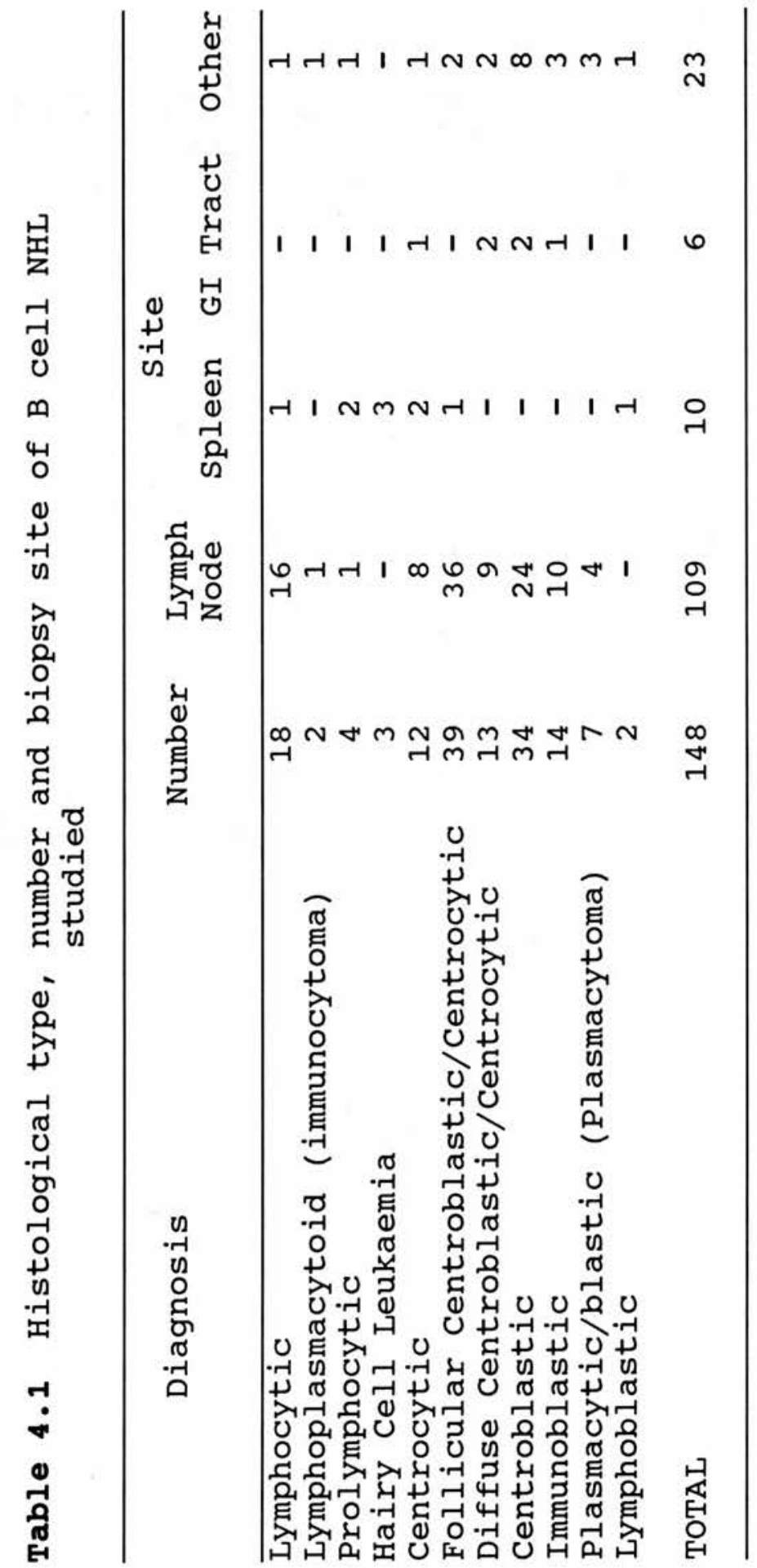

77. 


\begin{tabular}{|c|c|c|}
\hline & 旺昌 & MMNNHNNNNNMMMMM-OM \\
\hline & 画吕 & NMMMNMMMMMNMMMMNMM \\
\hline & 哥器 & 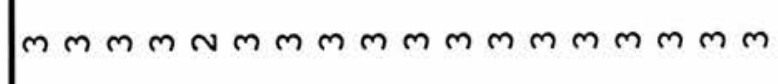 \\
\hline & $\underset{\sim}{N}$ & HNNNNNHNNHMmM-100mm \\
\hline & ठำ & HNHAm \\
\hline & ชి이 & 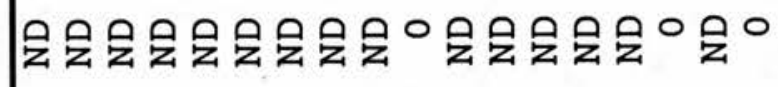 \\
\hline & ชิ & $00 \mathrm{mo0} 000000 \mathrm{mmm} 00 \mathrm{~m} \mathrm{~N}$ \\
\hline & ปึ & 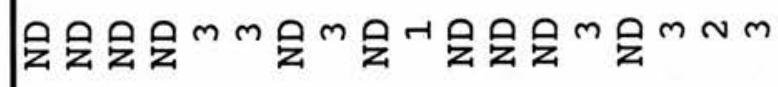 \\
\hline & 己ે & 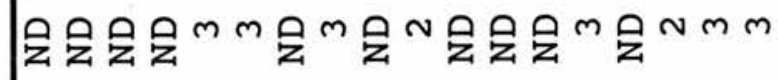 \\
\hline & つ̊ & 1000000000000000000 \\
\hline & ठ욤 & 1000000000000000000 \\
\hline & ○ी & OMmNHOMHOOOMOOONH \\
\hline & ○ & $m m m m m m m m m m m m M m m m m m$ \\
\hline & 己 용 & $M m M M m M M M M M M M M M M M M M$ \\
\hline 胥 & 己 & 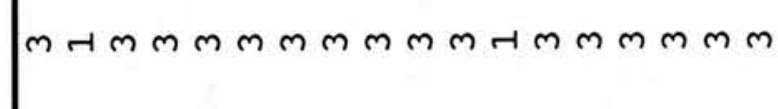 \\
\hline 号 & 융 & O \\
\hline & 임 & 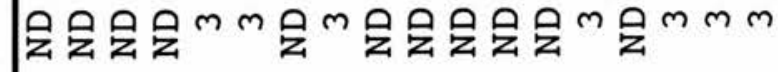 \\
\hline c & $\varangle$ & 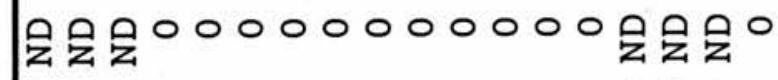 \\
\hline 而 & ט & 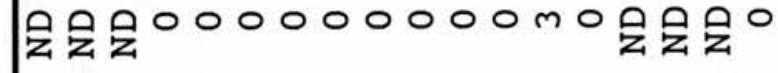 \\
\hline 芦 & D & 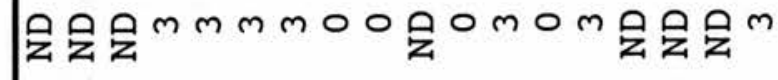 \\
\hline$\stackrel{4}{0}$ & $\Sigma$ & MmMmMmMMOMOMMMMMMm \\
\hline U & • & $000000000 \mathrm{m000m0000}$ \\
\hline 5 & 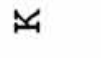 & $m m m m m m m m m O M m M O M m m m$ \\
\hline A & 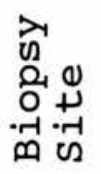 & 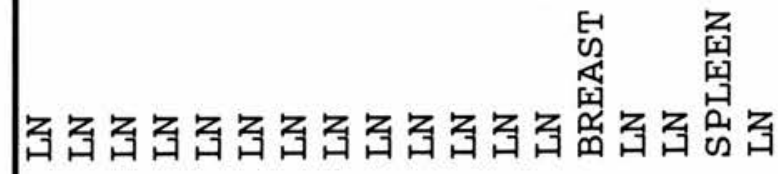 \\
\hline \& & ن & 엉 \\
\hline
\end{tabular}




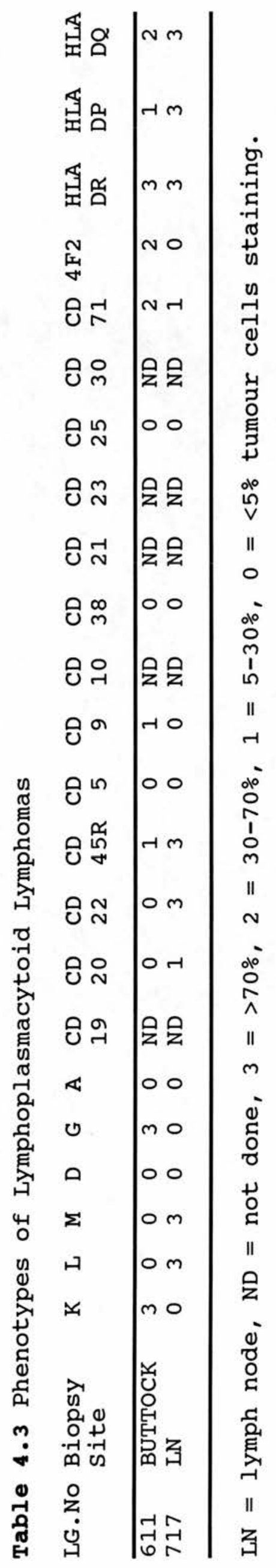

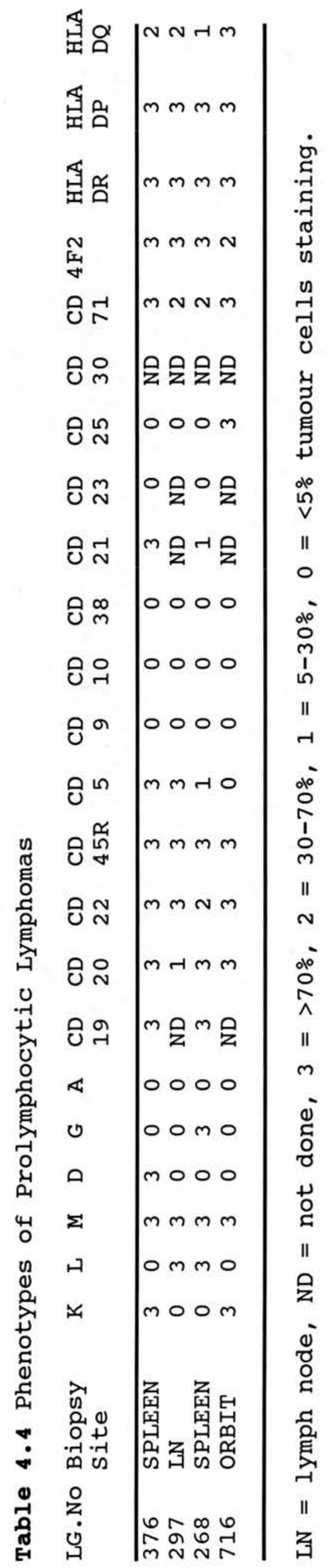




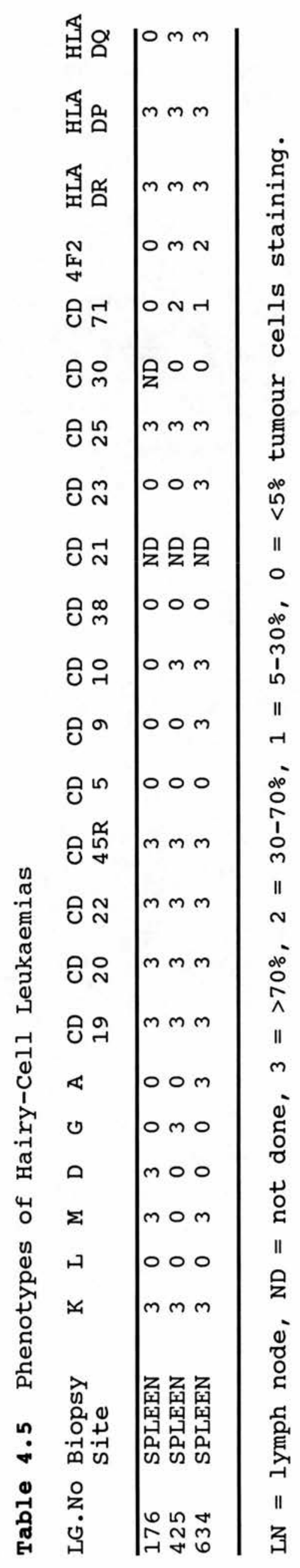

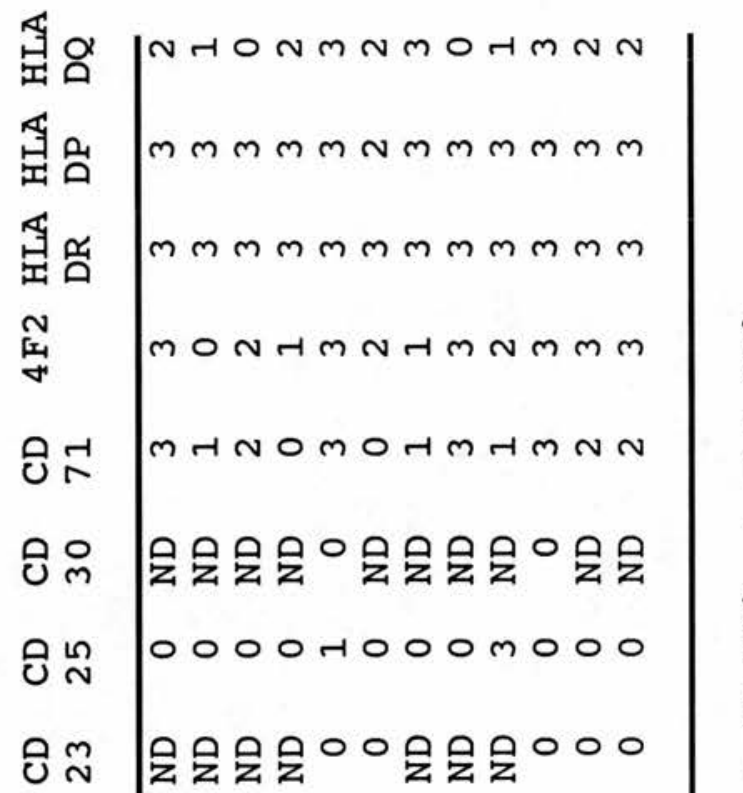

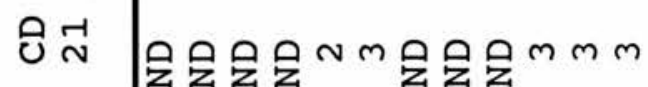

ปิ N N 00000000 N

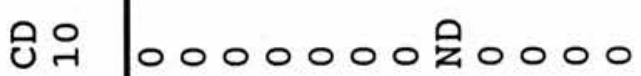

ชิ

ชิ

ชินี้

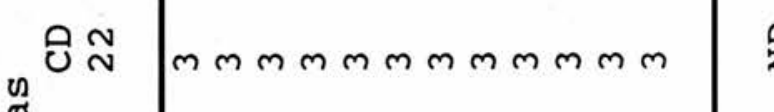

ขึ

ํํํㅇำ

会mmmommm m 号会

욜

दิำ

u

芹

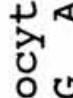

난

起口

藏

II 0

${ }_{0}^{\Sigma}$

บค

0

고노

i) गे

용

⿷匚

की

究

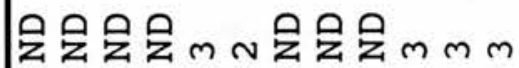
会 00000000 会 0 只 00000000 会 00 台oOmmommo 云mo लmmलm m m m m m OMOOOMOMOMmo mommmomomoom 


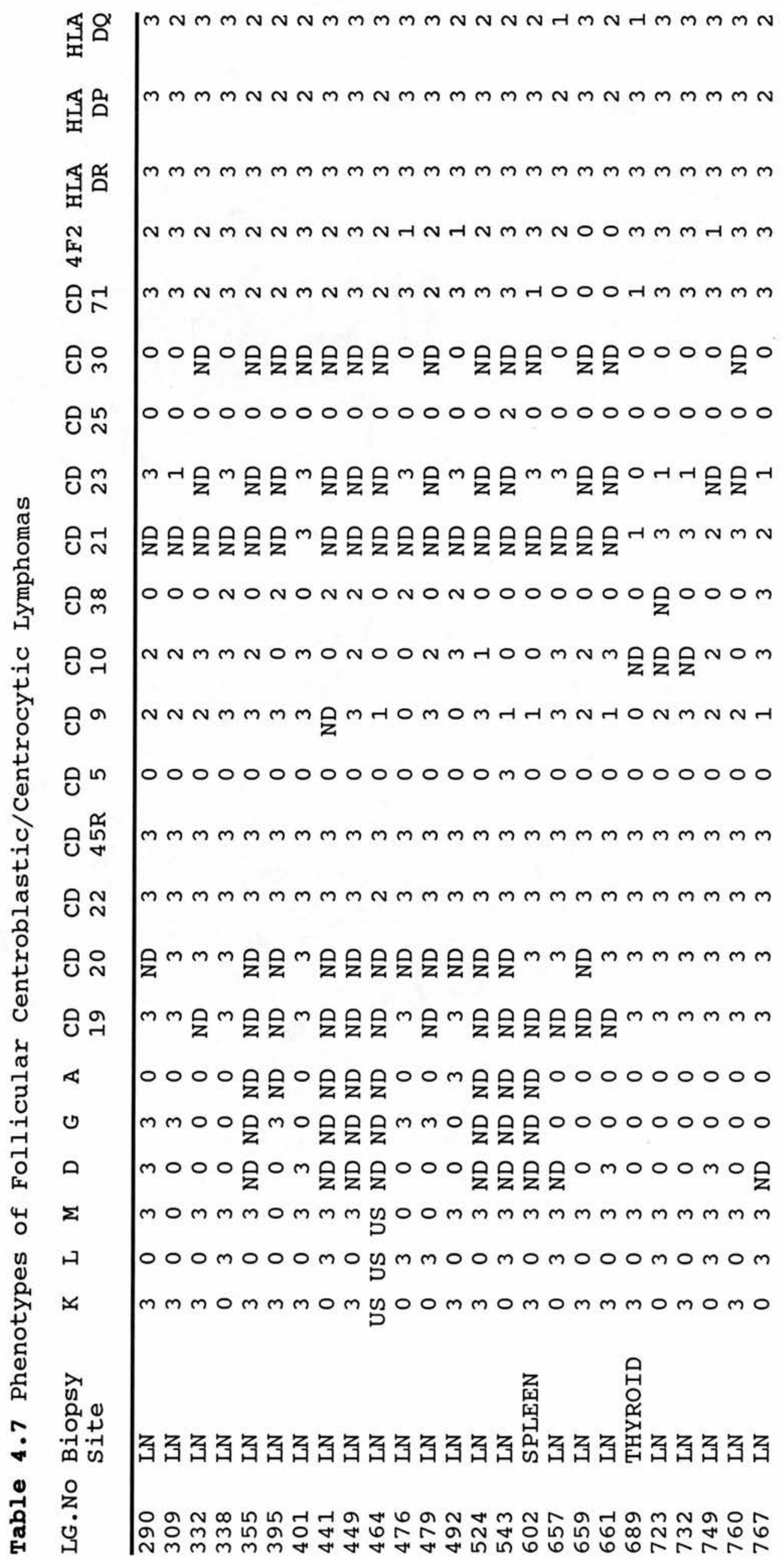




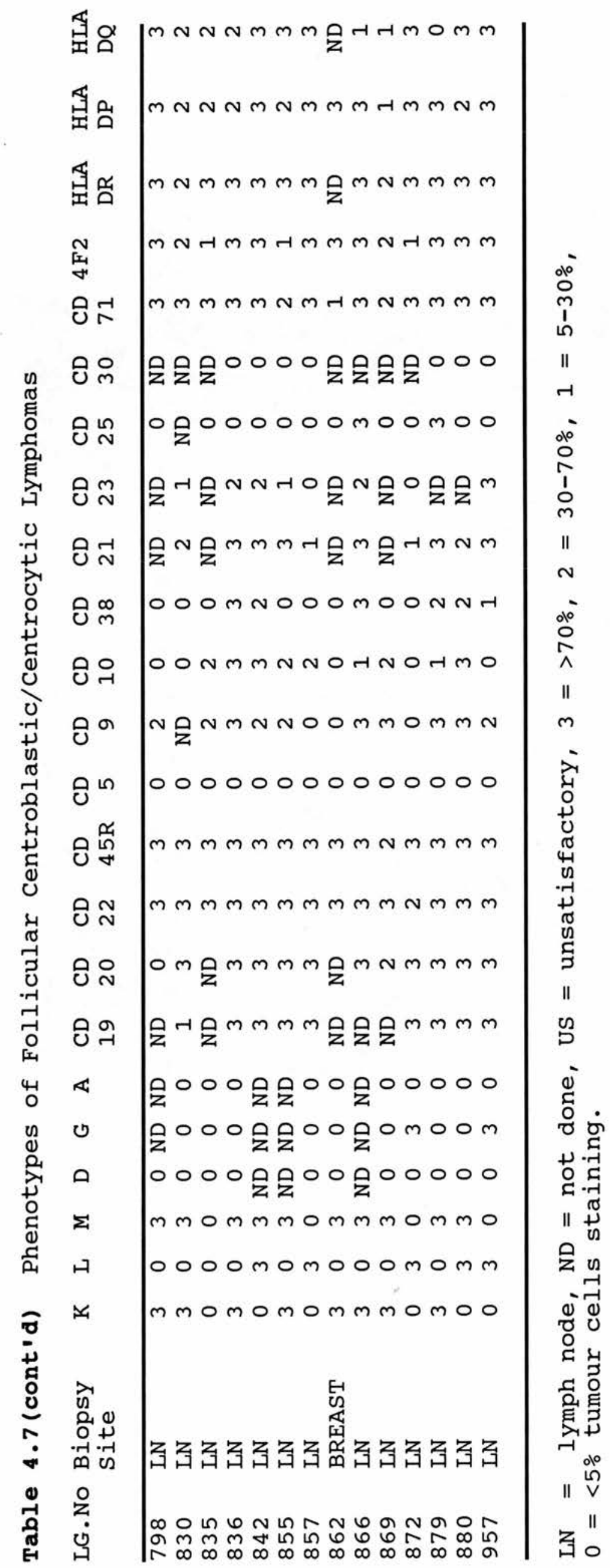

82. 


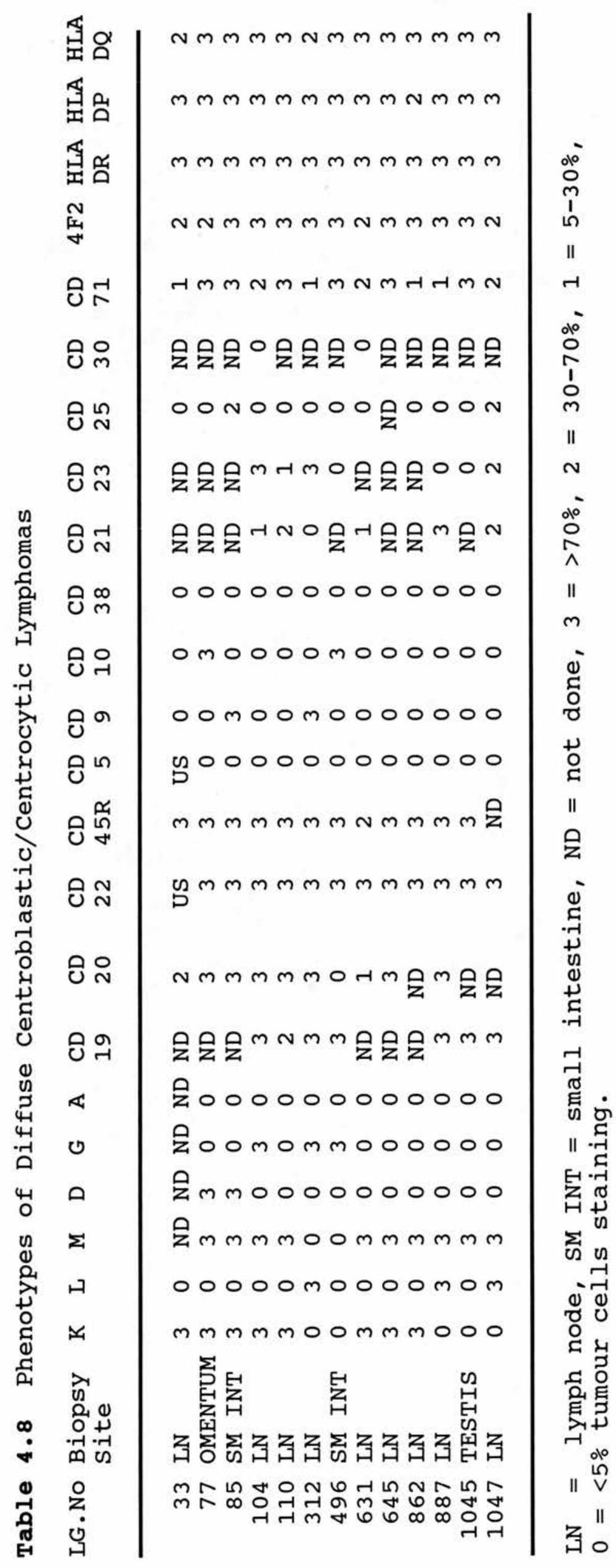




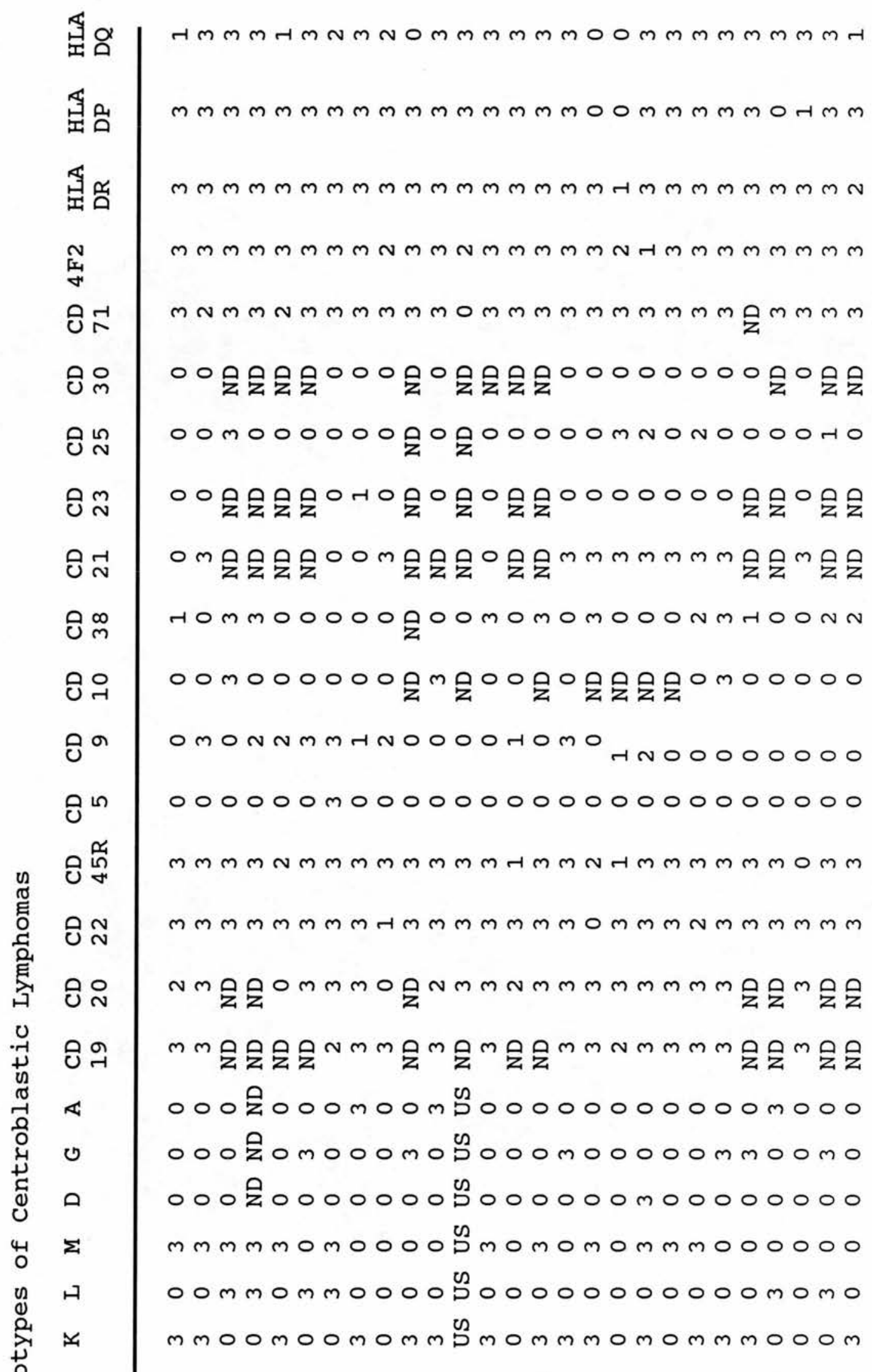




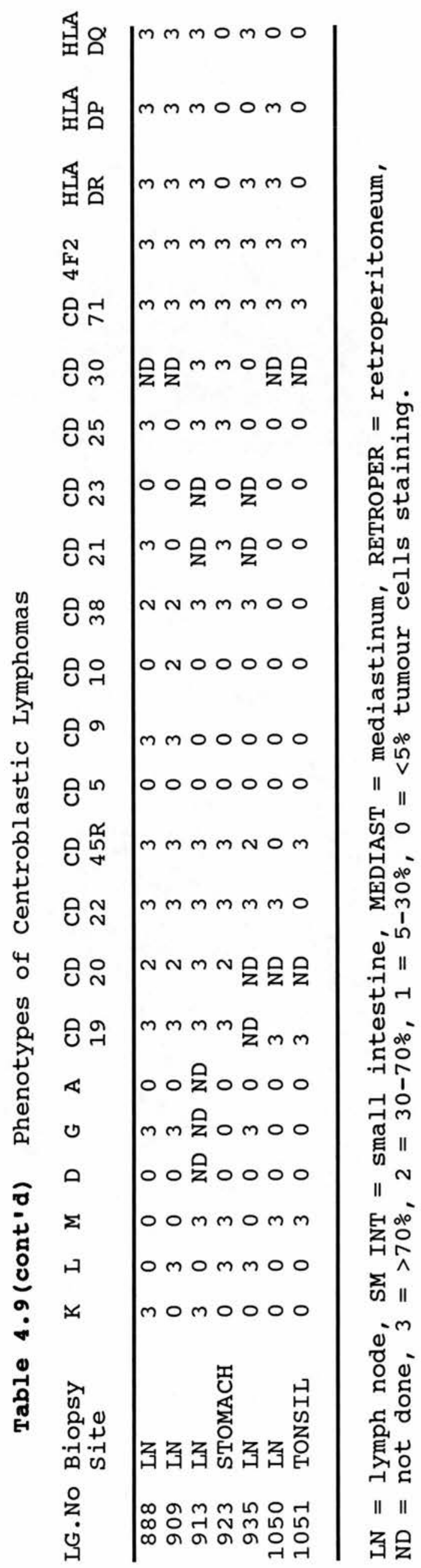




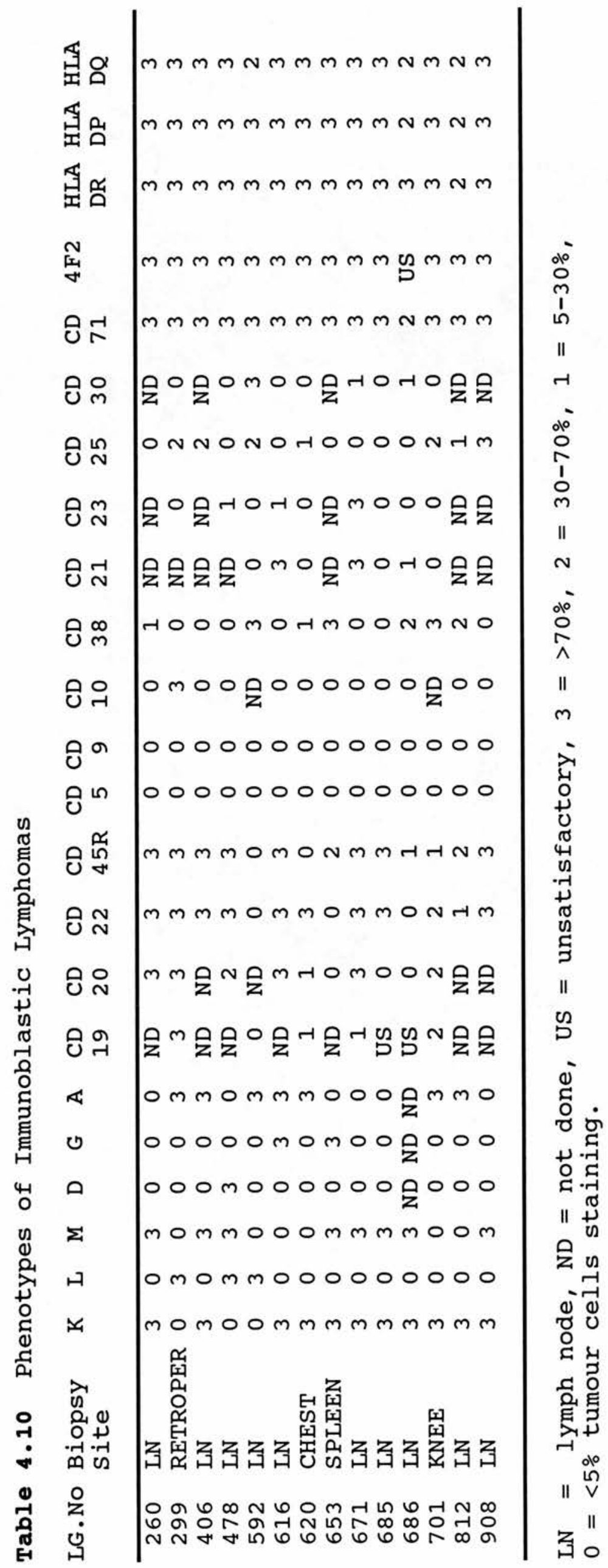




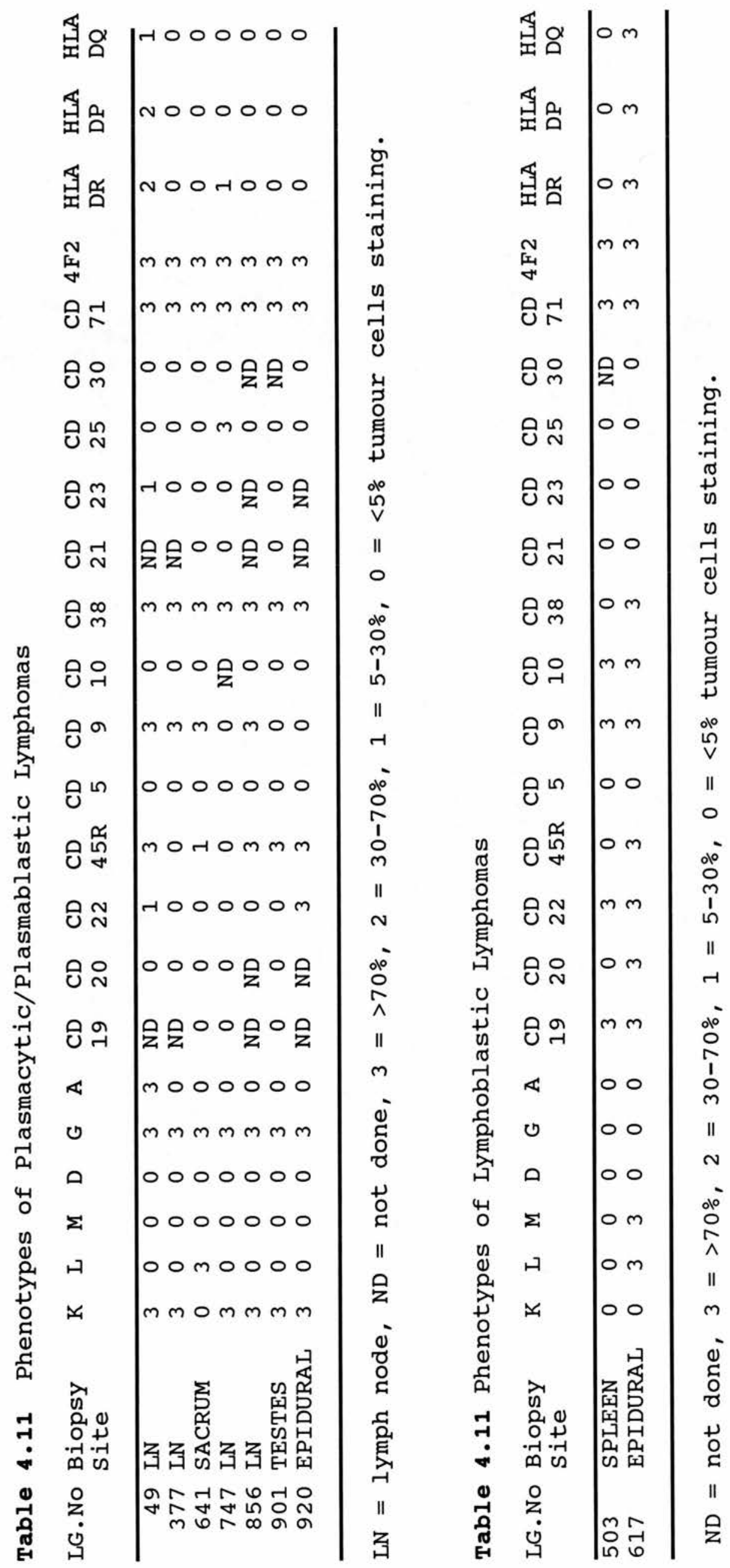




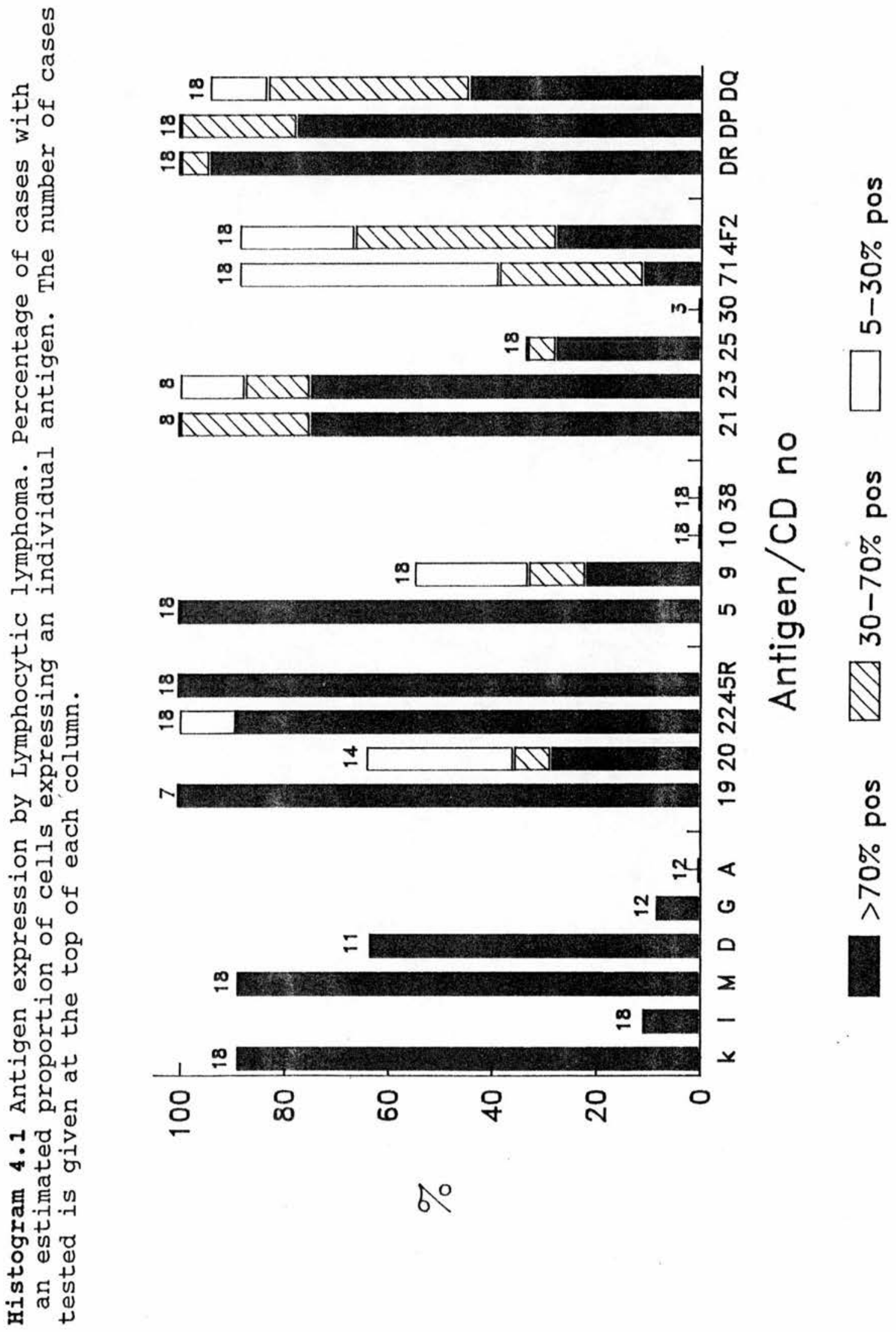




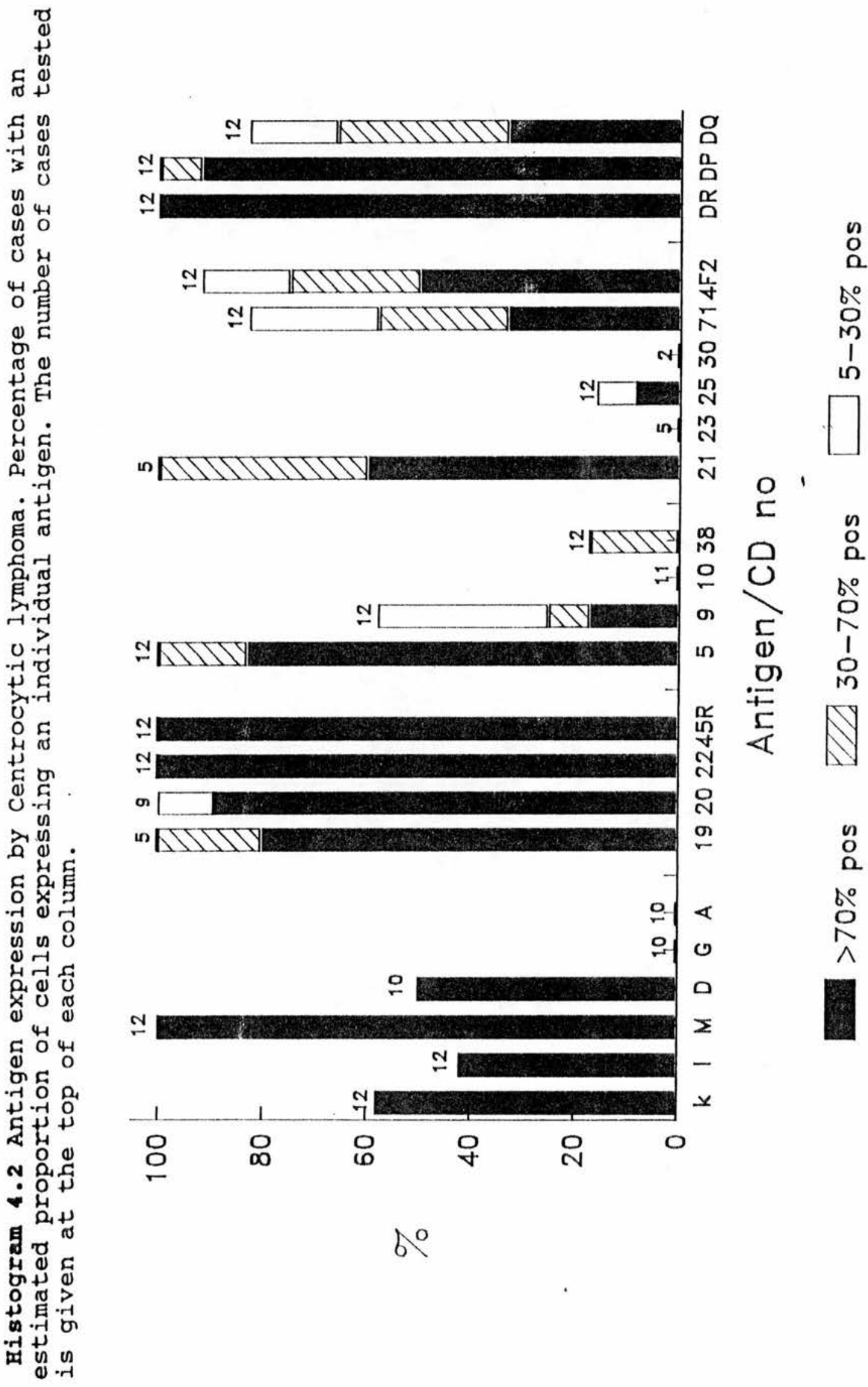




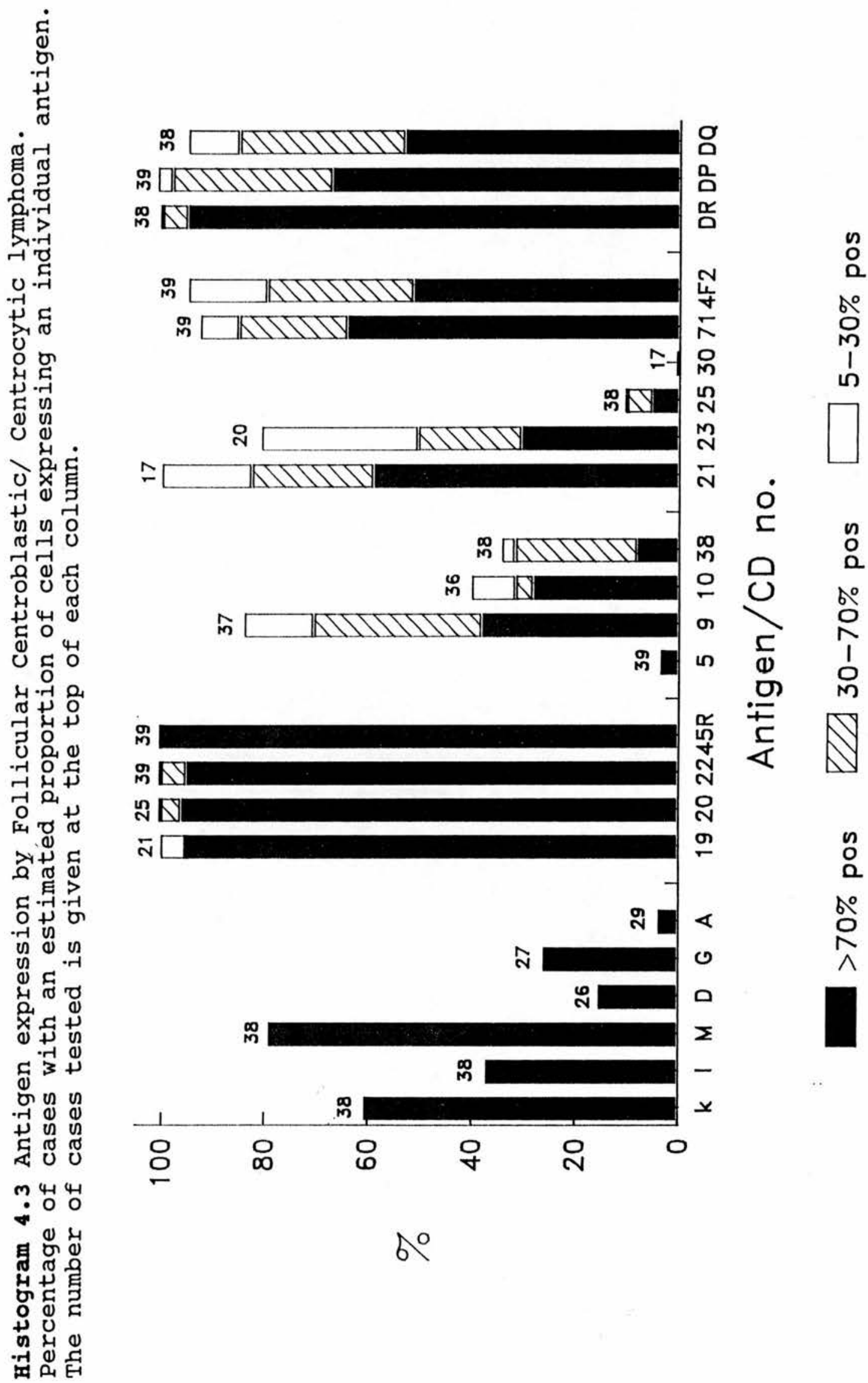




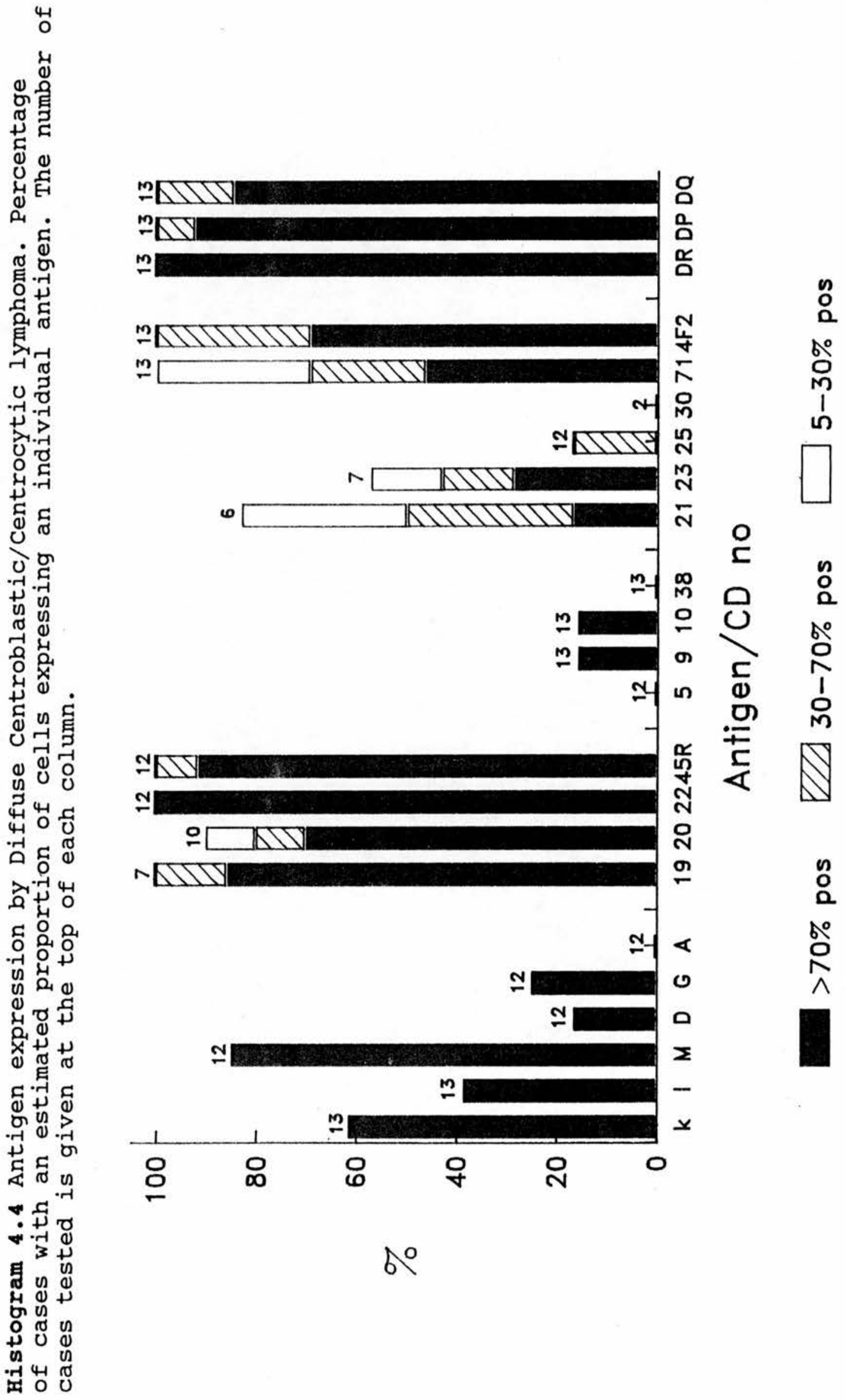




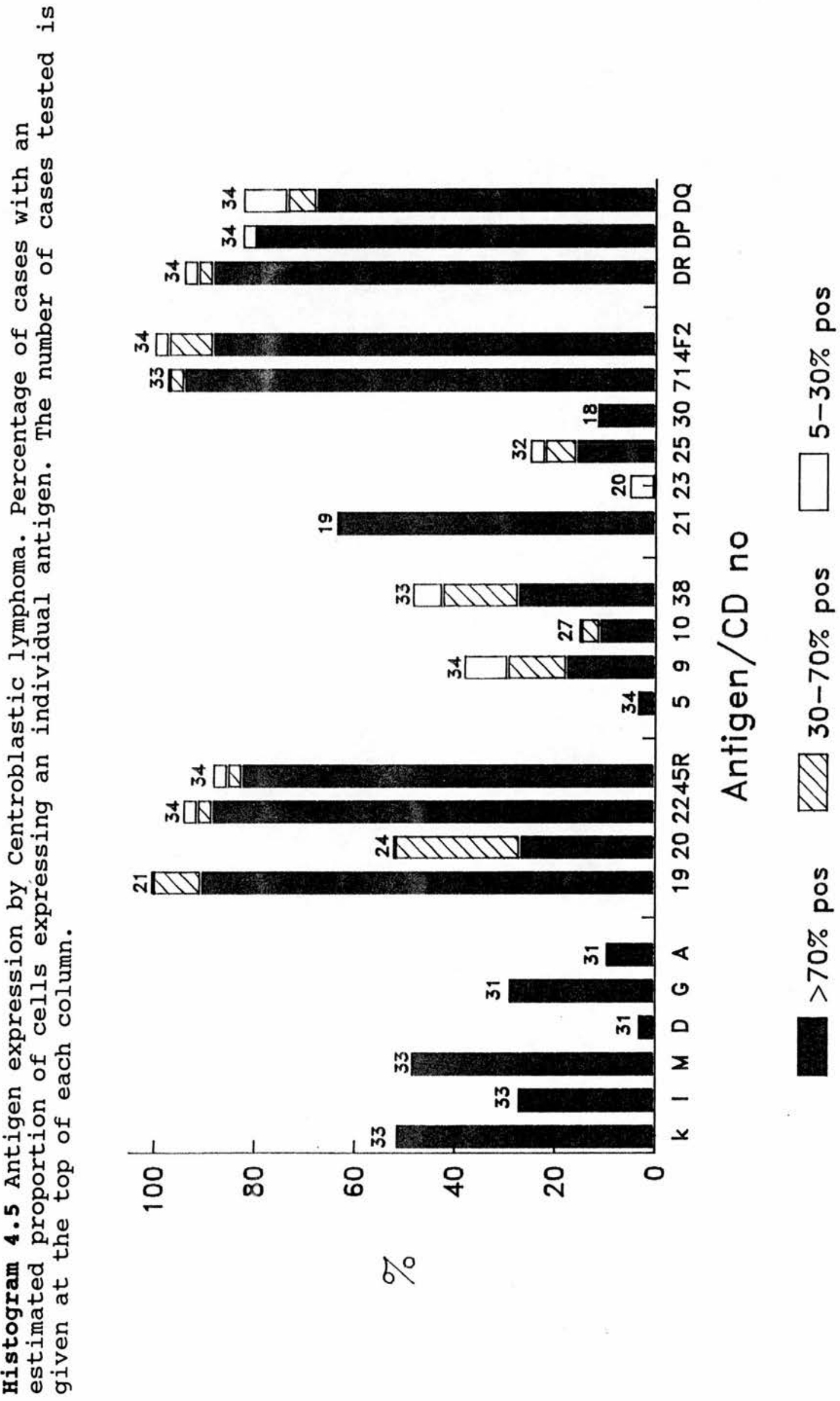




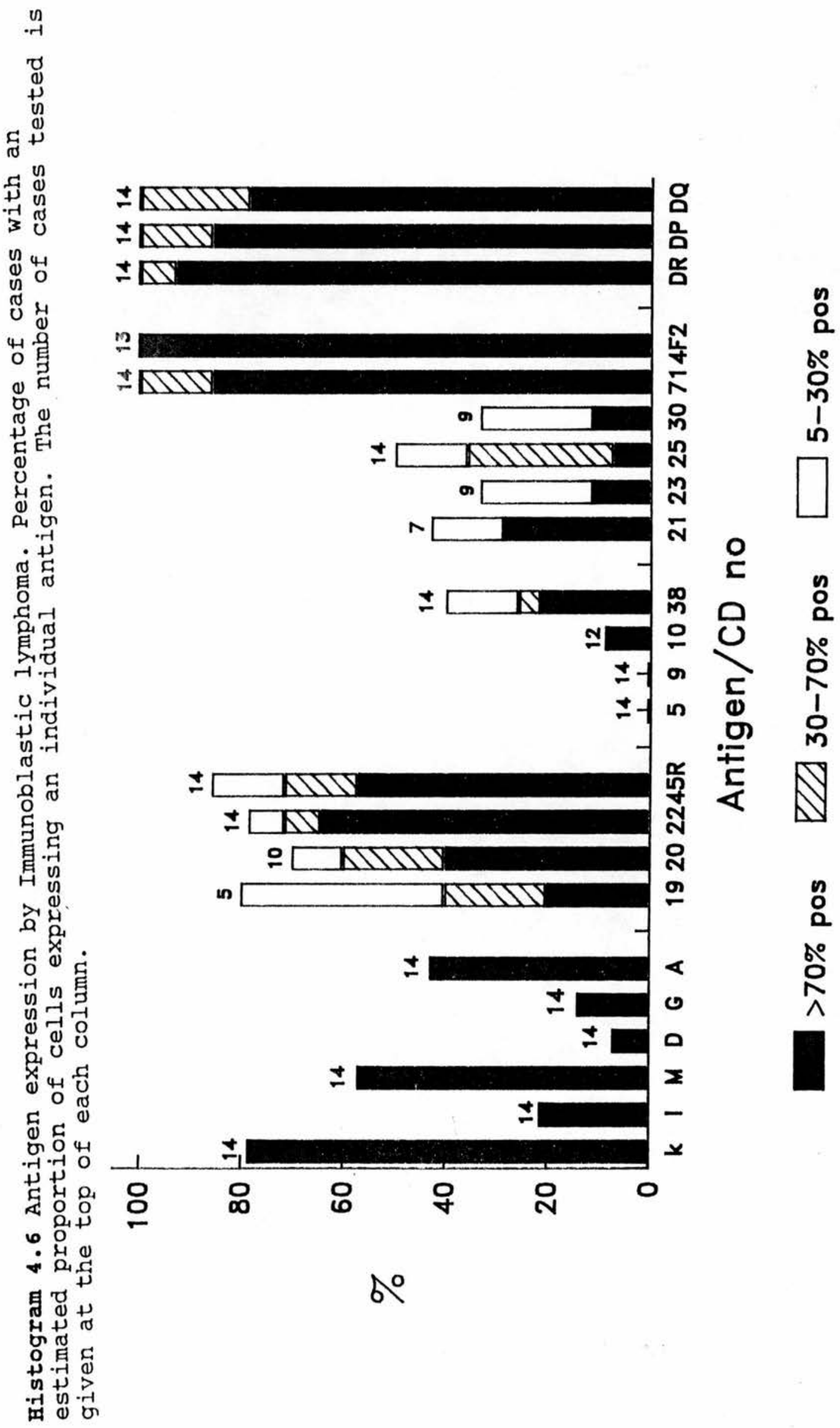




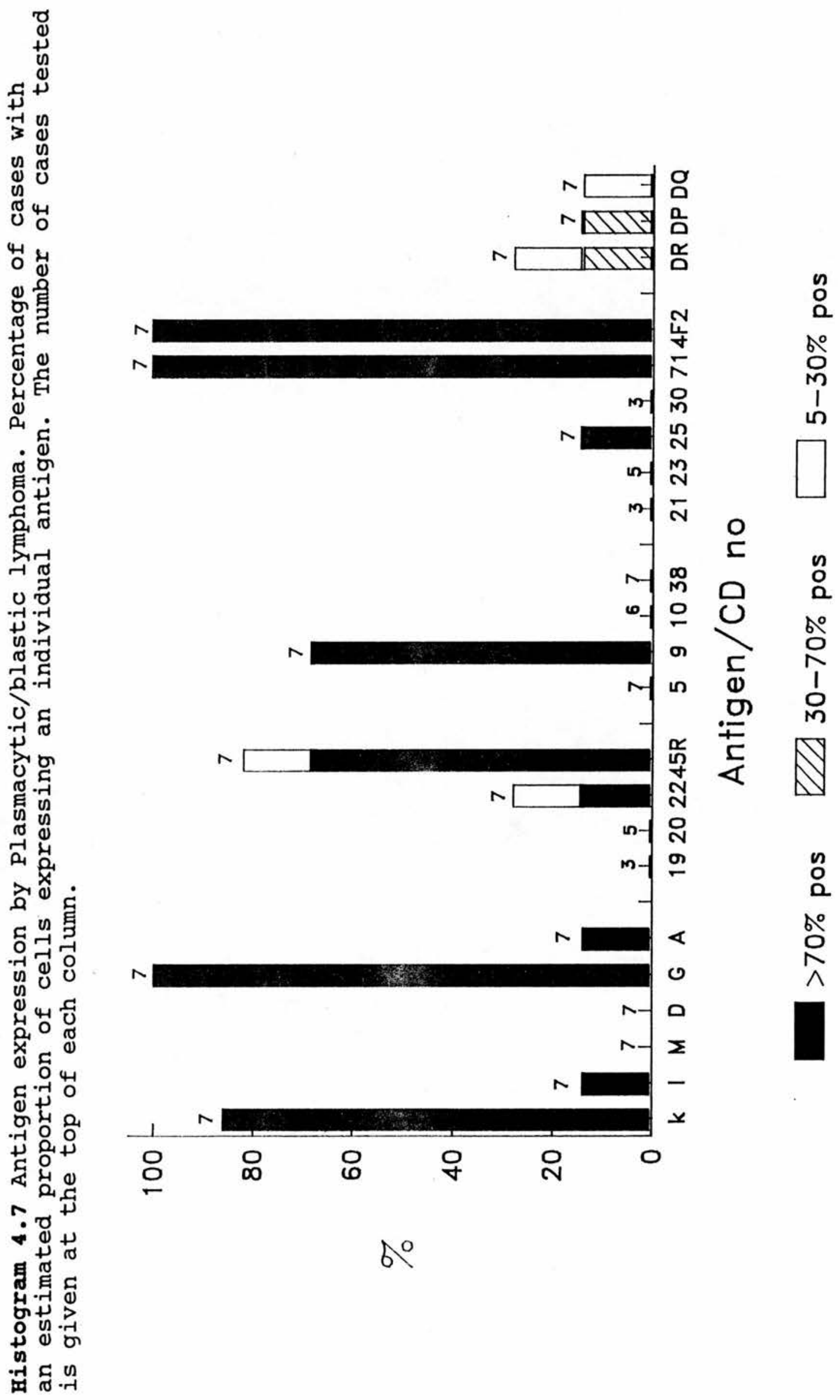


Figure 4.1

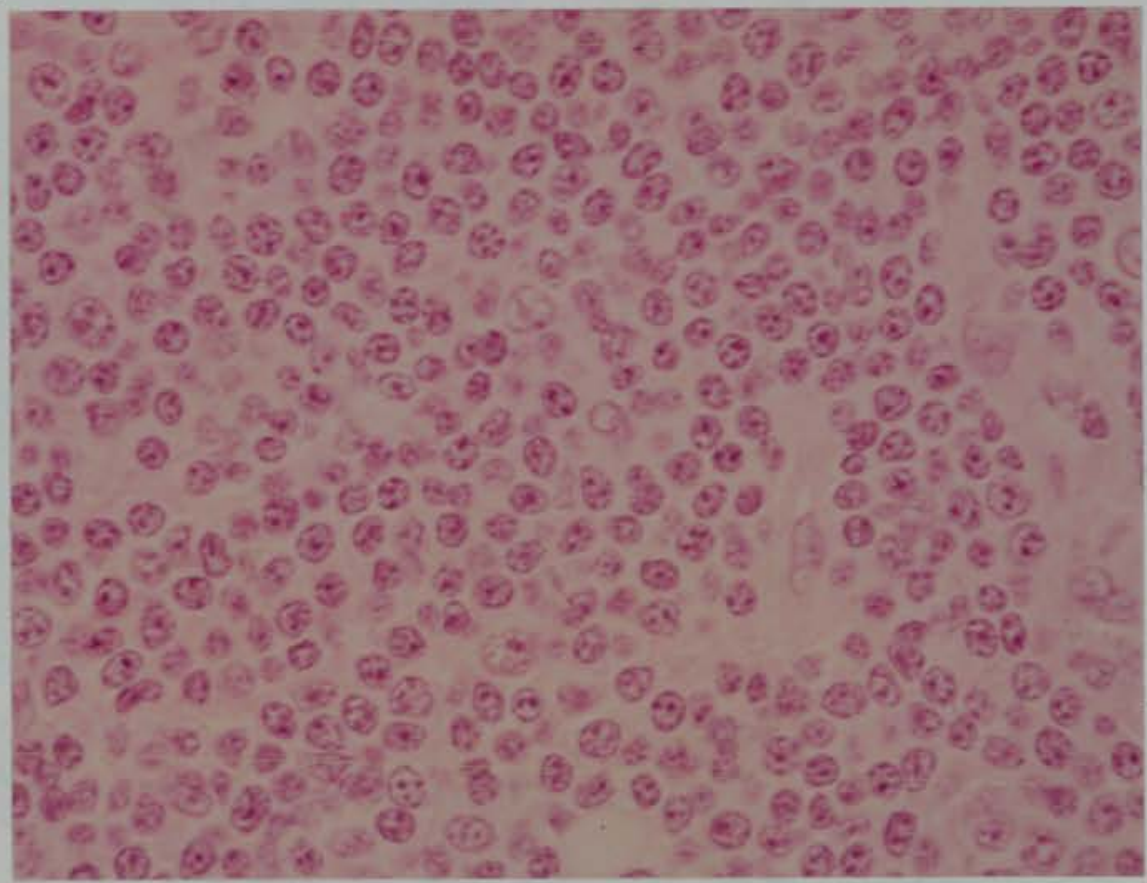

Lymphocytic lymphoma (LG no. 961) comprising a diffuse infiltrate of small lymphocytes with occasional nucleolated paraimmunoblasts.

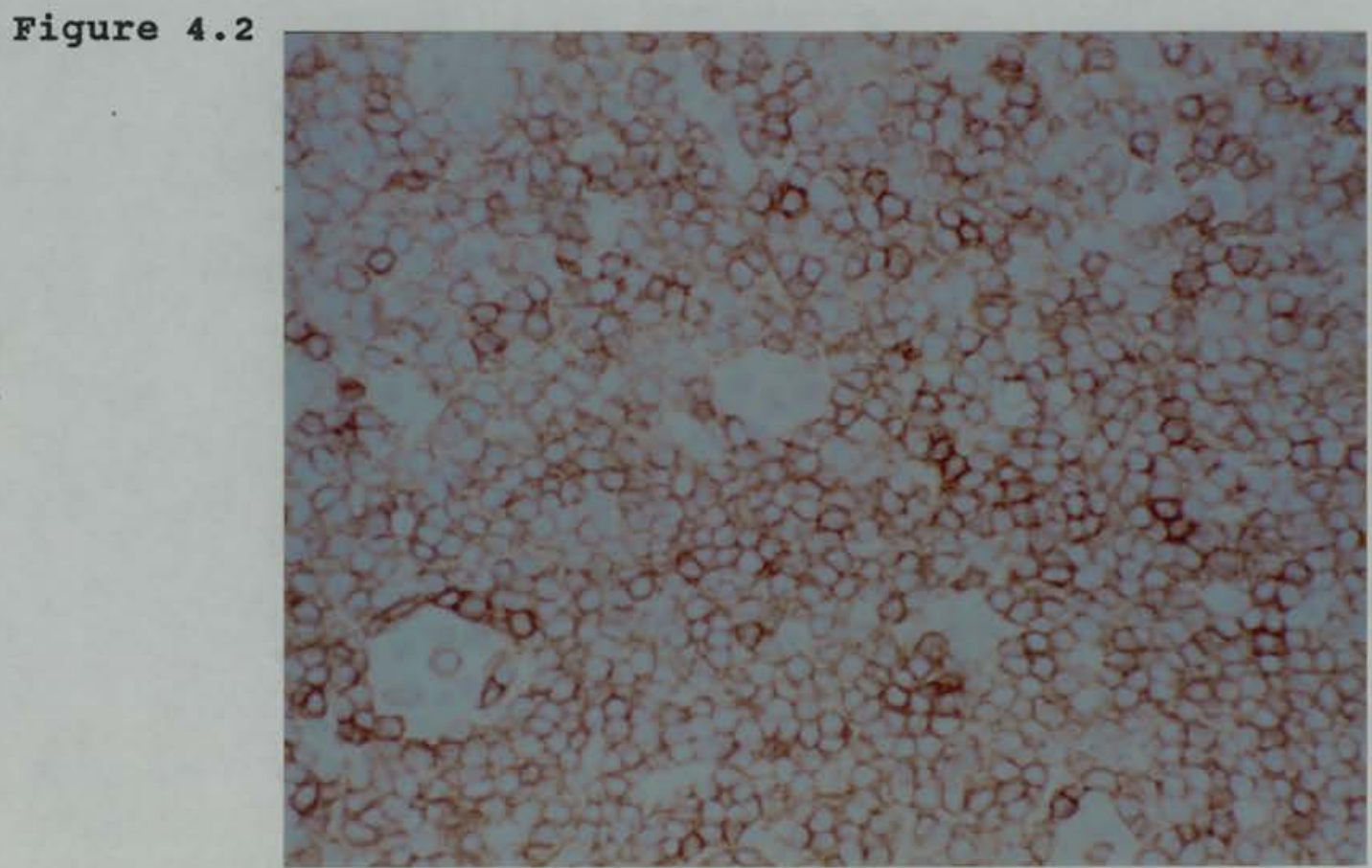

Lymphocytic lymphoma (LG no. 961). The majority of cells express CD5. 
Figure 4.3

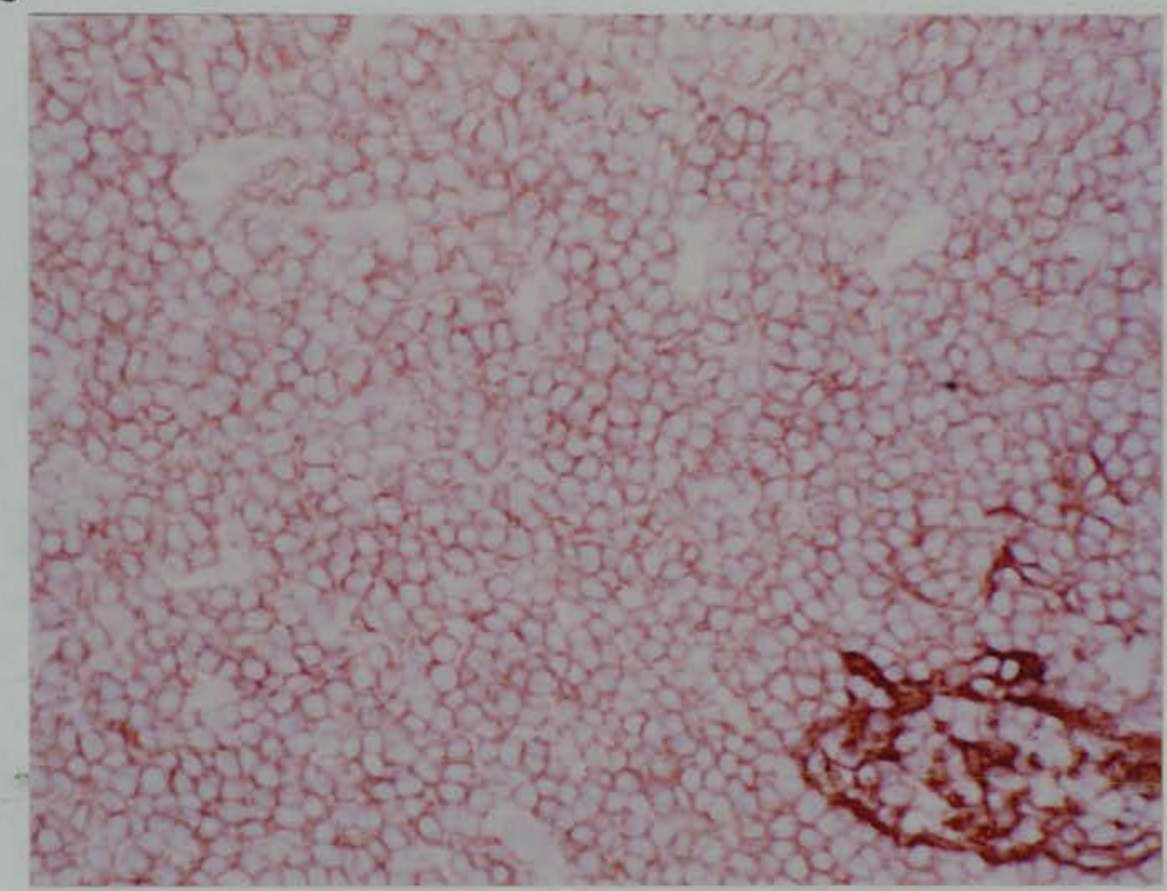

Lymphocytic lymphoma (LG no. 961). There is strong expression of CD21 by tumour cells and residual DRCs.

\section{Figure 4.4}

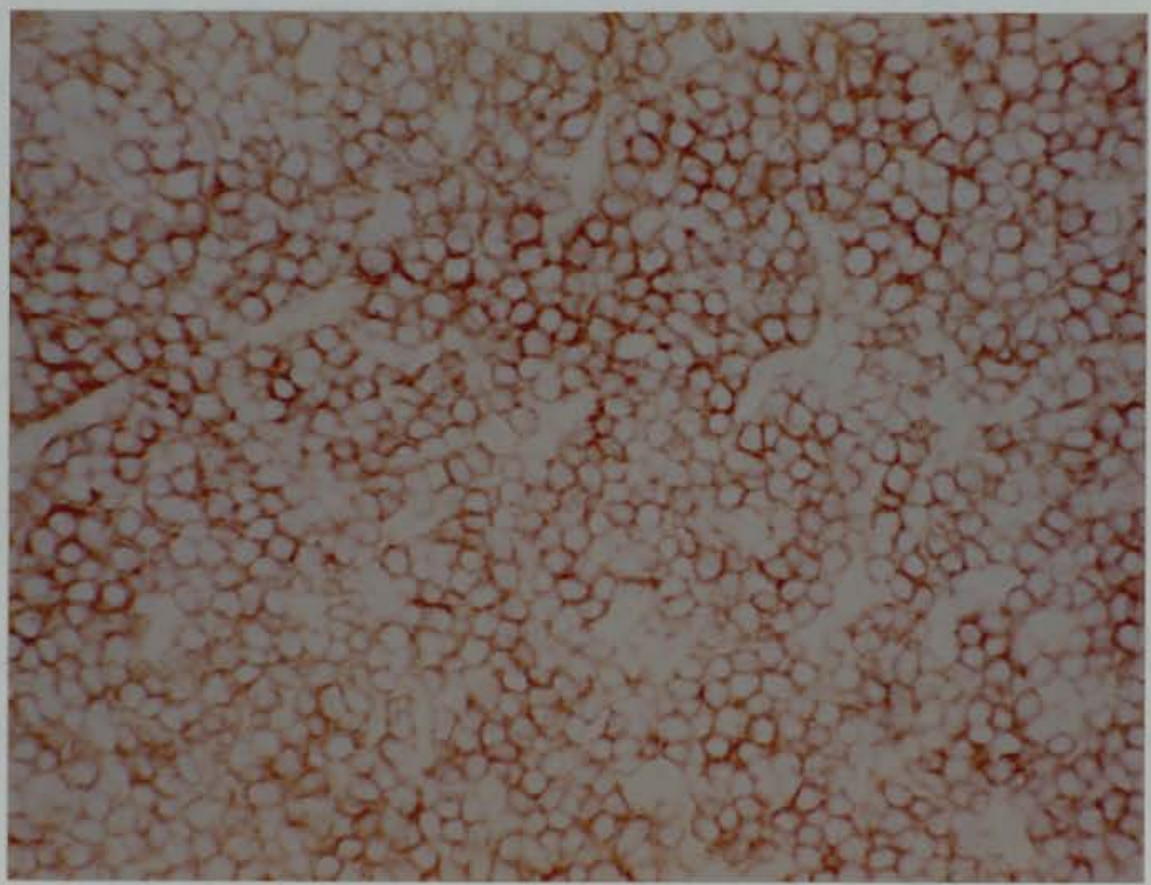

Lymphocytic lymphoma (LG no.961). There is strong expression of CD23 by the majority of cells. 
Figure 4.5

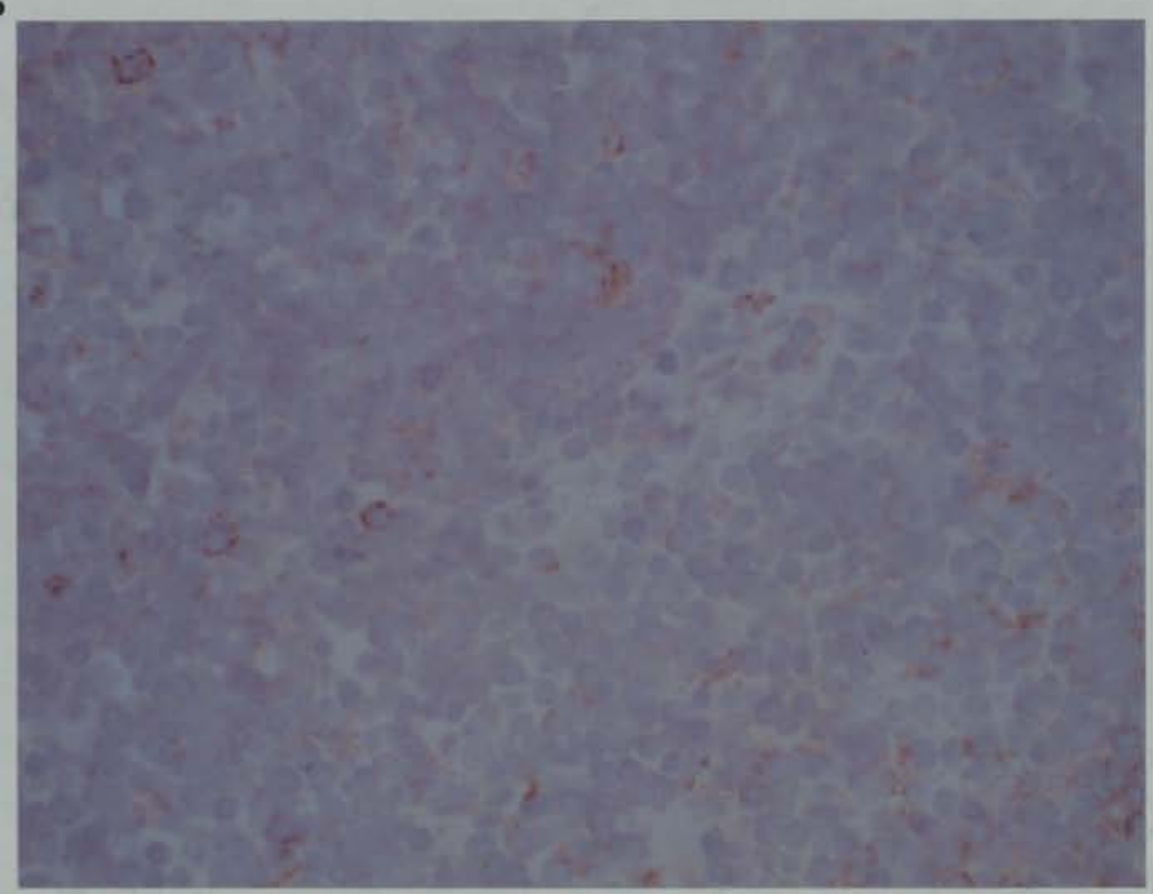

Lymphocytic lymphoma (LG no. 807). Only a minor population of cells are expressing the activation associated antigen $4 \mathrm{~F} 2$.

Figure 4.6

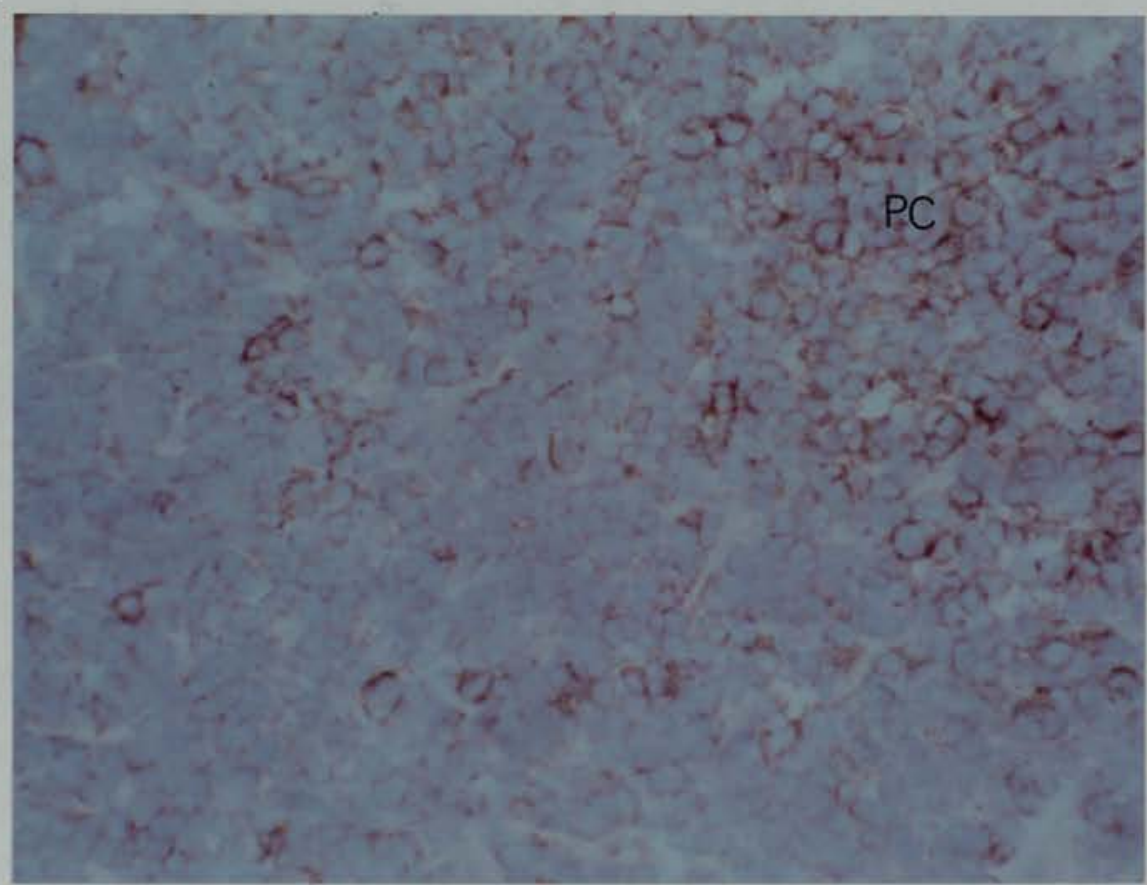

Lymphocytic lymphoma (LG no.597). Expression of CD71 is enhanced in proliferation centres (PC). 
Figure 4.7

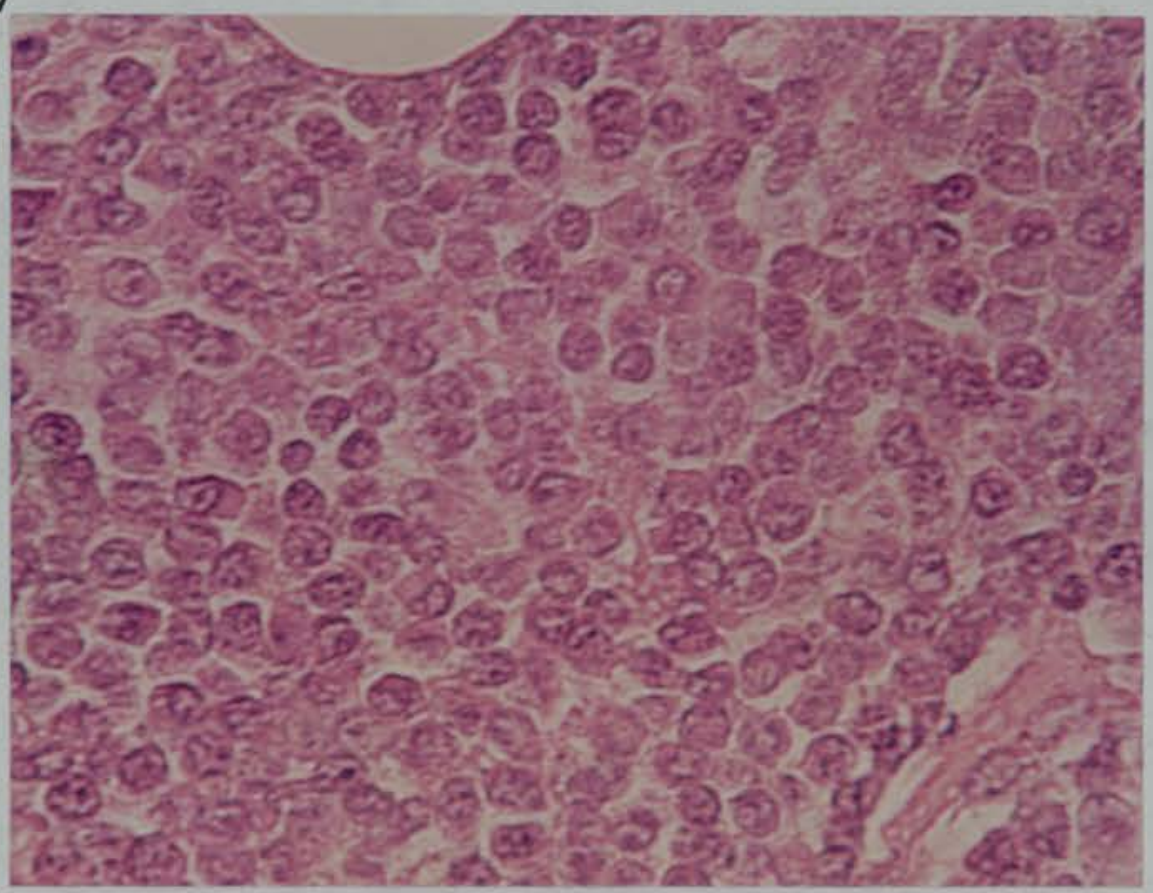

Lymphoplasmacytic lymphoma (LG no. 717). The tumour comprises a diffuse infiltrate of small lymphoid cells with clumped nuclear chromatin and moderate amounts of basophilic cytoplasm.

Figure 4.8

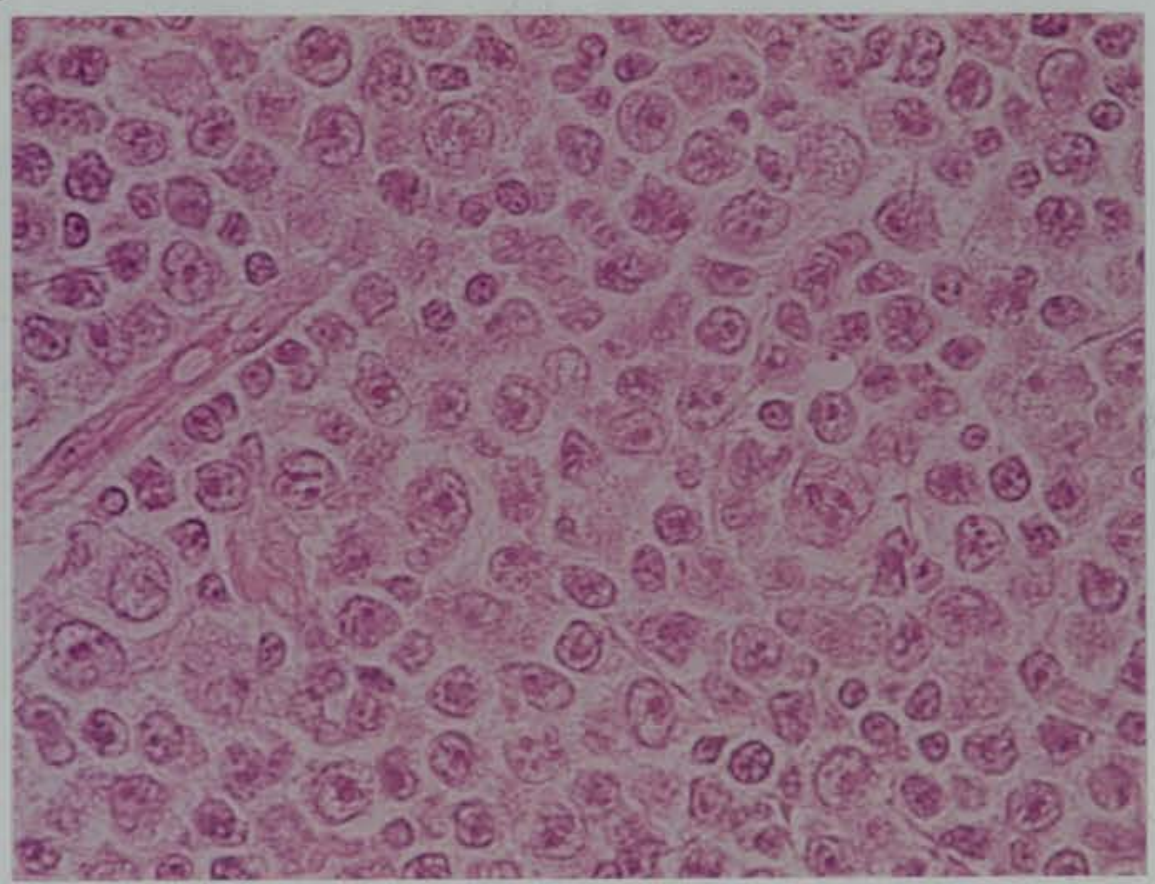

Prolymphocytic lymphoma (LG no. 297). The predominant cell is a small to medium sized lymphoid cell with one or more small nucleoli. 
Figure 4.9

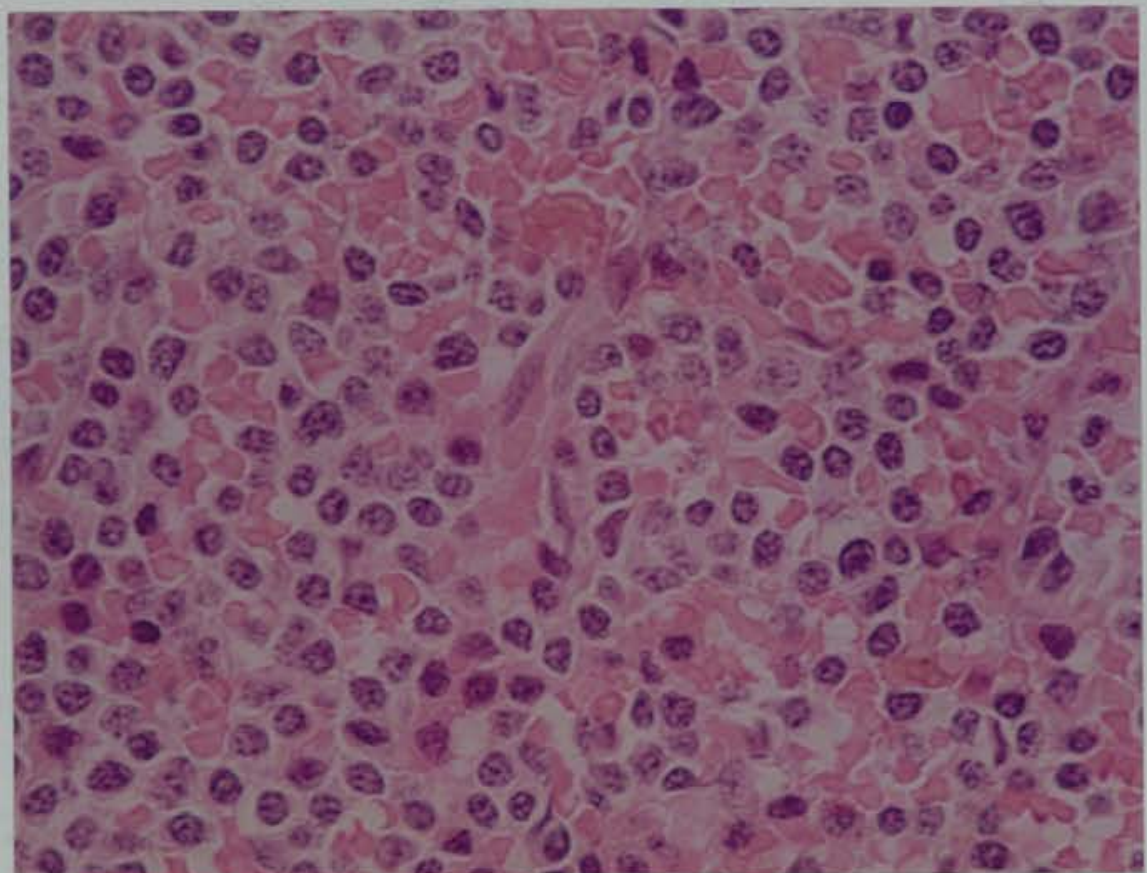

Hairy cell leukaemia (LG no. 425). The splenic red pulp contains a diffuse infiltrate of small to medium sized cells with clumped nuclear chromatin and moderate amounts of pale cytoplasm.

Figure 4.10

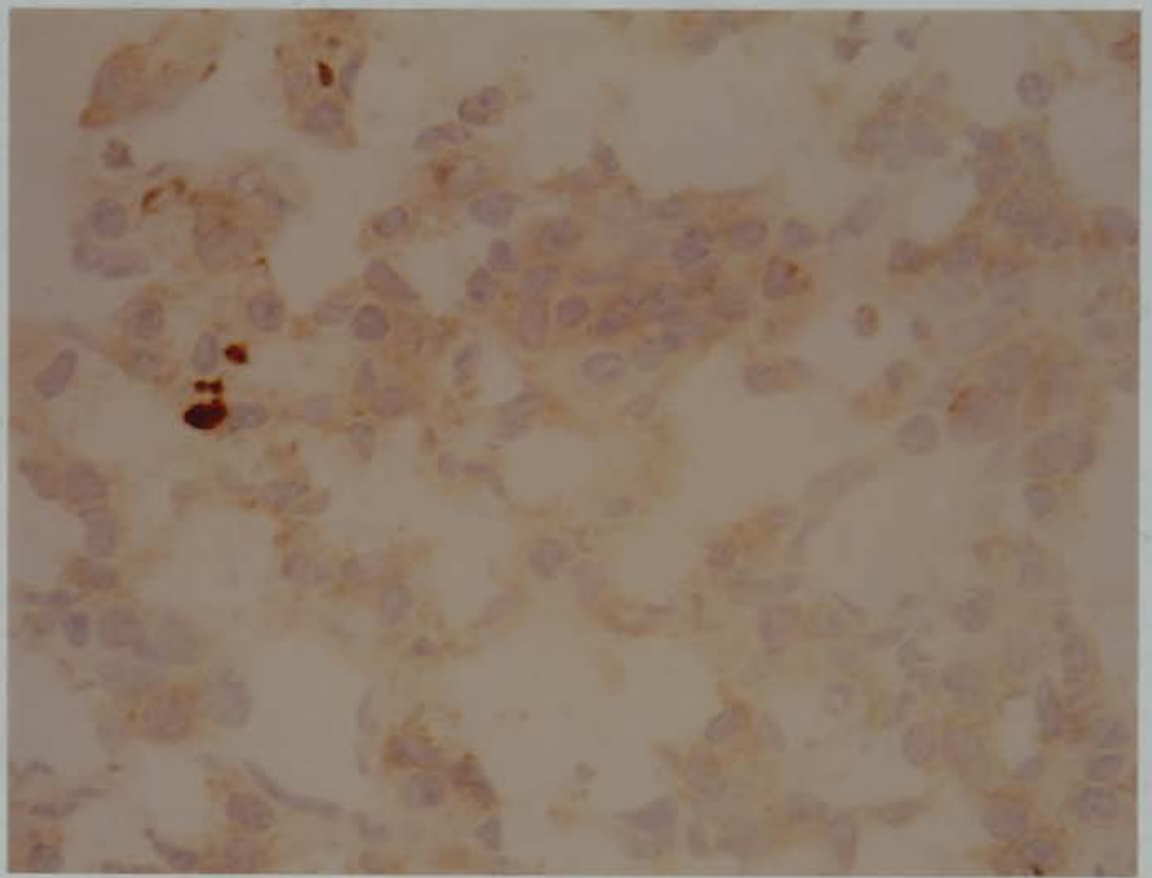

Hairy cell leukaemia (LG no. 425). There is predominantly cytoplasmic expression of CD25. 
Figure 4.11

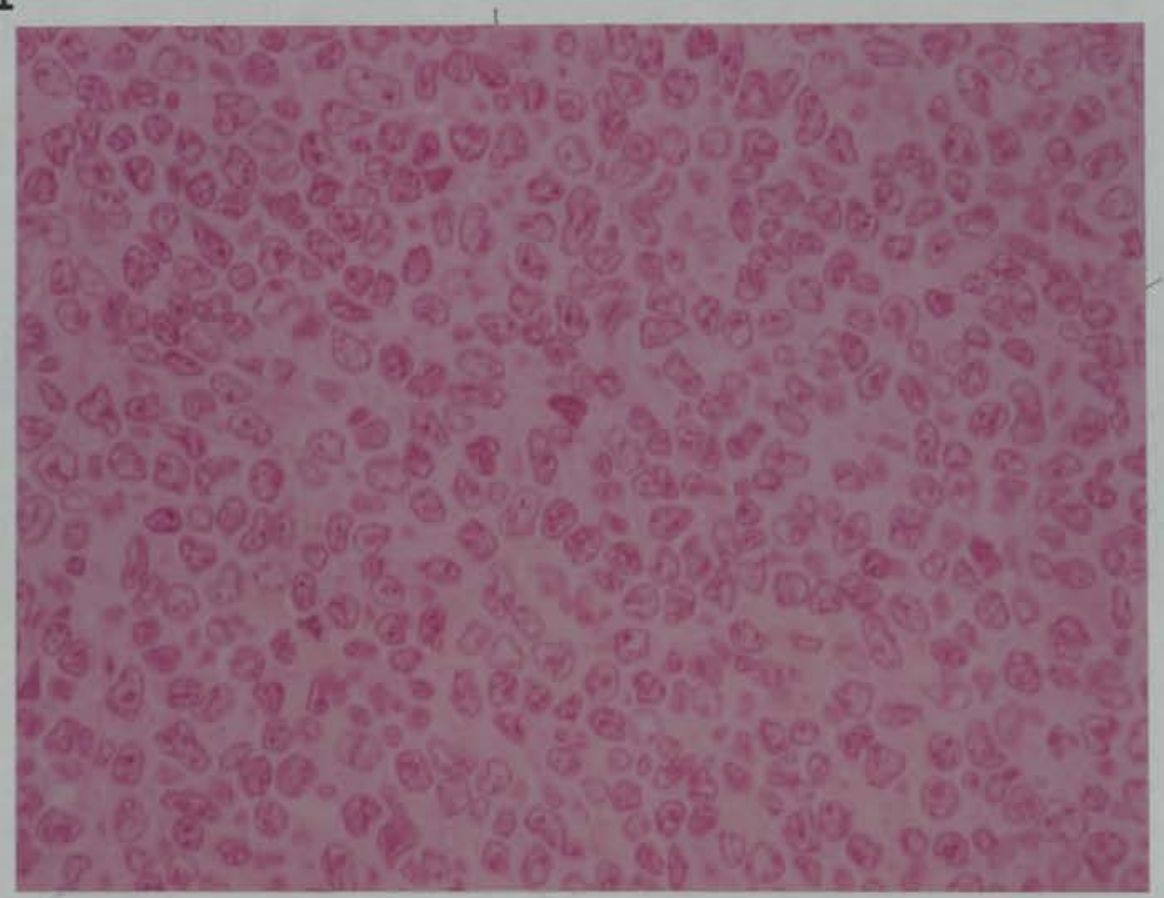

Centrocytic lymphoma (LG no. 960). There is a diffuse infiltrate of small to medium sized cells with irregular nuclei and clumped nuclear chromatin.

Figure 4.12

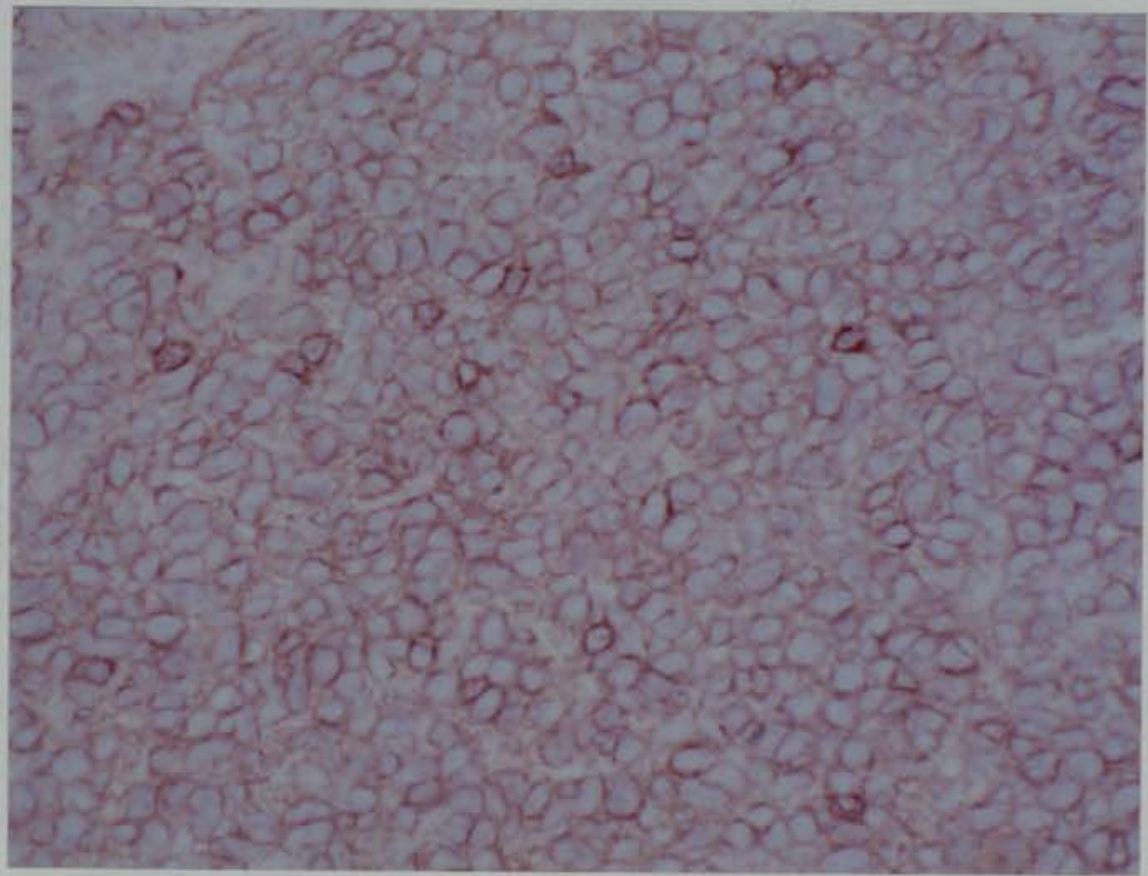

Centrocytic lymphoma (LG no. 960). There is strong expression of CD5 by the majority of cells. 
Figure 4.13

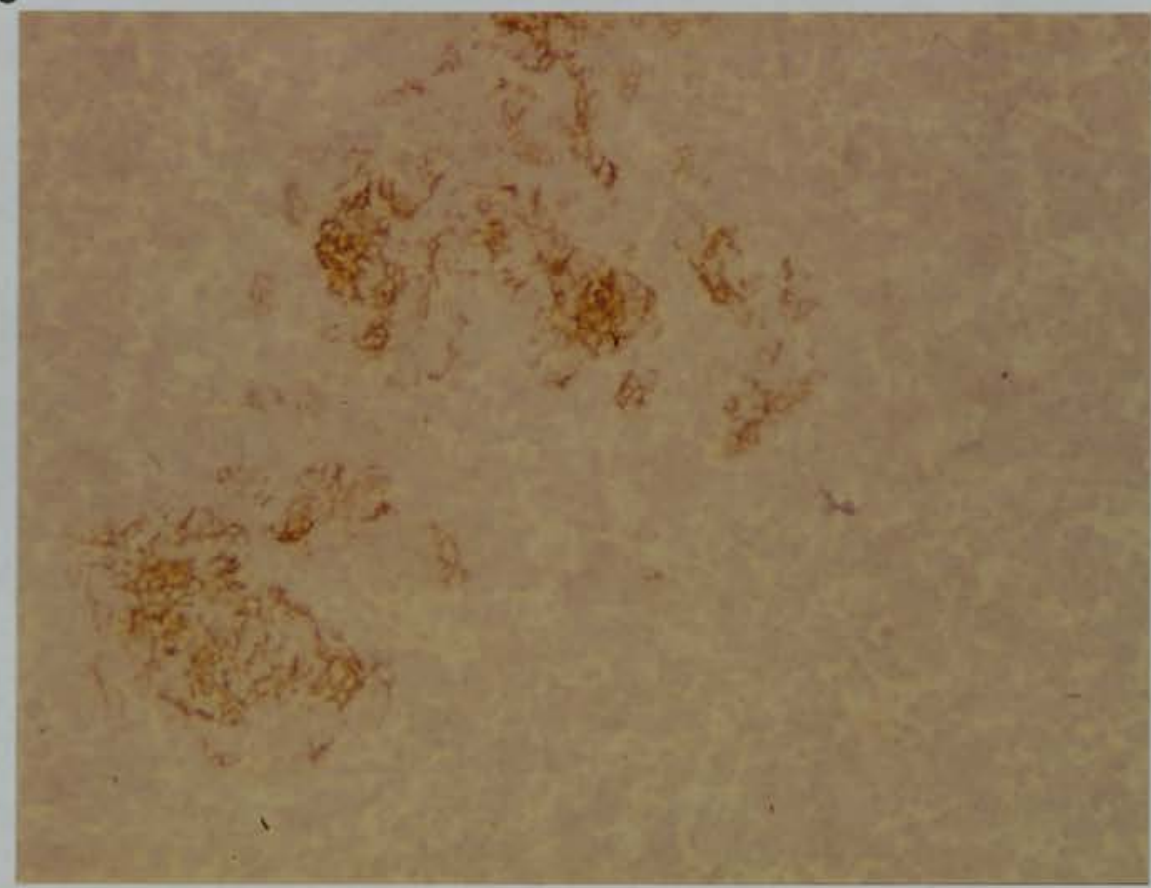

Centrocytic lymphoma (LG no. 960). The tumour cells do not express CD23. DRCs are positive.

\section{Figure 4.14}

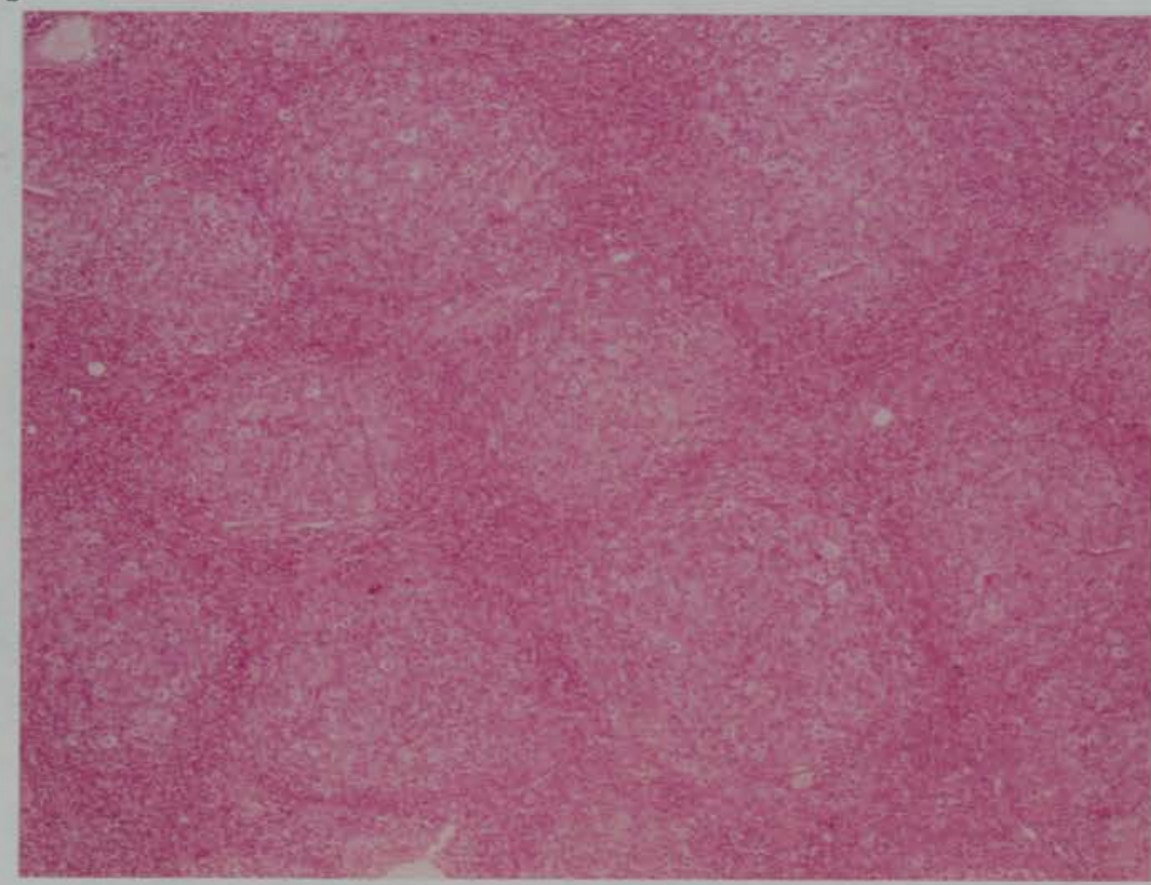

Follicular centroblastic/centrocytic lymphoma (LG no. 866). The normal lymph node architecture is replaced by a follicles containing an admixture of centroblasts and centrocytes. 
Figure 4.15

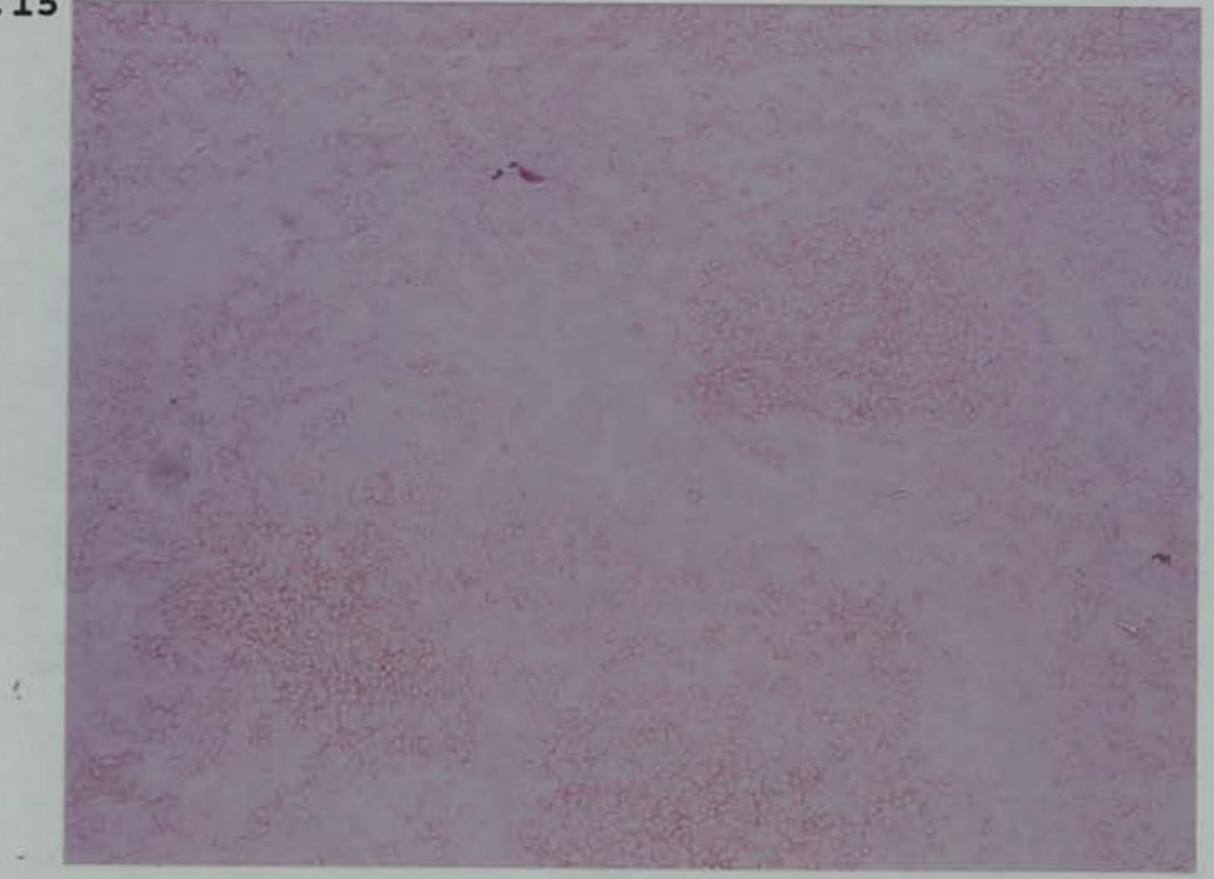

Follicular centroblastic/centrocytic lymphoma (LG no. 836). the neoplastic follicles are expressing CD10 strongly whereas the majority of interfollicular cells are negative.

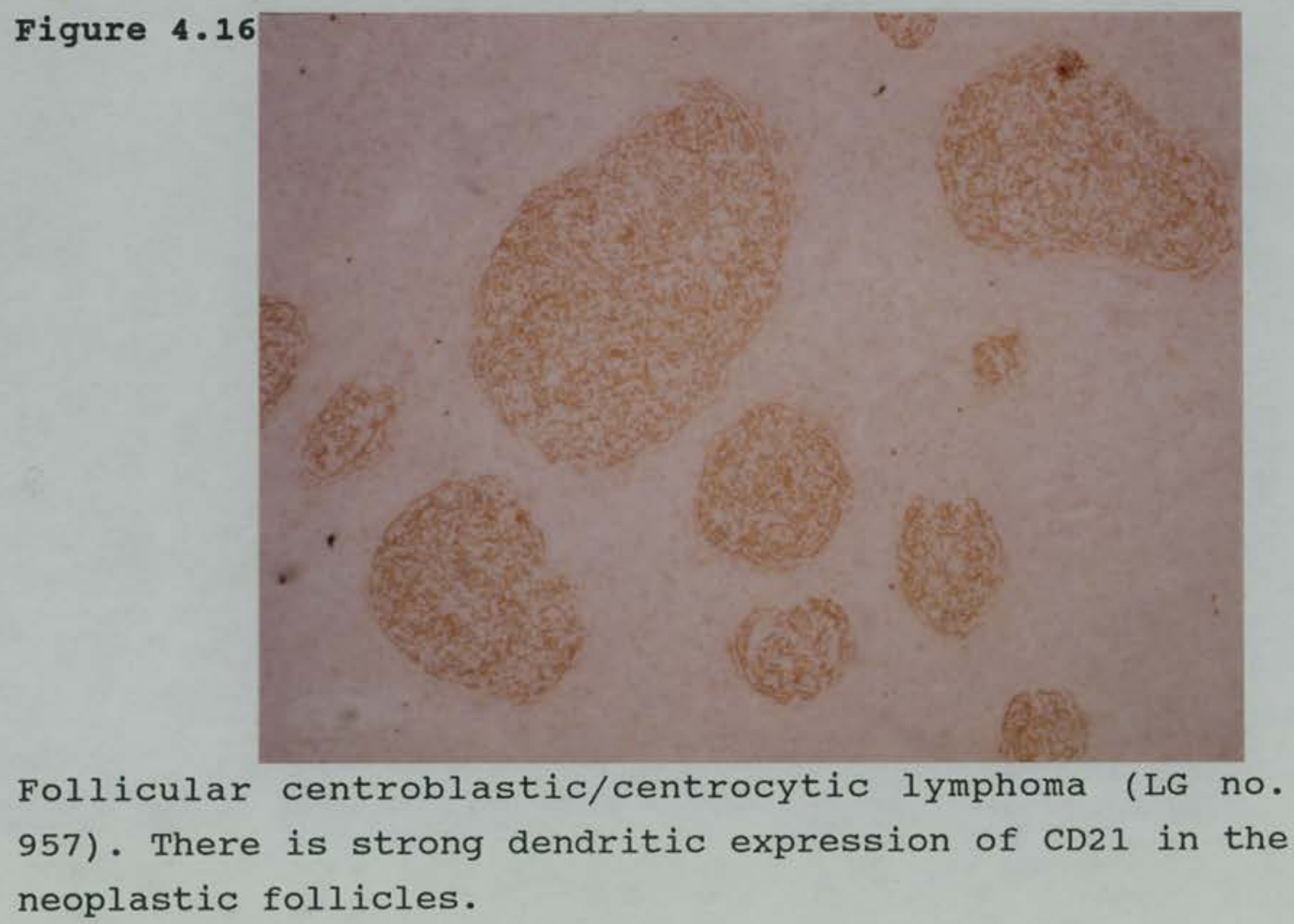




\section{Figure 4.17}

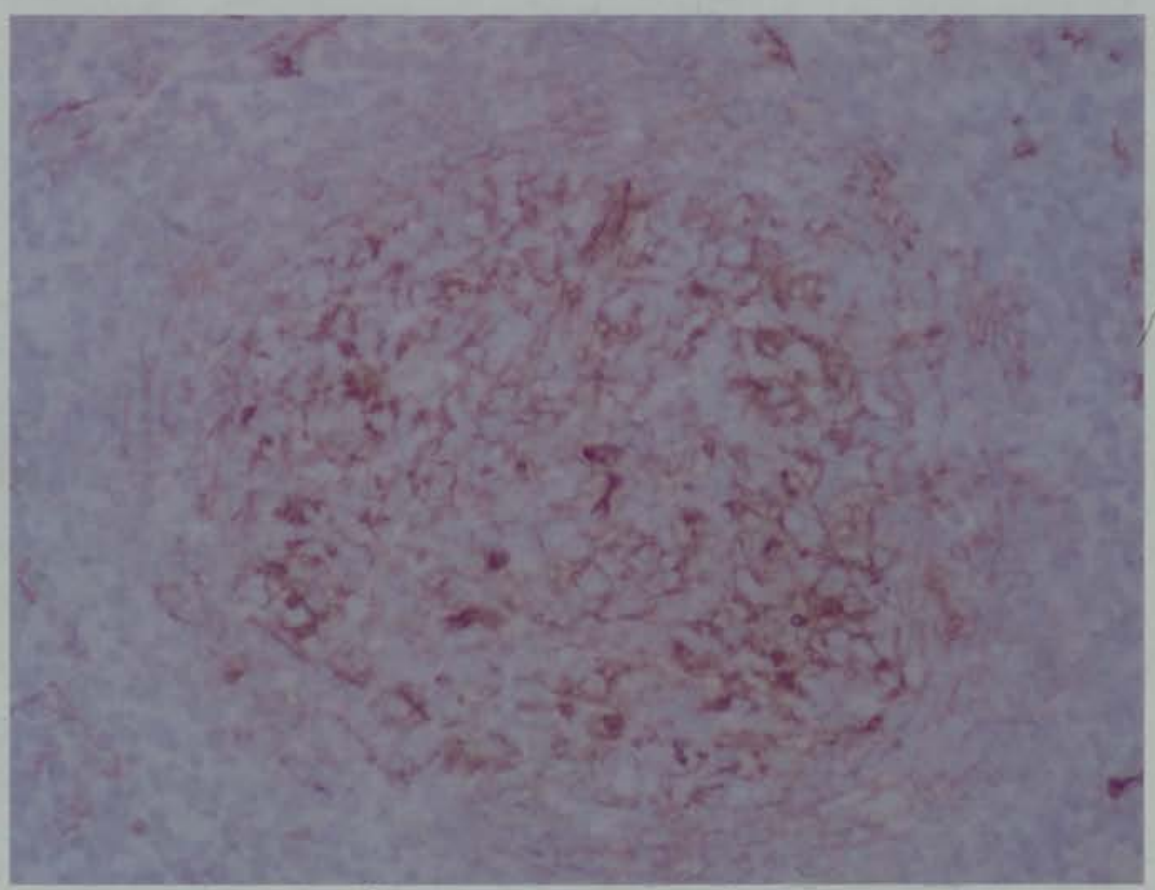

Follicular centroblastic/centrocytic lymphoma (LG no.866). There is dendritic network staining in the follicle but expression of CD9 by lymphoid cells can also be seen.

\section{Figure 4.18}

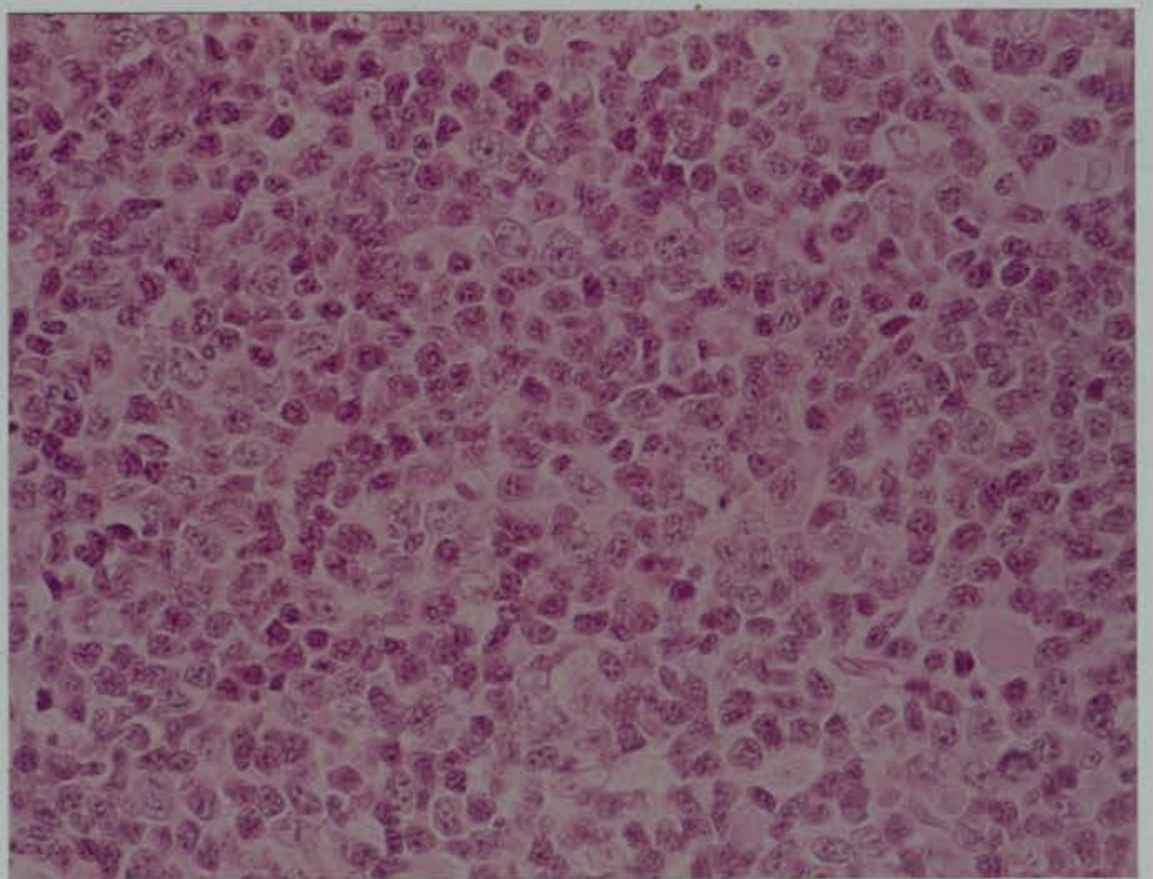

Diffuse centroblastic/centrocytic lymphoma (LG no. 85). The normal lymph node architecture is replaced by a diffuse infiltrate of irregular centrocytes and large nucleolated centroblasts. 
Figure 4.19

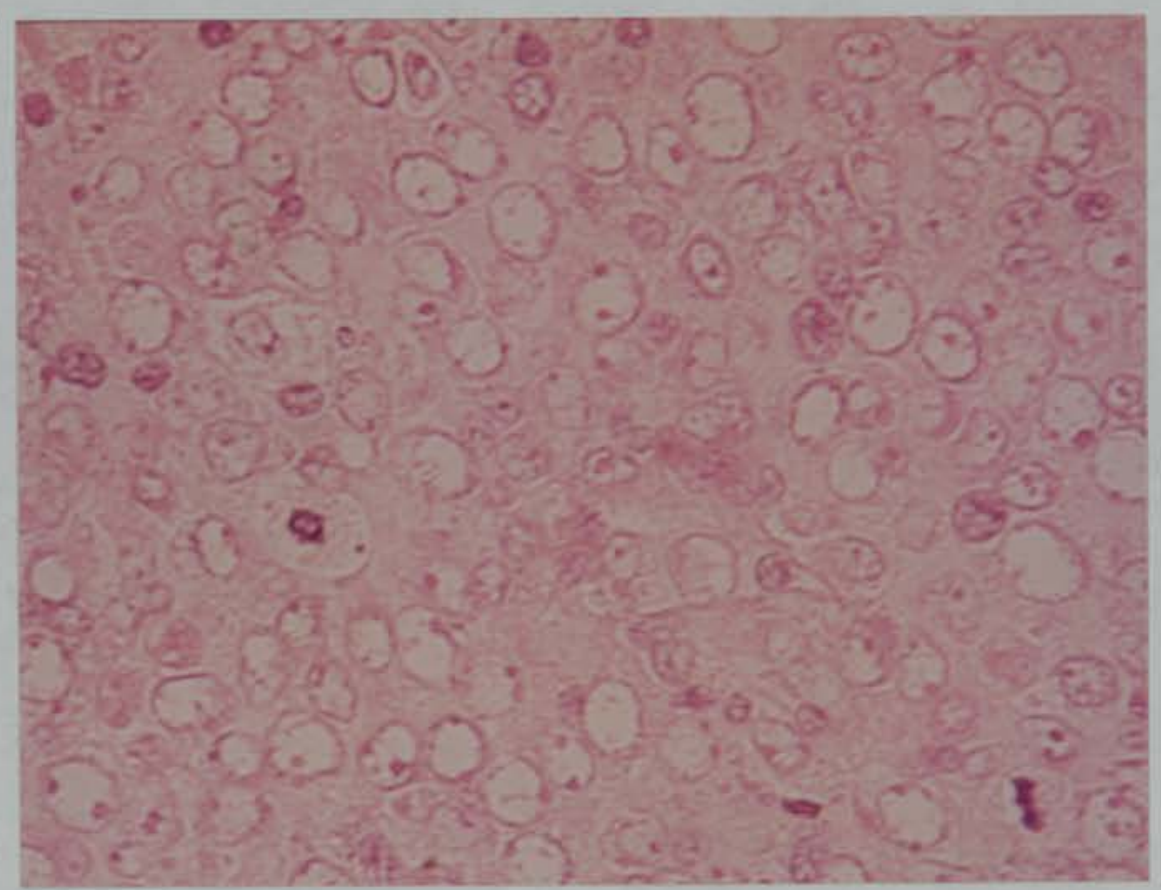

Centroblastic lymphoma (LG no. 563). The tumour consists of a diffuse infiltrate of large cells with vesicular nuclei and multiple peripheral nucleoli.

Figure 4.20

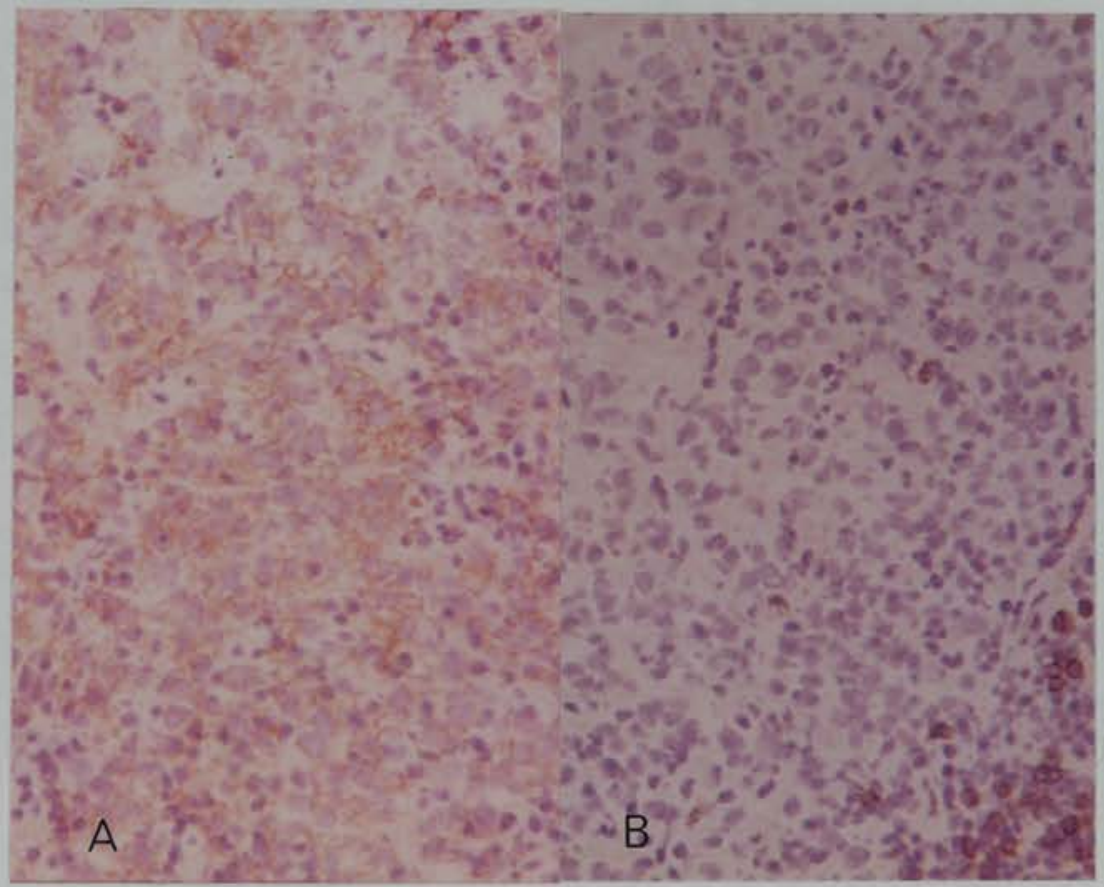

Centroblastic lymphoma (LG no.1050). The neoplastic cells are expressing CD19 (A) but not CD45R (B). 
Figure 4.21

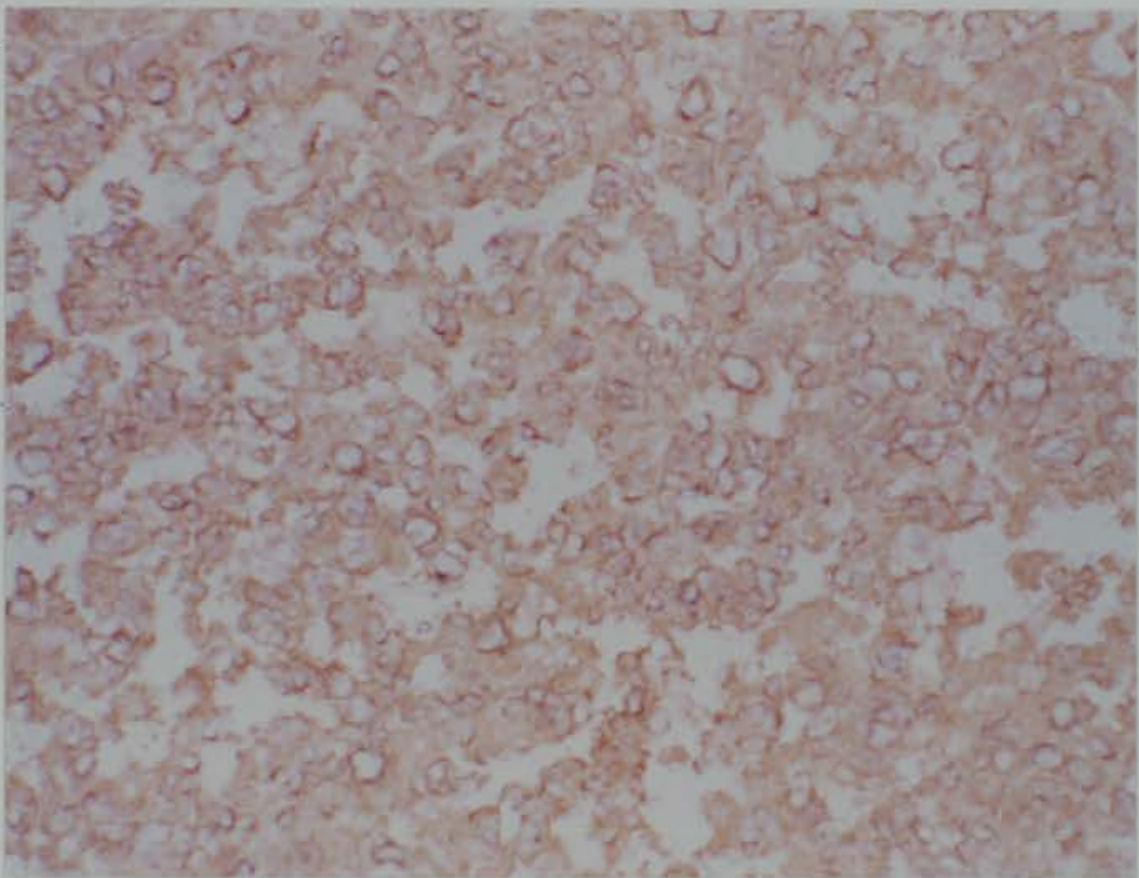

Centroblastic lymphoma (LG no. 745). THe majority of cells are expressing $4 \mathrm{~F} 2$ strongly.

Figure 4.22

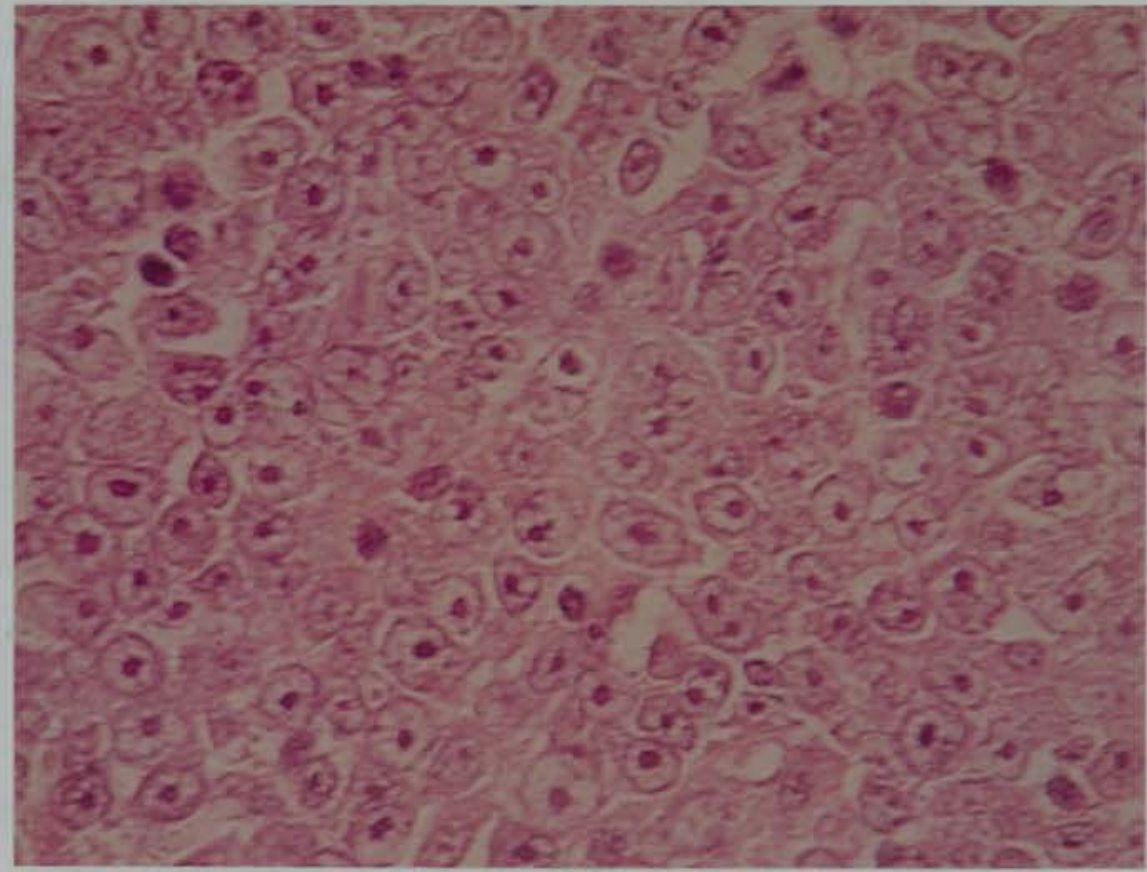

Immunoblastic lymphoma (LG no. 406). The predominant cell is large and has a vesicular nucleus with a single prominent central nucleolus. 
Figure 4.23

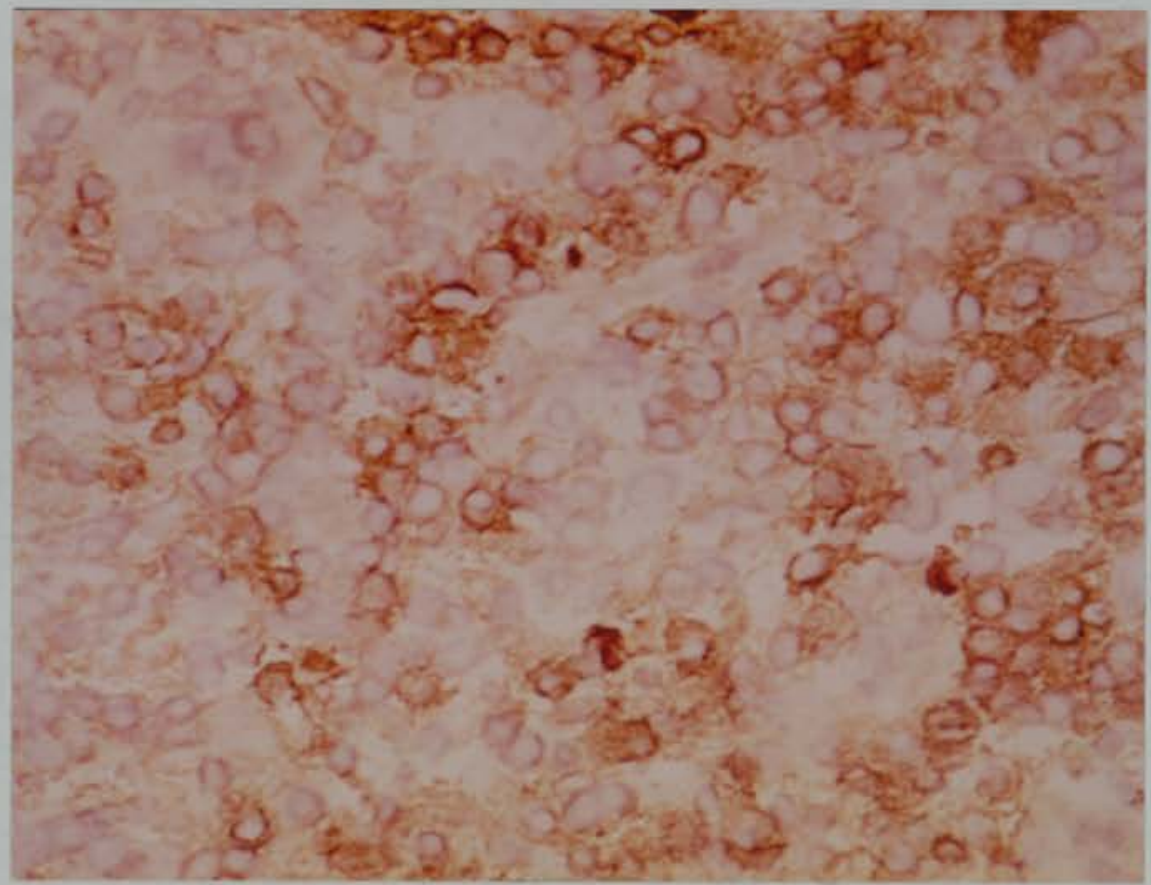

Immunoblastic lymphoma (LG no. 701). A proportion of cells only are expressing CD22.

Figure 4.24

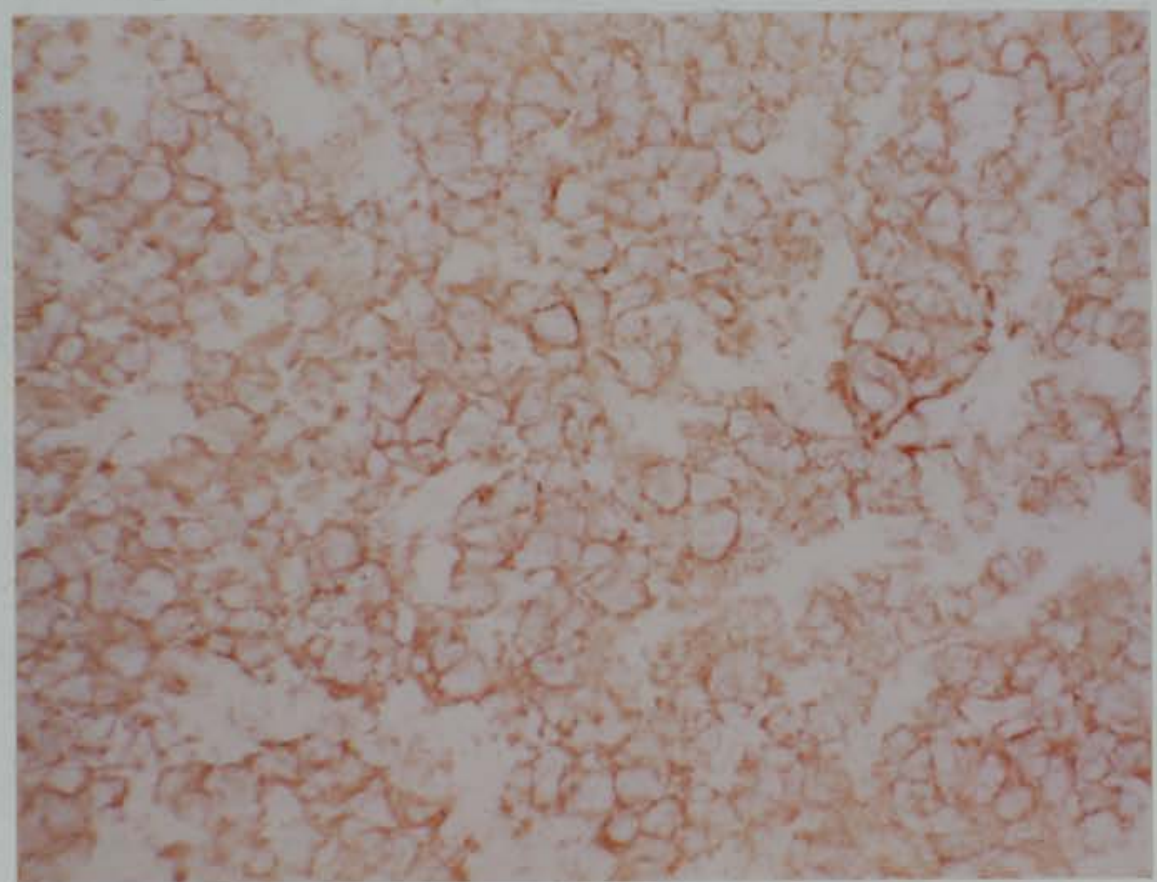

Immunoblastic lymphoma (LG no. 406). CD71 is expressed strongly by the majority of cells. 
Figure 4.25

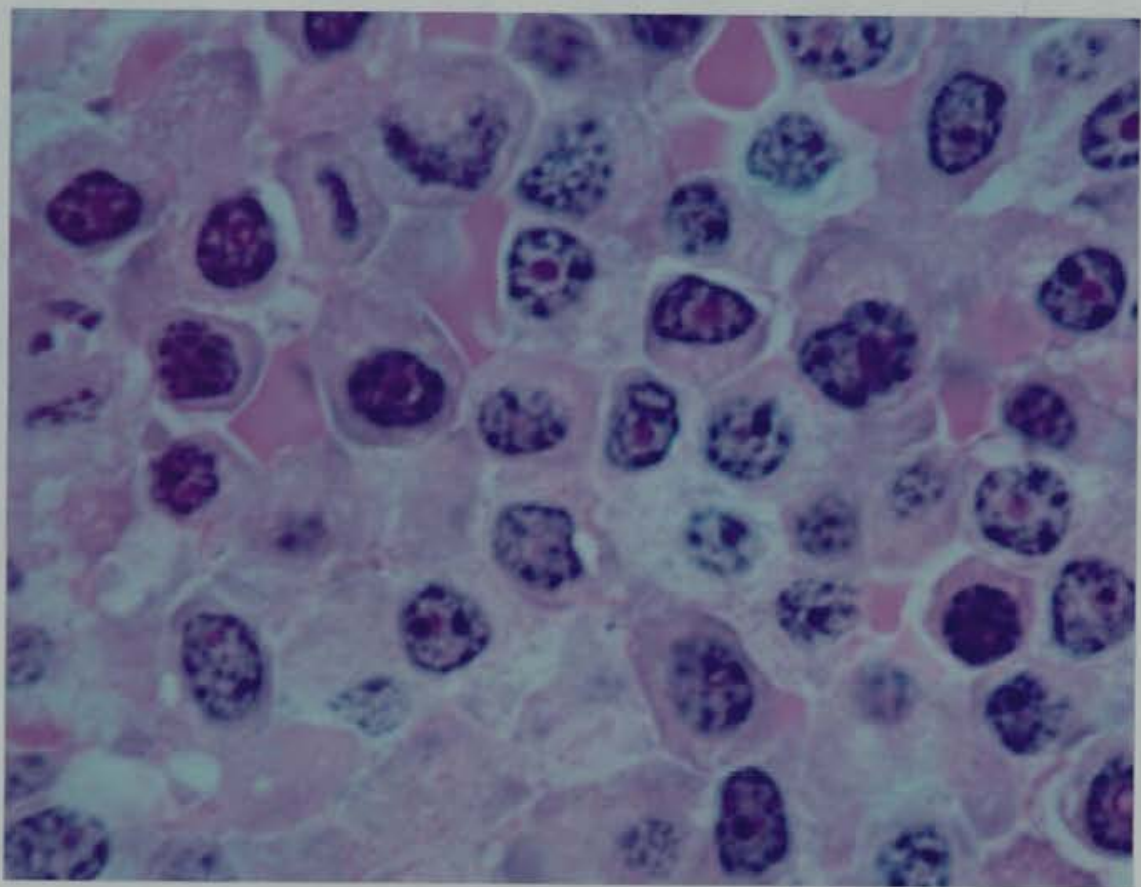

Plasmacytoma (LG no. 49). The tumour consists of a diffuse infiltrate of plasma cells.

Figure 4.26

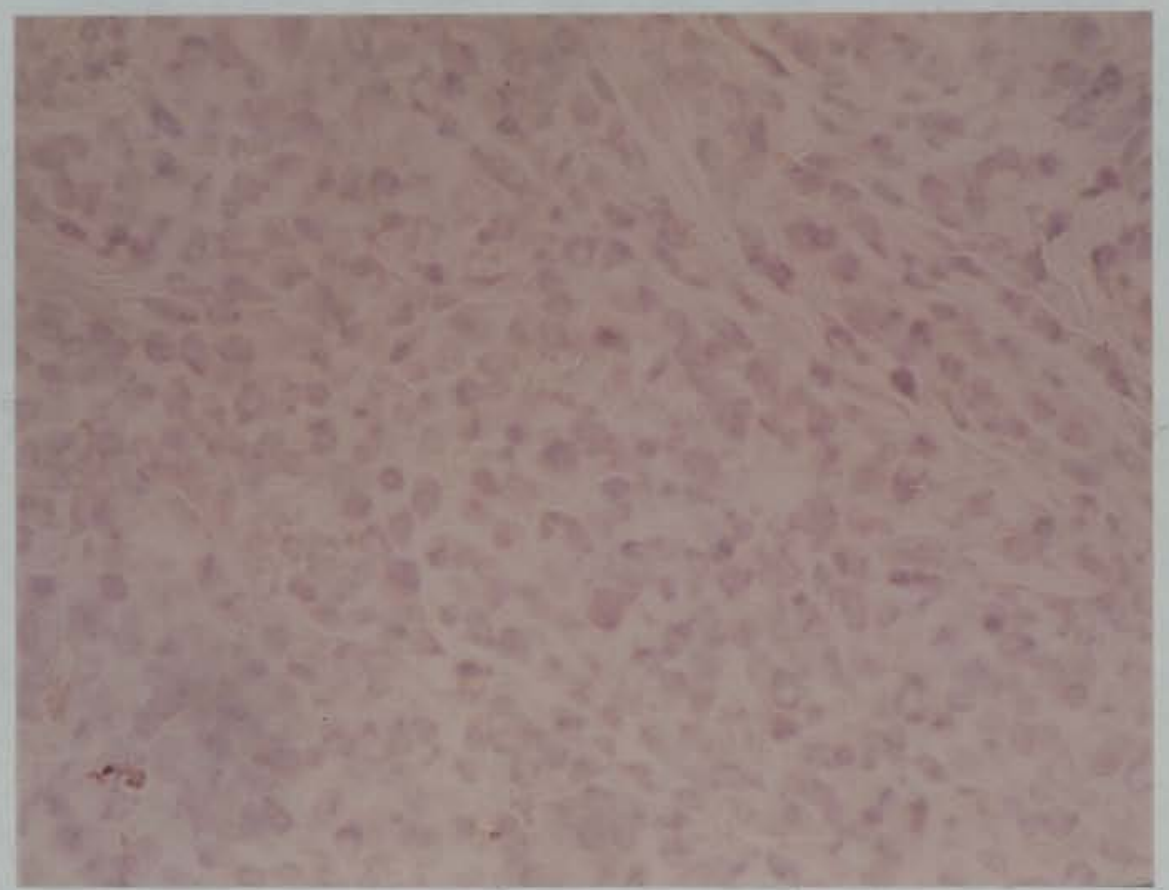

Plasmacytoma (LG no. 856). The neoplastic plasma cells do not express CD22. 
Figure 4.27

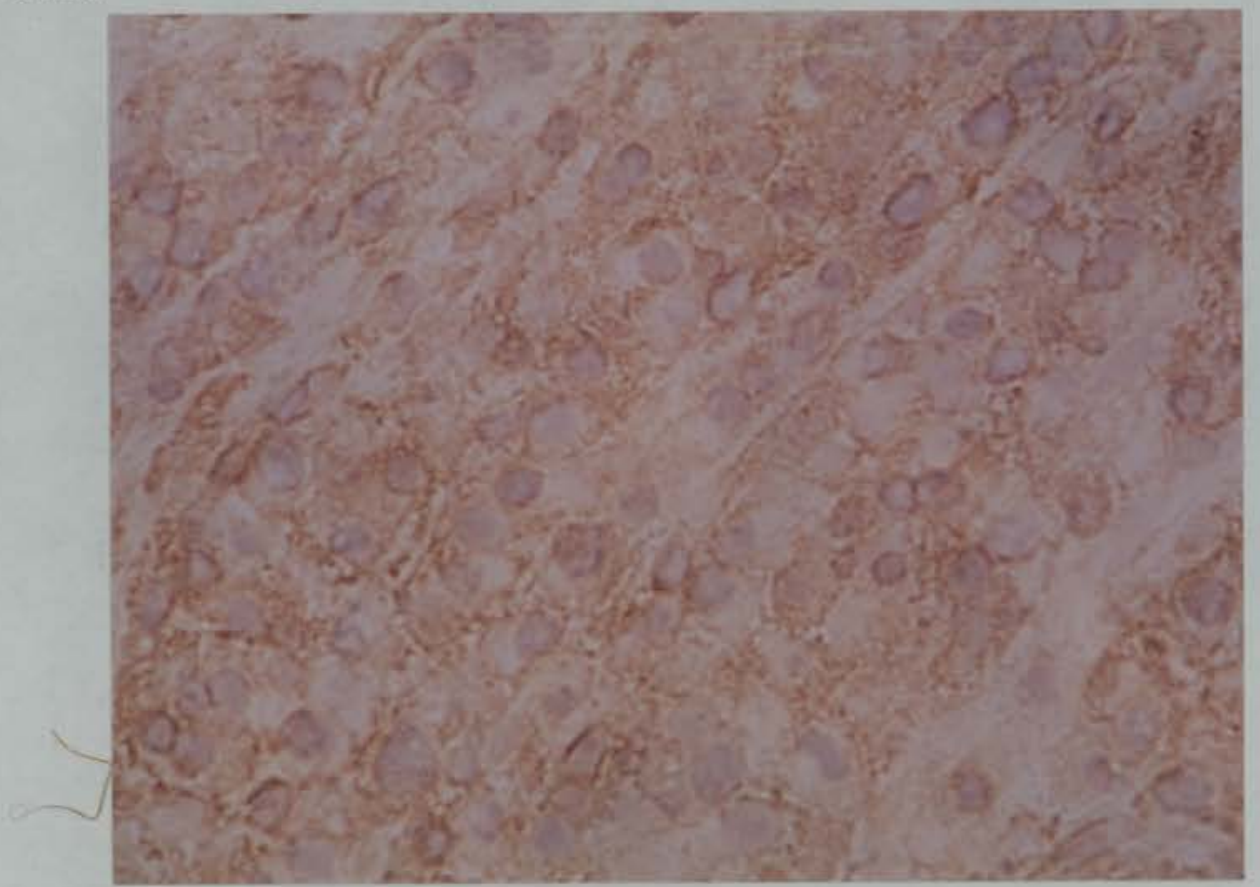

Plasmacytoma (LG no. 856). The majority of cells are expressing $\mathrm{CD} 38$.

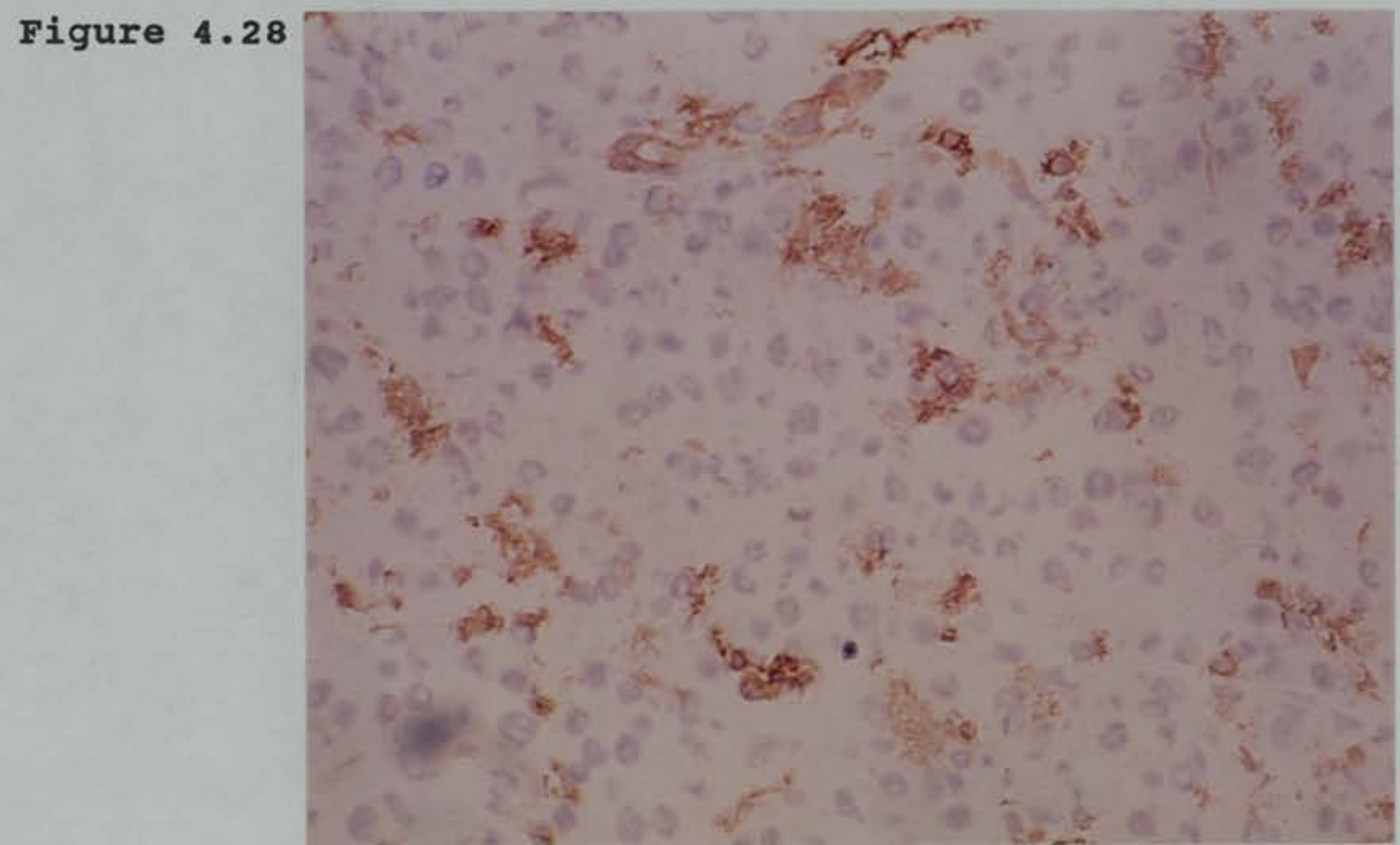

Plasmacytoma (LG no. 747). Only macrophages and dendritic cells are expressing MHC class II HLA DP. Tumour cells are negative. 
Figure 4.29

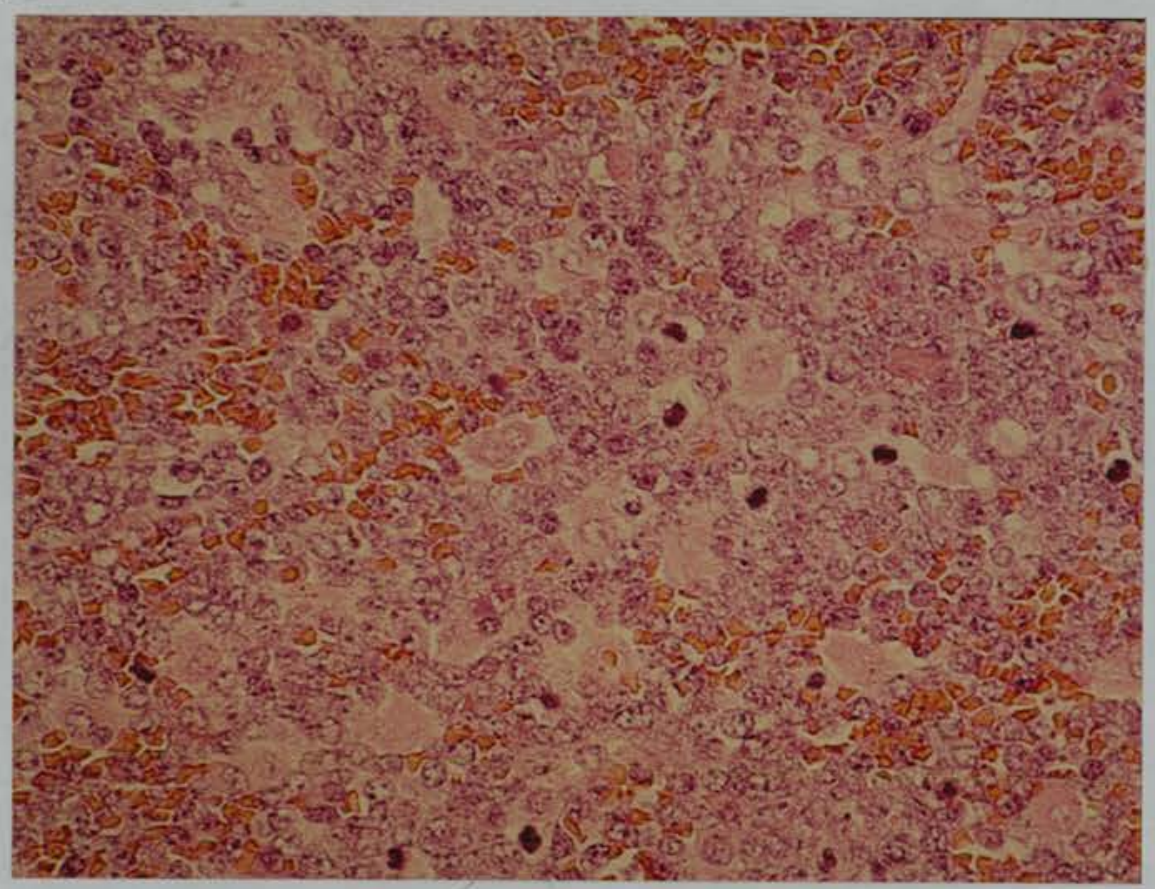

Lymphoblastic lymphoma (LG no. 503). The tumour consists of a diffuse infiltrate of medium sized blasts. There is a prominent starry-sky appearance.

Figure 4.30

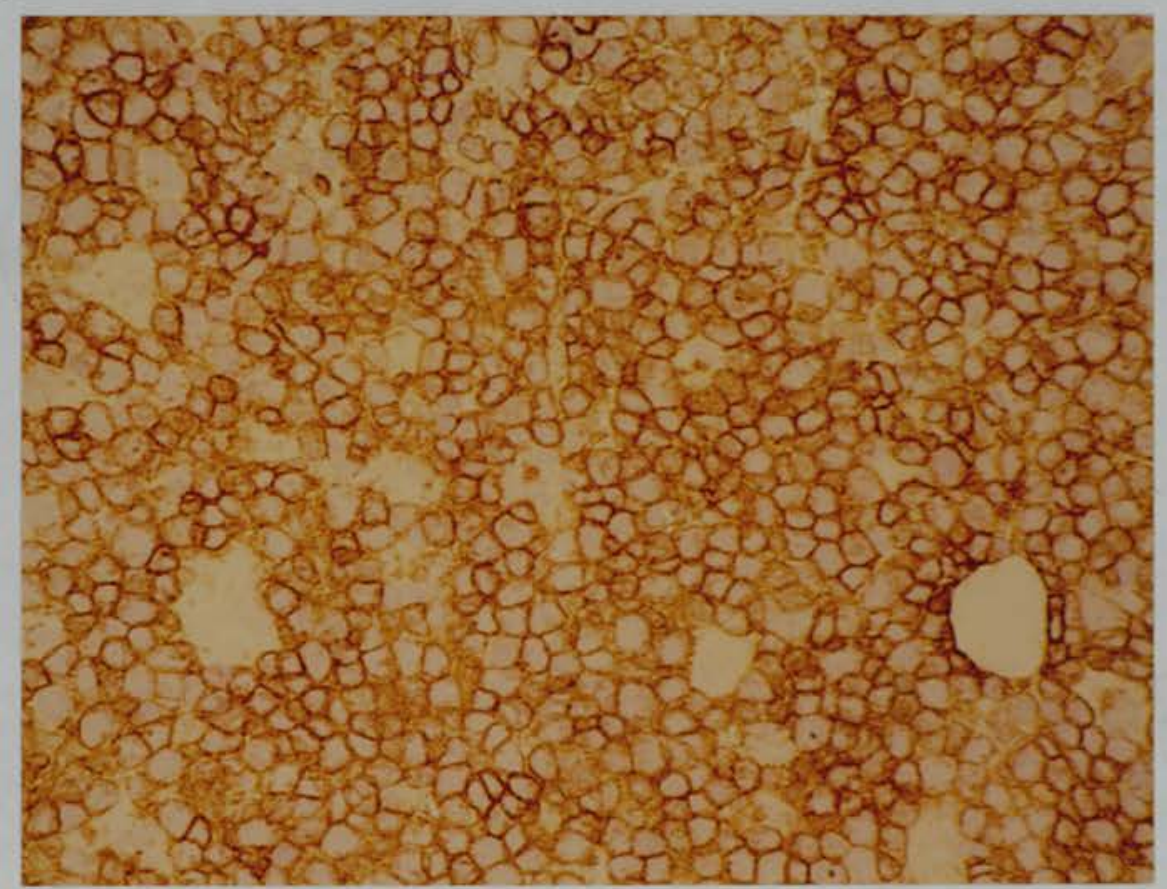

Lymphoblastic lymphoma (LG no. 503). There is strong expression of $\mathrm{CD} 10$. 


\subsection{DISCUSSION}

This part of the study reports the phenotypic expression of a series of B-cell NHL using a panel of MCA against B-cell differentiation and activation antigens. There was marked phenotypic heterogeneity both within and between the major morphological subgroups recognised by the Kiel classification. This heterogeneity was so extreme that a unique phenotype for one morphological group was not defined although common patterns of expression of certain antigens was apparent.

No single marker in the panel reacted with all cases tested. The B-cell histogenesis of the cases was confirmed by demonstrating either monotypic immunoglobulin light chain or expression of one or more pan-B-cell restricted antigens. A few cases, predominately within the centroblastic and lymphoblastic groups failed to express immunoglobulin. In these cases at least one or more pan-B-cell antigen could be demonstrated. Similar findings have been reported by others (Anderson et al 1984, Stein et al 1984, Horning et al 1984, Borowitz et al 1985). The finding that $B 1$ which recognises CD20 failed to stain or showed weak reactivity in a number of our cases confirms previous observations of poor reactivity of this antibody in tissue sections (Mason et al 1986, Horning et al 1984, Freedman et al 1985). This may be a technical artifact as strong reactivity is seen when cell suspensions are employed (Anderson et al 1984). Earlier reports have shown that 'null' cell tumours expressing neither surface immunoglobulin or sheep erythrocyte receptors constitute approximately $5 \%$ of NHL (Lukes et al 1978, Pinkus and said 1978). Many such cases have been shown to be of $\mathrm{B}$ or $\mathrm{T}$-cell lineage by immunophenotyping (Knowles et al 1985, cleary et al 1985). Using a panel of anti-B-cell, anti-T-cell and 
anti-macrophage MCA every case of approximately 250 NHL seen in the Pathology Department of Edinburgh University over the period of the study have been assigned to either B-cell, T-cell or macrophage/histiocyte lineage suggesting that "null"-cell tumours are rarely seen (unpublished observation).

Four of the MCA used in the panel are known to recognise antigens (CD5, CD9, CD10 and CD38) expressed at variable or multiple stages of B-cell differentiation. These are potentially useful for defining subgroups of B-cell NHL immunologically and for comparison with normal cellular counterparts. CD5, an antigen expressed predominantly by $T$ cells (Royston et al 1980) is expressed by a proportion of mantle zone B cells (Caligaris-Cappio 1982) and fetal primary B cell follicle cells (Bofill et al 1985). In this series CD5 expression was restricted predominantly to lymphocytic and centrocytic lymphomas confirming the findings of others (Swerdlow et al 1983 1984, Cossman et al 1984b, Anderson et al 1984). A few cases of follicular centroblastic/centrocytic, centroblastic and prolymphocytic groups were also CD5 positive. A small number of CD5 positive follicular lymphomas have previously been reported (Anderson et al 1984, Borowitz et al 1985). The finding that prolymphocytic lymphoma was frequently CD5 positive agrees with stein et al (1984) but contrasts with Gobbi et al (1983) who found 12 cases of prolymphocytic leukaemia to be CD5 negative. The latter studies employed a MCA RFA-2 on suspensions of peripheral blood cells and may reflect differences in antigen expression between neoplastic cells in tissues and blood. Alternatively histologically recognised prolymphocytic lymphoma may be a different disease entity from prolymphocytic leukaemia. The case of prolymphocytic lymphoma from the orbit could possibly be a high grade MALToma (Isaacson et al 1988). 
CD9 which is expressed by a proportion of germinal centre and mantle zone cells (Hsu and Jaffe 1984, Murray et al 1984) in reactive lymph nodes was variably expressed in all groups studied except immunoblastic lymphomas which were all negative. It was therefore not of value for subtyping B-NHL whereas others using a different CD9 MCA $(B A-2)$ have suggested this antigen may be selectively expressed by mantle zone lymphomas (Cossman et al 1984a). In lymphocytic lymphomas expression of CD9 was either absent or reduced in proliferation centres, suggesting this antigen reflects a stage of activation rather than differentiation.

CD10 expression by lymphoblastic lymphomas is well recognised (Ritz et al 1981), and expression by reactive follicle centre cells has been described (HSu and Jaffe 1984, Murray et al 1984). The results presented here confirm the expression of this antigen by at least a proportion of neoplastic follicle centre cell tumours (Anderson et al 1984, stein et al 1984, Swerdlow et al 1985, Williamson et al 1986). CD10 positivity has been shown to correlate with more aggressive myeloma (Durie and Grogan 1985). This raises the possibility that the variable expression of $\mathrm{CD} 10$ in cases of centroblastic and immunoblastic lymphoma seen in our study represents similar aggressive subgroups. None of the plasmablastic/plasmacytomas in this study expressed CD10.

In normal lymphoid tissue CD38 is a marker of plasma cells (Bhan et al 1981, Anderson et al 1984) and is expressed by follicle centre cells but not mantle zone cells (Anderson et al 1984, Gobbi et al 1983, Hsu and Jaffe 1984, Murray et al 1984). CD38 showed corresponding expression in this series being expressed by a proportion of follicular lymphomas and plasmacytomas as previously documented (Anderson et al 1984, Gobbi et al 1983). Similarly reactivity with B cell lymphoblastic 
lymphomas has been described (Gobbi et al 1983). Although CD38 positivity frequently correlated with plasma cell differentiation histologically, in 2 cases of lymphoplasmacytoid lymphomas (immunocytoma) and in two cases of immunoblastic lymphoma with large numbers of plasmablasts this antigen was not expressed. Unlike other plasma cell tumours the cases of lymphoplasmacytoid lymphoma expressed MHC class II antigens and in 1 case pan-B cell antigens. In contrast to lymphocytic lymphomas they were CD5 negative. other workers have also recognised the distinct phenotypic characteristics of this group of NHL and have postulated that they may represent proliferations of a subpopulation of normal lymphoid cells (Stein et al 1984, Harris and Bhan 1985).

The panel of MCA included some which recognise activation associated' antigens. CD21, the C3d receptor (Iida et al 1983, Tedder et al 1984) is present on resting Bcells but is lost following in vitro activation (Stashenko et al 1981, Dorken et al 1985); others, such as CD23, CD25, CD30, CD71 and $4 \mathrm{~F} 2$, are absent from resting cells but can be induced by mitogens (Waldmann et al 1984, Stein et al 1985, Haynes et al 1981, Thorley-Lawson et al 1985, Walker et al 1986, Walker and Gordon 1987). Expression of one of these antigens, CD71, has been shown to be correlated with histological grade and clinical outcome of NHL (Habeshaw et al 1983, Pileri et al 1984). In nearly all cases tested at least a proportion of neoplastic cells were activated as shown by expression of CD23, CD71 or 4F2. Many cases also expressed CD21, an antigen lost rapidly following activation of splenic $B$ cells by anti-Ig (Boyd et al 1985a,1986, Dorkan et al 1985). Other workers have reported similar heterogeneity in expression of CD21 (Horning et al 1984, Borowitz et al 1985) and it is possible that the expression of this antigen by activated cells represents abnormal regulation by the neoplastic cells. Continual stimulation of the 
cell via this antigen may contribute to uncontrolled proliferation.

CD23 is expressed within 3 hours following activation of resting B-cells, before cells enter the cell cycle (Thorley-Lawson et al 1985, walker et al 1986). In reactive lymph nodes and tonsil it is expressed at variable intensity by mantle zone lymphocytes and by a proportion of DRCs (Mason et al 1986) but not by germinal centre centrocytes or centroblasts. CD23 was maximally expressed by the low grade lymphomas (lymphocytic lymphomas) and infrequently expressed by high grade (centroblastic or immunoblastic) tumours. Similar observations have been made by others (Stein et al 1984) and it is possible that $\mathrm{CD} 23$ is expressed only transiently during B-cell activation and is lost after a certain stage of committed differentiation. Failure of germinal centre cells to express CD23 would support this idea. The observation that lymphocytic lymphomas were CD23 positive whereas centrocytic lymphomas were negative is consistent with previous reports (Stein et al 1984) and may be a useful means of differentiating these subtypes although CD23 positive centrocytic lymphomas have been reported (Williamson et al 1986).

CD25 was initially shown to be expressed by activated Tcells (Uchiyama et al 1981). Recent work however has also demonstrated its expression by activated normal Bcells (Waldmann et al 1984, Tsudo et al 1984) and by hairy cell leukaemia (Korsmeyer et al 1983). The findings in this study are that $\mathrm{CD} 25$ is also variably expressed in most histological groups of B-NHL although there was no correlation with histological grade. Chronic lymphocytic leukaemia cells proliferate and differentiate in response to IL2 (Lantz et al 1985, Hivroz et al 1986) and it is possible the growth of at least some B-cell lymphomas is regulated through abnormal receptor expression and stimu- 
CD30 (Kil) was initially described as reacting selectively with Reed-Sternberg cells in Hodgkin's disease and with a small population of large cells in reactive lymph nodes (Schwab et al 1982). Recent work has shown that CD30 can be induced in B-cells by mitogens and infection with Epstein-Barr virus (Stein et al 1985). CD30 was present in only a small number of high grade lymphomas (centroblastic or immunoblastic) in this series consistent with the findings of others (Stein et al 1985).

The activation-associated antigens $4 \mathrm{~F} 2$ and $\mathrm{CD} 71$ were most strongly expressed by high grade lymphomas and less often and more weakly by low grade lymphocytic and follicular lymphomas. Increased expression of transferrin receptor in high grade lymphomas has been shown previously (Habeshaw et al 1983, Pileri et al 1984), but the results presented here demonstrate more heterogeneity in low grade lymphomas than has been previously described.

The expression of MHC Class II antigens extends and confirms results previously published (Krajewski et al 1985, Guy et al 1986, Smith et al 1987) with coordinate and non-coordinate expression of $D R, D P$ and $D Q$ being evident in many histological groups. The increased expression of class II antigens in the proliferation centres of lymphocytic lymphomas and in-vitro following entry of B-cells into the cell cycle (Kehrl et al 1985) suggests that these antigens are involved in B-cell activation. However the finding that their expression is decreased or absent in tumours showing plasma-cell differentiation and that centrocytic lymphomas and some centroblastic lymphomas tend to show low DQ expression suggests that MHC class II antigens may also be differentiation related. 
Many of the histological groups of B-NHL recognised by the Kiel Classification system show cytomorphological and phenotypic similarities to normal B-cells. It is generally accepted that neoplastic cells reflect normal Bcells frozen at various stages of maturation. However, the phenotypic heterogeneity observed within the various histological categories shows that direct comparison with morphologically similar normal counterparts cannot be made in all cases. There are a number of possible reasons for this. Phenotypic heterogeneity may represent multiple stages of activation/differentiation arrest along a linear pathway which are only transient in vivo and therefore seldom seen. Alternatively it may indicate maturation arrest of morphologically similar cells which are already committed to different non-linear differentiation pathways. The phenotypic diversity, especially marked in high grade NHL, is likely in part to represent abnormal expression of differentiation and activation antigens secondary to loss of genomic regulation in neoplastic cells. As many of these activation and differentiation antigens appear to have a functional role in control of B-cell differentiation and proliferation abnormal expression may be intimately involved in lymphomagenesis.

In conclusion detailed analysis of B-cell NHL using a panel of MCA against B-cell activation and differentiation antigens shows marked phenotypic heterogeneity both between and within morphological groups. The B-cell histogenesis in some cases can only be confirmed by using a panel of immunoglobulin and pan B-cell markers. Pan-Bcell (CD19, CD20, CD22, CD45R) and 'restricted' B-cell antigens ( $\mathrm{CD} 5, \mathrm{CD} 9, \mathrm{CD} 10, \mathrm{CD} 38$ ) were in general unhelpful markers of morphological groups although CD5 (lymphocytic and centrocytic NHL) and CD38 (plasma cell tumours) were expressed strongly by some groups. Activation antigens were expressed by cases in all histologic groups but $4 \mathrm{~F} 2$ 
and CD71 (transferrin receptor) were more often and more strongly expressed by high grade lymphomas. They may therefore be of prognostic significance. other activation antigens like $\mathrm{CD} 23$ and $\operatorname{CD} 25$ did not appear to be more frequently associated with high grade tumours but CD23 may be useful in the discrimination between centrocytic and lymphocytic lymphoma.

Detailed phenotyping by a large panel of MCA such as used in this study may be of value for elucidating biologically important characteristics and cellular abnormalities in NHL. However for routine diagnostic purposes such extensive typing of NHL is probably not of practical use at present. As an adjunct to routine histological examination a limited panel of MCA against leucocyte antigens CD3, CD5, CD19 or CD22, CD45, IgM, kappa and lambda would be sufficient for frozen section immunohistochemistry for diagnostic purposes. This panel allows diagnosis of most cases of NHL. The use of additional MCA's against other leucocyte antigens ( $C D 1, C D 4, C D 8, C D 23, C D 25)$ would need to be undertaken only in selected cases where the initial screen gives equivocal results.

Detailed analysis of immunophenotypes therefore does not appear to be of much value to the histopathologist for diagnostic purposes. The variation of expression of many of the antigens studied, a number of which have been shown to be involved in B-cell activation and proliferation or to function as receptors for growth factors, raises the possibility that there expression may be associated with progression of the disease and clinical prognosis. The next component of the study was to investigate this possibility. 


\subsection{INTRODUCTION}

Classifications of NHL such as the Kiel classification (Lennert 1978, Stansfeld 1988) and Working Formulation (Rosenberg 1982) identify different morphologic categories which may be separated into major prognostic groupings. Immunophenotyping aids categorisation of NHL into $T$ and B-cell groups. As demonstrated in Chapter 4 detailed analysis of the expression of activation and differentiation antigens using a large panel of antibodies shows phenotypic heterogeneity within morphologically similar groups. Previous studies of antigen expression have shown a correlation with survival in NHL although in these studies only a limited number of markers have been used. CD71 (transferrin receptor) and $4 \mathrm{~F} 2$ expression is associated with poor survival (Habeshaw et al 1983, Pileri et al 1984, Holte et al 1987), whereas MT2 expression by colorectal lymphomas is associated with a better prognosis (Shepard et al 1988). CD23 expression has been associated with prolonged disease-free survival in aggressively treated lymphomas (Schuurman et al 1988). Thus although a large panel of MCA provides only a limited amount of additional information which is of use to the diagnostic pathologist it is possible that the variation of antigen expression is associated with clinically important parameters. The next stage of the study was therefore to correlate the clinical presentation and follow up of the series of B-cell NHL phenotyped in an attempt to determine whether detailed phenotyping using such a panel of MCA against antigens whose expression is associated with activation, cell-cycle transit, and differentiation provides additional clinically useful information. 


\subsection{MATERIALS AND METHODS}

\subsubsection{Cases and Clinical Data}

clinical follow-up was obtained from case notes of 111 cases of B cell NHL analysed in chapter 4, clinical data being unobtainable on 37 .

\subsubsection{Histological Classification and Immunophenotyping}

Cases were classified by the Kiel classification and Working Formulation. Immunophenotyping was by indirect immunoperoxidase as detailed in chapter 2.

\subsubsection{Statistical Analyses}

Correlation between antigen expression, histology and clinical behaviour was only undertaken for markers in the "restricted B-cell", and "activation - associated" groups of antigens. The antigens in these two groups showed most variation of expression in the initial immunophenotype analysis, strongly positive and weakly positive/negative subsets could readily be identified for comparison. The "pan-B-cell" and MHC Class II antigens were expressed by the large majority of lymphomas and correlations between positive and negative subsets could not be made.

In Chapter 4 antigen expression was assessed in a semiquantitative manner with strongly ( $>70 \%$ cells staining), moderately $(30-70 \%)$ and weakly $(5-30 \%)$, positive or negative groups being identified. For statistical analysis in this component of the study groups were separated into moderate to strongly positive ( $>30 \%$ positive) and weakly positive/negative subsets ( $<30 \%$ positive). 


\subsection{RESULTS}

\subsubsection{Histology and clinical Features}

A total of 111 cases were studied. The histological classification and clinical features are summarised in Table 5.1 with more detailed results of each of the separate morphological groups in Tables 5.2 - 5.7 (pages 125-131). Two cases classified as plasmablastic lymphomas were included in the immunoblastic group for analysis as high grade tumours of terminally differentiating cells. Three cases of follicular centroblastic lymphoma were classified as high grade Kiel.

The series included 64 males and 47 females, age range 15-88 (mean 59 years). The majority of cases showed disseminated disease at presentation (11 stage 1, 10 Stage II, 20 stage III, and 67 stage IV, 3 not staged). 63 of 109 cases showed bone marrow involvement.

Cases were treated by a number of different therapeutic regimes. These have been grouped as simple or aggressive. Simple therapies were those not intended to induce remission and included surgery, radiotherapy and or simple drug regimes (chlorambucil \pm prednisolone \pm vincristine). Aggressive therapy included drug regimes designed to achieve complete remission (CHOP \pm bleomycin, BACOD, MOPP, MVPP, CHIVPP M-PEEC, MCHOP \pm bleomycin).

44 cases were given simple therapy and 67 cases given aggressive therapy. Kiel high grade tumours were more often treated aggressively (36 of 42) than low grade tumours (31 of 69). There was a strong correlation with type of therapy and induction of complete remission ( $p<$ $0.00001)$, but none between grade of lymphoma and induction of remission. 


\subsubsection{Immunophenotype Analyses and clinical correlation}

The immunotypes of the cases available for clinical correlation are summarised in Table 5.8. Detailed analysis of these cases is available in chapter 4. Low grade lymphomas expressed CD5 ( $p<0.0001), \operatorname{CD10}(\mathrm{p}<0.05)$ and CD23 ( $p<0.001)$ significantly more often than high grade tumours. $\operatorname{CD} 38(\mathrm{p}<0.01), \operatorname{CD} 71(\mathrm{p}<0.0001)$ and $4 \mathrm{~F} 2(\mathrm{p}<$ $0.05)$ were more frequently expressed by high grade lesions.

There was no association between antigen expression and clinical findings including stage, bone marrow involvement or response to therapy.

\subsubsection{Survival Analyses}

The results are given in Tables 5.9 and 5.10 .

\subsubsection{1 clinical Data}

A number of clinical parameters were associated with better survival. (Table 5.9). These included age less than 60 ( $p<0.001$, figure 5.1), stage at presentation ( $p$ $<0.01$, figure 5.2) and response to therapy ( $<<0.00001$, figure 5.3). There was no association between survival and sex or bone marrow involvement.

\subsubsection{Histology}

Histological grading showed significant correlation with survival (Table 5.9) for both Kiel ( $p<0.015$, figure 5.4) and WF (overall $\mathrm{p}<0.0001$; low $\mathrm{v}$ intermediate $\mathrm{p}<$ 0.002 ; low $\mathrm{v}$ high $\mathrm{p}<0.0001$; intermediate $\mathrm{v}$ high $\mathrm{p}<$ 0.025 figure 5.5). 


\subsubsection{Immunophenotype}

Survival was correlated with expression of individual markers for 1) all cases 11) cases within histological grades, WF and Kiel, and 111) cases given aggressive therapy. The results are summarised in Table 5.10. There were significant associations between expression of 4 F2 ( $p<0.01$ figure 5.6) and $\operatorname{CD71}(\mathrm{p}<0.015$ figure 5.7) and survival with all cases included. Expression of 4F2 by low grade tumours was associated with a shortened survival in Kiel ( $p<0.05$ figure 5.8) but not WF (figure 5.9) whereas CD71 expression and survival in low grade lymphomas reached significant levels with WF ( $p<0.05$ figure 5.10) but not Kiel (figure 5.11). As almost all high grade lymphomas expressed $4 \mathrm{~F} 2$ and $\mathrm{CD} 71$ it was not possible to undertake separate analysis of this group. There was no significant association with survival and the other antigens studied before or after histological grading. There was no association between survival and antigen expression in the group of NHL given 'aggressive' therapy.

\subsubsection{Multivariate Analysis}

The association between both $4 \mathrm{~F} 2$ and $\mathrm{CD} 71$ and survival was independent of age, Kiel classification and stage ( $p$ $<0.05)$, but not WF. When $4 \mathrm{~F} 2$ and CD71 were included together CD71 was not independent of $4 \mathrm{~F} 2$ as a prognostic marker. 


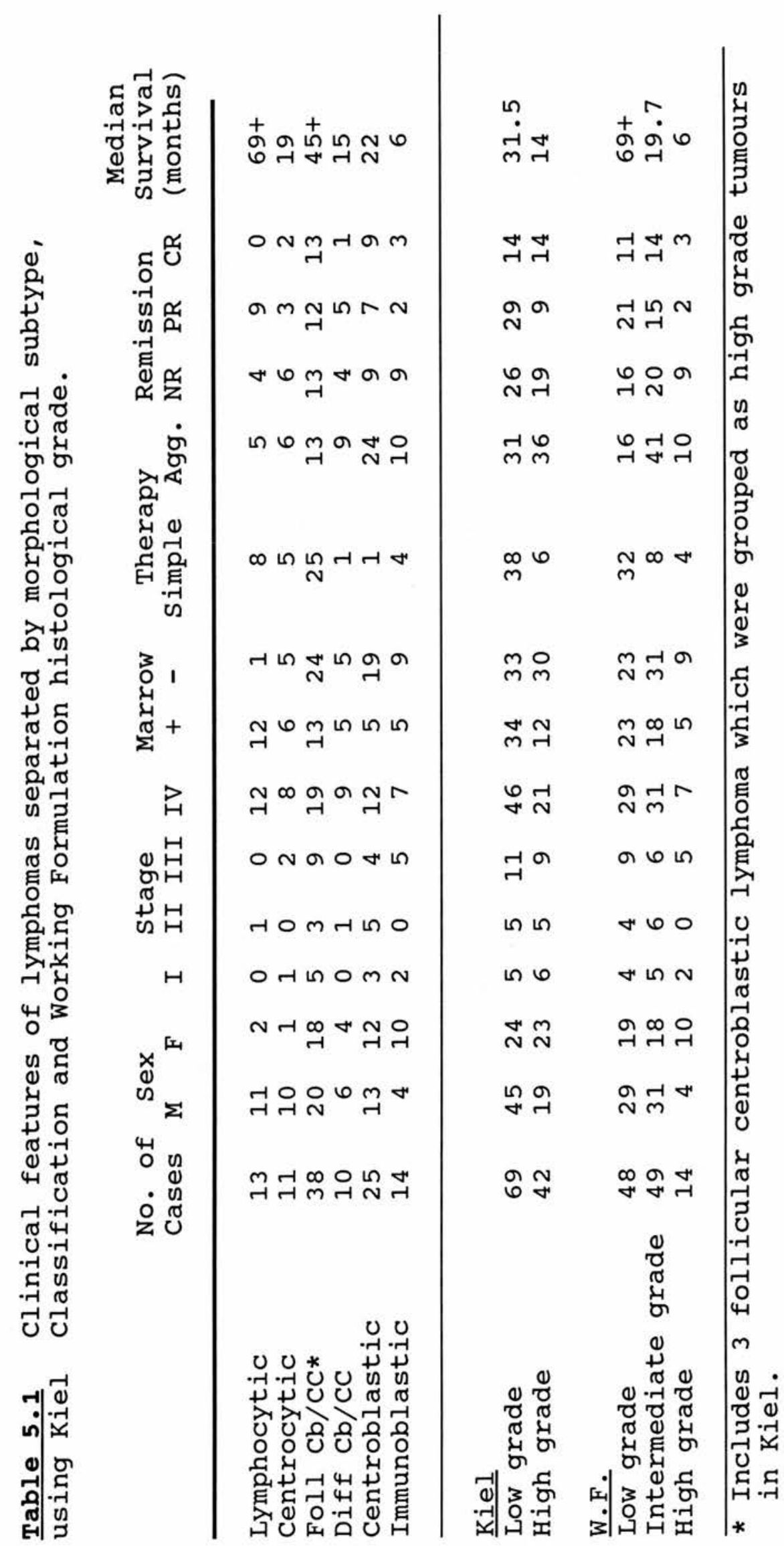




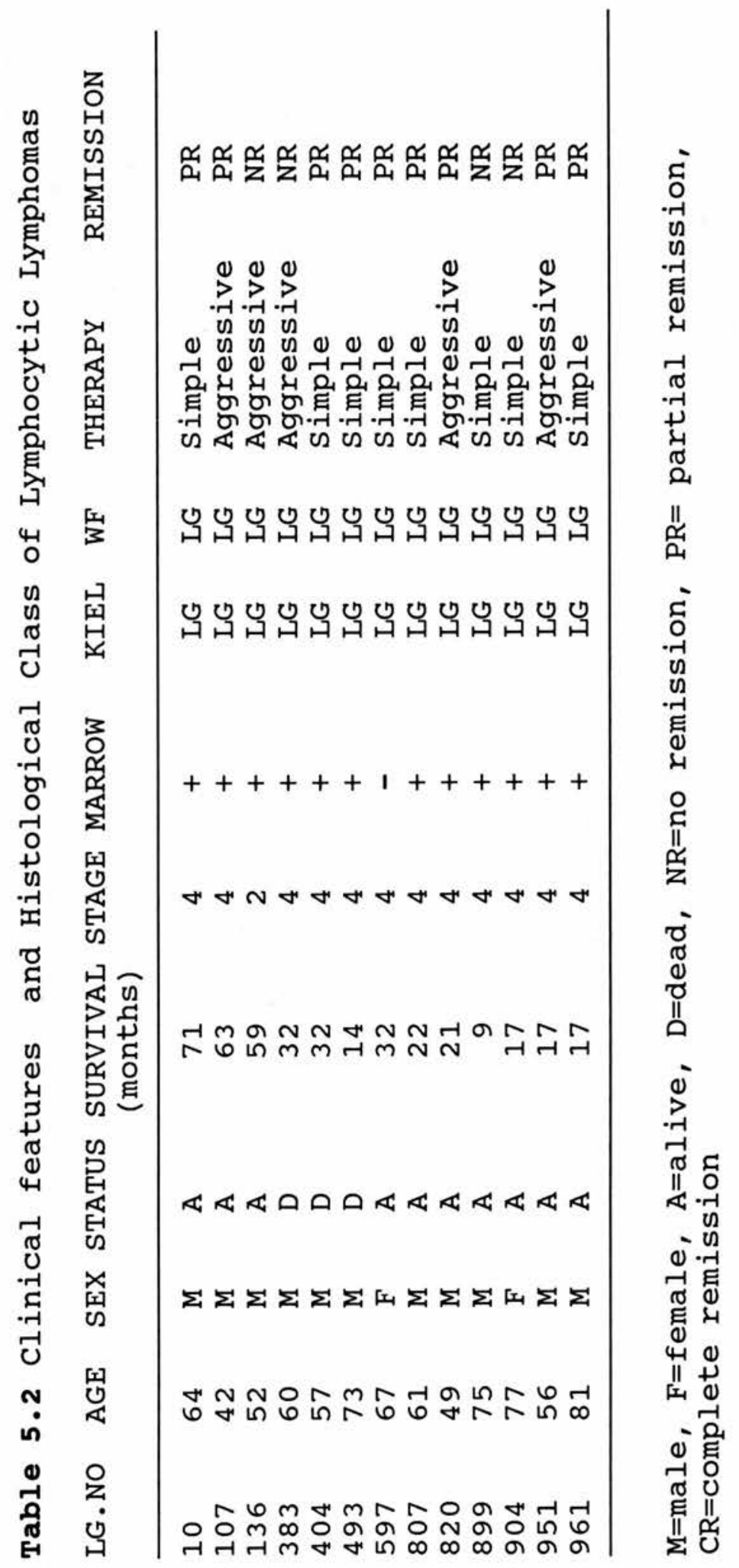




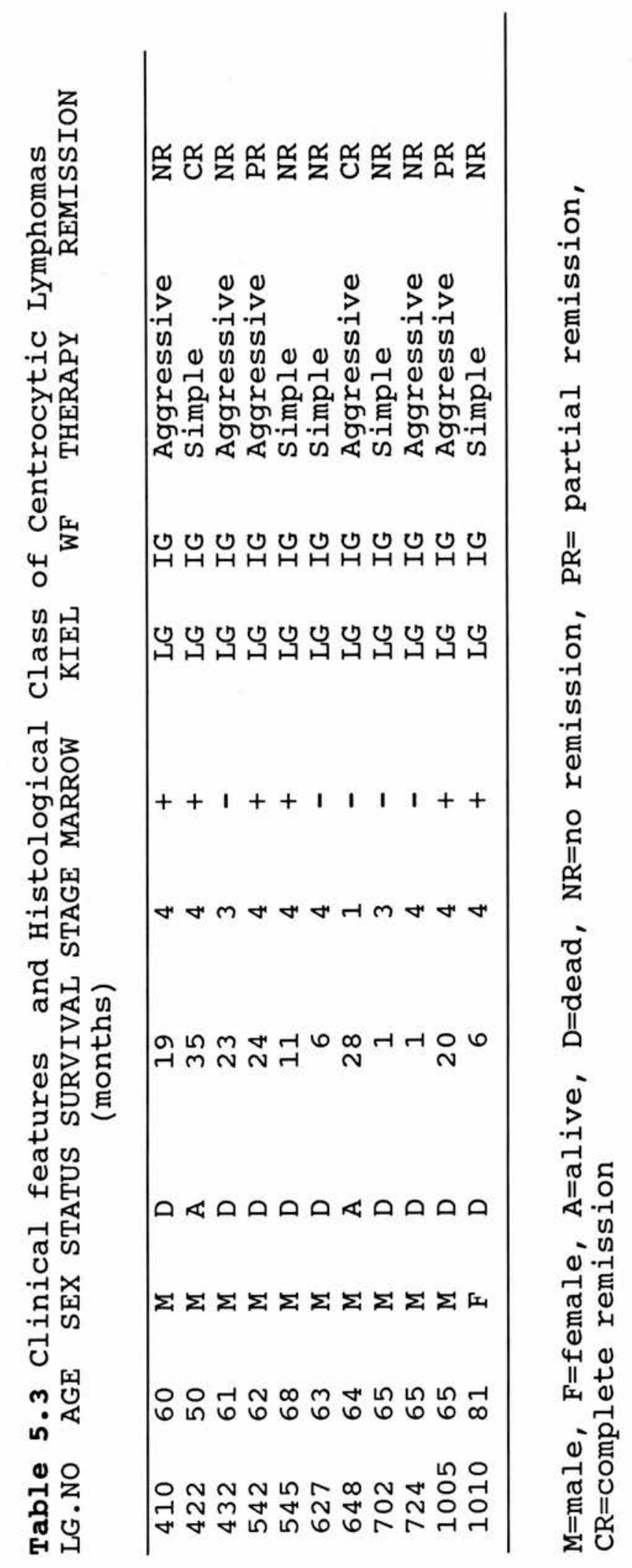




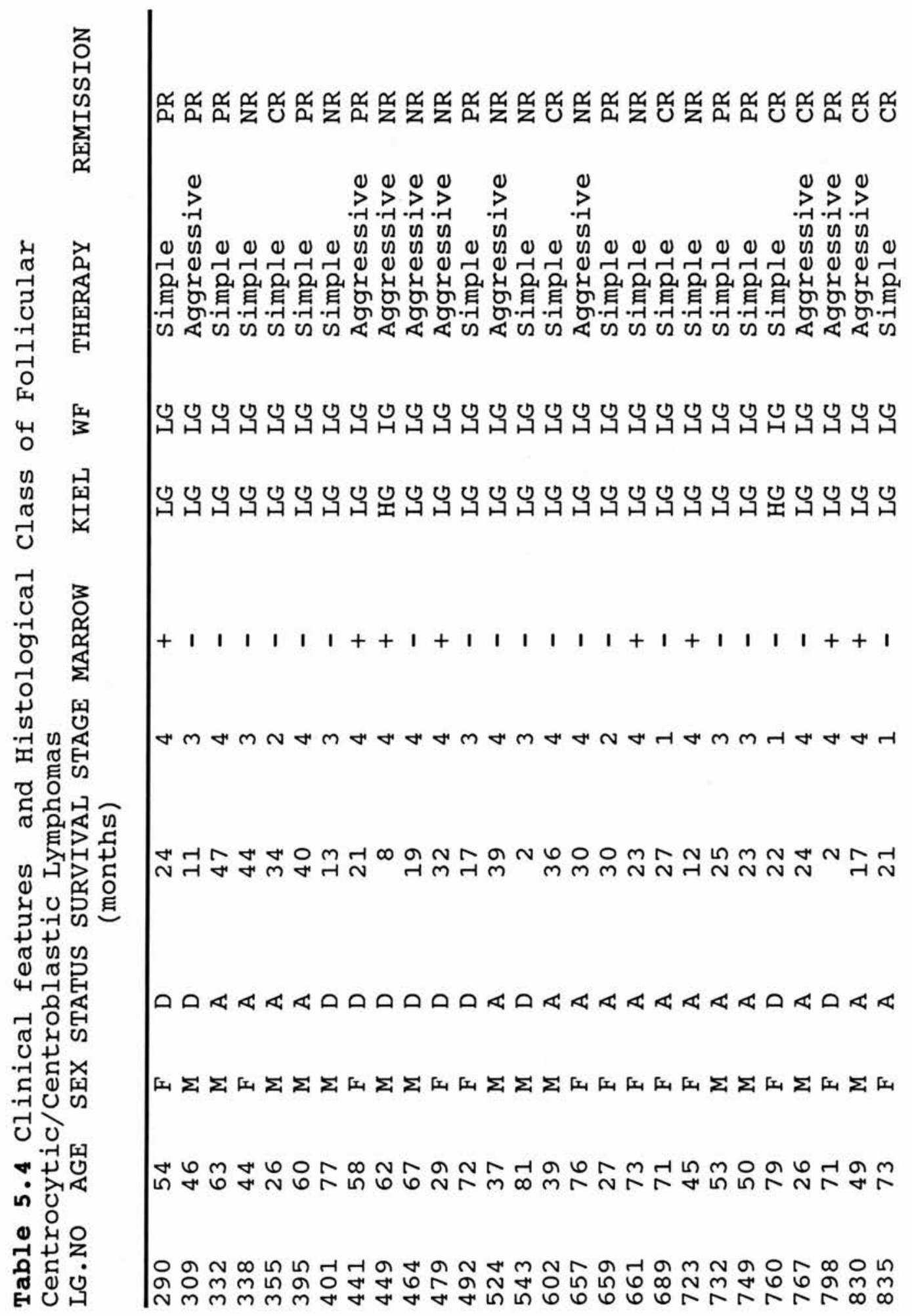




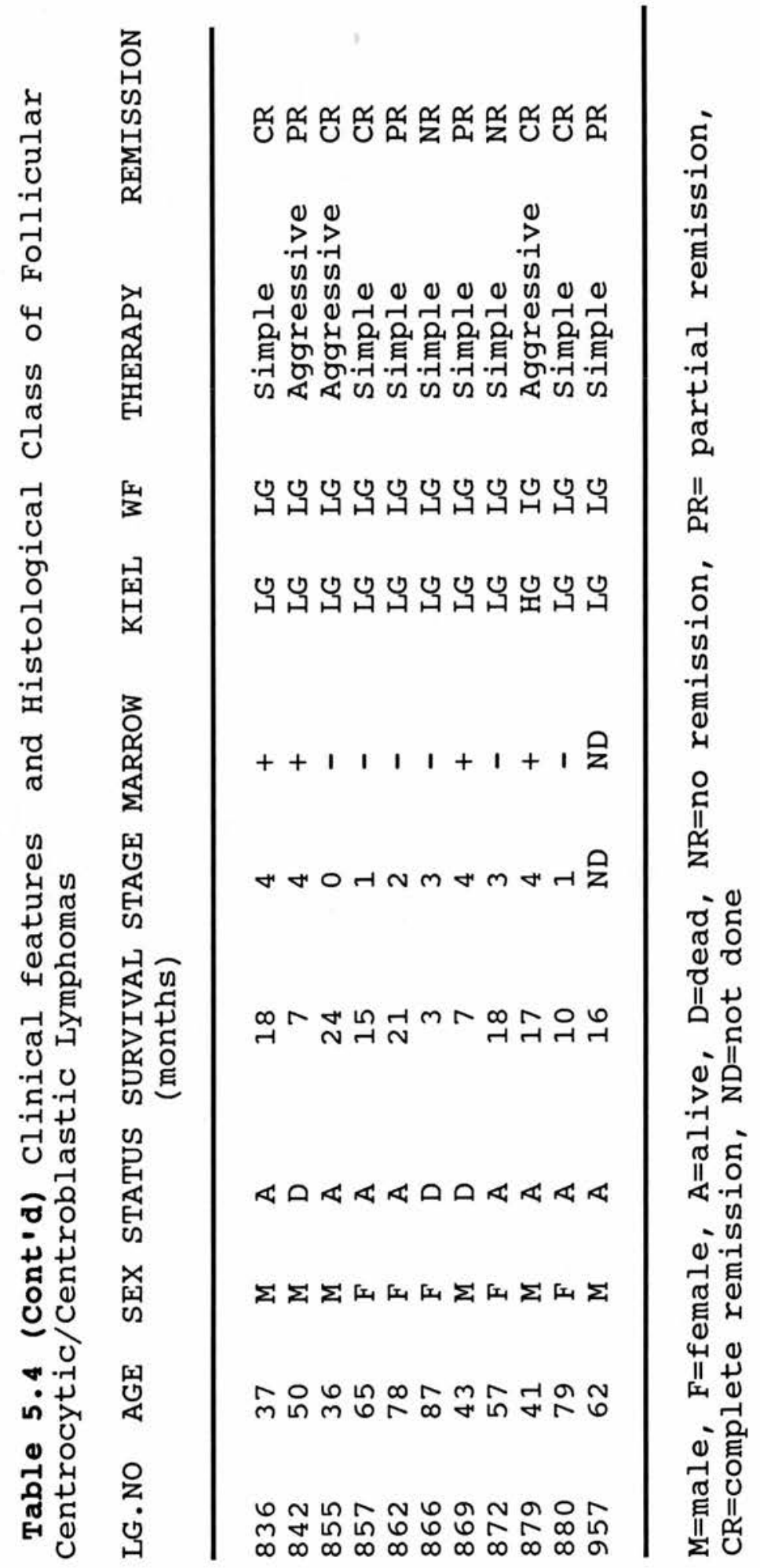




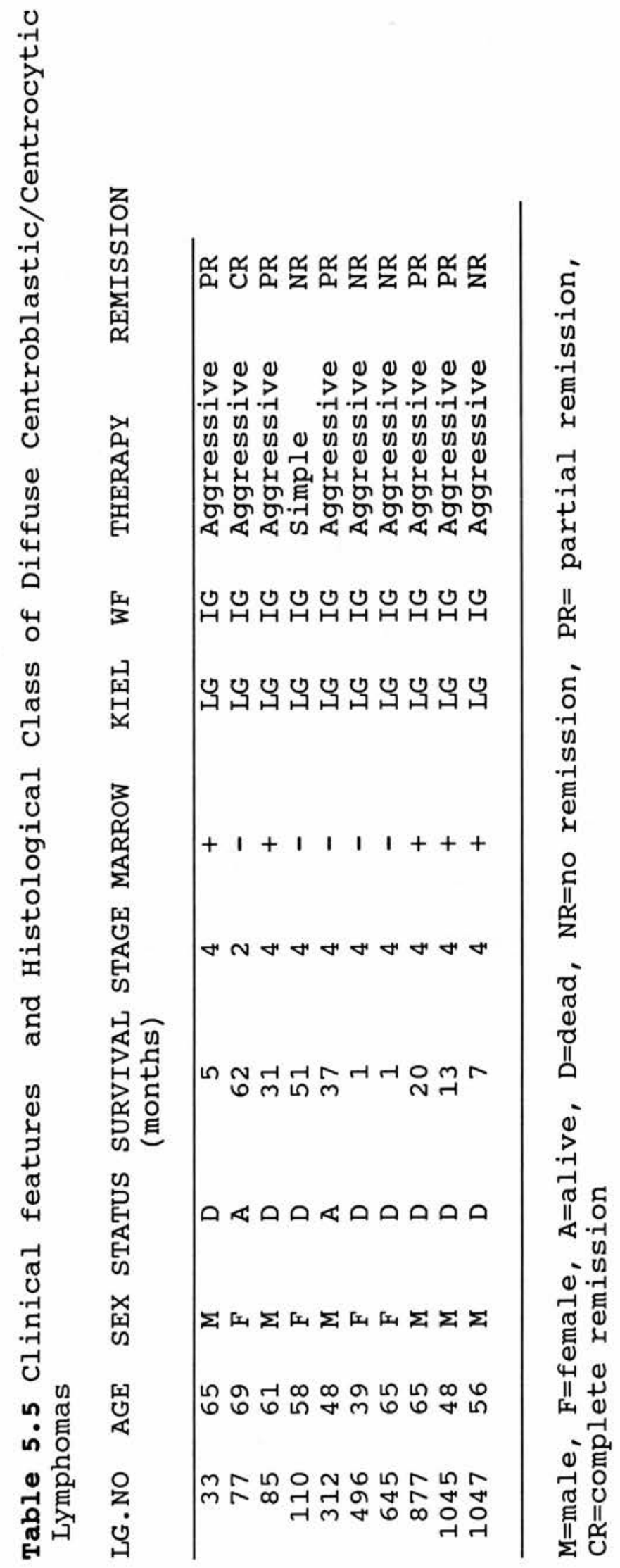




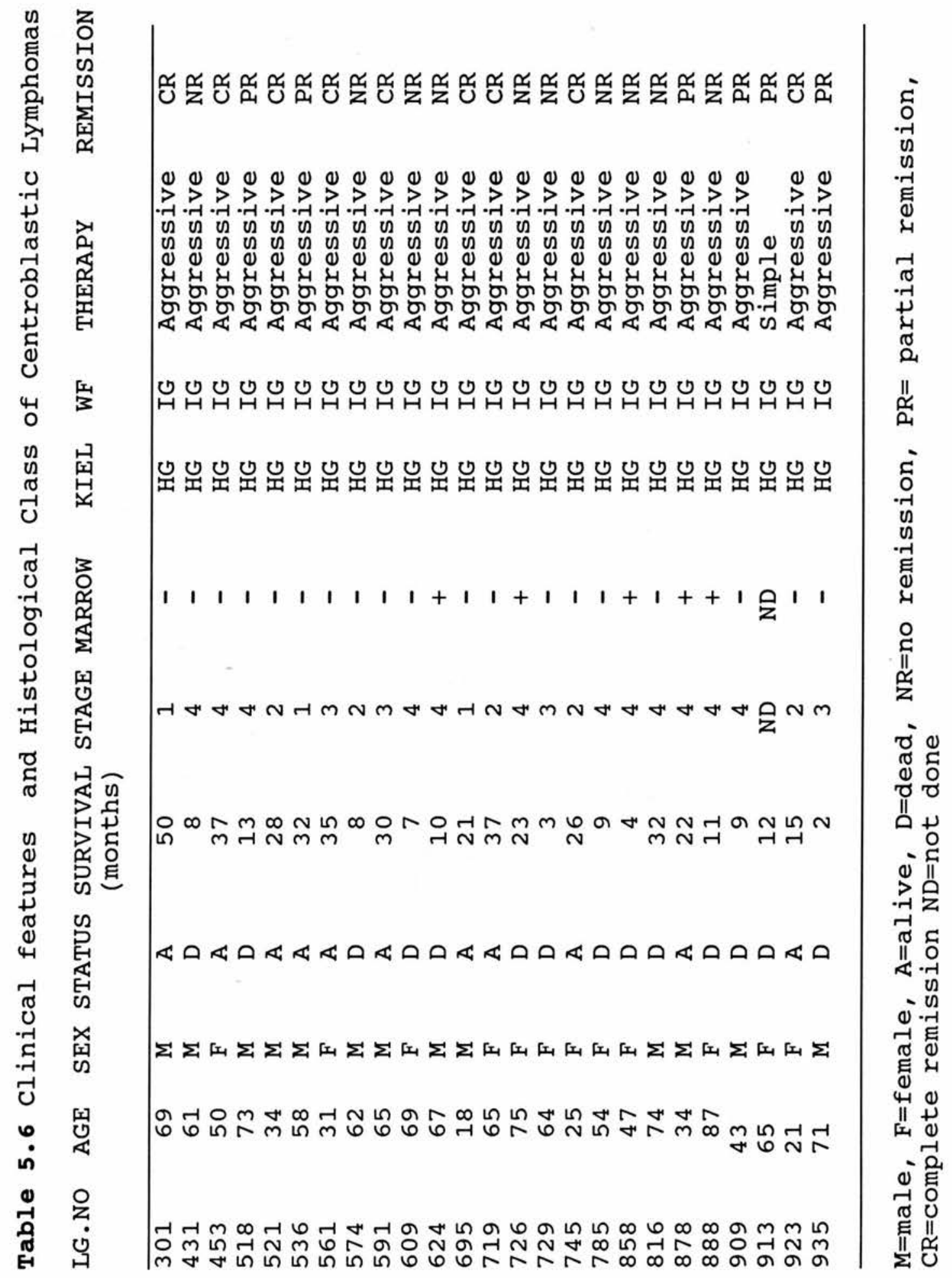




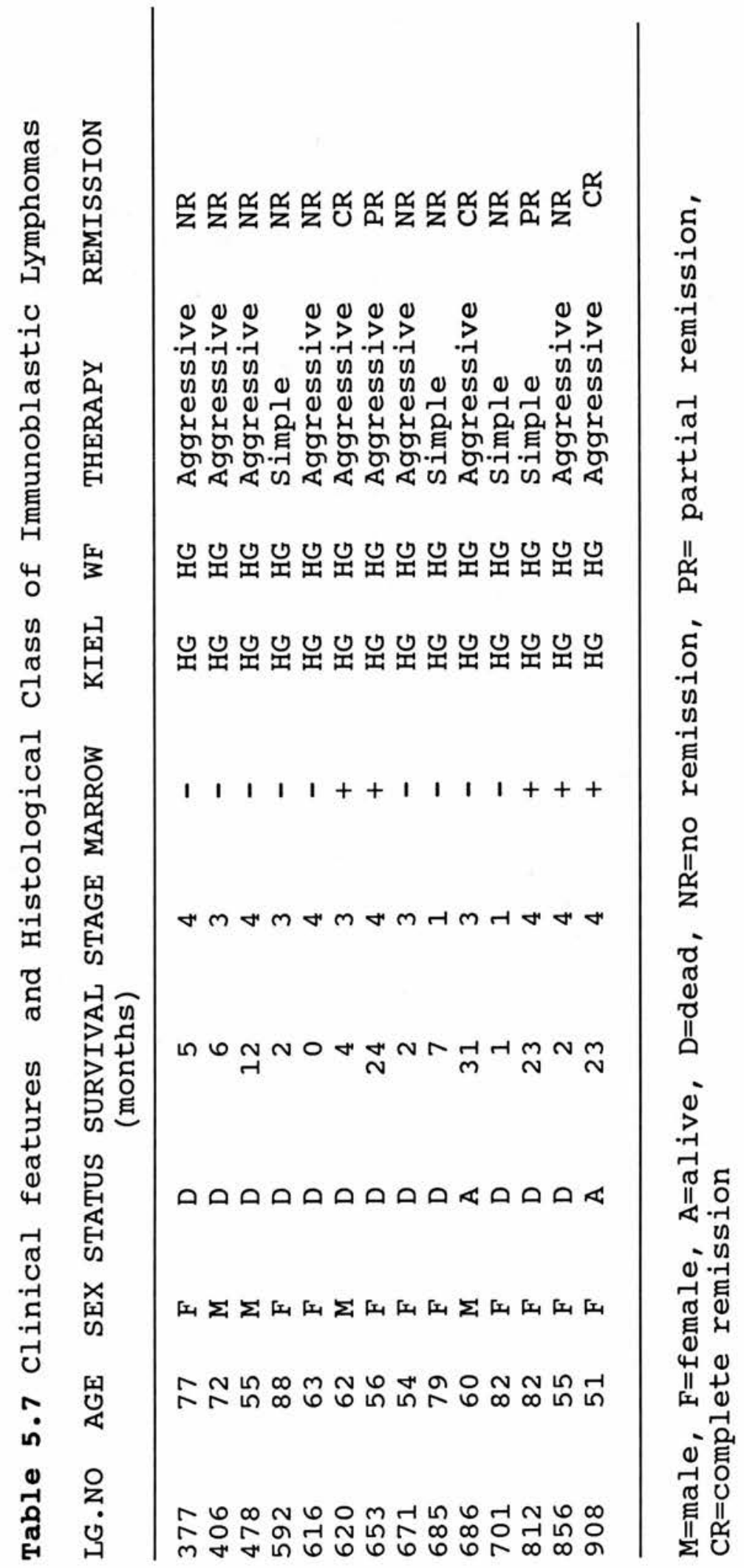




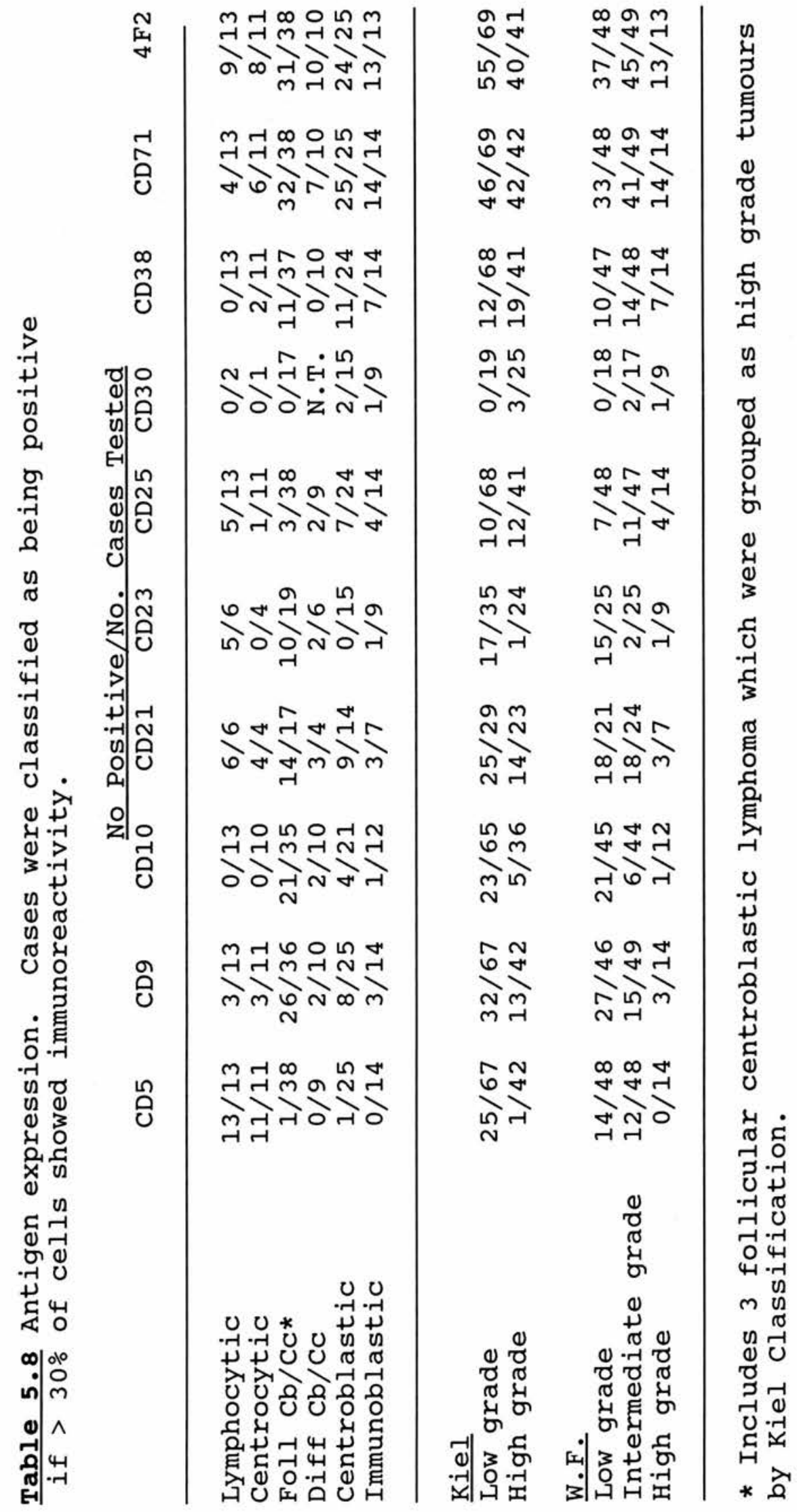


Table 5.9 Median survival of cases when separated by clinical features and histological grade.

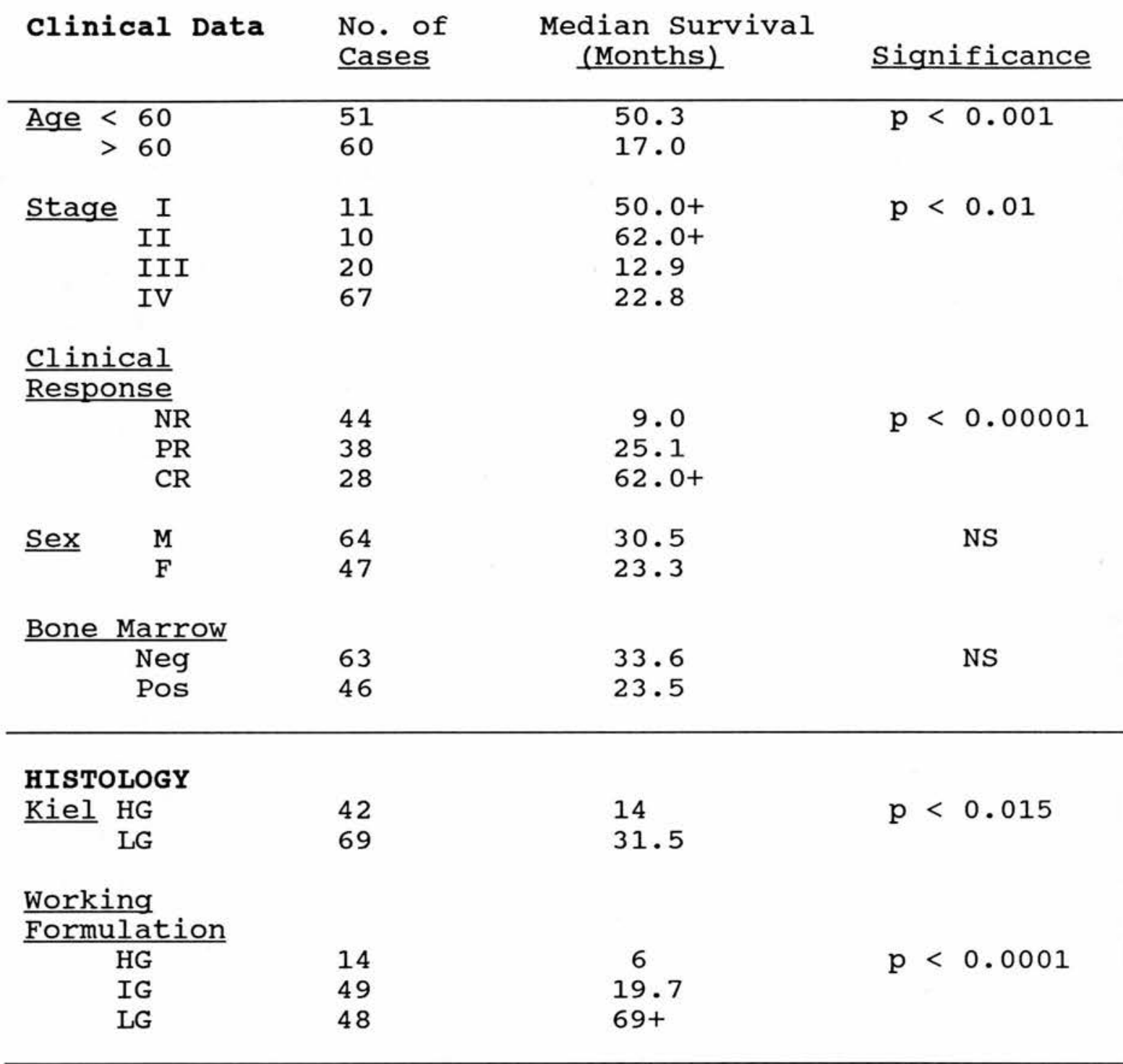

HG = high grade, IG = intermediate grade, LG = low grade . NS $=$ not significant. 


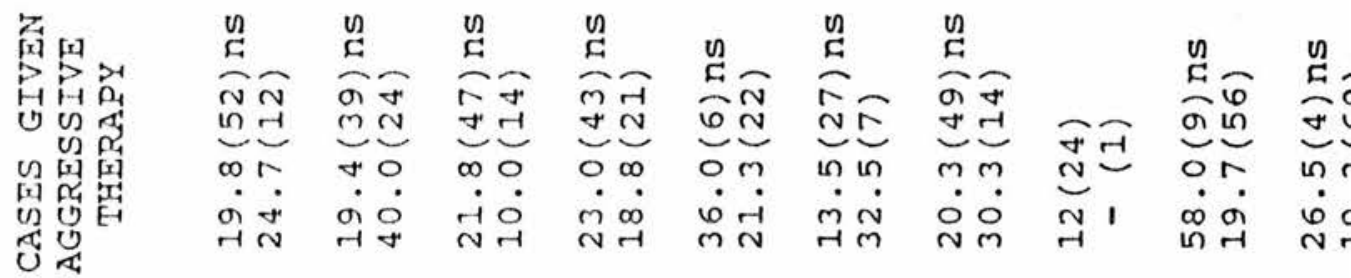

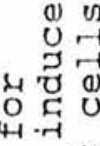

ข)

战

บ '0

3 व

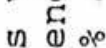

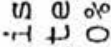

U) $\mathrm{F}$

P.न

त्र $>$

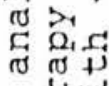

मे

त्र

$>$ is U

䒚 $\mathrm{a}$

द्व

is $>$ o

- U

U 01

(1) U)

on us

i) 0.

E.

का 40

1 $\begin{array}{r}\mathrm{O} \\ \mathrm{H}\end{array}$

背告

(1) न्न

(i) $\cdot$ म 4

$4-100$

ठण थ

况 U

ह त

न म

U or

() $\rightarrow$ 岳

다

R. U न

(i) ช U

U

(1) $\mathrm{O}$ 的

⿰冫) . .

of on +

-

4 is

04

a)

(1) 4

st 0

E $\triangle \mathrm{C}$

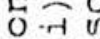

E. $\cdot-r-1$

$-1-0$

तो in है

$>00$

>

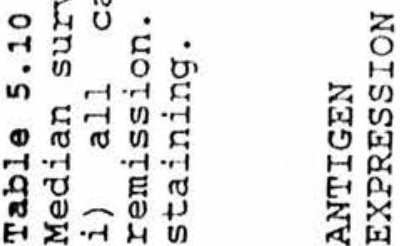

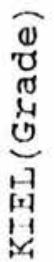

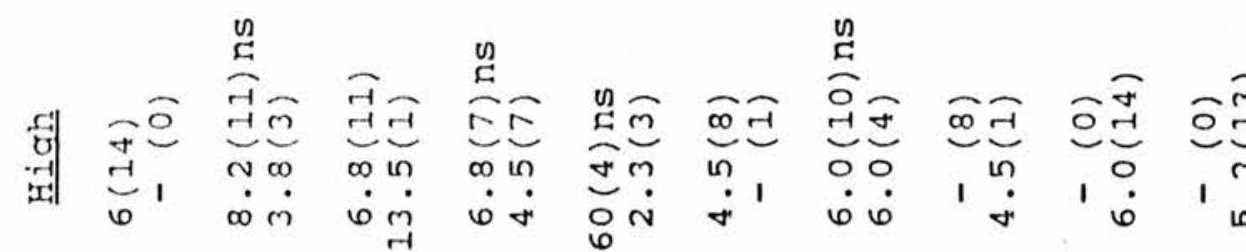

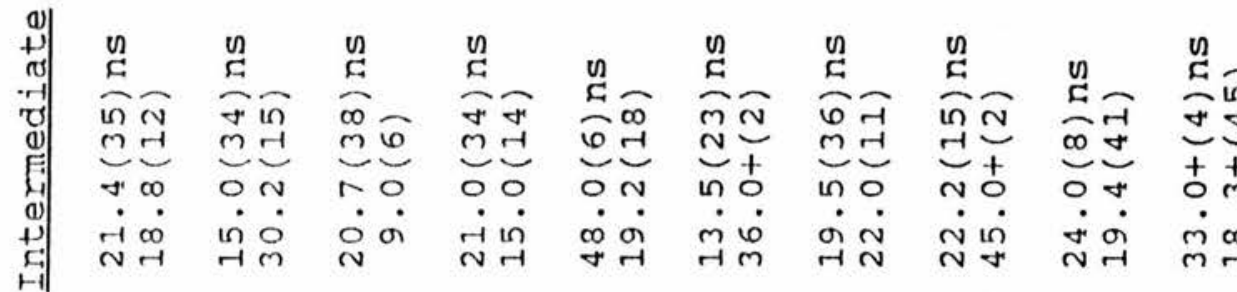

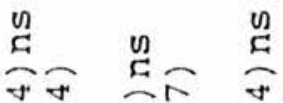

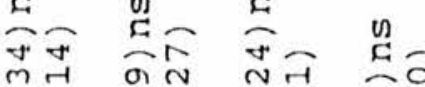

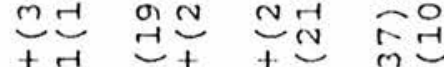

翟

i。

00 o o 10

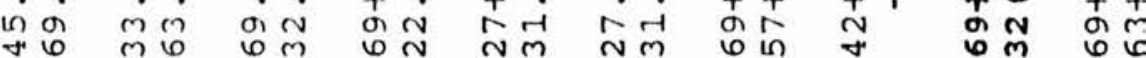

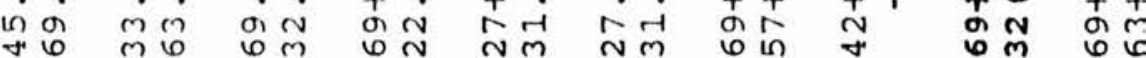

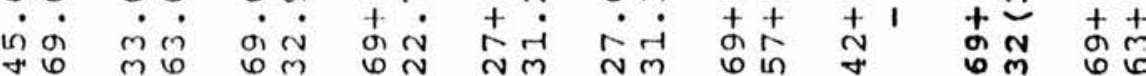

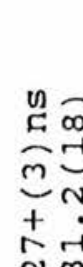

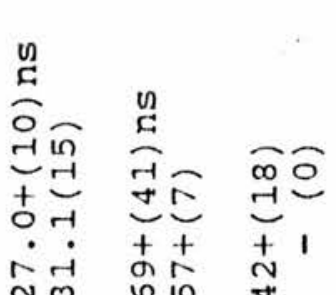

:

气

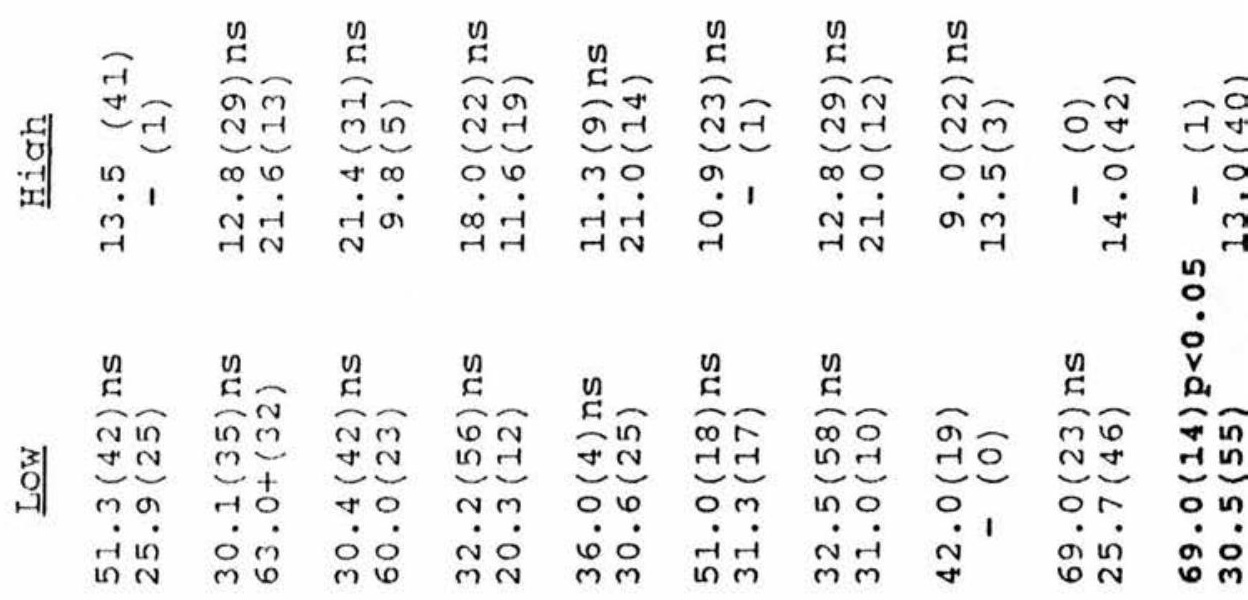

H

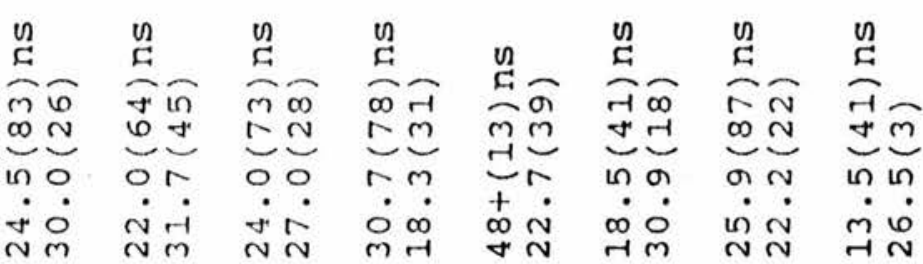

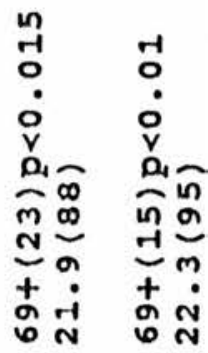

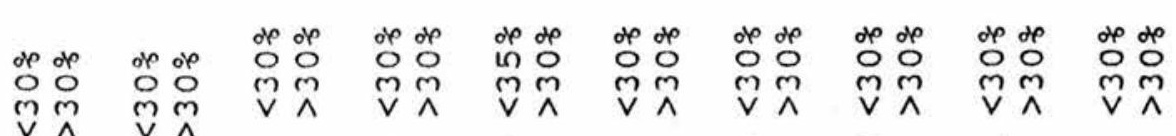

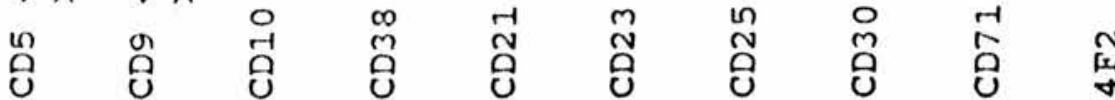

133. 
Figure 5.1 Survival of B-cell NHL separated by age.

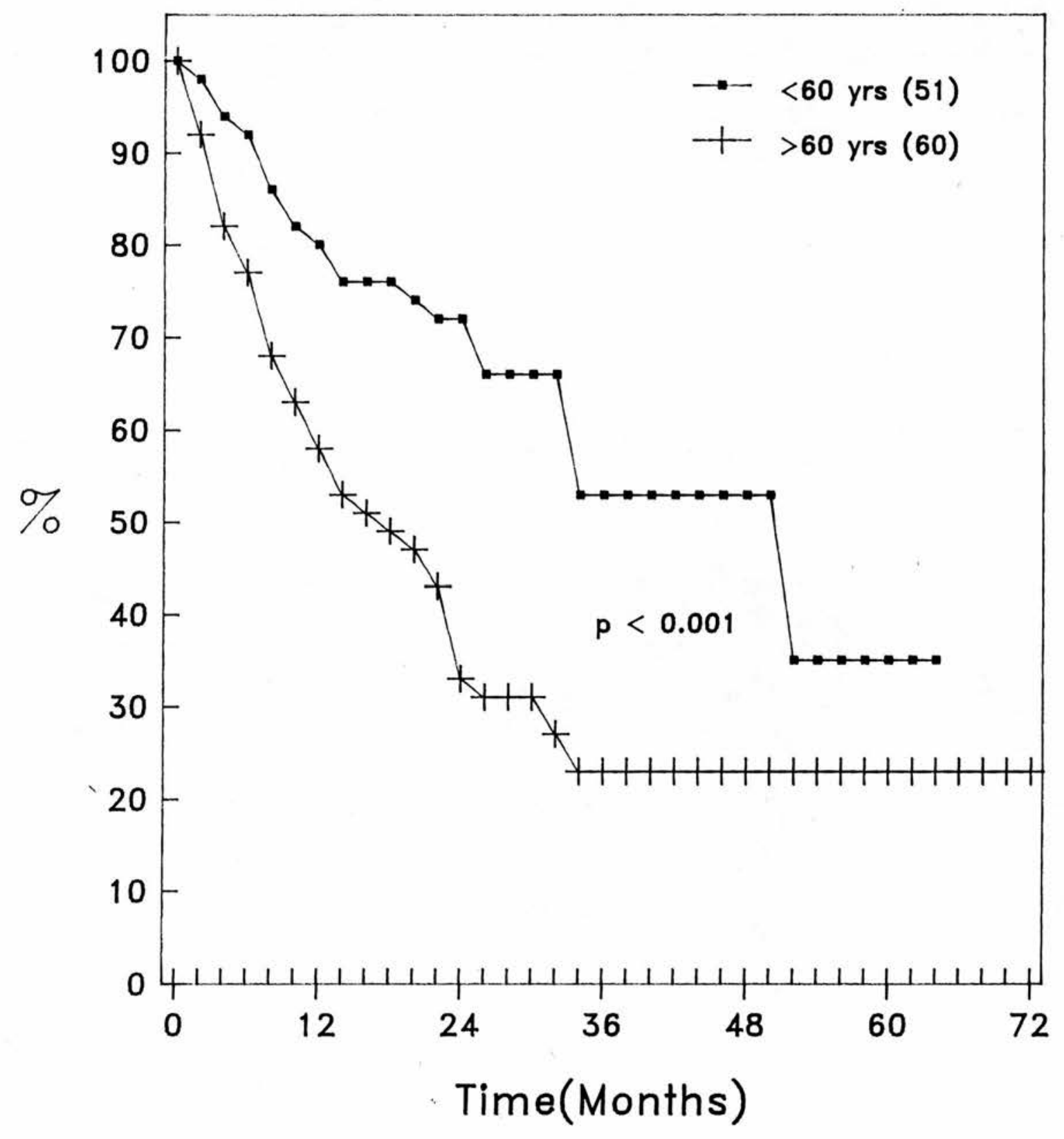


Figure 5.2 Survival of B-cell NHL separated by stage at presentation.

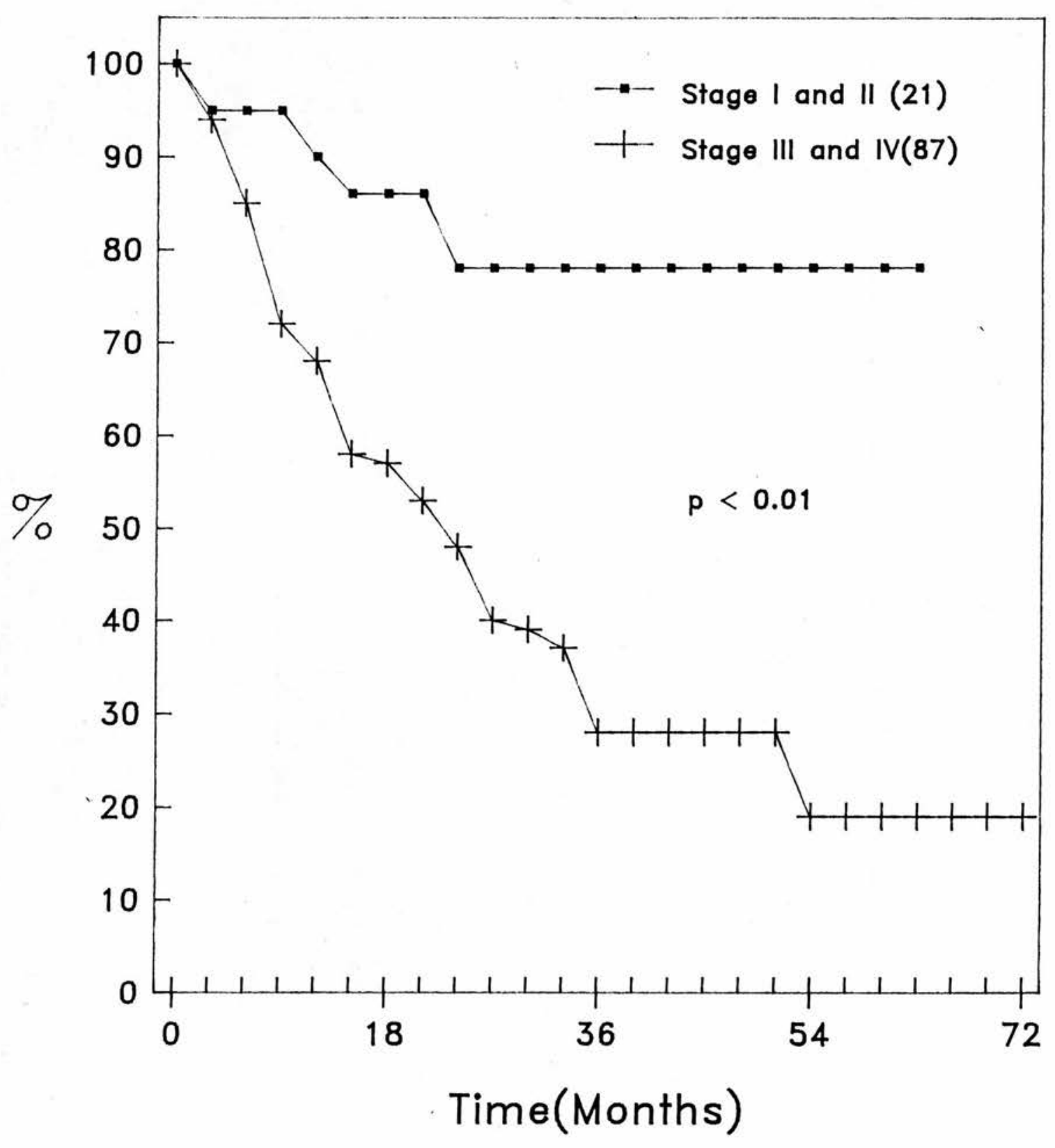


Figure 5.3 Survival of B-cell NHL separated by response to therapy.

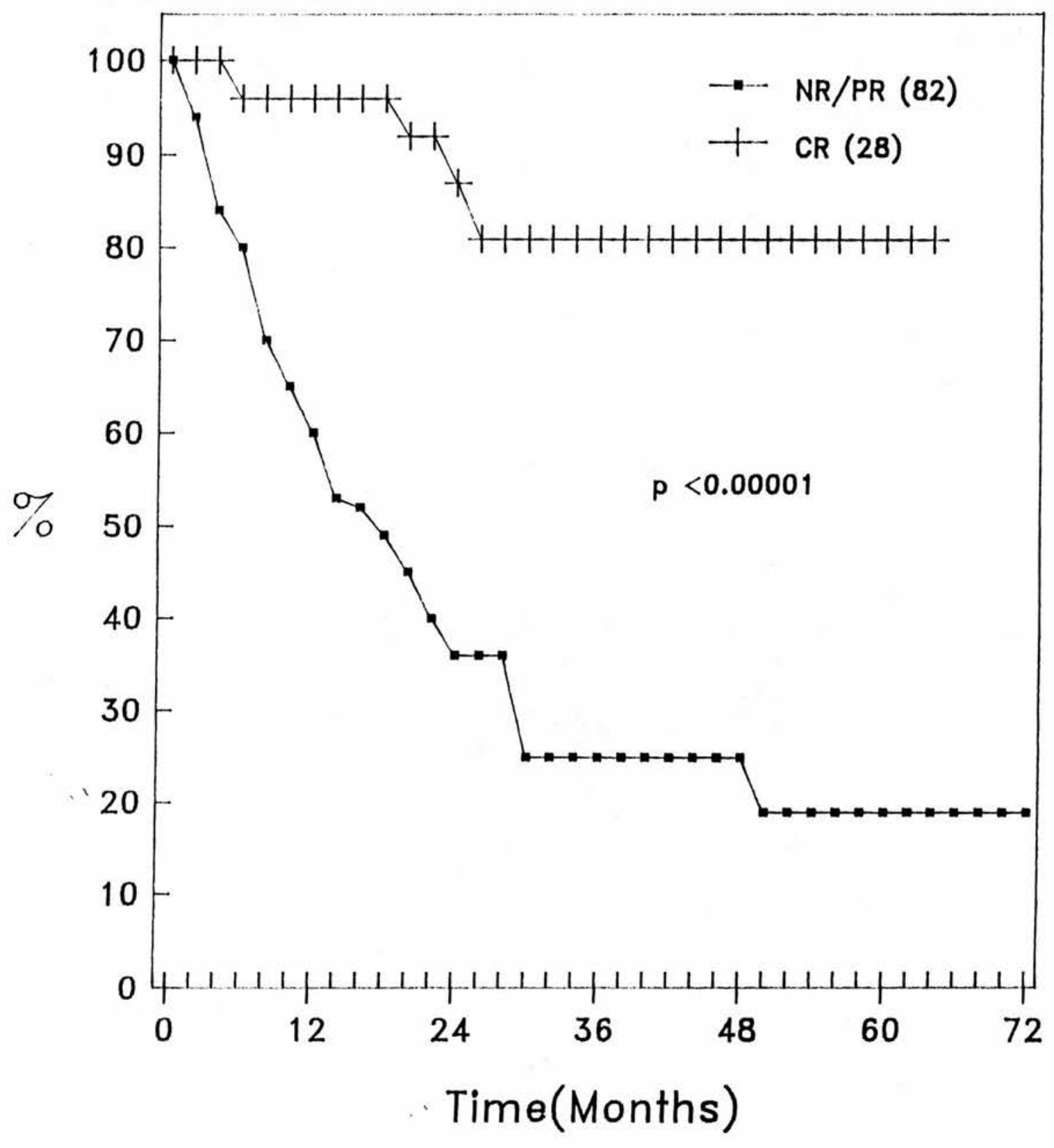


Figure 5.4 Survival of B-cell NHL separated by Kiel histological grade.

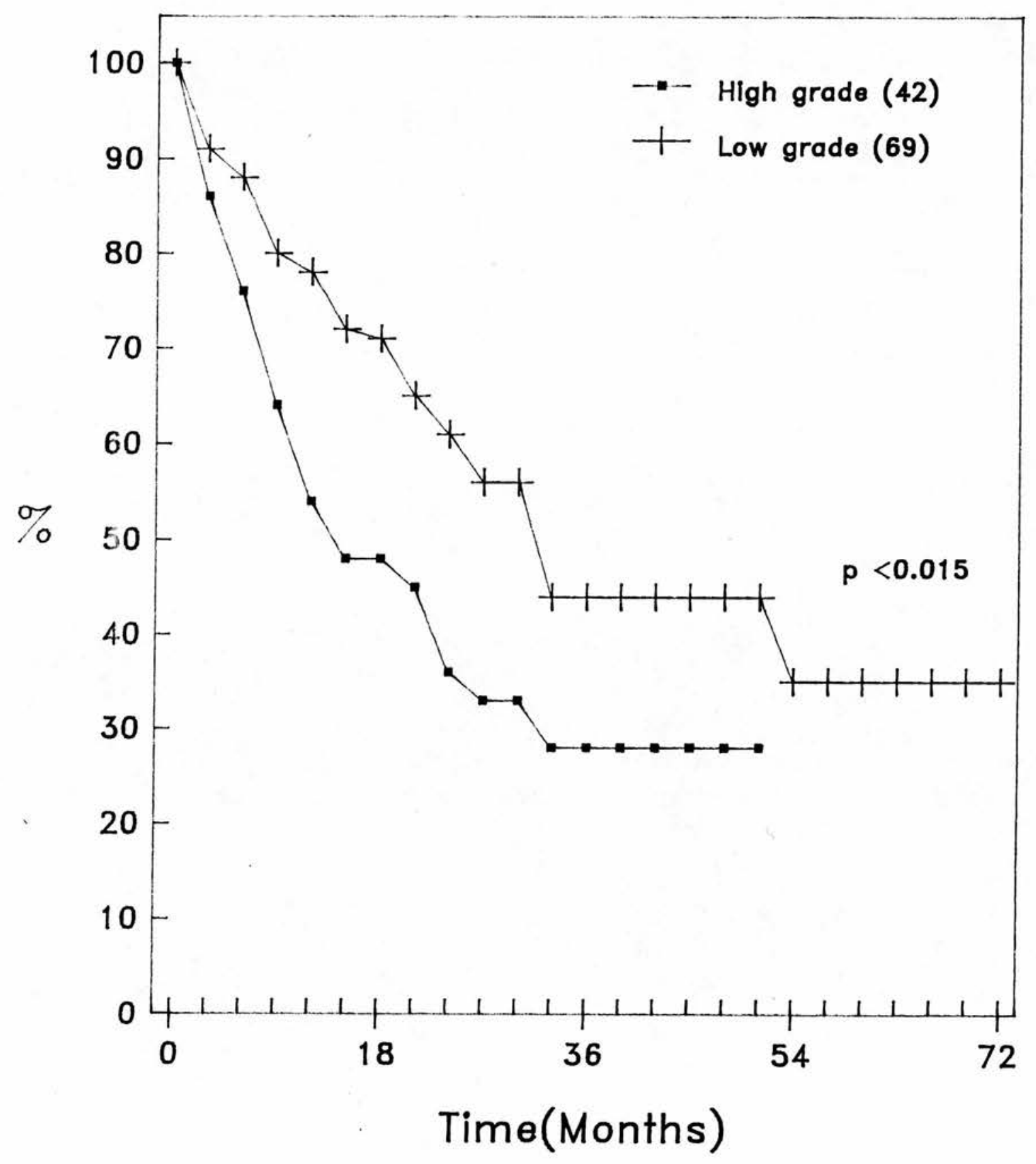


Figure 5.5 Survival of B-cell NHL separated by Working Formulation.

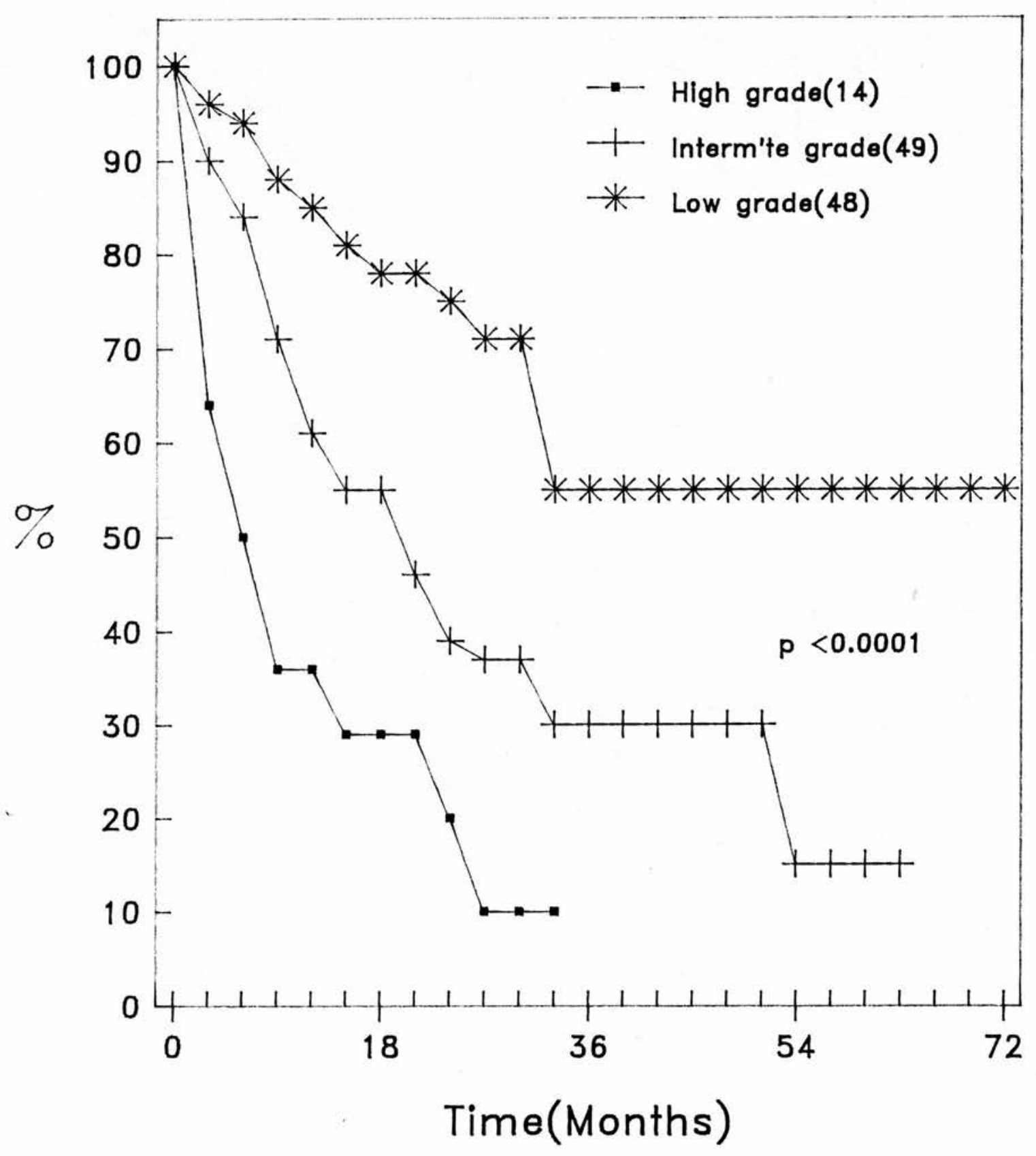


Figure 5.6 Survival of B-cell NHL separated by expression of $4 \mathrm{~F} 2$.

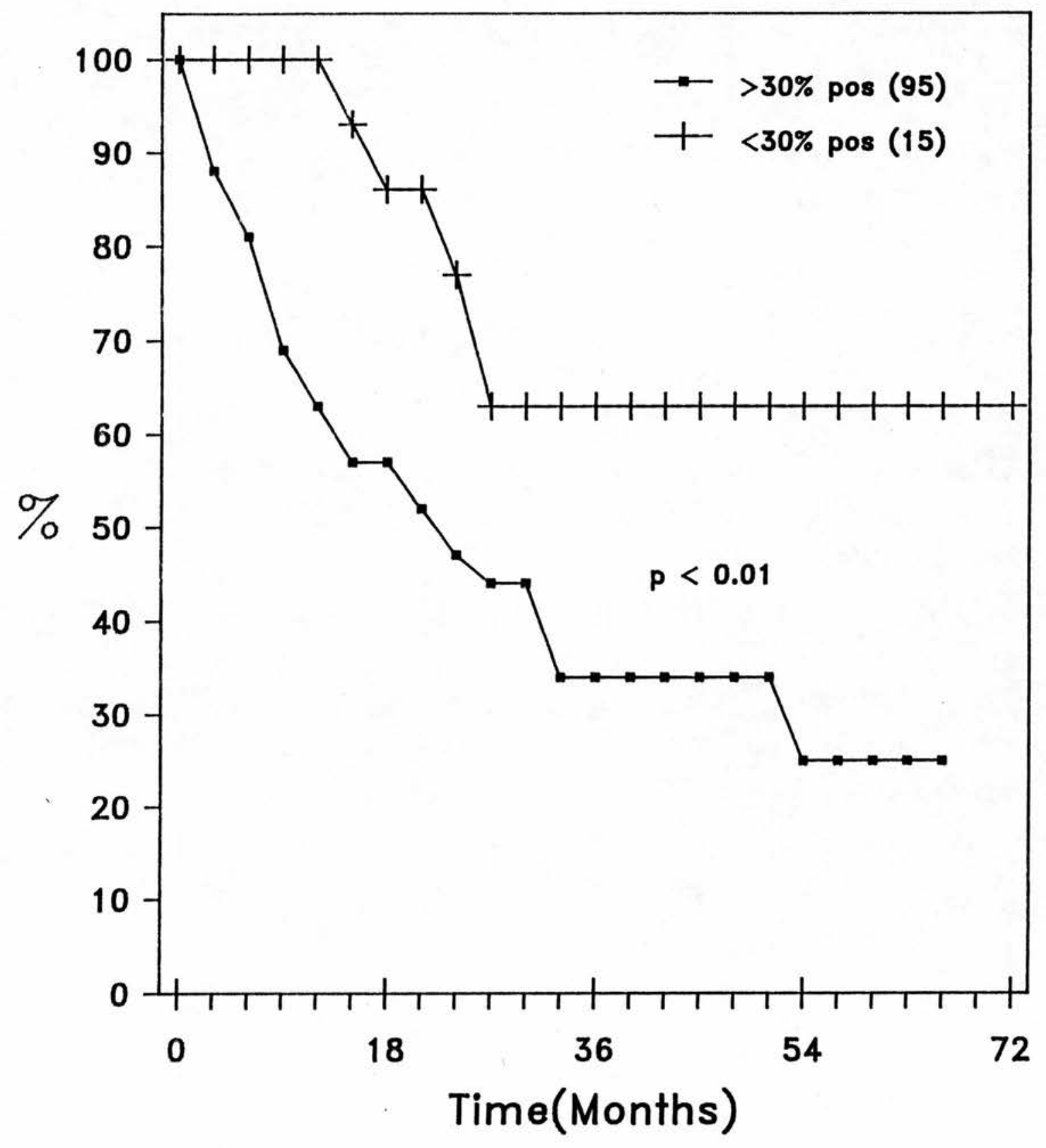


Figure 5.7 Survival of B-cell NHL separated by expression of CD71.

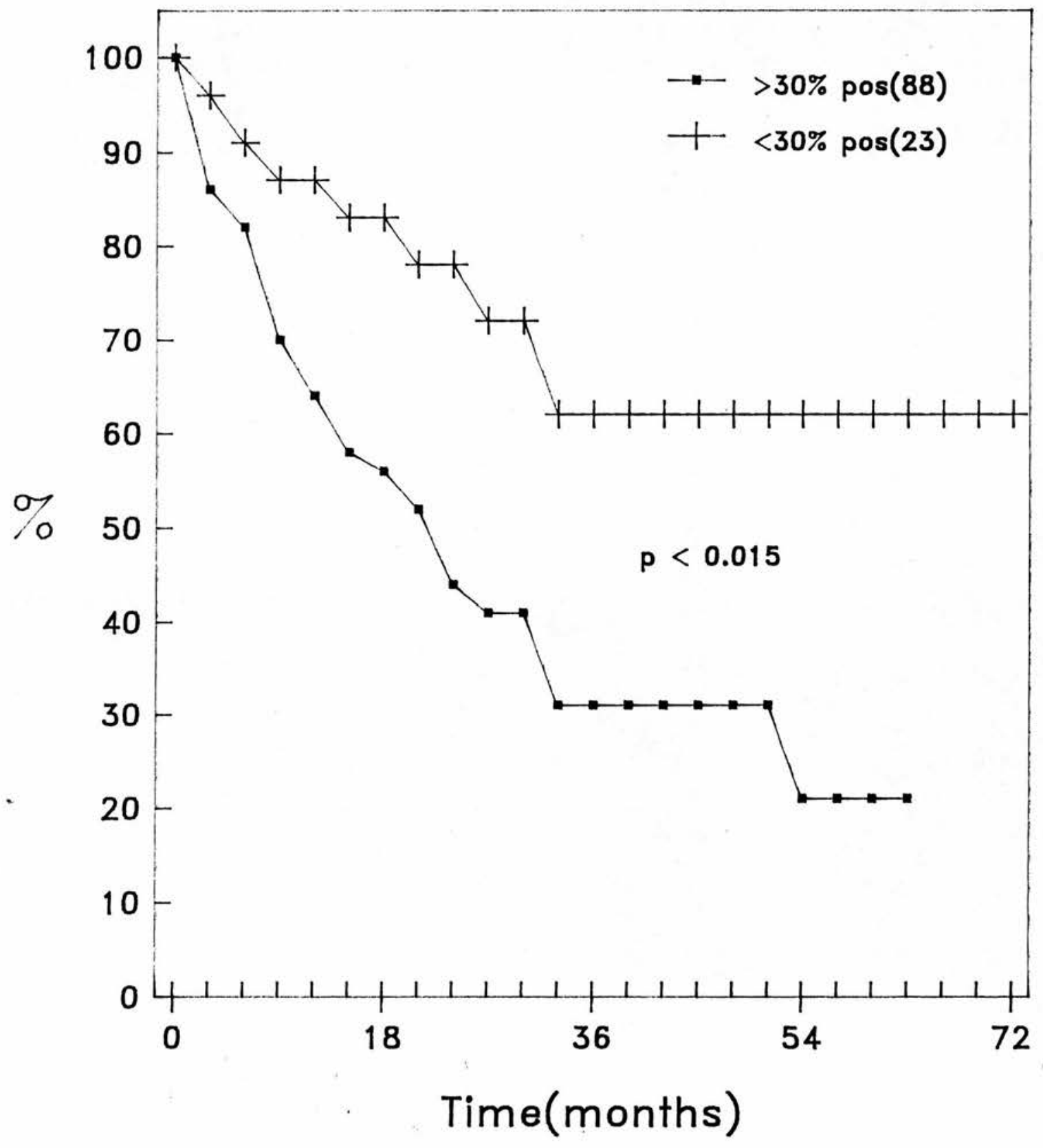


Figure 5.8 Survival of B-cell NHL (low grade Kiel) separated by 4 F2 expression.

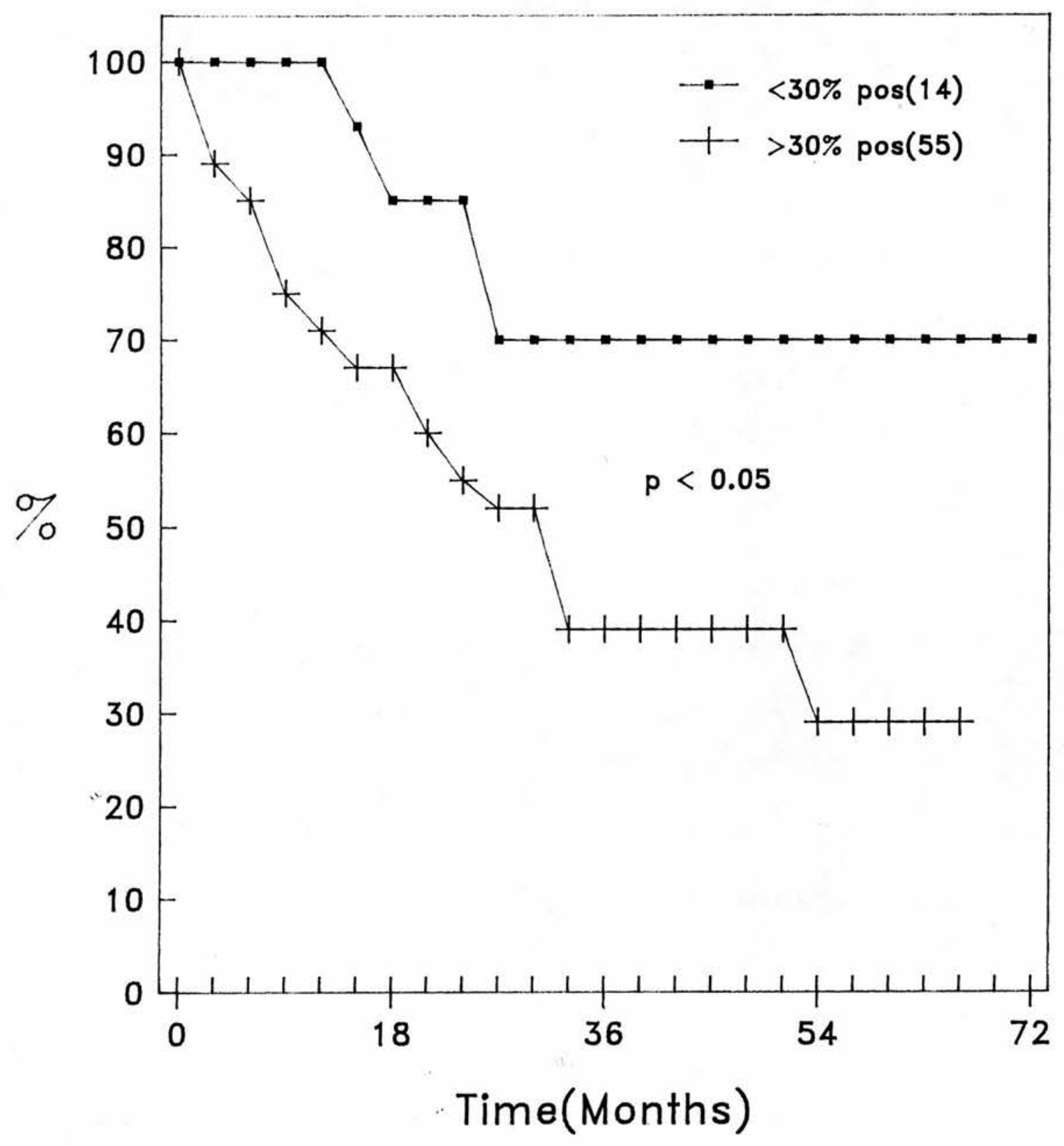


Figure 5.9 Survival of B-cell NHL (low grade Working Formulation) separated by $4 \mathrm{~F} 2$ expression.

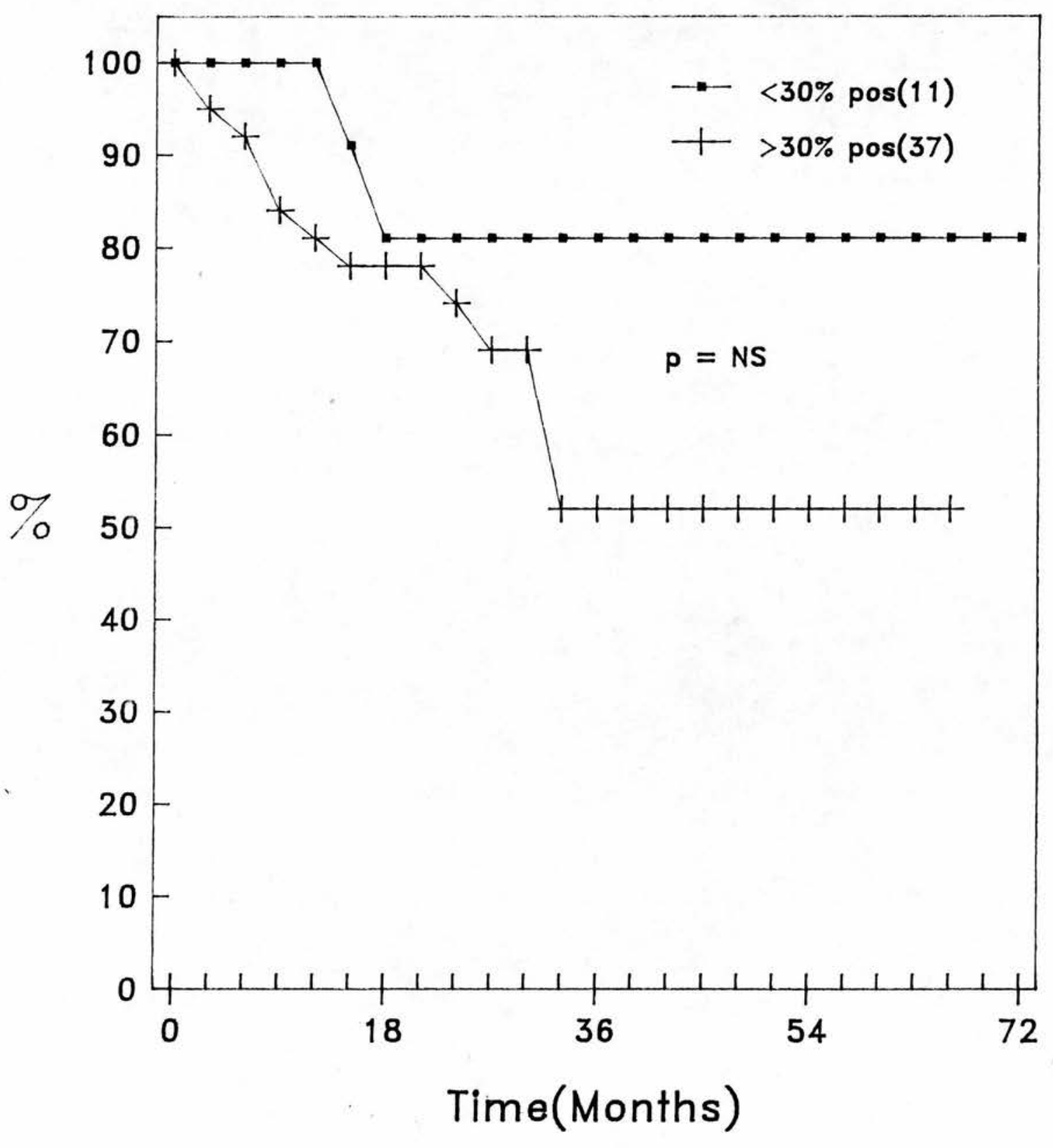


Figure 5.10 Survival of B-cell NHL (low grade Working Formulation) separated by CD71 expression.

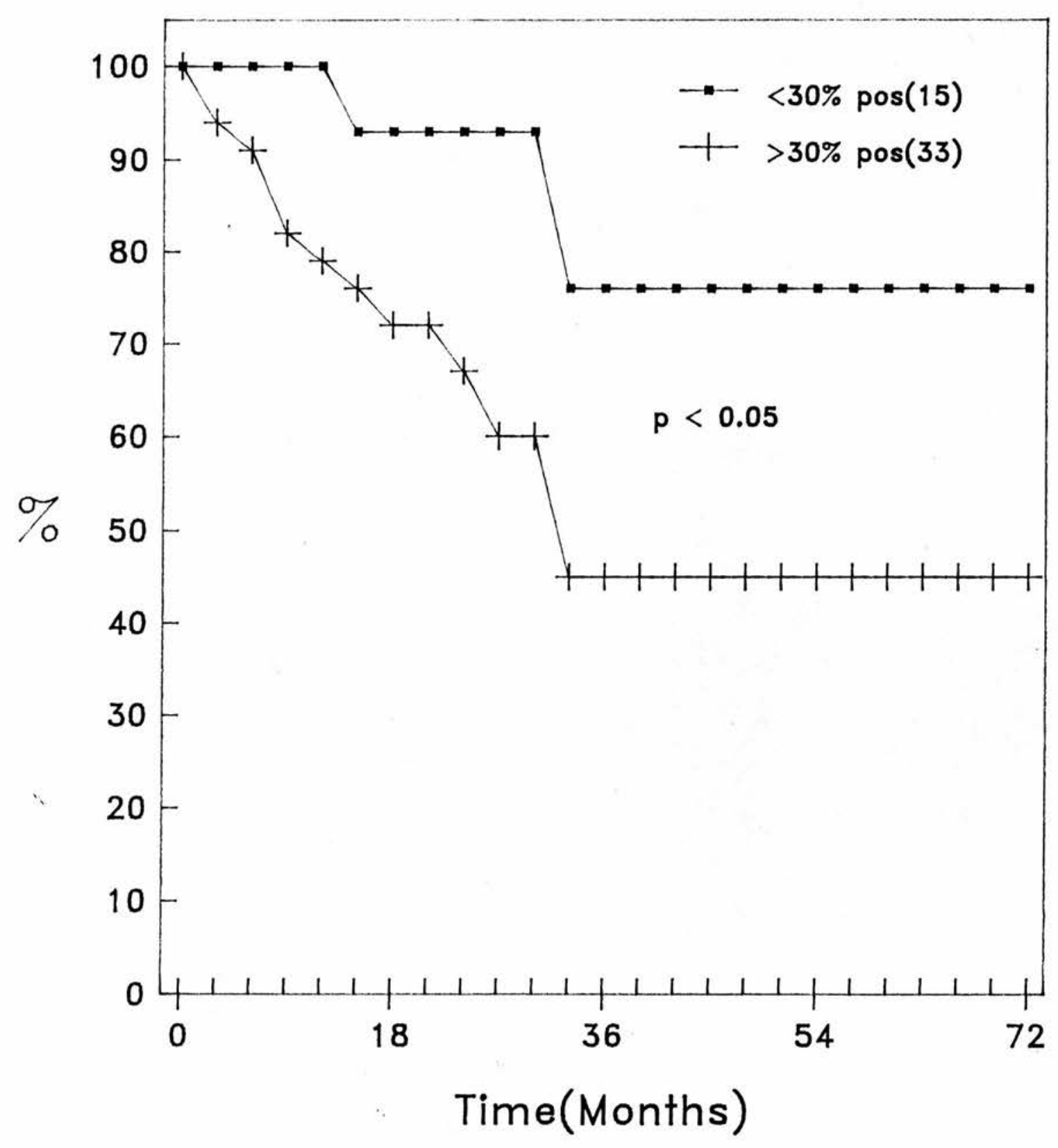


Figure 5.11 Survival of B-cell NHL (low grade Kiel) separated by CD71 expression.

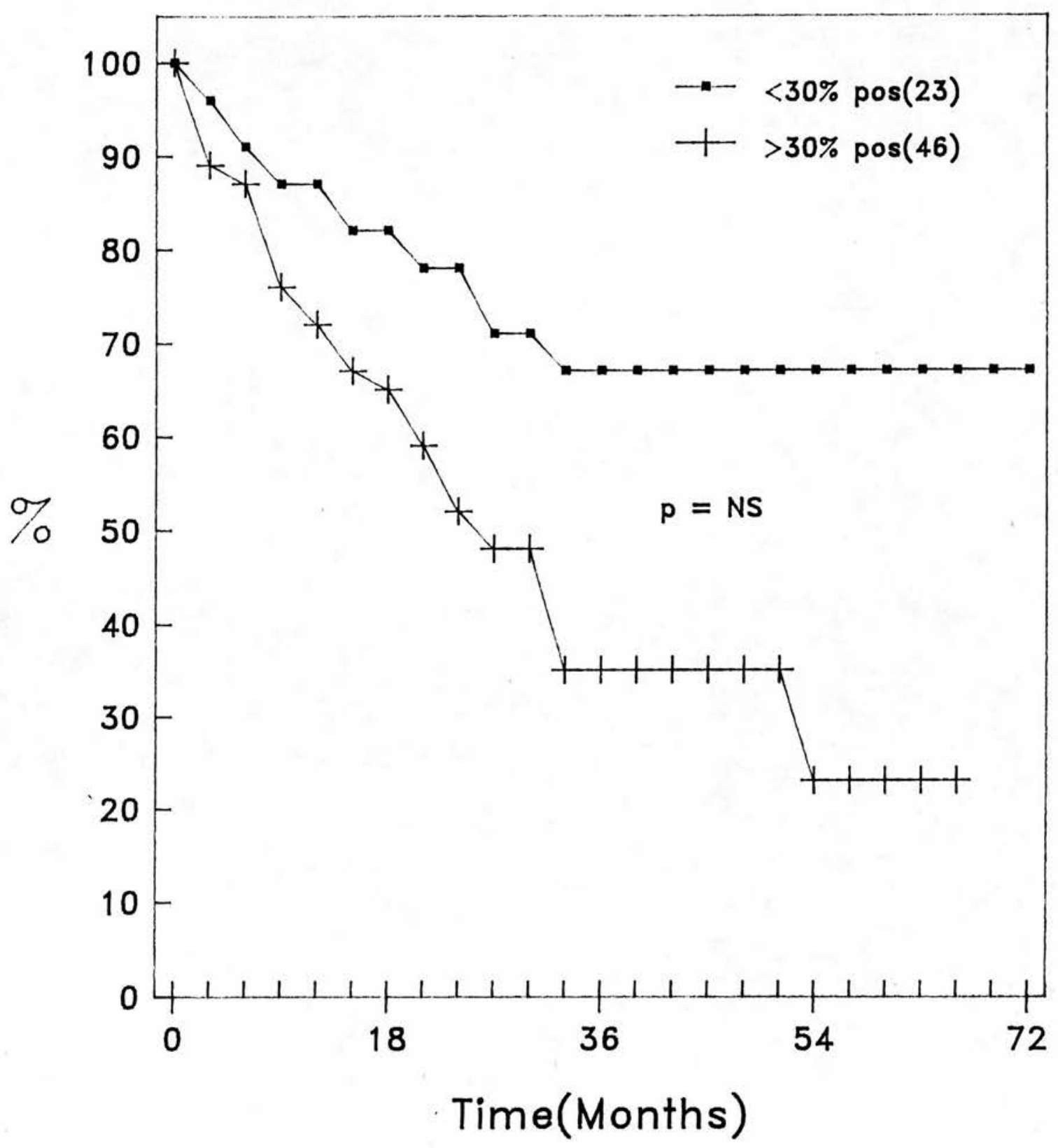




\subsection{DISCUSSION}

A large number of antibodies are available for immunophenotyping lympho-proliferative lesions. Immunophenotyping is useful in clinical practice to distinguish between lymphoid and non-lymphoid neoplasms, reactive and neoplastic lymphoid proliferation, and for determining $T$ or $\mathrm{B}-\mathrm{cell}$ lineage of NHL. When a large panel of antibodies is used for phenotyping B-cell NHL only a relatively few consistent features of antigen expression are seen, eg., CD5 is expressed by lymphocytic and centrocytic NHL and rarely by other B-cell tumours (Chapter 4, Schuurmann et al 1987).

Previous studies have shown correlation with antigen expression and clinical behaviour. 4F2 and CD71 expression is associated with poor prognosis in NHL (Habeshaw et al 1983, Holte et al 1987, Pileri et al 1984). The results presented here confirm these observations. No association could be found between clinical behaviour and expression of other activation and differentiation associated antigens studied. Both $4 \mathrm{~F} 2$ antigen and CD71/transferrin receptor are expressed more frequently by histologically high grade tumours whose overall prognosis is known to be poor. Expression of these antigens can therefore in part be predicted by histology, but multivariate analysis shows that the association with survival is independent of age, stage and Kiel histological grade. Expression of $4 \mathrm{~F} 2$ antigen and $C D 71$ was also associated with clinical behaviour of low grade tumours but reached significant levels only in the Kiel classification with $4 \mathrm{~F} 2$ and in the WF for CD71. These markers may therefore be useful for predicting clinically poor prognostic cases of low grade lymphomas.

A large number of statistical analyses were undertaken in 
this study and at a 5 per cent significance level significant results could be seen by chance in 1 of 20 tests. The tests with significant associations were mostly at the $\mathrm{p}<0.01$ level. Within the low grade groups statistically significant results were marginal with both CD71 and 4F2 $(p<0.5)$ and although could be accounted for by chance alone the trends in the survival curves suggest that these are truly significant results. The borderline nature of the results is probably secondary to the small numbers in each group.

other membrane associated antigens have been shown to have prognostic significance. CDlo myelomas behave aggressively (Durie and Grogan 1985), but in our series of B-NHL there was no significant correlation between expression of this antigen and survival. This is probably in part because of the large number of low grade follicular lymphomas we see expressing CD10 and few cases of lymphoblastic lymphoma (often CD10 positive (Ritz et al 1981)) in our series.

CD23 expression has been associated with prolonged relapse free survival in NHL (Schuurmann et al 1988). This is not unexpected as it is expressed predominantly by low grade lesions. An association between CD23 and survival could not be confirmed in this study. These results may in part be accounted by the poor survival of centrocytic lymphomas in our series. Schuurman et al (1988), correlated the expression of a panel of markers similar to that used in this study (including CD9, CD10, CD21, CD23, CD25, and CD71) with relapse-free survival in cases of NHL given therapy intended to achieve complete remission. This form of treatment was given to only 65 of our cases. When these were analysed separately we were still unable to show an association between survival and CD23 expression or other markers. This may in part be a reflection of the larger proportion of low grade lymphomas given 
aggressive therapy in the study of schuurman et al (1988).

While immunophenotyping of NHL has allowed greater understanding of the biology of this group of neoplasms and is an invaluable research tool, the clinical application and usefulness of many of the antibodies used for phenotyping lymphoid cells is in doubt. A limited panel of antibodies which aids identification of lymphoid neoplasms and helps ascertain lineage of these tumours is probably all that is necessary for routine clinical use at present. New markers need to be developed which will differentiate between good and poor prognosis cases in histological grades, allowing the pathologist to make more accurate predictions of behaviour of NHL. The results presented suggest that $4 \mathrm{~F} 2$ and $C D 71$ may identify poor prognostic cases of histologically low grade NHL. Immunostaining for the proliferation marker Ki67 may allow similar discrimination (Hall et al 1988). The number of different chemotherapeutic regimes given to a series of NHL in a retrospective study such as this creates some problems in assessment of associations between phenotype and clinical behaviour but the identification of potentially useful markers such as $4 \mathrm{~F} 2$, and CD71 suggests a need for immunophenotypically identified antigens as well as histological grade to be taken into consideration in prospective trials of the efficacy of different treatment modalities in the management of NHL. 


\section{BIBLIOGRAPHY}

Akerman A, Brandt L, Johnson A, Olsson H. (1987). Mitotic activity in non-Hodgkins lymphoma. Relation to the Kiel classification. $\mathrm{Br} \mathrm{J}$ Cancer. 55: 219-223.

Aman P, Gordon J, Lewin N et al. (1985). Surface marker characterisation of EBV target cells in normal blood and tonsil B lymphocyte populations. J Immunol. 135: 2362-

Anderson J, Melchers F. (1974). Maturation of mitogen activated bone marrow derived lymphocytes in the abscence of proliferation. Eur J Immunol. 4 : 533-539.

Anderson KC, Bates MP, Slaughenhoupt BL, Pinkus GS, Schlossman SF, Nadler LM. (1984). Expression of human B cell-associated antigens on leukaemias and lymphomas. A model of human B cell differentiation. Blood 63: 14241433 .

Anderson KC, Boyd AW, Fisher DC, et al. (1985). Isolation and functional characterisation of human B-cell populations. I. Characterisation of the $\mathrm{B} 1+\mathrm{B} 2+$ and $\mathrm{B} 1+\mathrm{B} 2-$ subsets. J.Immunol. 136: 820-827.

Banks PM, Berard CW. (1977). Lymphoreticular disorders malignant proliferative response - Histopathology of the malignant lymphomas. In Hematology (eds. Williams WJ, Beutler E, Erslev AJ, Rundles RW.) pp1026-1036. McGrawHill, New York.

Bazin H, Gray D, Patteau B, Maclennan ICM. (1982). Distinct delta+ and delta- B lymphocyte lineages in the rat. Ann. NY. Acad Sci. 399: 157-174.

Bennett MH, Farrer-Brown G, Henry K, Jellife AM. (1974). 
Classification of non-Hodgkins lymphoma. Lancet ii, 405.

Bernard A, Boumsell L, Dausset J, Milstein C, Schlossman SF. (1984). Leukocyte Typing. Human leucocyte differentiation antigens detected by monoclonal antibodies. springer-Verlag, Berlin and New York.

Bhan AK, Nadler LM, Stashenko P, McCluskey RT, Schlossman SF. (1981). Stages of B cell differentiation in human lymphoid tissue. J Exp Med. 154: 737-749.

Bloomfield CD, Goldman A, Dick F, Bruning RD, Kennedy BJ. (1974). Multivariate analysis of prognostic factors in non-Hodgkin's lymphomas. Cancer 33: 870-891.

Bloomfield CD, Gajl-Peczalska KJ, Frizzera G, Kersey JH, Goldman AI. (1979). Clinical utility of lymphocyte surface markers combined with the Lukes-collins histologic classification in adult lymphoma. N Engl J Med. 301: 512518.

Bodger MP, Janossy G, Janossa M, et al. (1983). The ontogeny of terminal deoxynucleotidyl transferase positive cells in the human fetus. Blood 61: 1125-1131.

Bofill M, Janossy G, Janossa M, et al. (1985). Human B cell development.II. Subpopulations in the human fetus. J Immunol. 134 1531-1538.

Bonnefoy JY, Aubrey JP, Peronne C, Wijdenes J, Bancherau J. (1987) . Production and characterization of a monoclonal antibody specific for the human lymphocyte low affinity receptor for IgE:CD23 is a low affinity receptor for IgE. J Immunol. 138: 2970-2978.

Bonnefoy JY, Guillot O, Spits H, Blanchard D, Ishizaka K, Banchereau J. (1988). The low affinity receptor for 
IgE (CD23) on B lymphocytes is spatially associated with HLA DR antigens. J Exp Med. 167: 57-72.

Borowitz MJ, Bousvaros A, Brynes RK et al. (1985). Monoclonal antibody phenotyping of B-cell non-Hodgkin's lymphomas. The Southeastern Cancer Study Group experience. Am J Pathol 121: 514-521.

Boue DR, Lebien TW. (1988). Structural characterisation of the human B lymphocyte-restricted differentiation antigen CD22: comparison with CD21 (complement type 2/Epstein Barr virus receptor). J Immunol. 140: 192-199.

Boyd AW and Metcalfe D. (1984). Activation of human murine B cells by anti-immunoglobulin antibody: Dependence of the response on the preexisting level of $\mathrm{B}-\mathrm{cell}$ activation. Cell Immunol. 89: 75-83.

Boyd AW, Anderson KC, Freedman AS et al. (1985a). Studies of in vitro activation of human B lymphocytes. I. Phenotypic and functional characterisation of the $B$ cell population responding to anti-Ig antibody. J Immunol. 134: 1516-1523.

Boyd AW, Fisher DC, Fox DA, Schlossman SF, Nadler LM. (1985b) Structural and functional characterization of IL2 receptors on activated human B cells. J Immunol. 134: 2387-2391.

Boyd AW, Freedman AS, Anderson KC, et al. (1986). Phenotypic changes occuring during in-vitro activation of human splenic B lymphocytes. In Leucocyte Typing II.(eds Reinherz E et al). Vol 2 Human B Lymphocytes. pp 429-442, Springer Verlag, New York.

Boyd AW, Fecondo J.(1988). Role of the CD21 antigen in 
lymphocyte transformation by Epstein-Barr virus. Immunol.Cell Biol. 66: 159-165.

Braun MP, Martin PJ, Ledbetter JA, Hansen JA. (1983). Granulocytes and cultured human fibroblasts express common acute lymphoblastic leukaemia antigens. Blood 62: 718-725.

Briggs PG, Kraft N, Atkins RL. (1987). Functional activity of CD5, CD9 and common leukocyte antibodies in $B$ chronic lymphatic leukaemia. In Leucocyte Typing III (Eds McMichael AJ et al) p498. Oxford University Press, oxford.

Brodsky FM. (1984). A mature approach to human class II histocompatibility antigens; reaction of four monoclonal antibodies with the products of nine haplotypes. Immunogenetics 19: 179-184.

Brooks DA, Bradley J, Zola H. (1982). A differentiation antigen expressed selectively by a proportion of human blood cells, detection with a monoclonal antibody. Pathology 14: 5-11.

Brown DC. Heryet A, Gatter KC, Mason DY. (1989). The prognostic significance of immunophenotype in high grade non-Hodgkins lymphoma. Histopathol. 14: 621-627.

Cabanillas F, Smith T, Bodey GD, Gutterman JU, Freirich GJ. (1980). Nodular malignant lymphomas. Cancer $\underline{44}$ : 1984-1989.

Caligaris-Cappio F, Gobbi M, Bofill M, Janossy G. (1982). Infrequent normal B lymphocytes express features of Bchronic lymphocytic leukaemia. J. Exp. Med. 155: 623-628.

Callard RE, Booth RT, Brown MH, McCaughan GW. (1985). T 
cell replacing factor in specific antibody responses to influenza virus by human blood B cells. Eur J Immunol 15: $52-59$.

Callard RE. (1988). Measurement of human B lymphocyte function in vitro. In B lymphocytes in human disease (eds Bird G, Calvert JE) pp295-332. Oxford University Press. oxford.

Cambier JC, Monroe JG. (1984). B cell activation. V. Differential signalling of $B$ cell membrane depolarization, increased I-A expression, GO to G1 transition and thymidine uptake by anti-IgM and anti-IgD antibodies. J Immunol. 133: 576-581.

Cambier JC and Ransom RT. (1987). Molecular mechanism of transmembrane signalling in B lymphocytes. Annu Rev Immunol $\underline{5}$ : 179-199.

Campana D, Janossy G, Bofill M, et al. (1985). Human B cell development. I. Phenotypic differences of B lymphocytes in the bone marrow and peripheral lymphoid tissue. J Immunol. 134: 1524-1529.

Carbonne PP, Kaplan HS, Musshof K, et al. (1971). Report of the committee on Hodgkin's staging classification. Cancer Res. 31: 1860-1861.

Casali P, Burastero SE, Nakamura M, Inghirami G, Notkins AL. (1987). Human lymphocytes making rheumatoid factor and antibody to ssDNA belong to the Leu-1+ B-cell subset. Science 236: 77-81.

Clark EA, Shu G, Ledbetter JA. (1985). Role of the Bp35 cell surface polypeptide in human B-cell activation. Proc Nat Acad Sci. 82: 1766-1770. 
Clark EA, Ledbetter JA. (1986). Activation of human B cells mediated through two distinct cell surface differentiation antigens. Proc Natl Acad Sci USA. 83: 44944498 .

Clark EA, Einfield DA. (1986). Human B cell surface molecules defined by an international workshop panel of monoclonal antibodies. In Leucocyte Typing II (eds Reinherz EL et al) Vol 2. Human B Lymphocyts, pp155-167. Springer Verlag. New York.

Clark EA, Yip TC, Ledbetter JA, et al. (1988). CDW40 and BLca-specific monoclonal antibodies detect two distinct molecules which transmit progression signals to human $B$ lymphocytes. Eur J Immunol 18: 451-457.

Clark EA, Ledbetter JA. (1989). Structure, function, and genetics of human B cell-associated surface proteins. Adv. Cancer Res. 52: 81-149.

Cleary ML, Trela MJ, Weiss LM, Warnke R, Sklar J. (1985). Most null large cell lymphomas are B lineage neoplasms. Lab Invest 53: 521-525.

Cobbold S, Hale G, Waldmann H. (1987). Non-lineage, LFA-1 and leucocyte common antigens: new and previously defined clusters. In Leucocyte Typing III. (Eds McMichael AJ et al 1987). pp 788-803. Oxford University Press, Oxford.

Coico RF, Bhogol BS, Thorbecke T. (1983). Relationship of germinal centres in lymphoid tissue to immunologic memory. VI. Transfer of B memory with lymph node cells fractionated according to their receptors for peanut lectin. $\mathrm{J}$ Immunol. 131 2254-2257.

Cooper MD. (1987). B lymphocytes. Normal development and function. N Engl J Med 317: 1452-1456. 
Cossman $J$, Neckers ML, Hsu SM, Longo D, Jaffe ES. (1984a). Low grade lymphomas: expression of developmentally regulated $\mathrm{B}-\mathrm{cell}$ antigens. Am J Pathol 115: 117124 .

Cossman J, Jaffe ES, Fisher RI. (1984b). Immunologic phenotypes of diffuse, aggressive non-Hodgkin's lymphoma. Cancer 54: 1310-1317.

Costa A, Bonadonna G, Villa E, Valgussa P, Silvestrini R. (1981). Labelling index as a prognostic factor in nonHodgkin's lymphomas. J Natl Cancer Inst. 66: 1-5.

Cox DR. (1972) Regression models and life tables (with discussion). Journal of the Royal Statistical Society $B$. 34: $187-220$.

Daar As, Fuggle SV, Fabre JW, Ting A, Morris PJ. (1984). The detailed distribution of MHC classII antigens in normal human organs. Transplantation. 38: 293-298.

Dalchau R, Fabre JW. (1981). Identification with a monoclonal antibody of a predominantly B lymphocyte-specific determinant of the human leucocyte common antigen. $J$ Exp Med 153: 755-765.

Devita VT, Canellos GP, Chabner B, Schein P, Hubbard SP, Young RC. (1975). Advanced diffuse histiocytic lymphoma, a potentially curable disease: Results with combination chemotherapy. Lancet $\underline{i}$ : 248-250.

DeVita VT, Hubard SM, Young RC, Longo DL. (1988). The role of chemotherapy in diffuse aggressive lymphomas. Sem Haematol. 25: suppl 2, 2-10.

de-Rie MA, Schumacher TN, van-Schijndel GM, van-Lier RA, 
Miedema F. (1989). Regulatory role of CD19 molecules in B-cell activation and differentiation. Cell Immunol. 118: 368-381.

Dorfman RF. (1974). Classification of non-Hodgkin's lymphoma. Lancet $\underline{i}$ : 1295-1296.

Dorkan B, Moldenhauer G, Pezzutto A et al. (1985). HD39 (B3) a B lineage-restricted antigen whose cell surface expression is limited to resting and activated human $B$ lymphocytes. J Immunol 136: 4470-4479.

Durie BGM, Grogan TM. (1985). Calla-positive myeloma: An aggressive subtype with poor survival. Blood 66: 229232 .

Einfeld DA, Brown JP, Valentine MA, Clark EA, Ledbetter JA. (1988). Molecular cloning of the human B cell CD20 receptor predicts a hydrophobic protein with multiple transmembrane domains. ЕMBO.J ㅁ: 711-717.

Ellison DJ, Nathwani BN, Metter GE, et al. (1987). Mitotic counts in follicular lymphomas. Hum. Pathol. 18: 502505 .

Evans HL, Butler JJ, Youness EL. (1978). Malignant lymphoma small lymphocytic type: a clinicopathologic study of 84 cases with suggested criteria for intermediate lymphocytic lymphoma. Cancer 41: 1440-1455.

Falkoff RJM, Zhu LP, Fauchi AS. (1982). Seperate signals for human B cell proliferation and differentiation to staphylococcus aureus, evidence for a two signal madel of B cell activation. J Immunol 129: 97-102.

Fingeroth JD, Weis JJ, Tedder TF, strominger JL, Biro PA, Fearon DT. (1984). Epstein-Barr virus receptor of human B 
lymphocytes is the C3d receptor CR2. Proc Nat Acad Sci USA. 81: 4510-4514.

Fisher RI, Hubbard SM, DeVita VT, et al. (1980). Prognostic factors affecting the curability of diffuse mixed, diffuse histiocytic and diffuse undifferentiated lymphoma. Proc. Am Assoc Cancer Res. 21: 162-169.

Frade R, Barel M, Ehlin-Henrikson B, Klein G. (1985a). gp 140, the C3d receptor of human B lymphocytes, is also the Epstein Barr virus receptor. Proc Natl Acad Sci USA 82: 1490-1493.

Frade R, Crevon MC, Barel M, et al. (1985b). Enhancement of human B cell proliferation by an antibody to the c3d receptor, the gp 140 molecule. Eur J Immunol. 15: 73-76.

Freedman AS, Boyd AW, Anderson KC et al. (1985). Immunologic heterogeneity of diffuse large cell lymphoma. Blood 65: 630-637.

Freedman AS, Boyd AW, Fisher DC, Schlossman SF, Nadler LM. (1986). Changes with activation of the $B$ cell panel antigens. In Leucocyte Typing II (Eds Reinherz EL et al) Vol 2. Human B Lymphocytes, pp443-454. Springer Verlag, New York.

Freedman AS, Boyd AW, Berrebi A, et al. (1987). Expression of $B$ cell activation antigens on normal and malignant $B$ cells. Leukemia. 1: 9-15.

Freedman AS, Freeman G, Whitman J, et al. (1989). Studies of in vitro activated CD5+ B cells. Blood 구 202-208. Gadol N, Peacock MA, Ault KA. (1988). Antigenic phenotype and functional characterization of human tonsil B cells Blood 71: 1048-1055. 
Gathings WE, Lawton AR, Cooper MD. (1977). Immunofluorescent study of the development of pre-B-cell, B lymphocyte and immunoglobulin diversity in humans. Eur $\mathrm{J}$ Immunol. $\underline{7}$ : 804-810.

Gerdes H, Dallenbach F, Lennert $K$, Lemke $H$, stein $H$. (1984). Growth fractions in malignant lymphoma (NHL) as determined in situ with the monoclonal antibody Ki67. Hem oncol $\underline{2}$ : $365-371$.

Giles RC, Capra JD. (1985). Structure, function and genetics of human class II molecules. Adv Immunol. 37: 171.

Gobbi M, Caligaris-Cappo F, Janossy G. (1983). Normal equivalent cells of B cell malignancies: analysis with monoclonal antibodies. Br J Haematol 54, 393-403.

Gobbi PG, Ricevuti G, Balduini C, et al. (1985). Prognostic factors in Non-Hodgkins lymphomas. Acta Haematol. 74: 86-91.

Godal T, Davies C Smeland EB, et al. (1985). Antibodies to surface IgM and IgD increase the expression of various class 11 antigens on human B cells. Eur J Immunol. 15: 173-177.

Golay JT, Clark EA, Beverley PCL. (1985). The CD20 (Bp35) antigen is involved in activation of $B$ cells from the GO to the G1 phase of the cell cycle. J Immunol. 135: 37953799 .

Gordon J, Ley SC, Melamed MD, English LS, Hughes-Jones NC. (1984a). Immortalised B lymphocytes produce B-cell growth factor. Nature $\underline{310}: 145-147$.

Gordon J, Ley SC, Melamed MD, Hughes-Jones NC. (1984b). 
Anti-immunoglobulin inhibits DNA synthesis in EpsteinBarr virus-transformed lymphoblastoid cell lines. Immunology $\underline{58}$ : 79-85.

Gordon J, Guy G, Walker L. (1985). Autocrine models of Blymphocyte growth. 1.Role of cell contact and soluble factors in $\mathrm{T}$-independant $\mathrm{B}-\mathrm{cell}$ responses. Immunology $\underline{56}$ : 329-335.

Gordon J, Walker L, Guy G, Brown G, Rowe M, Rickenson A. (1986a). Control of human B lymphocyte replication. II. Transforming Epstein-Barr virus exploits three distinct viral signals to undermine three seperate control points in B-cell growth. Immunology 58: 590-596.

Gordon J, Webb AJ, Walker L. (1986b). Evidence for an association between $\mathrm{CD} 23$ and the receptor for a low molecular weight B cell growth factor. Eur $\mathrm{J}$ Immunol. 16: 1627-1630.

Gordon J, Guy G, Walker L. (1986C). Autocrine models of B-lymphocyte growth.II. Interleukin-1 supports the proliferation of transformed lymphoblasts but not the stimulation of resting $\mathrm{B}-\mathrm{cell}$ s triggered through their receptors for antigen. Immunology 57: 419-423.

Gordon J, Webb AJ, Guy GR, Walker L. (1987). Triggering of B lymphocytes through CD23: epitope mapping and studies using antibody derivatives indicate an allosteric machanism of signalling. Immunology 60: 517-521.

Gordon J, Cairns JA, Millsum MJ, Gillis S, Guy GR. (1988). Interleukin 4 and soluble CD23 as progression factors for human B lymphocytes: analysis of their interactions with agonists of the phosphoinositide "dual pathway of signalling. Eur.J Immunol. 18: 1561-1565. 
Gordon J, Guy GR. (1987). The molecules controlling B lymphocytes. Immunol Today. $\underline{8}$ : 339-344.

Gordon J, Guy G. (1988). Control of human B lymphocyte growth and differentiation. In B lymphocytes in human disease (eds Bird G, Calvert JE), pp148-173. Oxford University Press, oxford.

Gray D, Maclennan ICM, Bazin H, Khan N. (1982). Migrant mut deltat and static mu+ delta- B lymphocyte subsets. Eur J Immunol. 12: 564-569.

Gray D, Chassoux D, MacLennan ICM, Bazin H. (1985). Selective depression of thymus-independant anti-DNP antibody responses induced by adult but not neonatal splenectomy. Clin Exp Immunol. $\underline{6}$ : 78-86.

Gray D, Maclennan ICM, Lane PJL. (1986). Virgin B cell recruitment and the lifespan of memory clones during antibody responses to 2,4-dinitrophenyl-hemocyanin. Eur $\mathrm{J}$ Immunol. 16: 641-648.

Greaves MF, Brown G, Rapson NT, Lister TA. (1975). Antisera to acute lymphoblastic leukaemia cells. Clin Immunol Immunopathol. $\underline{4}$ : 67-84.

Grey HM, Rabellino E, Pirofsky B. (1971). Immunoglobulin on the surface of lymphocytes.IV. Distribution in hypogammaglobulinaemia, cellular immune deficiency and chronic lymphatic leukaemia. J Clin Invest. 50: 2368-2375.

Guy K, Krajewski AS, Dewar AE. (1986). Expression of MHC class II antigen in human B cell leukaemia and non-Hodgkin's lymphoma. $\mathrm{Br} \mathrm{J}$ Cancer $\underline{53}, 161-173$.

Habeshaw JA, MacAuley RAA, Stuart AE. (1977) . Correlation of surface receptors with histological appearance in 29 
cases of non-Hodgkin lymphoma. Br J Cancer. 35:858-867.

Habeshaw JA, Catley PF, Stansfeld AG, Brearley RL. (1979). Surface phenotyping, histology and the nature of non-Hodgkins lymphoma in 157 patients. $\mathrm{Br} \mathrm{J}$ Cancer. 40: 11-34.

Habeshaw JA, Bailey D, Stansfield AG, Greaves MF. The cellular content of non-Hodgkin's lymphomas. A comprehensive analysis using monoclonal antibodies and other surface marker techniques. Br J Cancer 1983; 47: 327351 .

Habeshaw JA, Lister TA, Stansfeld AG, Greaves MF.(1983) Correlation of transferrin receptor expression with histological class and outcome in non-Hodgkin's lymphoma. Lancet i: 498-501.

Hall PA, D'Ardenne AJ, Richards MA, Stansfeld AG. (1987). Lymphoplasmacytoid lymphoma: an immunohistological study. J Pathol. 153: 213-223.

Hall PA, Richards MA, Gregory WM, D'Ardenne AJ, Lister TA, Stansfeld AG. (1988) The prognostic value of Ki 67 immunostaining in non-Hodgkins lymphoma. J. Pathol 154: 223-236.

Hardy RP, Hayakawa K, Shimizu M, Yamasaki K, Kishimoto T. (1987). Rheumatoid factor secretion by human Leu-1+ $B$ cells. Science 236: 81-83.

Harris NL, Bhan AK. (1985). B Cell neoplasms of the lymphocyte, lymphoplasmacytoid and plasma cell types. Immunohistologic analysis and clinical correlation. Hum Pathol 16: 829-837.

Haynes BF, Hemler ME, Mann DL, et al. (1981). Character- 
isation of a monoclonal antibody (4F2) that binds to human monocytes and to a subset of activated lymphocytes. J. Immunol. 126: 1409-1414 .

Heinen E, Tsunoda R. (1987). Microenvironments for B cell production and stimulation. Immunol Today. $\underline{8}$ : 142-144.

Hemler ME, Strominger JL. (1982). Characterisation of antigen recognised by the monoclonal antibody (4F2): different molecular forms on $T$ and $B$ lymphoblastoid lines. J Immunol. 129: 623-628.

Hirano T, Kuritani T, Kishimoto T, Yamamura Y. (1977). In vitro immune response of human peripheral lymphocytes.I. The mechanism(s) in $\mathrm{T}$ cell helper function in the pokeweed mitogen induced differentiation and proliferation of B cells. J Immunol 119: 1235-1241.

Hivroz C, Grillot-Courvalin C, Brouet JC, Seligmann M. (1986). Heterogeneity of responsiveness of chronic lymphocytic leukaemic B cells to B cell growth factor or interleukin2. Eur J Immunol 16: 1001-1004.

Hokland P, Rosenthal P, Griffen JD et al. (1983). Purification and characterisation of fetal hematopoietic cells that express the common acute lymphoblastic leukaemia antigen. J Exp Med. 157: 114-129.

Hokland P, Ritz J, Schlossman SF, Nadler LM. (1985). orderly expression of $B$ cell antigens during the in vitro differentiation of non-malignant human pre-B cells. J Immunol. 135: 1746-1751.

Hollander NL, Pillemer E, Weissman IL. (1981). Effect of Lyt antibodies on $\mathrm{T}$ cell functions : augmentation by anti-Lyt-1 as opposed to inhibition of anti-Lyt-2. Proc Natl Acad Sci USA. 78:1148-1151. 
Holte H, Davies CDL, Kvaloy S et al. (1987). The activation antigen $4 \mathrm{~F} 2$ predicts patient survival in low grade B-cell lymphomas. Int J Cancer 39: 590-594.

Horning SJ, Dogget RS, Warnke RA, Dorfman RF, Cox RS, Levey R. (1984). Clinical relevance of immunologic phenotype in diffuse large cell lymphoma. Blood 63: 12091215.

Horwich A, Peckham M. (1983). "Bad risk" non-Hodgkin's lymphoma. Sem Hematol. 20: 35-56.

Hsu SM, Jaffe ES. (1984). Phenotypic expression of Blymphocytes. I. Identification with monoclonal antibodies in normal lymphoid tissues. Am J Pathol 114: 387395.

Iida K, Nadler LM, Nussenweig V. (1983). Identification of the membrane receptor on the complement fragment c3d by means of a monoclonal antibody. J Exp Med 158: 10211033.

Isaacson PG, Wright DH, Judd MA, Jones DB, Payne SV. (1980). The nature of immunoglobulin containing cells in malignant lymphoma: An immunoperoxidase study. J Histochem Cytochem. 28: 701-710.

Isaacson PG, Wright DH. (1984). Extranodal malignant lymphoma arising from mucosa-associated lymphoid tissue. Cancer 53: 2515-2524.

Isaacson PG, spencer J. (1987). Malignant lymphoma of mucosa-associated lymphoid tissue Histopathol. 11: 445462 .

Isaacson PG, Spencer J, Wright DH. (1988). Classifying 
primary gut lymphoma. Lancet ii:1148-1149.

Isakson PC, Simpson L. (1984). Phorbol esters inhibit murine $B$ cell differentiation to immunoglobulin secretion but not proliferation. J Immunol. 133: 17788-1791.

Jaffe ES, Shevach EM, Frank MM, Berard CW, Green I. (1974) Nodular lymphoma evidence for origin from follicular B cells. N Engl J Med. 290: 813-819.

Jelinek DF, Lipsky PE. (1983). The role of B cell proliferation in the generation of immunoglobulin-secreting cells in man. $\mathrm{J}$ Immunol 130: 2597-2604.

Jelinek DF, Lipsky PE. (1987). Regulation of human B lymphocyte activation, proliferation and differentiation. Adv. Immunol. 40: 1-59.

Jones NH, Clabby ML, Dialynas DP, Huang HJ, Herzenberg LA, strominger JL. (1986). Isolation of complementary clones encoding the human lymphoid glycoprotein T1/Leul. Nature 323: 346-348.

June CH, Rabinovitch PS, Ledbetter JA. (1987). CD5 antibodies increase intracellular ionised calcium concentration in $\mathrm{T}$ cells. J Immunol 138: 2782-2792.

Jung LKL, Hara T, Fu SM. (1984) Detection and functional studies of p60-65 (Tac antigen) on activated human Bcells. J. Exp. Med 160: 1597-1602.

Kehrl J, Muraguchi A, Fauchi A.S. (1984a) Differential expression of cell activation markers after stimulation of resting B lymphocytes. J. Immunol. 132: 2857-2861.

Kehrl JH, Muraguchi A, Butler JL, Falkoff RJM, Fauchi AS. $(1984 \mathrm{~b})$. Human B-cell activation, proliferation and 
differentiation. Immunol Rev 78: 75-96.

Kehrl JH, Muraguchi A, Fauci AS. (1985). The modulation of membrane Ia on human B lymphocytes. Cell Immunol. 92, 391-403.

Kersey JH, LeBien TW, Abramson CS, Newman R, Sutherland R Greaves M. (1981). P24: A human leukaemia-associated and lymphopoietic cell surface structure idenitified with monoclonal antibody. J Exp Med 153: 726-731.

Kikutani HS, Inui S, Sato R, Barsumian EL, Owaki H, Yamasaki K, (1986a). Molecular structure of the human lymphocyte receptor for immunoglobulin E. Cell 47: 657665.

Kikutani H, Kimura R, Nakamura H, et al. (1986b). Expression and function of an early activation marker restricted to human B cells. J Immunol. 136: 4019-4026.

Kincade PW. (1987). Experimental models for understanding B lymphocyte formation. Adv. Immunol. 41: 181-267.

Kishimoto T, Yoshizaki K, Kimoto M et al. (1984). B cell growth and differentiation factors and mechanisms of $B$ cell activation. Immunol Rev. 78: 97-118.

Kishimoto TA. (1985). Factors affecting B-cell growth and differentiation. Annu Rev Immunol. 3: 133-157.

Klaus GGB, Humphrey JH, Dongworth DW. (1980). The follicular dendritic cell: Its role in antigen presentation in the generation of immunological memory. Immunol Rev. $\underline{53}$ : 3-28.

Klaus GGB, Kunkl A. (1981). The role of germinal centers in the generation of immunological memory. In Microenvi- 
ronments in haemopoietic and lymphoid differentiation. pp265-280. Pitman Medical, London.

Klauss GGB, Humphrey JH. (1986). A reevaluation of the role of $\mathrm{C} 3$ in $\mathrm{B}$ cell activation. Immunol Today. 7: 163165 .

Knapp W, Rieber P, Dorken B, Schmidt RE, Stein H, Borne AEGKr.v.d. (1989). Towards a better definition of human leucocyte surface molecules. Immunol Today 10: 253-258.

Knowles III DM, Dodson L, Burke JS et al. (1985). SIg- E("Null- Cell") non-Hodgkin's lymphomas: Multiparametric determination of their B- or T-cell lineage. Am J Pathol 120: $356-370$.

Kohler G, Milstein C. (1975). Continuous cultures of fused cells secreting antibody of predefined specificity. Nature 256: 495-497.

Korsmeyer SJ, Greene WC, Cossman J et al. (1983) . Rearrangement and expression of immunoglobulin genes and expression of Tac antigen in hairy cell leukaemia. Proc Natl Acad Sci USA 80: 4522-4526.

Krajewski AS, Guy K, Dewar AE, Cossar D. (1985). Immunohistochemical analysis of human MHC class II antigens in B cell non-Hodgkin's lymphoma. J Pathol 145: 185-194.

Krajewski AS, Myskow M, Cachia P, Salter DM, Sheehan T, Dewar AE. (1988). T-cell Lymphoma: morphology, immunophenotype and clinical features. Histopathology 13: 19-41.

Kuritani T, Cooper MD. (1982). Human B cell differentiation. II. Pokeweed mitogen-responsive B cells belong to a surface immunoglobulin D-negative subpopulation. J Exp Med. 155: 1561-1566. 
Kuritani T, Cooper MD. (1983). Human B cell differentiation. IV. Effect of monoclonal anti-immunoglobulin $M$ and $D$ on $B$ cell proliferation and differentiation induced by T-cell factors. J Immunol. 131: 1306-1311.

Kvaloy S, Langholm R, Kaalhus O, et al. (1984). Transferrin receptor and $B-1 y m p h o b l a s t$ antigen: their relationship to DNA synthesis, histology and survival in B-cell lymphomas. Int $\mathrm{J}$ Cancer. 33: 173-177.

Kvaloy S, Morton PF, Kaalhus O, Hie J, Foss-Abrahamsen A, Godal T. (1985). H-Thymidine uptake in B cell nonHodgkin's lymphomas. Relationship to treatment response and survival. Scand J Haematol. 34: 429-435.

Lampour LA, Levy R. (1980). Two populations of Ia-like molecules on a human B cell line. J Immunol 125: 293299 .

Lantz O, Grillot-Courvalin C, Schmitt C, Fernand JP, Brouet JC. (1985). Interleukin-2 induced proliferation of leukaemic B cells. J Exp Med. 161: 1225-1230.

Ledbetter JA, Evans RC, Lipinski M, Cunningham-Rundles C, Good RA, Lietzenberg LA. (1981). Evolutionary conservation of surface molecules that distinguish $\mathrm{T}$ lymphocyte helper/inducer and $\mathrm{T}$ cytotoxic suppressor subpopulations in mouse and man. J Exp Med 53: 310-323.

Ledbetter JA, Martin PH, spooner CE, et al. (1985). Antibodies to Tp67 and Tp44 augment and sustain proliferative responses of activated $T$ cells. J Immunol 135: 2331-2336.

Ledbetter JA, Tonks NK, Fischer E, Clark EA. (1988). CD45 regulates signal transduction and lymphocyte activation 
by specific association with receptor molecules on $\mathrm{T}$ or $\mathrm{B}$ cells. Proc Natl Acad Sci USA. 85: 8628-8632.

Lee E, Desu M. (1972) A computer program for comparing K samples with right-censored data. Computer Programs in Biomedicine $\underline{2}$ : 315-321.

Lee F, Yokata T, Otsuka T, Meyerson P, Villoret D, Coffman R. (1986). Isolation and characterisation of a mouse interleukin CDNA clone that expresses B cell stimulatory factor 1 activity and T-cell and mast cell-stimulatory activities. Proc Natl Acad Sci USA. 83: 2061-2065.

Leonard RC, Cuzick J, MacLennan IC, Van Hagan RI, Mackie PH, McCormick CV. (1983). Prognostic factors in nonHodgkin's lymphoma: the importance of symptomatic stage as an adjunct to the Kiel histological classification. Br J Cancer. 47: 91-102.

Leonard WJ, Depper JM, Uchyama T, Smith KA, Waldmann TA, Green WC. (1982). A monoclonal antibody that appears to recognise the receptor for human $T$ cell growth factor: partial characterisation of the receptor. Nature 300 : 267-269.

Lennert K. (1978) Malignant Lymphomas other than Hodgkin's Disease. Springer, Berlin.

Lesley JF, Schulte RJ. (1984). Selection of cell lines resistant to anti-transferrin receptor antibody: evidence for a mutation in transferrin receptor. Mol Cell Biol. $\underline{4}$ : 1675-1681.

Lindemalm C, Christensson B, Johansson B, Melstedt H, Ost A, Biberfeld P. (1983). A clinicopathological and immunological study of unfavourable non-Hodgkins lymphoma. Acta Pathol Microbiol Immunol Scand. (A) . 91: 435-443. 
Ling NR, MacLennan ICM, Mason DY. (1987). Analysis of the B-cell and plasma cell panels. In Leucocyte Typing III (eds McMichael AJ et al) pp 302-355. Oxford University Press, oxford.

Ling NR. (1988). The relationship of B lymphocyte surface marker to cell differentiation. In B lymphocytes in human disease. (eds Bird G, Calvert JE) pp 174-192. Oxford University Press, oxford.

Lortan JE, Roobottom CA, Oldfield S, MacLennan ICM. (1987). Newly produced virgin B cells migrate to secondary lymphoid organs but their capacity to entefollicles is restricted. Eur J Immunol. 7: 1311-1316.

Lukes RJ, Collins RD. (1974). Immunologic characterisation of malignant lymphomas. Cancer $\underline{34}$ (4 suppl): 14881503 .

Lukes RJ, Taylor CR, Parker JW, Lincoln TC, Pattengale PK, Tindle BH. (1978). A morphologic and immunologic surface marker study of 299 cases of non-Hodgkin's lymphomas and related leukaemias. Am J Pathol 90: 461-486.

MacLennan ICM, Gray DW. (1986). Antigen-driven selection of virgin and memory B cells. Immunol Rev. 91: 61-85

MacLennan ICM, Gray K, Kumararatne DS, Bazin H. (1982). The lymphocytes of splenic marginal zones:a distinct $B$ cell lineage. Immunol Today. $\underline{3}$ : 305-307.

MacLennan ICM, Bazin H, Chassoux D, Gray D, Lortan J. (1985). Comparative analysis of the development of $B$ cells in marginal zones and follicles. Adv Exp Biol Med. 186: $139-145$. 
Martin PJ, Hansen JA, Nowinski RC, Brown MA. (1980). A new human $T$ cell differentiation antigen. Unexpected expression on chronic lymphocytic leukaemia cells. Immunogenetics 11: 429-438.

Marujama S, Kubagawa K, Cooper MD. (1983). Activation of human B cells and inhibition of their terminal differentiation by monoclonal anti-mu antibodies. J Immunol. 135: 192-199

Mason DY, Ladyman H, Gatter KC. (1986) Immunohistochemical analysis of monoclonal anti-B cell antibodies. In Leucocyte Typing II. (eds Reinherz EL, Haynes BF, Nadler LM, Bernstein ID) Vol 2. Human B lymphocytes. pp 245255, Springer Verlag, New York.

Mason DY, Stein H, Gerdes J, Pulford KAF, Ralfkaier E, Falini B, et al. (1987). Value of monoclonal antiCD22 (p135) antibodies for the detection of normal and neoplastic B lymphoid cells. Blood 69: 836-840.

Mathe G, Rappaport H, O'Connor GT, Torloni H. (1976). Histological and cytological typing of neoplastic disease of haemopoietic and lymphoid tissues. World Health organisation, Geneva. International histological classification of tumours, No 14 .

Mccormack RT, Nelson RD, LeBien TW. (1986). Structure/function studies of of the common acute lymphoblastic leukaemia antigen (CALLA/CD10)expressed on human neutrophils. J Immunol 137: 1075-1082.

McKenzie IFC, Zola H. (1983). Monoclonal antibodies to B cells. Immunol Today. $\underline{4}:$ 10-15.

McMichael AJ, Beverley PCL, Cobbold S, et al (Eds) (1987) Leucocyte Typing III. Oxford University Press, oxford. 
Meeker TC, Miller RA, Link MP, Bindl J, Warnke R, Levy R. (1984). A unique human B lymphocyte antigen defined by a monoclonal antibody. Hybridoma $\underline{3}$ : 305-309.

Mehta SR, Conrad D, Sandler R, Morgan J, Montagna R, Maizel AL. (1985). Purification of human B cell growth factor. J Immunol. 135: 3298-3302.

Melchers F, Anderson J.(1986). Factors controlling the B cell cycle. Annu Rev Immunol 4: 13-36.

Melchers F, Erdei A, Schultz T, Dierich MP. (1985). Growth control of activated, synchronized murine B cells by the c3d fragment of human complement. Nature 137: 264266 .

Mendolsohn J, Trowbridge IS, Castagnola T. (1983). Inhibition of human lymphocyte proliferation by monoclonal antibody to transferrin receptor. Blood 92: 821-826.

Metzgar RS, Borowitz MJ, Jones NH, Dowell BL. (1981). Distribution of common acute lymphoblastic leukaemia antigen in non-haematopoietic tissues. J Exp Med 154: 1249-1254.

Miller RA, Gralow J. (1984). The induction of leu-1 antigen expression in human malignant and normal B cellsby phorbol myristate acetate (PMA). J Immunol. 133: 34083414 .

Mingari MC, Gerosa F, Moretta A, Zubler RH, Moretta L. (1985) . B cell growth factor activity of immunoaffinitypurified and recombinant human interleukin 2. Eur $\mathrm{J}$ Immunol. 15: 193-196.

Mittler RS, Talle MA, Carpenter K, Rao PE, Goldstein G. 
(1983) Generation and characterisation of monoclonal antibodies reactive with human B lymphocytes. J Immunol. 131: 1754-1761.

Mittler R, Rao P, olini G, et al. (1985). Activated human B cells display a functional IL2 receptor. J Immunol. 134: 2393-2400.

Mittler RS, Greenfield RS, Shacter BZ, Richard NF, Hoffman AK. (1987). Antibodies to the common leucocyte antigen (T200) inhibit an early phase in the activation of human B cells. J Immunol. 138 3159-3166.

Miyawaki T, Ohzeki S, Ikuta N, Seki H, Taga K, Taniguchi N. (1984). Immunohistologic localization and immune phenotypes of lymphocytes expressing Tac antigen in human lymphoid tissues. J Immunol. 133: 2996-3000.

Moldenhauer G, Schwartz R, Dorkan B, Hammerling GJ. (1987). Biochemical characterisation and eputope analysis of B-lymphocyte specific surface antigens defined by clustering workshop monoclonal antibodies. In Leucocyte Typing III. (eds McMichael AJ et al) pp 378-382. Oxford University Press, oxford.

Morgan DR, Williamson JMS, Quirke P, et al. (1986). DNA content and prognosis of non-Hodgkin's lymphoma. Br. J. Cancer 54: 643-649.

Mori N, oka K, Kojima M. (1988). Immunohistochemical study of mantle zone lymphoma. Am J Clin Pathol. 90: 143148 .

Morris HB, Mason DY, stein H, Lennert K. (1983). An immunohistological study of reactive lymphoid tissue. Histopathology. ㄱ: 809-823. 
Munroe JG, Cambier JC. (1983). B cell activation.II. Recepter cross linking by thymus independant and thymus dependant antigens induces a rapid decrease in the plasma membrane potential of antigen binding B lymphocytes. J Immunol. 131: 2641-2649.

Muraguchi A, Kishimoto T, Niki Y, et al. (1981). T-cellreplacing-factor-(TRF) induced IgG secretion in a human $B$ blastoid cell line and demonstration of acceptors for TRF. J Immunol 127: 412-416.

Muraguchi A, Kehrl J, Fauchi AS. (1985a). Activation, proliferation and differentiation of human B lymphocytes. Lymphokines 10: 33-56.

Muraguchi A, Kehrl JH, Longo DL, Volkmann DJ, Smith KA, Fauchi AS. (1985b). Interleukin 2 receptors on human $B$ cells. Implications for the role of interleukin 2 in human B cell function. J Exp Med. 161: 181-197.

Murray LJ, Swerdlow SH, Habeshaw JA. (1984). Distribution of B lymphocyte subsets in normal lymphoid tissue. Clin Exp Immunol. 56: 399-406.

Nadler LM, Stashenko P, Ritz J, Hardy R, Pesando JM, Schossman SF. (1981). A unique cell surface antigen identifying lymphoid malignancies of $\mathrm{B}$ cell origin. J clin Invest. 67: 134-140.

Nadler LM, Anderson KC, Marti G, Bates M, Park E, Daley JF, et al. (1983). B4 a human B lymphocyte-associated antigen expressed on normal, mitogen-activated and malignant B lymphocytes. J Immunol 131: 244-250.

Nadler LM. (1986). B cell/leukaemia workshop panel. Summary and comments. In Leucocyte Typing II. (Eds Reinherz EL, Haynes BF, Nadler LM, Bernstein ID), Vol 2 , 
Human B Lymphocytes, pp1-43. Springer Verlag, New York.

Nakagawa T, Hirano T, Nakagawa N, Yoshizaki K, Kishimoto T. (1985). Effect of recombinant IL2 and IFN on proliferation and differentiation of human B cells. J Immunol. 134: 959-964.

Nash JRG. (1986). An immunohistochemical study of nonHodgkin's lymphomas: correlation of morphological appearances and immunophenotype in 148 cases. Histopathology 10: 793-813.

Nathwani BN, Winberg CD. (1983). Non-Hodgkin's lymphomas: an appraisal of the "Working Formulation" of nonHodgkin's lymphomas for clinical usage. In Malignant lymphomas: A pathology monograph. (eds Sommers SC, Rosen PP.) ppl-64. Appleton-Century Crofts, Norwalk Connecticut.

Neckers LM, Yenokida G, Trepel JB, Impford E, James S. (1985). Transferrin receptor induction is required for human B-lymphocyte activation but not immunoglobulin secretion. J Cell Biochem 27: 377-389.

Nemerow GR, MCNaughton ME, Cooper NR. (1985). Binding of monoclonal antibody to the Epstein -Barr virus (EBV)/CR2 receptor induces activation and differentiation of human B lymphocytes. J Immunol 135: 3068-3073.

Newman RA, Sutherland R, Greaves MF. (1981). The biochemical characterisation of a cell surface antigen associated with acute lymphoblastic leukaemia and lymphocyte precursors. J Immunol 126: 2024-2030.

Newman R, Schneider G, Sutherland R, Vodinelich L, Greaves M. (1982). The transferrin receptor. Trends Biochem Sci 7: 397-400. 
Ng CS, Chan JK. (1987). Monocytoid B-cell lymphoma Hum.Pathol 18: 1069-1071.

Niewenhaus P, Keuning FJ. (1974) Germinal centres and the origin of the B cell system. II. Germinal centres in the rabbit spleen and popliteal lymph nodes. Immunology. 26 509-516.

Niewenhaus P, Ford WL. (1976). Comparitive migration of $\mathrm{T}$ and $B$ cells in the rat spleen and lymph nodes. Cell Immunol 23: 254-267.

Norton AJ, Isaacson PG. (1989). Lymphoma phenotyping in formalin-fixed and paraffin wax-embedded tissues. I. Range of antibodies and staining patterns. Histopath. 14: 437-446.

O'Garra A, Umland S, De France T, Christiansen J. (1988). 'B-cell factors' are pleiotropic. Immunol Today. 9 : 4553.

opettgen HC, Bayard PJ, Ewijk WV, Nadler LM, Terhorst CP. (1983). Further biochemical studies of the human B-cell differentation antigens B1 and B2. Hybridoma. $\underline{2}$ : 17-28.

Opelstelten D, Osmond DG. (1985). Regulation of pre-B cell proliferation in the bone marrow: immunofluorescence stathmokinetic studies of cytoplasmic mu chain bearing cells in anti-IgM-treated mice, hematologically deficient mutant mice and mice given sheep red blood cells. Eur J Immunol 15: 599-605.

Oudemans PB, Brutel de la Riviere G, Hart GA, van-Heerde P, Scholte G, Vroom TM. (1986). Determination of transferrin receptors on frozen sections of malignant B-cell lymphomas by immunofluorescence with a monoclonal anti- 
body. Cancer 58: 1252-1259.

Pallesen G, Beverley PC, Lane EB, Madsen M, Mason DY, Stein H. (1984). Nature of non-B, non-T lymphomas: an immunohistological study on frozen tissues using monoclonal antibodies. J Clin Pathol. 37: 911-918.

Palleson G, Hager H. (1987). An immunohistological approach to the characterisation of monoclonal antibodies in the activation antigen associated panel. In Leucocyte Typing III (eds McMichael AJ et al) pp368-570. Oxford University Press, oxford.

Parrot DMV. (1976). The gut as a lymphoid organ. Clin Gastroenterol. $\underline{5}$ 211-228.

Paul WE, Ohara J. (1987). B-cell stimulatory factor1/interleukin 4. Annu Rev Immunol. $\underline{5}$ : 429-459.

Pawelec OP, Shaw S, Ziegler A, Muller C, wernet P. (1982). Differential inhibition of HLA-D- or SB-directed secondary lymphoproliferative responses with monoclonal antibodies detecting human Ia-like determinants. J Immunol 129: 1070-1075.

Pesando JM, Ritz J, Levine H, Terhorst C, Lazurus H, Schlossman SF. (1980). Human leukaemia associated antigen: relation to a family of surface glycoproteins. J Immunol. 124: 2794-2799.

Pezzutto A, Dorken B, Feller A, et al. (1986). HD37 monoclonal antibody: a useful reagent for further characterization of "non-T, non-B" lymphoid malignancies. In Leucocyte Typing II. (Eds Reinherz et al) Vol 2. Human B Lymphocytes, pp391-402. Springer, New York. 
Pezzutto A, Dorken B, Rabinovitch PS, Ledbetter JA, Moldenhauer G, Clark EA. (1987a). CD19 monoclonal antibody HD37 inhibits anti-immunoglobulin induced B cell activation and proliferation. J Immunol 138: 2793-2799.

Pezzutto A, Dorken B, Rabinovitch PS, Ledbetter JA, Moldenhauer G, Clark EA. (1987b). CD19 monoclonal antibodies inhibit B-cell activation and proliferation. In Leucocyte Typing III (Eds AJ McMichael et al), pp358-361, oxford University Press, oxford.

Pezzutto A, Dorken B, Moldenhauer G, Clark EA. (1987C). Amplification of human $B$ cell activation by a monoclonal antibody to the B cell specific antigen CD22, Bp 130/140. J Immunol. 138: 98-103.

Pezzutto A, Rabinovitch PS, Dorken B, Moldenhauer G, Clark, EA. (1988). Role of the CD22 human B cell antigen in $B$ cell triggering by anti-immunoglobulin. J Immunol. 140: 1791-1795.

Pileri S, Gobbi M, Rivano MT, Martinelli G. (1984). Immunohistological study of transferrin receptor expression in non-Hodgkin's lymphoma. Br J Haematol 58: 501508 .

Pileri S, Gerdes J, Rivano M, et al. (1987). Immunohistochemical determination of growth fractions in human permanent cell lines and lymphoid tumours: a critical comparison of the monoclonal antibodies OKT9 and Ki-67 Br J Haematol. $\underline{65}$ : 271-276.

Pinkus GS, Said JW. (1978). Characterisation of nonHodgkin's lymphomas using multiple cell markers. Immunologic, morphologic and cytochemical studies of 72 cass. Am J Pathol 90: 461-486. 
Portlock CS. (1983). Good risk non-Hodgkins lymphomas: Approaches to management. Sem Hematol 20: 25-34.

Rabinovitch PS, Clark EA, Pezutto A, Ledbetter JA, Draves KE. (1987). Modulation of human B-cell activation with workshop monoclonal antibodies to the B-cell-associated differentation antigens. In Leucocyte Typing III. (Eds McMichael AJ et al), pp435-439, Oxford University Press, oxford.

Raff MC. (1969). Theta isoantigen as a marker of thymusderived lymphocytes in mice. Nature 224: 378-379.

Raff MC, Sternberg M, Taylor RB. (1970). Immunoglobulin determinants on the surface of mouse lymphoid cells. Nature 225: 50-51.

Raff MC, Megson M, Owen JTT, Cooper MD. (1976). Early production of intracellular IgM by B lymphocyte precursors in the mouse. Nature. 259: 224-226.

Rappaport H. (1966). Tumors of the hemopoietic system. Atlas of Tumour Pathology. Armed Forces Institute of Pathology. Fasc 8 , sec 3 .

Reinherz EL, Schlossman SF. (1980). The differentiation and function of human T lymphocytes. Cell 19: 821-827.

Reinherz EL, Kung PC, Goldstein G, Levy RH, Schlossman SF. (1980). Discrete stages of human intrathymus differentiation: analysis of normal thymocytes and leukaemic lymphoblasts of $\mathrm{T}$ lineage. Proc Natl Acad Sci USA. 77: 1588-1592.

Reinherz EL, Waynes BF, Nadler LM, Bernstein ID. (1986) Leucocyte Typing II. Vol 2. Human B lymphocytes. Springer-Verlag: New York. 
Ritz J, Pesando M, Notis-McConarty J, Lazarus H, Schlossman SF. (1980). A monoclonal antibody to human acute lymphoblastic leukaemia antigen. 283: 583-585

Ritz J, Nadler LM, Bhan AK, Notis-McConarty J, Pesando JM, Schlossman SF. (1981). Expression of common acute lymphoblastic leukaemia antigen (CALLA) by lymphomas of $B$ cells and $\mathrm{T}$ cell lineage. Blood $\underline{58}$ : 648-652.

Roos G, Dige U, Lenner P, Lindh H, Johanson H. (1985). Prognostic importance of DNA analysis by flow cytometry in non-Hodgkin's lymphoma. Hem oncol $\underline{3}$ : 233-242.

Rosenberg SA. (1982). National Cancer Institute sponsered study of classifications of non-Hodgkin's lymphomas: summary and a working formulation for clinical usage. Cancer $\underline{49}$ : 2112-2135.

Rowe M, Hildreth JEK, Rickman AB, Epstein MA. (1982). Monoclonal antibodies to Epstein-Barr virus-induced transformation-associated cell surface antigens. Binding patterns and effects upon virus specific T-cell cytotoxicity. Int $\mathrm{J}$ Cancer 15: 373-381.

Royston J, Jarida JA, Baird SM. (1980). Human T cell antigens defined by monoclonal antibodies to the 65,000dalton antigen of $\mathrm{T}$ cells (T65) is also found on chronic lymphocytic leukaemia cells bearing surface immunoglobulin. J Immunol. 125: 725-731.

Salter DM, Krajewski AS, Dewar AE. (1985). Immunohistochemical staining of non-Hodgkin's lymphoma with monoclonal antibodies specific for the leucocyte common antigen. J Pathol.146: 345-353.

Schuurman HJ, van-Baarlen J, Huppes W, Lam BW, Verdonck 
LF, van-Unnik, JA. (1987) Immunophenotyping of nonHodgkin's lymphoma: lack of correlation between immunophenotype and cell morphology. Am J Pathol 129:140-151.

Schuurman HJ, Huppes W, Verdonck LF, Van-Baarlen J, VanUnnik JA. (1988). Immunophenotyping of non-Hodgkin's lymphoma: Correlation with relapse-free survival. Am J Pathol. 131: 102-111.

Schwab U, Stein H, Gerdes J, et al. (1982) Production of a monoclonal antibody specific for Hodgkin and SternbergReed cells of Hodgkin's disease and a subset of normal lymphoid cells. Nature 299: 65-67.

Schwartz R, Moldenhauer G, Dorken B, Pezuuto A, Momberg F, Schirrmacher V. (1986). TPA-induced modulation of $B$ cell differentiation antigens defined by monoclonal antibodies (HD6, HD28, HD37, HD39). In Leucocyte Typing II (Eds Reinherz EL et al), Vol 2, Human B lymphocytes. pp527-540, Springer-Verlag, New York.

Scribner DJ, Weiner HL, Moorhead JW. (1978). Anti-Ig stimulation of murine lymphocytes. V. Age related decline in FC receptor-mediated immunoregulation. J Immunol. 121: $377-382$.

Seehafer J, Longenecker BM, Shaw ARE. (1984). Human tumour cell membrane glycoprotein associated with protein kinase activity. Int $\mathrm{J}$ Cancer $\underline{34}$ : 815-819.

Shaw ARE, Chan JKW, Reid C, Seehafer J. (1985). HLA-DR synthesis induction and expression in HLA-DR negative carcinoma cell lines of diverse origin by interferon gamma but not interferon beta. J Natl Cancer Inst. 14 : 1261-1268.

Sheibani K, Fritz RM, Winberg CD, Burke JS, Rappaport H. 
(1985). "Monocytoid" cells in reactive follicular hyperplasia with and without multifocal histiocytic reactions: an immunohistochemical study of 21 cases including suspected cases of toxoplasmic lymphadenitis. Am J Clin. Pathol 81: 453-458.

Sheibani K, Winberg CD, van-de Velde S, Blayney DW, Rappaport H. (1987). Distribution of lymphocytes with interleukin-2 receptors (TAC antigens) in reactive lymphoproliferative processes, Hodgkin's disease, and nonHodgkin's lymphomas. An immunohistologic study of 300 cases. Am J Pathol. 127: 27-37.

Shepherd NA, Hall PA, Coates PJ, Levison DA. (1988) primary colorectal lymphoma: a histopathological and immunohistochlemical study with clinical correlation. Histopathology 12: 235-252.

Siden E, Alt FW, Shinefeld L, Sato V, Baltimore D. (1981). Synthesis of immunoglobulin mu chain products precedes synthesis of light chains during B cell development. Proc Natl Acad Sci USA. 78: 1823-1827.

Smeland EB, Godal T, Rudd E, et al. (1985). The specific induction of myc protooncogene expression in normal human B cells is not a sufficient event for acquisition of competance to proliferate. Proc Natl Acad Sci USA 82 : 6255-6259.

Smeland EB, Beiske K, Ohlsson R, et al (1987). Activation of human B cells: Alternate options for initial triggering and effects of non-mitogenic anti-IgM antibodies on resting and activated cells. J Immunol. 138: 3179-3184.

Smith KA. (1987). The two chain structure of high affinity IL-2 receptors. Immunol Today. $\underline{8}$ : 11-13. 
Smith KA. (1989). The bimolecular structure of the interleukin 2 receptor. Immunol Today. $\underline{9}$ : 36-37.

Smith MEF, Holgate CS, Williamson JMS, Grigor I, Quirke P, Bird CC. (1987). Major histocompatibility complex class II antigen expression in $\mathrm{B}$ and $\mathrm{T}$ cell non-Hodgkin's lymphoma. J Clin Pathol 40: 34-41.

Spencer J, Finn T, Isaacson PG. (1985). Gut associated lymphoid tissue: a morphological and immunocytochemical study of the human appendix. Gut. $\underline{26}$ : 672-679.

Spencer $J$, Finn T, Pulford KAF, Mason DY, Isaacson PG. (1986). The human gut contains a novel population of $B$ lymphocytes which resemble marginal zone cells. Clin Exp Immunol. 62: 607-612.

Stamenkovic I, seed B. (1988a). Analysis of two CDNA clones encoding the B lymphocyte antigen CD20 (B1, Bp35), a type III integral membrane protein. J Exp Med 167: 1975-1981.

Stamenkovic I, seed B. (1988b) . CD19, the earliest differentiation antigen of the B cell lineage, bears three extracellular immunoglobulin-like domains and an EpsteinBarr virus-related cytoplasmic tail. J Exp Med. 168: 1205-1210.

Stansfeld AG, Diebold J, Noel H, et al. (1988). Updated Kiel Classification for lymphomas. Lancet $\underline{i}$ : 292-293.

Stanton T, Stevens TL, Ledbetter JA, Wofsy D. (1986). Anti-Ly-1 antibody induces interleukin release from $T$ cells. J Immunol. 136: 1734-1737.

Stashenko P, Nadler LM, Hardy R, Schlossman SF. (1980). Characterization of a human B lymphocyte-specific anti- 
gen. J Immunol 125: 1678-1685.

Stashenko P, Nadler LM, Hardy R, Schlossman SF.(1981). Expression of cell surface markers after human B cell activation. Proc Natl Acad Sci. USA. $\underline{78}$ : 3848-3852.

Stein H, Lennert K, Parwaresch MR. (1972). Malignant lymphomas of B cell type. Lancet ii: 855-857.

Stein H, Kaiserling E, Lennert K. (1974). Evidence for Bcell origin of reticulum cell sarcoma. Virchows Archives (A). 51: 51-67.

Stein H, Bonk A, Tolksdorf G, Lennert K, Rodt H, Gerdes J. (1980). Immunohistologic analysis of the organisation of normal lymphoid tissue and non-Hodgkin's lymphomas. J Histochem Cytochem. 28: 746-760.

Stein H, Gerdes J, Mason DY. (1982). The normal and malignant germinal centre. Clin Haematol. 11: 531-559.

Stein H, Lennert K, Feller A, Mason DY. (1984). Immunohistological analysis of human lymphoma: Correlation of histological and immunological categories. Adv Cancer Res. 62 : 67-147.

Stein M, Mason DY, Gerdes et al. (1985). The expression of the Hodgkin's disease associated antigen Kil in reactive and neoplastic lymphoid tissue. Evidence that Reed-sternberg cells and histocytic malignancies are derived from activated lymphoid cells. Blood 66: 848858 .

Strauchen JA, Breakstone BA. (1987). IL-2 receptor expression in human lymphoid lesions. Immunohistochemical study of 166 cases. Am J Pathol. 126: 506-512. 
Stuart AE, Habeshaw JA. (1976). Receptor studies on 19 cases of non-Hodgkin's malignant lymphocytic lymphoma. Acta Haematol. 55:160-168.

Sutherland R, Delia D, Schneider C, Newman R, Kemsheed J, Greaves M. (1981). Ubiquitous cell surface glycoprotein on tumour cells is proliferation associated receptor for transferrin. Proc Natl Acad Sci. USA. 78: 4515-4519.

Suzuki T, Butler JL, Cooper MD. (1985). Human B cell responsiveness to $\mathrm{B}$ cell growth factor after activation by phorbol ester and monoclonal anti-mu antibody. J Immu nol. 134: 3111-3119.

Swendeman SL, Thorley-Lawson D. (1987). The activation antigen BLAST2 when shed is an autocrine BCGF for normal and transformed B cells. ЕMBO J. $\underline{6}$ : 1637-1642.

Swendeman SL, Thorley-Lawson D. (1988). Soluble CD23/BLAST-2 (S-CD23/Blast-2) and its role in B cell proliferation. Curr Top Microbiol Immunol. 141: 157-164.

Swerdlow SH, Habeshaw JA, Murray LJ, Dhaliwal HS, Lister TA, Stansfeld AG. (1983). Centrocytic lymphoma: a distinct clinicopathologic and immunologic entity. A multiparameter study of 18 cases of diagnosis and relapse. Am J Pathol 113: 181-197.

Swerdlow SH, Murray LJ, Habeshaw JA, Stansfeld AG. (1984). Lymphocytic lymphoma/B-chronic lymphocytic leukaemia - An immunohistopathological study of peripheral B lymphocyte neoplasia. Br J Cancer. 50: 587-599.

Swerdlow SH, Murray LJ, Habeshaw JA, Stansfeld AG. (1985). B- and T-cell subsets in follicular centroblastic/centrocytic (cleaved follicular center cell) lymphoma: an immunohistologic analysis of 26 lymph nodes and 
three spleens. Hum Pathol.16: 339-352.

Taniguchi O, Miyajima H, Hirano T, et al. (1987). The Leu-1 B-cell subpopulation in patients with rheumatoid arthritis. J Clin Immunol. 7: 441-448.

Tedder TF, Clement LT, Cooper MD. (1984). Expression of C3d receptor during human B cell differentiation: immunofluorescence analysis with the HB-5 monoclonal antibody. J Immunol. 133: 678-683.

Tedder TF, Clement LT, Cooper MD. (1985a). Development and distribution of a human B-cell subpopulation identified by the HB-4 monoclonal antibody. J Immunol. 134: 1539-1544 .

Tedder TF, Boyd AW, Freedman AS, Nadler LM, Schlossman SF. (1985b). The B cell surface molecule Bl is functionally linked with $B$ cell activation and differentiation. J Immunol. 135: 973-979.

Tedder TF, Forsgren A, Boyd AW, Nadler LM, Schlossman SF. (1986a). Antibodies reactive with the B1 molecule inhibit cell progression but not activation of human B lymphocytes. Eur J Immunol. 16: 881-887.

Tedder TF, Goldmacher VS, Lambert JM, Schlossman SF. $(1986 \mathrm{~b})$. Epstein Barr virus binding internalisation of the C3d receptor: A novel immunotoxin delivery system. J Immunol. 137: 1387-1391.

Tedder TF, Schlossman SF. (1988). Phosphorylation of the B1 (CD20) molecule by normal and malignant human B lymphocytes. J Biol. Chem. 263: 10009-10015.

Tedder TF, Disteche CM, Louie E, et al. (1989a). The gene that encodes the human $\mathrm{CD} 20$ (B1) differentiation antigen 
is located on chromosome 11 near the $t(11 ; 14)$ (q13;q32) translocation site. J Immunol. 142: 2555-2559.

Tedder TF, Klejman G, Schlossman SF, Saito H. (1989b). structure of the gene encoding the human B lymphocyte differentiation antigen $\mathrm{CD} 20$ (B1). J Immunol. 142: 25602568 .

Thomas ML, LeFrancois L. (1988). Differential expression of the leucocyte-common family. Immunol Today. 9 : 320326 .

Thomas ML. (1989). The leucocyte common antigen family. Ann Rev Immunol. 7: 339-369.

Thorley-Lawson DA, Mann KP. (1985). Early events in Epstein-Barr virus infection provide a model for B cell activation. J Exp Med. 162: 45-59.

Thorley-Lawson DA, Nadler LM, Bhan AK, Schooley RT. (1985) - B-LAST-2 (EBVCS), an early cell surface marker of human B cell activation is superinduced by Epstein-Barr virus. J Immunol. 134: 3007-3012.

Thorley-Lawson DA, Swendeman SL, Edson CM. (1986). Biochemical analysis suggests distinct functional roles for the Blast-1 and Blast-2 antigens. J Immunol. 136: 17451751 .

Trowbridge IS, Omary MB. (1981). Human cell surface glycoprotein related to cell proliferation is the receptor for transferrin. Proc Natl Acad Sci USA. 78: 30393043 .

Tsudo M, Uchiyama, Uchino H. (1984). Expression of Tac antigen on activated normal human B cells. J Exp Med. 160: 612-617. 
Uchiyama T, Broder S, Waldmann TA. (1981). A monoclonal antibody (anti-Tac) reactive with activated and functionally mature human $T$ cells. I. Production of anti-Tac monoclonal antibody and destination of Tac(+) cells. J Immunol.126: 1393-1397.

Uckun FM, Ledbetter JA. (1988a). Immunologic differences between normal and leukaemic B cells. Proc Natl Acad Sci USA. 85: 8603-8607.

Uckun FM, Jaszez W, Ambrus JL, et al. (1988b). Detailed studies on expression and function of CD19 surface determinant using B43 monoclonal antibody and the clinical potential of anti-CD19 immunotoxins. Blood 71: 13-29.

Valentine MA, Shu G, Gaur L, Ledbetter JA, Clark EA. (1987a). Structure and function of the $B$ cell specific 35-37 kDa CD20 protein. In Leucocyte Typing III (eds McMichael AJ et al) pp440-443, Oxford University Press, oxford.

Valentine MA, cotner T, Gaur L, Torres R, Clark EA. (1987b). Expression of the human B-cell surface protein CD20: alteration by phorbol 12-myristate 13-acetate. Proc Natl Acad Sci USA. 84: 8085-8089.

Valentine MA, clark EA, Shu GL, Norris NA, Ledbetter JA. (1988). Antibody to a novel 95-kDa surface glycoprotein on human B cells induces calcium mobilization and B cell activation. J Immunol. 140: 4071-4078.

van-Baarlen J, Schuurman HJ, van-Unnik JA. (1988). Multilobated non-Hodgkin's lymphoma. A clinicopathologic entity. Cancer. 61: 1371-1376.

van-den Oord-JJ, De-Wolf Peeters-C, Pulford KA, Mason DY, 
Desmet VJ. (1986). Mantle zone lymphoma. Immuno- and enzymehistochemical studies on the cell of origin. Am J Surg Pathol. 10: 780-788.

Van-der Valk-P, Meijer CJ. (1988). The non-Hodgkin's lymphomas: old and new thinking. Histopathology. 13: 367384 .

Van Krieken JHJM, te-Velde J. (1988). Normal histology of the spleen. Am J Surg Path. 12:777-785.

Waldmann TA, Goldman CK, Robb RJ, et al. (1984). Expression of interleukin-2 receptors on activated human $B$ cells. J Exp Med. 160: 1450-1466.

Walker L, Guy G, Brown G, Rowe M, Milner AE, Gordon GJ. (1986). Control of human B lymphocyte replication. I. Characterisation of novel activation states that precede entry of GO B cells into cycle. Immunology 58: 583-590.

Walker L, Gordon J. (1987). A detailed kinetic study oo the appearance of surface antigens defined by the workshop activation panel following stimulation of purified GO B lymphocytes. In Leucocyte Typing III. (eds McMichael AJ et al) pp 555-557. Oxford University Press, Oxford.

Warnke RA, Strauchen JA, Burke JS et al. (1982). Morphologic types of diffuse large cell lymphoma. Cancer 50 : 690-695.

Watson AJ, Demars R, Trowbridge IS, Bach FH. (1983). Detection of a novel class II antigen. Nature 304: 358361 .

Weisenburger DD. (1984). Mantle-zone lymphoma. An immunohistologic study. Cancer. 53: 1073-1080. 
Weissman IL, Warnke RA, Butcher EL, Rouse R, Levy R. (1978). The lymphoid system. Its architecture and the potential for understanding the system through the study of lymphoproliferative disease. Hum Pathol. $\underline{9}$ : 25-45.

Weiss LM, Strickler JG, Medeiros LJ, Gerdes J, stein H, Warnke RA. (1987). Proliferative rates of non-Hodgkin's lymphomas as assessed by Ki-67 antibody. Hum Pathol. 18: 1155-1159.

Weiss JJ, Tedder TF, Fearon DT. (1984). Identification of a 145,000 Mr membrane protein as the C3d receptor (CR2) on human B lymphocytes. Proc Natl Acad Sci USA. 81:881885.

Weiss RL, Kjeldsberg CR, Colby TV, Marty J. (1985). Multilobated B cell lymphomas. A study of 7 cases. Hematol oncol. $\underline{3}: 79-86$.

Williamson JMS, Grigor I, Smith MEF et al. (1986). cluster differentiation antigen expression, proliferative activity and clinical stage in centroblastic lymphomas. J Pathol 150, 51-59.

Williamson JM, Grigor I, Smith ME, et al. (1987). Ploidy, proliferative activity, cluster differentiation antigen expression and clinical remission in high-grade nonHodgkin's lymphoma. Histopathology. 11: 1043-1054.

Wilson BS, Platt JL, Kay NE. (1985). Monoclonal antibodies to the $140,000 \mathrm{~mol}$.wt. glycoprotein of B lymphocyte membranes (CR2 receptor) initiates proliferation of B cells in vitro. Blood. 66: 824-829.

Yokota T, otsuka T, Mosmann T, et al. (1986). Isolation and characterisation of a human interleukin cDNA clone, homologous to mouse B cell stimulatory factor 1 that 
expresses $\mathrm{B}-\mathrm{cell}$ and $\mathrm{T}$-cell- stimulating activities. Proc Natl Acad Sci USA. $\underline{83}$ : 5849-

Yunis JJ, Mayer MG, Arneson MA, Aeppi DP, Oken MM,Frizzera G. (1989) $\cdot$ bcl-2 and other genetic alterations in the prognosis of large cell lymphomas. N Engl J Med. 320: 1047-54.

Zipf TF, Lauzon GJ, Longenecker BM. (1983). A monoclonal antibody detecting a 39000 MWmolecule that is present on B lymphocytes and chronic lymphatic leukaemia cells but rare on acute lymphocytic leukaemia cells. J Immunol 131: 3064-3072.

Zipf TF, Antoun GR, Lauzon GJ, Longenecker BM. (1986). A monoclonal antibody detecting a 39,000 m.w. molecule that is present on B lymphocytes and chronic lymphatic leukaemia cells but is rare on acute lymphocytic leukaemia blasts. In Leucocyte Typing II. (eds Reinherz et al). Vol 2. B lymphocytes. pp 203-211. Springer, New York.

Zola H, McNamara PJ, Moore HA, smart IJ, Brooks DA, Beckman IGR et al . (1983). Maturation of human B lymphocytes-studies with a panel of monoclonal antibodies against membrane antigens. Clin exp. Immunol. 52: 655664 .

Zola H. (1987). The surface antigens of human B lymphocytes. Immunol Today $\underline{8}$ : 308-305. 


\section{APPENDIX}

Part of this work has already been published as the following papers:-

1) Salter DM, Krajewski AS, Cunningham S. (1988). Activation and differentiation antigen expression by B-cell non-Hodgkin's lymphoma. J Pathol 154:209-222.

2) Salter DM, Krajewski AS, Sheehan T, Turner G, Cuthbert RJG, McLean A. (1989). Prognostic significance of activation and differentiation antigen expression in B-cell non-Hodgkin's lymphoma. J Pathol. 159: 211-220. 
JOURNAL OF PATHOLOGY, VOL. 154: 209-222 (1988)

\section{ACTIVATION AND DIFFERENTIATION ANTIGEN EXPRESSION IN B-CELL NON-HODGKIN'S LYMPHOMA}

DONALD M. SALTER, ANDREW S. KRAJEWSKI AND SCOTT CUNNINGHAM

Department of Pathology, University Medical School, Teviot Place, Edinburgh EH8 9AG, U.K.

Received 21 April 1987

Accepted 20 July 1987

\section{SUMMARY}

In an attempt to establish whether extended immuno-phenotyping allows more accurate definition of subgroups of B-cell non-Hodgkin's lymphoma (NHL) we have stained a series of 145 cases with a large panel of monoclonal antibodies that recognize B-cell differentiation and activation antigens. No antigen was expressed by all cases. The Bcell histogenesis in many cases could be confirmed only by using a panel of immunoglobulin and pan B-cell markers. There was marked phenotypic heterogeneity within and between major groups of B-cell NHL as delineated by the Kiel classification although the differentiation antigens CD5 (lymphocytic and centrocytic NHL) and OKT10 (plasma cell tumours) were more often expressed by certain morphological groups. The activation antigens 4F2 and transferrin receptor were expressed more strongly and more often by high grade NHL but other activation antigens (CD23 and CD25) were not more frequently associated with these tumours. Extended phenotyping may be of value in improving the understanding of biological abnormalities and processes involved in B-cell NHL, but we conclude that a limited panel of markers (CD3, CD5, CD22, CD45, IgM, kappa, and lambda) should be sufficient for routine diagnosis and classification of most cases.

KEY WORDS-B-Cell non-Hodgkin's lymphoma, activation antigens, differentiation antigens, monoclonal antibodies.

\section{INTRODUCTION}

Non-Hodgkin's lymphomas (NHL) are believed to result from proliferation and accumulation of lymphoid cells at different stages of differentiation. Currently used classifications of NHL, such as the Kiel classification, are based on the belief that the morphology and immunophenotypes of NHL correspond to normal cells at varying stages of differentiation and activation ranging from lymphoid precursor cells to terminally differentiated $\mathrm{T}$ or B cells, e.g., lymphoblastic NHL-immature pre-B/thymic $\mathrm{T}$ cells; centroblastic/centrocytic NHL - follicle centre cells; immunoblastic NHL and plasmacytoma - terminally differentiated cells. Previous studies have shown some correlation between antigen expression and certain morphological features of B-cell $\mathrm{NHL}^{1-4}$ but only a relatively limited number of anti-B-cell monoclonal

Addressee for correspondence: Dr D. M. Salter, University Medical School, Edinburgh EH8 9AG, U.K. antibodies (MCA) were used. A large number of MCA which react with $\mathrm{B}$-cell associated antigens expressed at different stages of differentiation and activation have now been identified ${ }^{5}$ and it is possible that the differential expression of such antigens may allow a more accurate definition of the subtypes of NHL within morphologically similar groups. We report here the results of a study in which we have investigated this possibility.

\section{MATERIALS AND METHODS}

The cases described in this study include all cases of B-cell NHL diagnosed in the Immunopathology Laboratory, Edinburgh University Pathology Department during the period August 1984 to December 1986 and all cases of B-cell NHL diagnosed during the period July 1982 to July 1984 in which tissue blocks had been stored at $-70^{\circ} \mathrm{C}$.

Tissue was received fresh from the operating theatre. Representative portions were taken for 
Table I-Antibodies used in this study

\begin{tabular}{|c|c|c|c|}
\hline Antibody & $\begin{array}{l}\text { Mol. wt of antigen } \\
(\mathrm{kD}) / \mathrm{CD} \text { number }\end{array}$ & Source & Ref. \\
\hline \multicolumn{4}{|l|}{ Anti-immunoglobulin } \\
\hline Anti-kappa & & Dakopatts & \\
\hline Anti kappa-FITC/anti kappa-TRIC & & Kallestad & \\
\hline Anti lambda & & Dakopatts & \\
\hline Anti lambda-FITC/anti lambda-TRIC & & Kallestad & \\
\hline Anti IgM/DA6127/anti IgM-FITC & & Dakopatts/K. Guy/Kallestad & \\
\hline Anti IgD-FITC & & Kallestad & \\
\hline Anti IgD/anti IgG-FITC & & Dakopatts/Kallestad & \\
\hline Anti IgA/anti IgA-FITC & & Dakopatts/Kallestad & \\
\hline \multicolumn{4}{|l|}{ 'Pan' B cell } \\
\hline HD37 & $40 / \mathrm{CD} 19$ & Dakopatts & 7 \\
\hline B1 & $35 / \mathrm{CD} 20$ & Ortho & 8,9 \\
\hline Dako-B & $135 / \mathrm{CD} 22$ & Dakopatts & 10 \\
\hline F8-11-13 & $220 / \mathrm{CD} 45 \mathrm{R}$ & J. Fabre & 6,11 \\
\hline \multicolumn{4}{|l|}{ 'Restricted' B cell } \\
\hline Leu 1 & $65 / \mathrm{CD} 5$ & $\mathrm{BD}$ & 12 \\
\hline FMC8 & 24/CD9 & H. Zola & 13 \\
\hline Dako Calla & $100 / \mathrm{CD} 10$ & Dakopatts & 14 \\
\hline OKT10 & 45/NA & Ortho & 9,15 \\
\hline \multicolumn{4}{|l|}{ 'Activation-associated' } \\
\hline S/RFB6 & $140 / \mathrm{CD} 21$ & SAPU & 16,17 \\
\hline MHM6/101B7 & $45 / \mathrm{CD} 23$ & J. Gordon/Dakopatts & 7,18 \\
\hline Dako-IL2-R & $55 / \mathrm{CD} 25$ & Dakopatts & $19-21$ \\
\hline Dako-Kil & $116,126 / \mathrm{CD} 30$ & Dakopatts & 22,23 \\
\hline OKT9 & 90/NA(Trf-R) & Ortho & 24 \\
\hline $4 \mathrm{~F} 2$ & $40,80 / \mathrm{NA}$ & K. Guy & 25 \\
\hline \multicolumn{4}{|l|}{ MHC class II } \\
\hline L243 & DR & S. Howie (ATCC) & 26 \\
\hline $\mathrm{B} 7 / 21$ & DP & I. S. Trowbridge & 27 \\
\hline Leu 10/Tu22 & DQ & $\mathrm{BD} / \mathrm{A}$. Ziegler & 28,29 \\
\hline
\end{tabular}

$\mathrm{BD}=$ Becton Dickenson, $\mathrm{NA}=$ not allocated, SAPU $=$ Scottish Antibody Production Unit, Trf $-\mathrm{R}=$ transferrin receptor, $\mathrm{ATCC}=$ American Tissue Culture Collection.

cryostat sections and for formalin fixation and paraffin embedding. Cryostat sections were cut at 3-4 $\mu \mathrm{m}$ from either fresh frozen material or blocks stored at $-70^{\circ} \mathrm{C}$. Immunohistochemical staining was by an indirect immunoperoxidase technique as described fully elsewhere. ${ }^{6}$ In some cases, the presence of monoclonal immunoglobulin was also demonstrated by direct immunofluorescence on cryostat section using $\mathrm{F}(\mathrm{ab})_{2}$ conjugated antibodies; kappa-fluorescein isothiocyanate (FITC)/lambdatetraethylrhodamine urothiocyanate (TRIC), kappa-TRIC/lambda-FITC, and immunoglobulin heavy chain FITC.
The B-cell associated antibodies used in this study are shown in Table I. The antigens they recognize can be broadly separated into five main groups: (a) immunoglobulin; (b) 'pan' B-cell antigens which are expressed early in B-cell ontogeny and lost at a pre-plasma cell stage; (c) 'restricted' B-cell antigens which although not lineage-specific are expressed at limited stages of B-cell differentiation; (d) 'activation-associated' antigens; these include antigens, such as CD21, which are present on resting $\mathrm{B}$ cells and lost following activation; the other activation-associated antigens (CD23, 25, 30, transferrin receptor (Trf-R), and $4 \mathrm{~F} 2$ ) are absent 
Table II-Histological type, number and biopsy site of B-cell NHL studied

\begin{tabular}{lrrrrr}
\hline & & & & Site \\
Diagnosis & No. & $\begin{array}{c}\text { Lymph } \\
\text { node }\end{array}$ & Spleen & $\begin{array}{c}\text { GI } \\
\text { tract }\end{array}$ & Other \\
\hline Lymphocytic & 19 & 17 & 1 & - & 1 \\
Lymphoplasmacytoid (immunocytoma) & 2 & 1 & - & - & 1 \\
Prolymphocytic & 4 & 1 & 2 & - & 1 \\
Hairy cell leukaemia & 3 & - & 3 & - & -1 \\
Centrocytic & 12 & 7 & 3 & - & 2 \\
Follicular centroblastic/centrocytic & 39 & 36 & 1 & 2 & 1 \\
Diffuse centroblastic/centrocytic & 11 & 8 & - & 2 & 8 \\
Centroblastic & 32 & 22 & - & 1 & 3 \\
Immunoblastic & 14 & 10 & - & - & 4 \\
Plasmacytic (plasmacytoma) & 7 & 3 & - & - & 1 \\
Lymphoblastic & 2 & - & 1 & 6 & 23 \\
Total & 145 & 105 & 11 & & 1 \\
\hline
\end{tabular}

from resting cells but their expression can be induced following stimulation of B cells by antiimmunoglobulin or mitogens; and (e) major histocompatibility complex (MHC) class II antigens. In addition, all cases were stained with and (apart from reactive T cells) found to be non-reactive with the pan T-cell anti-CD3 antibody Leu 4 (Becton Dickinson ${ }^{30}$ ).

\section{RESULTS}

A total of 145 B-cell NHL were studied. The numbers in each histological group and anatomical site of biopsy are shown in Table II.

\section{Lymphocytic lymphoma}

Nineteen cases of lymphocytic lymphoma were studied (Fig. 1) derived from lymph nodes (17), spleen (1), and breast (1). All cases expressed monotypic immunoglobulin: 17 expressed IgM with coexpression of $\mathrm{IgD}$ in eight and $\mathrm{IgG}$ in one; one case expressed IgG alone and one monotypic kappa light chain without heavy chains. The pan B-cell markers CD19, CD22, and CD45R were strongly expressed by all cases. The CD20 marker B1 showed variable and often weak staining between and within cases. All cases tested expressed the CD5 antigen. CD9 was variably expressed in 11 cases. Staining was strongest outside proliferation centres.
There was no staining for CD10 or OKT10. The CD21 antigen (C3d receptor) was expressed by the majority of cells in all cases. Lymphomas which expressed IgMD tended to show stronger reactivity than those expressing $\operatorname{IgM}$ alone. CD23 was expressed by the majority of cells in seven cases and by a minority in one. CD25, the interleukin 2 receptor (IL2-R), was expressed weakly by the majority of cells in eight cases and by a proportion in two others. There was no expression of CD30 in the three cases tested. The transferrin receptor and 4F2 were variably expressed: in some cases both antigens were expressed by the majority of cells while in others only a proportion of cells stained. Expression of both antigens was enhanced in proliferation centres. All cases expressed HLA DR and DP antigens with absent or low DQ expression in a proportion of cases. MHC class II expression was enhanced in proliferation centres.

\section{Lymphoplasmacytic lymphoma (immunocytoma)}

Two cases - one nodal and one soft tissue masswere studied. The nodal case was IgM positive with a phenotype similar to that of small lymphocytic lymphomas expressing CD22, CD45R, and MHC class II antigens but not CD5. The other case was IgGK positive and showed loss of pan B-cell antigens and $\mathrm{CD} 5$ with decreased MHC class II antigen expression. The OKT10 antigen was not expressed by either tumour. 


\section{Prolymphocytic lymphoma}

Four cases were available for study, these being from spleen (2), lymph node (1), and orbit (1). All cases expressed IgM together with $\operatorname{IgD}$ or $\operatorname{IgG}$ in two cases. All cases expressed pan B-cell antigens although expression of CD20 was weak in one. Two cases expressed CD5 strongly, one weakly, and one was negative. None expressed CD9, CD10 (three cases), or the OKT10 antigen. CD21 was expressed strongly by one case and by a minority of cells in the other studied. Neither of the two cases studied expressed CD23, and only $1 / 4$ cases expressed CD25 weakly. The one case tested did not express CD30. Both transferrin receptor and 4F2 were strongly expressed by all four cases. DR and DP were strongly expressed by all four cases, but DQ was expressed by only a proportion of cells in three cases.

\section{Hairy cell leukaemia}

All three cases of hairy cell leukaemia studied were resected spleens. All were kappa positive with one IgMA, one IgMD, and one IgG positive. They expressed the pan B antigens CD19, 20, 22, and 45R but not CD5. One was CD9 positive. Two expressed CD10 weakly in the cytoplasm. None of the cases expressed the OKT10 antigen but one was positive for CD23 and all expressed the CD25 antigen. Neither of the two cases tested expressed CD 30 . Transferrin receptor and $4 \mathrm{~F} 2$ expression were weak or absent in $2 / 3$ cases. DR and DP were strongly expressed by all three cases whereas only two showed DQ expression.

\section{Centrocytic lymphoma}

Twelve cases of centrocytic lymphoma were studied from lymph nodes (7), tonsil (1), spleens (3), and small intestine (1) (Fig. 2). All expressed monotypic $\operatorname{IgM}$, and 5/10 tested coexpressed IgD. Five cases expressed lambda and seven kappa light chains. All cases tested stained strongly for pan B-cell antigens and CD5. CD9 was expressed by a proportion of cells in seven cases. None expressed CD10 and only a proportion of cells in two cases expressed OKT10. All five cases tested were CD21 positive and CD23 negative. Two cases showed weak expression of CD 25 but not CD 30 . Numbers of cells staining with $4 \mathrm{~F} 2$ and transferrin receptor varied between cases. In most cases, staining was weak or restricted to a minority of cells. Although
DR and DP were expressed strongly in all cases, DQ was often absent or weak.

\section{Follicular centroblastic/centrocytic lymphomas}

A total of 39 cases were studied (Fig. 3) from lymph nodes (36), spleen (1), thyroid (1), and breast (1). Twenty-three cases expressed kappa, 14 lambda light chains, and in two cases immunoglobulin staining was negative or equivocal. Thirty cases expressed $\operatorname{IgM}$ with coexpression of $\operatorname{IgD}(3), \mathrm{IgG}$ (1), and IgA (1): six cases expressed IgG alone and one lacked heavy chains but expressed lambda light chain. The majority of cases expressed pan B-cell antigens strongly and were CD5 negative. CD10 $(24 / 36)$ and OK T10 (13/38) were variably expressed. CD9, CD21, and CD23 were also variably expressed, although assessment of their expression was complicated by strong dendritic reticulum cell (DRC) staining. CD25 was expressed by neoplastic cells in only $2 / 36$ cases. None of the cases tested expressed CD30. 4F2 and the transferrin receptor showed similar but variable expression between cases although in some cases there was differential expression, e.g., strong expression of $4 \mathrm{~F} 2$ and weak with transferrin receptor or vice versa. The majority of the cases expressed DR, DP, and DQ, although DQ expression was often reduced or absent.

It was not possible to correlate variation in cellular content of follicles (i.e., proportion of centroblasts to centrocytes) with any particular phenotype.

\section{Diffuse centroblastic/centrocytic lymphoma}

Eleven cases of diffuse centroblastic/centrocytic lymphoma were studied (Fig. 4) derived from lymph nodes (8, two of which had extranodal spread), small intestine (2), and omentum (1). Eight cases expressed $\mathrm{IgM}$ together with $\mathrm{IgD}$ in two instances. Three cases expressed IgG, one without light chain. The majority of cases expressed pan B-cell antigens CD19, 22, and 45R whereas in a few cases CD20 expression was weak or absent. None of the cases was CD5 or OKT10 positive. Two cases expressed CD9 and a further two CD10. CD21 was expressed by the majority of lymphoid cells in only two cases with DRC stained in $4 / 5$ cases. CD23 was expressed by the majority of cells in $2 / 6$ cases but CD25 staining was observed in only one case. Neither of the two cases tested expressed CD30.4F2 was expressed strongly in all cases whereas transferrin receptor staining was seen on only a minority of cells in four cases. The MHC class II antigens DR, DP, and DQ were strongly expressed in all cases. 


\section{LYMPHOCYTIC}

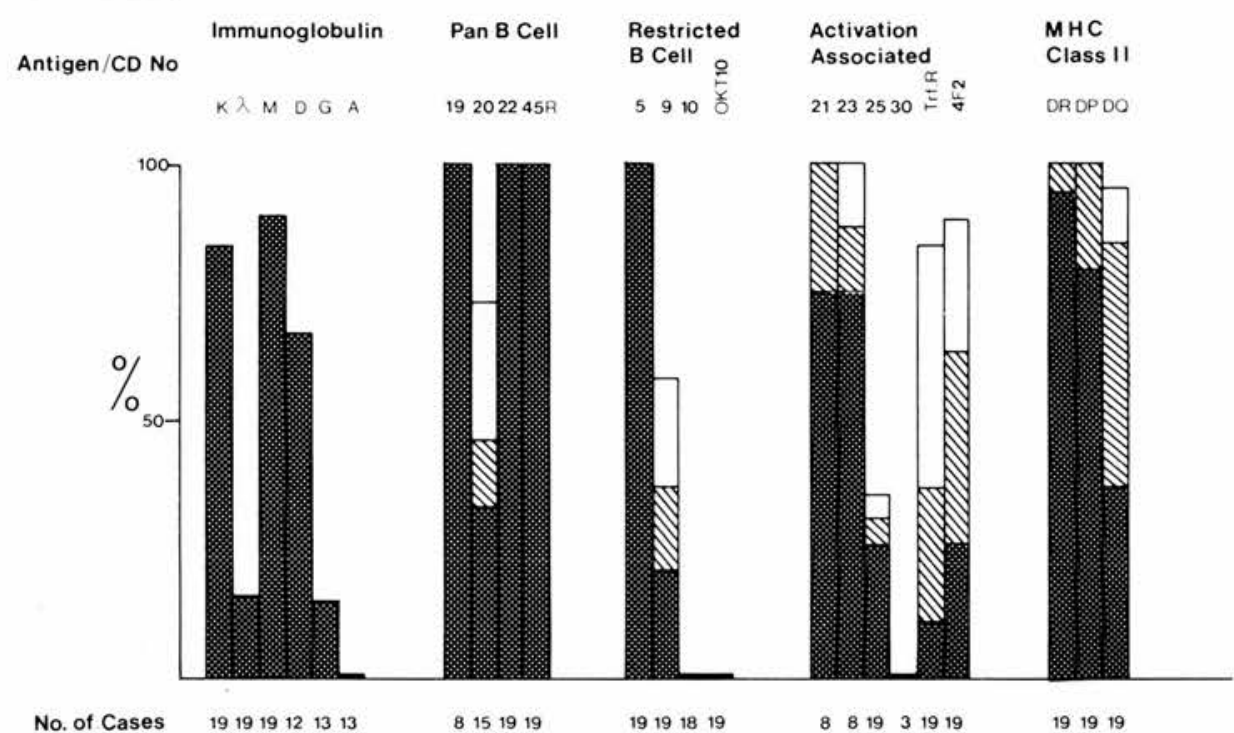

Fig. 1

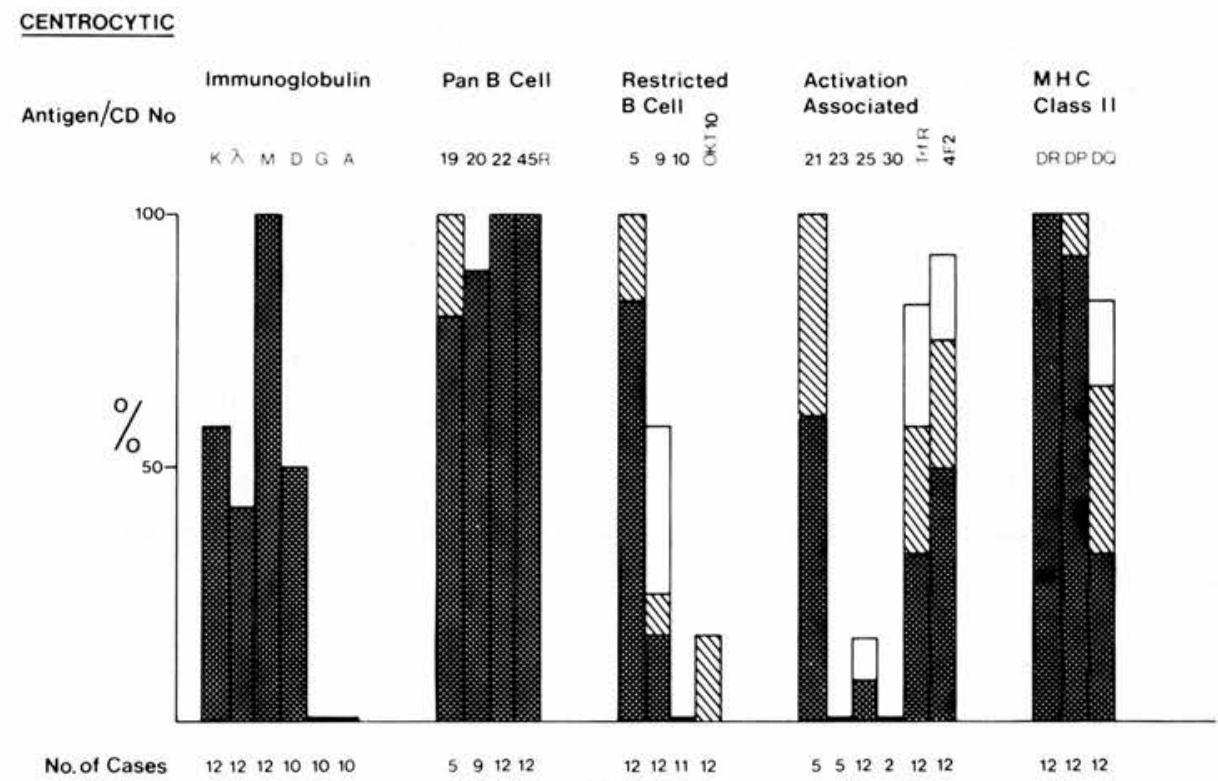

Fig. 2

Figs 1-7-The histograms illustrate the percentage of cases showing the estimated population of malignant B-cell staining. $=>70$ per cent. $\mathbb{N}=30-70$ per cent, $\square=5-30$ per cent of cells staining positively

\section{Centroblastic lymphomas}

Thirty-two cases of centroblastic lymphoma from lymph nodes (22), stomach (2), testis (2), omentum (1), mediastinum (1), tonsil (1), retroperitoneum (1), breast (1), and scalp (1) were studied (Fig. 5). Seventeen cases expressed kappa, eight lambda light chains, and one case gave equivocal results. One case expressed IgM heavy chain without light chains. Fourteen cases expressed IgM, one with $\mathrm{IgD}$, nine with $\mathrm{IgG}$, and three with $\operatorname{IgA}$; five cases did not express immunoglobulin. While the majority of cases expressed pan B-cell antigens strongly, a few cases showed loss of one or more of these antigens. CD5 expression was uncommon ( $1 / 32$ cases). There 


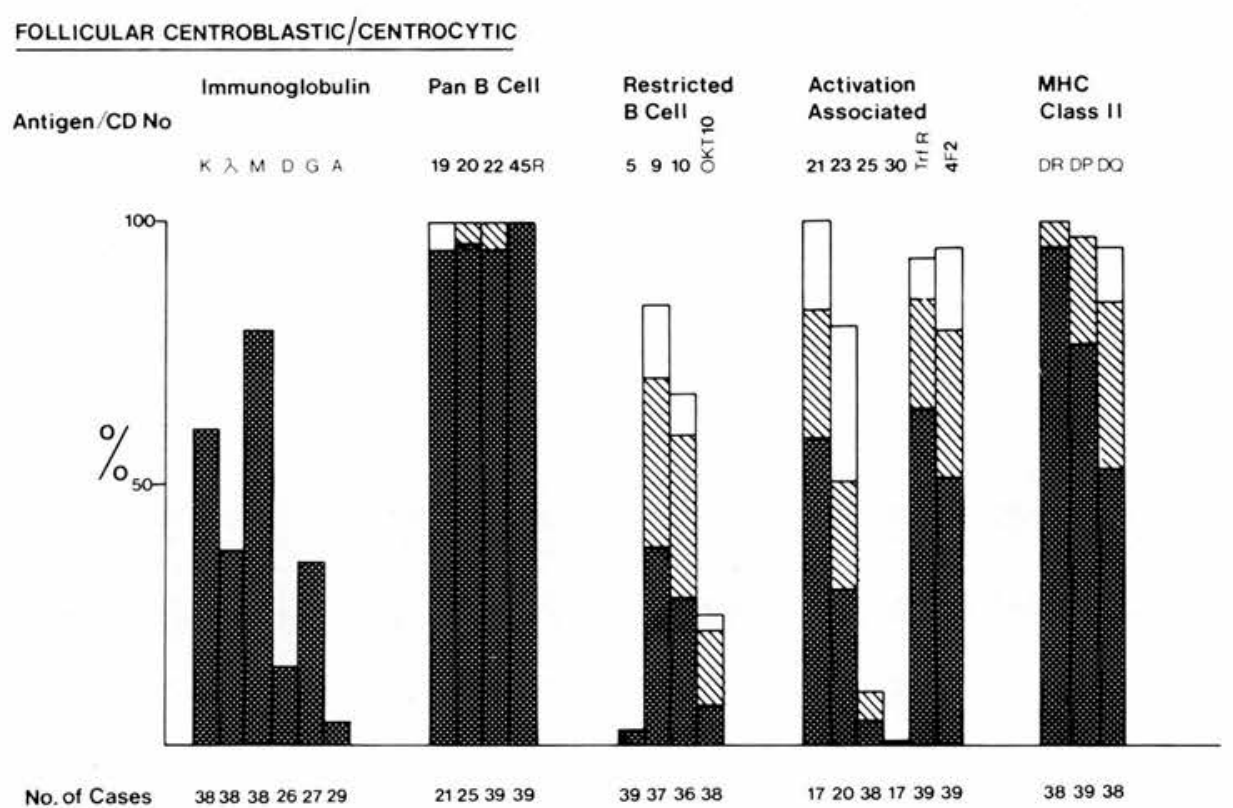

Fig. 3

DIFFUSE CENTROBLASTIC/CENTROCYTIC

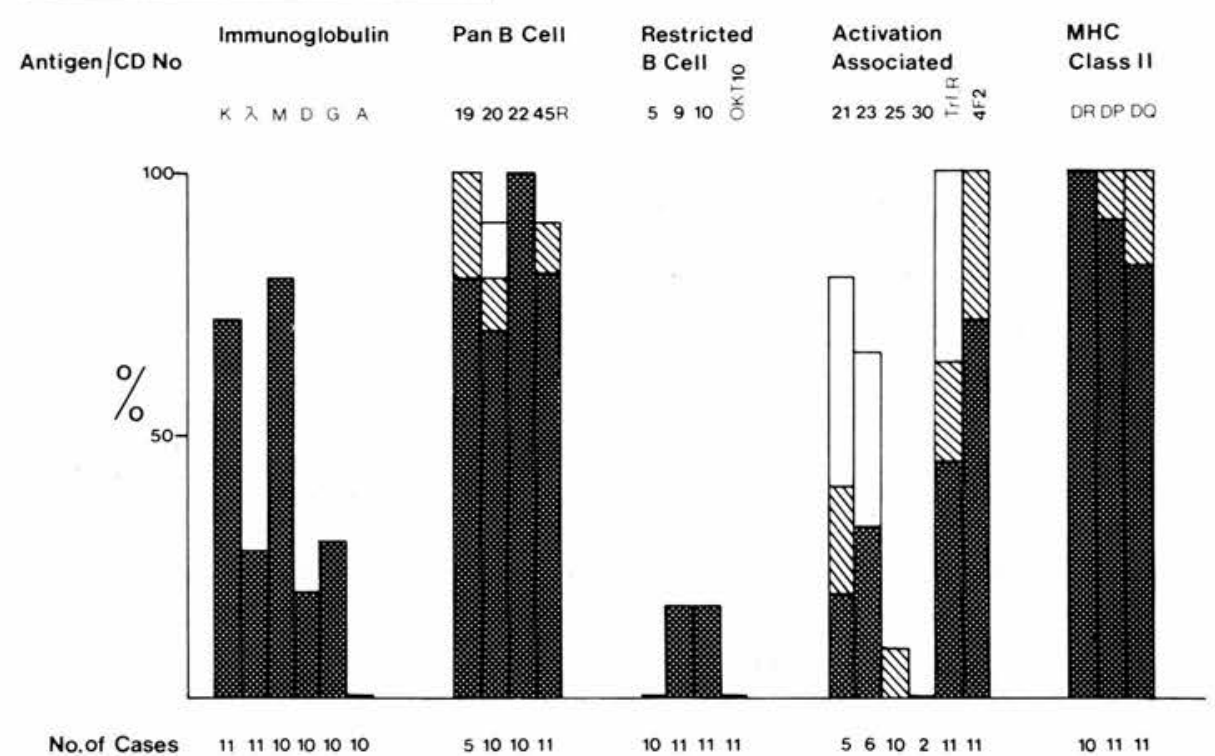

Fig. 4

was variable expression of CD9, CD10, and OKT10 antigens. No relationship was observed between the expression of these antigens, with all possible permutations being seen within the series. Twelve of 17 cases tested expressed CD21 although the intensity of staining was often weak in comparison with other lymphomas. Only one of 19 cases tested showed more than a minor population of cells or DRCs expressing CD23. CD25 and CD30 were expressed by a minority of cases only, whereas $4 \mathrm{~F} 2$ and transferrin receptor were strongly expressed by the majority. DR, DP, and DQ were expressed strongly 
CENTROBLASTIC

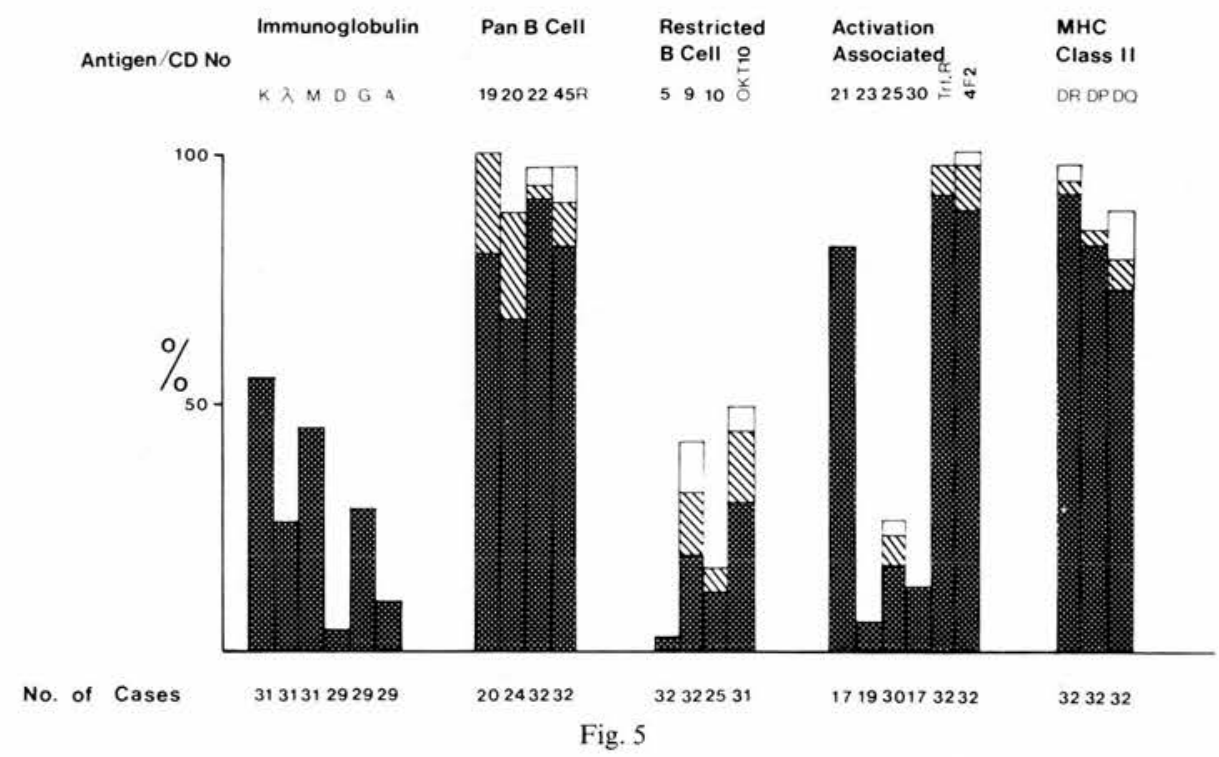

IMMUNOBLASTIC

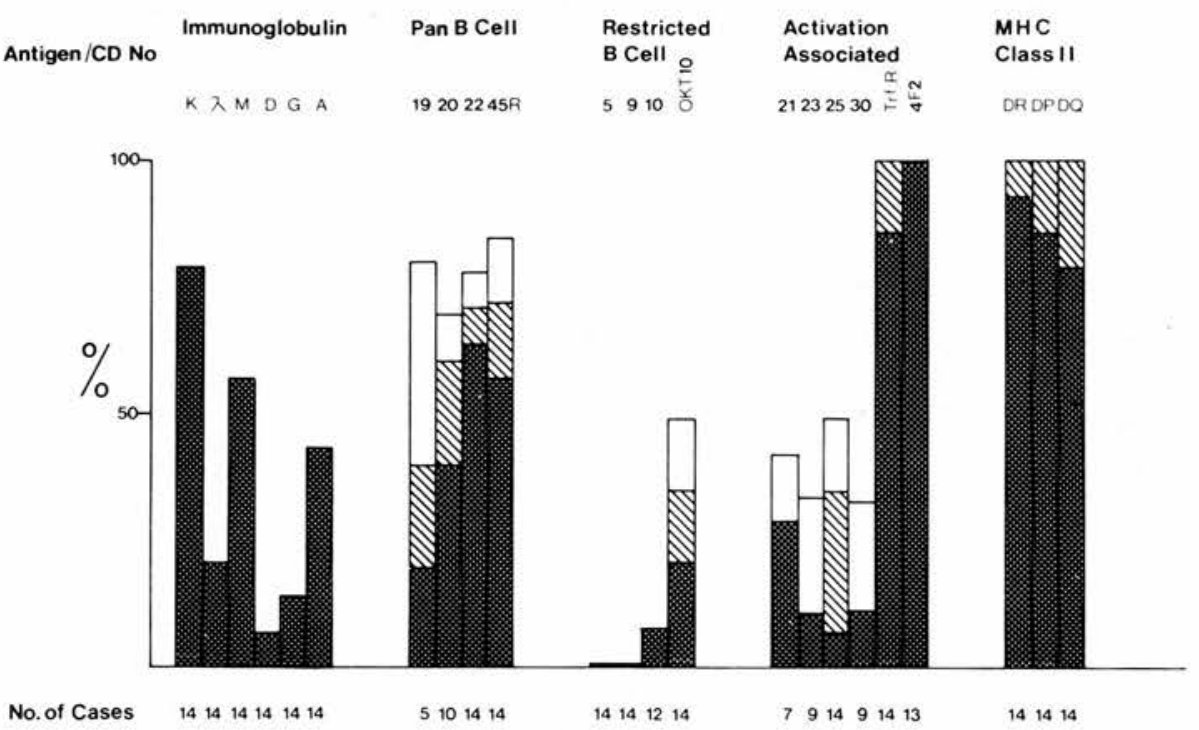

Fig. 6

by most of the cases, although a few showed loss of one or more antigens.

Within this group 2 'special' centroblastic subtypes were recognized. In one, a sclerosing mediastinal lymphoma in a young female expressed IgAK, pan B-cell, and HLA class II antigens. In the other, five cases contained a large proportion of multilobated cells expressing pan B-cell antigens and OKT 10 antigen; in two cases tested, these cells were
CD21 positive and CD23 negative. None expressed CD9.

\section{Immunoblastic lymphomas}

Fourteen cases of immunoblastic lymphoma were studied (Fig. 6) and included two cases of polymorphic immunocytoma containing an admixture of plasma cells and plasmablasts with a predomi- 


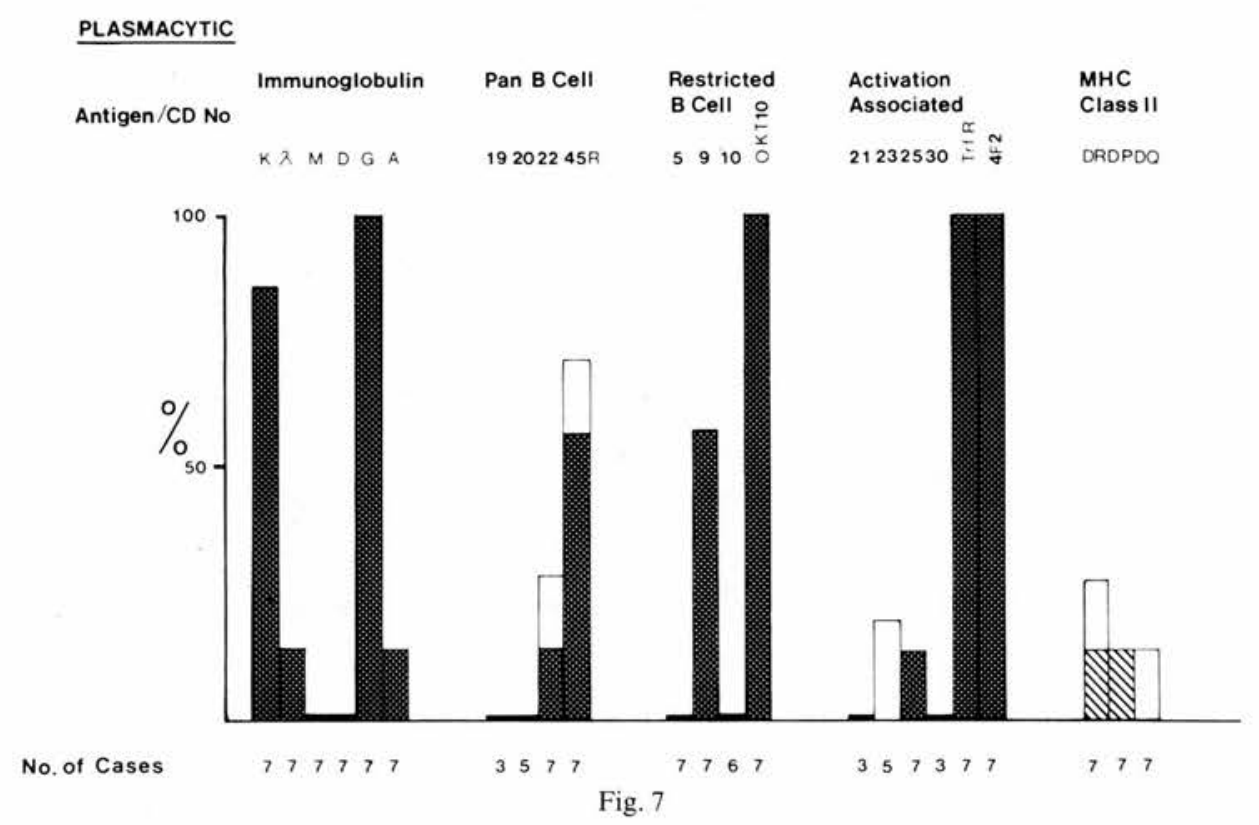

nance of immunoblasts. Ten cases were lymph nodes and four extranodal (1 retroperitoneum, 1 chest wall mass, 1 knee, and 1 spleen). Eleven cases expressed kappa and three lambda light chains. Eight expressed IgM together with IgD and in one case with IgA. Five cases expressed IgA alone and in one case IgA and IgG were coexpressed. There was variable expression of pan B-cell antigens. CD22 and CD45R were most commonly expressed; however, these and other pan B-cell antigens were often lost or only expressed by a minority of tumour cells. CD5 and CD9 were not expressed. CD10 staining was observed in only one case and this tumour, although showing a vast majority of immunoblasts, contained in addition a population of large centrocytes and centroblasts suggesting derivation from a diffuse centroblastic/centrocytic lymphoma. Almost half of the cases showed reactivity with OKT10. This was strongest in polymorphic immunocytoma and in cases showing plasmablastic differentiation. However, a few cases showing plasmacytoid differentiation did not express the OK T10 antigen. CD21 was expressed by a minority of cases and CD23 was expressed weakly by the majority of cells in only one case tested. Staining for CD25 was inconsistent, whereas both $4 \mathrm{~F} 2$ and transferrin receptor were strongly expressed by all cases. In one case, the majority of cells expressed CD30 and in two others, a minority of large blast cells were positive. The MHC class II antigens DR, DP, and DQ were strongly expressed in all cases.

\section{Plasmacytic lymphoma (plasmacytoma)}

Seven cases were studied (Fig. 7) from lymph nodes (3) and extranodal tissues (1 scalp, 1 sacral tumour, 1 epidural tumour, and 1 testicular tumour). Six expressed kappa and one lambda light chain. All seven expressed IgG, one in association with IgA. All of the cases tested had lost CD19 and CD20 while CD22 was expressed by a proportion of cells in two cases. CD45R expression was observed by a majority of cells in four cases. All cases expressed OKT10 antigen and 4/7 expressed CD9. None of the cases tested expressed CD5, CD10, CD21, CD23, or CD30, and only one showed weak expression of CD25. The MHC class II antigens were lost by $6 / 7$ cases although one did contain a minor population of class II positive plasma cells.

\section{Lymphoblastic lymphomas}

Only two cases morphologically diagnosed as lymphoblastic lymphomas were available for study. One was an epidural tumour and the other a spleen. Both were terminal deoxynucleotidyl transferase 
positive. One case did not express immunoglobulin and the other monotypic IgM lambda. The immunoglobulin negative case expressed CD19, CD22, CD9, and CD10 but none of the other pan B-cell or B-cell differentiation associated antigens including MHC class II. The other case expressed all four pan B-cell antigens, CD9, CD10, OKT10, and MHC class II antigens but did not express CD21 or CD23. Both cases were strongly $4 \mathrm{~F} 2$ and transferrin receptor positive.

\section{DISCUSSION}

The present study reports the phenotypic expression of a series of B-cell NHL using an extended panel of MCA against B-cell differentiation and activation antigens. We were able to identify marked phenotypic heterogeneity both within and between the major morphological subgroups recognized by the Kiel classification.

No single marker in our panel reacted with all cases tested. The B-cell histogenesis of our cases was confirmed by demonstrating the presence of either monotypic immunoglobulin light chains or the expression of one or more pan B-cell restricted antigens. A few cases, predominantly within the centroblastic and lymphoblastic groups, failed to express immunoglobulin and showed variable expression of pan B-cell antigens. In immunoglobulin negative cases, at least one or more pan B-cell antigens could be demonstrated. Similar findings have been reported by others., ${ }^{2,3,31,32}$ The finding that $\mathrm{B} 1$, which recognizes $\mathrm{CD} 20$, failed to stain or showed weak reactivity in a number of our cases confirms previous observations of poor reactivity of this antibody in tissue sections. ${ }^{7,31,33}$ This may be a technical artefact, as strong reactivity is seen when cell suspensions are employed. ${ }^{2}$ Earlier reports have shown that 'null' cell tumours expressing neither surface immunoglobulin nor sheep erythrocyte receptors constitute approximately 5 per cent of NHL. ${ }^{34,35}$ Many such cases have been shown to be of B- or T-cell lineage by immunogenotyping. ${ }^{36,37}$ Using an extended panel of anti-B-cell MCA and a similar panel of anti-T-cell and macrophage MCA, we have been able to assign every case of approximately 250 NHL seen in our laboratory over the last 4 years to either B-cell, T-cell, or macrophage/ histiocyte lineage, suggesting that 'null' cell tumours are rarely seen (unpublished observation).

Four of the MCA used in our panel are known to recognize antigens (CD5, CD9, CD10, and OKT10) expressed at variable or multiple stages of B-cell differentiation. These are potentially useful for defining subgroups of B-cell NHL immunologically and for comparison with normal cellular counterparts. CD5, an antigen expressed predominantly by T cells, ${ }^{12}$ has been shown recently to be expressed by mantle zone B cells ${ }^{38}$ and fetal primary follicle B-cells. $^{39}$ In our series, CD5 expression was restricted predominantly to lymphocytic and centrocytic lymphomas, confirming the findings of others. $^{2,3,38,40-42}$ We also identified a small number of cases in follicular centroblastic/ centrocytic, centroblastic, and prolymphocytic groups which were CD5 positive. Small numbers of follicular lymphomas have previously been reported as CD5 positive. ${ }^{2,3,32}$ The finding that prolymphocytic lymphoma was frequently CD5 positive agrees with Stein et al. ${ }^{3}$ but contrasts with Gobbi et al., ${ }^{43}$ who found 12 cases of prolymphocytic leukaemia to be CD5 negative. The latter studies employed RFA2 on suspensions of peripheral blood cells and may reflect differences in antigen expression between neoplastic cells in tissues and blood. Alternatively, histologically recognized prolymphocytic lymphoma may be a different disease entity from prolymphocytic leukaemia.

CD9, which reacts with a proportion of germinal centre cells ${ }^{44.45}$ and approximately $10-20$ per cent of mantle zone cells ${ }^{44}$ in reactive lymph nodes, showed variable reactivity in all groups studied, except immunoblastic lymphomas which were always negative. It was therefore not of value for subtyping B-cell NHL whereas others, using a different CD9 MCA (BA-2), have suggested this antigen may be selectively expressed by mantle-zone lymphomas. ${ }^{42}$ In lymphocytic lymphomas, expression of CD9 was either absent or reduced in proliferation centres, suggesting that this antigen reflects a stage of activation rather than differentiation.

CD10 expression by lymphoblastic lymphomas is well recognized, ${ }^{46}$ and expression by reactive follicle centre cells has recently been described..$^{3,44,45}$ Our results confirm the expression of this antigen by at least a proportion of neoplastic follicle centre cell tumours. ${ }^{2,3,47,48}$ CD10 positivity has been shown to correlate with more aggressive myeloma. ${ }^{49}$ This raises the possibility that the variable expression of CD10 in cases of centroblastic and immunoblastic lymphoma seen in our study represents similar aggressive subgroups.

In normal lymphoid tissue, OKT10 is a marker of plasma cells ${ }^{9,15}$ and stains follicle centre cells but not mantle zone cells..$^{9,43-45}$ OKT10 showed 
corresponding reactivity in our series, staining a proportion of follicular lymphomas and plasmacytomas as previously documented. ${ }^{2,43}$ Similarly, reactivity with B-cell lymphoblastic lymphomas has been described. ${ }^{43}$ Although OKT 10 positivity frequently correlated with plasma cell differentiation histologically, in two cases of lymphoplasmacytoid lymphomas (immunocytoma) this antigen was not expressed. Unlike other plasma cell tumours, these cases expressed MHC class II antigens and in one case pan B-cell antigens. In contrast to lymphocytic lymphomas, they were CD5 negative. Other workers have also recognized the distinct phenotypic characteristics of this group of NHL and have postulated that they may represent proliferations of a subpopulation of lymphoid cells. ${ }^{38,50}$

Our panel of MCA included some which recognize 'activation-associated' antigens. CD21, the C3d receptor, ${ }^{51,52}$ is present on resting $\mathrm{B}$ cells but is lost following in vitro activation; ${ }^{33,54}$ others, such as CD23, CD25, CD30, transferrin receptor, and 4F2, are absent from resting cells but can be induced by mitogens. ${ }^{21,23,25,55-57}$ Expression of one of these antigens, the transferrin receptor, has been shown to be correlated with histological grade and clinical outcome of NHL. ${ }^{58,59}$ In nearly all the cases tested, at least a proportion of neoplastic cells were activated, as shown by expression of CD23, transferrin receptor, or 4F2. Many cases also expressed CD21, an antigen lost rapidly following activation of splenic B cells by anti-Ig. ${ }^{17,54}$ Other workers have reported similar heterogeneity in expression of CD21 (B2) $)^{31,32}$ and it is possible its expression by activated cells represents abnormal regulation in neoplastic cells.

CD23 is expressed within $3 \mathrm{~h}$ following activation of resting B cells, before cells enter the cell cycle. ${ }^{56,57}$ In reactive lymph nodes and tonsil, it is expressed at variable intensity by mantle zone lymphocytes and a proportion of $\mathrm{DRC}^{7}$ but not by germinal centre cells. CD23 was maximally expressed by the low grade lymphomas (lymphocytic lymphomas) and infrequently expressed by high grade (centroblastic or immunoblastic) tumours. Other workers have made similar observations s.38 $^{3.3}$ and it is possible that CD23 is expressed only transiently during B-cell activation and is lost after a certain stage of committed differentiation. Failure of germinal centre cells to express CD23 would support this idea. The observation that lymphocytic lymphomas were CD23 positive whereas centrocytic lymphomas were negative is consistent with previous observations ${ }^{3}$ and may be a useful means of differentiating these subtypes, although other workers have reported CD23 positive centrocytic lymphomas. ${ }^{48}$

CD25 (IL2-R) was initially shown to be expressed by activated $\mathrm{T}$ cells. ${ }^{19}$ Recent work, however, has also demonstrated its expression by activated normal B cells ${ }^{20,21}$ and by hairy cell leukaemia. ${ }^{60,61}$ Our results show that CD25 is also variably expressed in most histological groups of B-NHL although there was no correlation with histological grade. Chronic lymphocytic leukaemia cells proliferate and differentiate in response to IL $2^{62,63}$ and it is possible that the growth of at least some B-cell lymphomas is regulated through abnormal receptor expression and stimulation by IL2.

CD30 (Kil) was initially described as reacting selectively with Reed-Sternberg cells in Hodgkin's disease and with a small population of large cells in reactive lymph nodes. ${ }^{22}$ Recent work has shown that $\mathrm{CD} 30$ can be induced in B cells by mitogens and infection with Epstein-Barr virus. ${ }^{23,24}$ CD30 was present in only a small number of high grade lymphomas (centroblastic or immunoblastic) in this series, consistent with the findings of others. ${ }^{23}$

The activation-associated antigens $4 \mathrm{~F} 2$ and transferrin receptor were most strongly expressed by high grade lymphomas and less often and more weakly by low grade lymphocytic and follicular lymphomas. Increased expression of transferrin receptor in high grade lymphomas has been shown previously, ${ }^{58,59}$ but our results demonstrate more heterogeneity in low grade lymphomas than has been previously described.

The expression of $\mathrm{MHC}$ class II antigens extends and confirms results previously published by us and others, ${ }^{64-66}$ with coordinate and non-coordinate expression of DR, DP, and DQ being evident in many histological groups. The increased expression of class II antigens in the proliferation centres of lymphocytic lymphomas and in vitro following entry of $\mathrm{B}$ cells into the cell cycle ${ }^{67}$ suggests that these antigens are involved in B-cell activation. However, the finding that their expression is decreased or absent in tumours showing plasma-cell differentiation and that centrocytic lymphomas and some centroblastic lymphomas tend to show low DQ expression suggests that MHC class II antigens may also be differentiation related.

Many of the histological groups of B-cell NHL recognized by the Kiel classificaticn system show cytomorphological and phenotypic similarities to normal B cells. It is generally accepted that neoplastic cells reflect normal B cells frozen at various stages of maturation. However, the phenotypic 
heterogeneity we have observed within the various histological categories shows that direct comparison with morphologically similar normal counterparts cannot be made in all cases. There are a number of possible reasons for this. Phenotypic heterogeneity may represent multiple stages of activation/ differentiation arrest along a linear pathway which are only transient in vivo and therefore seldom seen. Alternatively, it may indicate maturation arrest of morphologically similar cells which are already committed to different non-linear differentiation pathways. We believe that the phenotypic diversity, especially marked in high grade NHL, in part represents abnormal expression of differentiation and activation antigens secondary to loss of genomic regulation in neoplastic cells. As many of these activation and differentiation antigens appear to have a functional role in the control of B-cell differentiation and proliferation, abnormal expression may be intimately involved in lymphomagenesis.

In conclusion, using an extended panel of MCA against B-cell activation and differentiation antigens we have shown marked phenotypic heterogeneity both between and within morphological groups of B-cell NHL. The B-cell histogenesis in many cases could be confirmed only by using a panel of immunoglobulin and pan B-cell markers. Pan B-cell (CD19, 20, 22, 45R) and 'restricted' B-cell antigens (CD5, 9, 10, OKT10) were in general unhelpful markers of morphological groups although CD5 (lymphocytic and centrocytic NHL) and OKT10 (plasma cell tumours) were expressed strongly by some groups. Activation antigens were expressed by cases in all histological groups but $4 \mathrm{~F} 2$ and transferrin receptor were more often and more strongly expressed by high grade lymphomas. They may therefore be of prognostic significance. Other activation antigens such as CD23 and CD25 did not appear to be more frequently associated with high grade tumours but CD23 may be useful in the discrimination between centrocytic and lymphocytic lymphoma. Studies are underway to establish whether or not the phenotypic diversity recognized by this extended panel of MCA is reflected by an equivalent diversity in clinical behaviour.

Extended phenotyping by a large panel of MCA such as we have used in this study may be of value in elucidating biologically important characteristics and cellular abnormalities in NHL. However, for routine diagnostic purposes such extensive typing of NHL is probably not of practical use at present. As an adjunct to routine histological examination, we now employ a limited panel of MCA against leucocyte antigens CD3, CD5, CD22, CD45, IgM, kappa, and lambda. This panel allows diagnosis of most cases of NHL. The use of additional MCA against other leucocyte antigens (CD1, CD4, CD8, CD19, CD23, CD25) is undertaken only in selected cases where the initial screen gives equivocal results.

\section{ACKNOWLEDGEMENTS}

This work was supported by a grant from the Melville Trust. We would like to thank Mrs Carolyn Brown for typing the manuscript and Professor C. C. Bird for helpful criticism.

\section{REFERENCES}

1. Habeshaw JA, Bailey, D, Stansfeld AG, Greaves MF. The cellular content of non-Hodgkin's lymphomas. A comprehensive analysis using monoclonal antibodies and other surface marker techniques. $\mathrm{Br} J$ Cancer 1983; 47: 327-351.

2. Anderson KC, Bates MP, Slaughenhoupt BL, Pinkus GS, Schlossman SF, Nadler LM. Expression of human B cell-associated antigens on leukemias and lymphomas. A model of human B cell differentiation. Blood 1984; 63: 1424-1433.

3. Stein H, Lennert K, Feller A, Mason DY. Immunohistological analysis of human lymphoma: correlation of histological and immunological categories. $A d v$ Cancer Res 1984; 62: 67-147.

4. Nash JRG. An immunohistochemical study of nonHodgkin's lymphomas: correlation of morphological appearances and immunophenotype in 148 cases. Histopathology 1986; 10: 793-813.

5. Rheinherz EL, Haynes BF, Nadler LM, Bernstein ID (eds). Leucocyte Typing II. Vol. 2. Human B Lymphocytes. New York: Springer, 1986.

6. Salter DM, Krajewski AS, Dewar AW. Immunohistochemical staining of non-Hodgkin's lymphoma with monoclonal antibodies specific for the leucocyte common antigen. J Pathol 1985; 146: 345-353.

7. Mason DY, Ladyman H, Gatter KC. Immunohistochemical analysis of monoclonal anti-B cell antibodies. In: Reinherz EL, Haynes BF, Nadler LM, Bernstein ID, eds. Leucocyte Typing II. Vol. 2. Human B Lymphocytes. New York: Springer, 1986; 245.

8. Nadler LM, Stashenko P, Ritz J, Hardy R, Pesando JM, Schossman SF. A unique cell surface antigen identifying lymphoid malignancies of B cell origin. $J$ Clin Invest 1981; 67: 134-140.

9. Bhan AK, Nadler LM, Stashenko P, McCluskey RT, Schlossman SF. Stages of B cell differentiation in human lymphoid tissue. J Exp Med 1981; 154: 737-749. 
10. Stein H, Gerdes J, Mason DY. The normal and malignant germinal center. Clin Hematol 1982; 11: 531-559.

11. Dalchau R, Fabre JW. Identification with a monoclonal antibody of a predominantly B lymphocytespecific determinant of the human leucocyte common antigen. J Exp Med 1981; 153: 755-765.

12. Royston J, Jarida JA, Baird SM. Human T cell antigens defined by monoclonal antibodies to the 65000 dalton antigen of T cells (T65) is also found on chronic lymphocytic leukemia cells bearing surface immunoglobulin. J Immunol 1980; 125: 725-731.

13. Brooks DA, Bradley J, Zola H. A differentiation antigen expressed selectively by a proportion of human blood cells, detection with a monoclonal antibody. Pathology 1982; 14: 5-11.

14. Newman RA, Sutherland R, Greaves MF. The biochemical characterisation of a cell surface antigen associated with acute lymphoblastic leukemia and lymphocyte precursors. J Immunol 1981; 126: 2024-2030.

15. Anderson KC, Park ER, Batese MP, et al. Antigens on plasma cells identified by monoclonal antibodies. J Immunol 1983; 130: 1132-1138.

16. Campana D, Janossy G, Bofill M, et al. Human B cell development. I. Phenotypic differences in B lymphocyte in the bone marrow and peripheral lymphoid tissue. J Immunol 1985; 134: 1524-1529.

17. Boyd AW, Anderson KC, Freedman AS, et al. Studies of in vitro activation of human B lymphocytes. I. Phenotypic and functional characterisation of the B cell population responding to anti-Ig antibody. $J$ Immunol 1985; 134: 1516-1523.

18. Rowe M, Hildreth JEK, Rickman AB, Epstein MA. Monoclonal antibodies to Epstein-Barr virusinduced transformation-associated cell surface antigens. Binding patterns and effects upon virus specific T-cell cytotoxicity. Int J Cancer 1982; 15: 373-381.

19. Uchiyama T, Broder S, Waldmann TA. A monoclonal antibody (anti-Tac) reactive with activated and functionally mature human T cells. I. Production of anti-Tac monoclonal antibody and destination of Tac (+) cells. J Immunol 1981; 126: 1393-1397.

20. Tsudo M, Uchiyama T, Uchino H. Expression of Tac antigen on activated normal human B cells. $J$ Exp Med 1984; 160: 612-617.

21. Waldmann TA, Goldman CK, Robb RJ, et al. Expression of interleukin-2 receptors on activated human B cells. J Exp Med 1984; 160: 1450-1466.

22. Schwab U, Stein H, Gerdes J, et al. Production of a monoclonal antibody specific for Hodgkin and Sternberg-Reed cells of Hodgkin's disease and a subset of normal lymphoid cells. Nature 1982; 299: 65-67.

23. Stein M, Mason DY, Gerdes J et al. The expression of the Hodgkin's disease associated antigen Kil in reactive and neoplastic lymphoid tissue. Evidence that Reed-Sternberg cells and histocytic malignancies are derived from activated lymphoid cells. Blood 1985; 66: $848-858$.

24. Trowbridge IS, Omery MB. Human cell surface glycoprotein related to cell proliferation is the receptor for transferrin. Proc Natl Acad Sci USA 1981; 78: 3039-3043.

25. Haynes BF, Hemler ME, Mann DL, et al. Characterisation of a monoclonal antibody (4F2) that binds to human monocytes and to a subset of activated lymphocytes. J Immunol 1981; 126: 1409-1414.

26. Lampour LA, Levy R. Two populations of Ia-like molecules on a human B cell line. J Immunol 1980; 125: 293-299.

27. Watson AJ, Demars R, Trowbridge IS, Bach FH. Detection of a novel class II antigen. Nature 1983; 304: 358-361.

28. Brodsky FM. A mature approach to human class II histocompatibility antigens: reaction of four monoclonal antibodies with the products of nine haplotypes. Immunogenetics 1984; 19: 179-184.

29. Pawelec OP, Shaw S, Ziegler A, Muller C, Wernet P. Differential inhibition of HLA-D- or SB-directed secondary lymphoproliferative responses with monoclonal antibodies detecting human Ia-like determinants. J Immunol 1982; 129: 1070-1075.

30. Ledbetter JA, Evans RC, Lipinski M, CunninghamRundles C, Good RA, Lietzenberg LA. Evolutionary conservation of surface molecules that distinguish $\mathrm{T}$ lymphocyte helper/inducer and $\mathrm{T}$ cytotoxic suppressor subpopulations in mouse and man. $J$ Exp Med 1981; 53: 310-323.

31. Horning SJ, Doggett RS, Warnke RA, Dorfman RF, Cox RS, Levey R. Clinical relevance of immunologic phenotype in diffuse large cell lymphoma. Blood 1984; 63: 1209-1215.

32. Borowitz MJ, Bousvaros A, Brynes RK, et al. Monoclonal antibody phenotyping of B-cell non-Hodgkin's lymphomas. The Southeastern Cancer Study Group experience. Am J Pathol 1985; 121: 514-521.

33. Freedman AS, Boyd AW, Anderson $\mathrm{KC}$, et al. Immunologic heterogeneity of diffuse large cell lymphoma. Blood 1985; 65: 630-637.

34. Lukes RJ, Taylor CR, Parker JW, Lincoln TC, Pattengale PK, Tindle BH. A morphologic and immunologic surface marker study of 299 cases of non-Hodgkin's lymphomas and related leukemias. Am J Pathol 1978; 90: 461-486.

35. Pinkus GS, Said JW. Characterisation of nonHodgkin's lymphomas using multiple cell markers. Immunologic, morphologic and cytochemical studies of 72 cases. Am J Pathol 1979; 94: 349-380.

36. Knowles DM III, Dodson L, Burke JS, et al. S Ig-E('null-cell') non-Hodgkin's lymphomas: multiparametric determination of their B- or T-cell lineage. Am J Pathol 1985; 120: 356-370.

37. Cleary ML, Trela MJ, Weiss LM, Warnke R, Sklar J. Most null large cell lymphomas are B lineage neoplasms. Lab Invest 1985; 53: 521-525. 
38. Stein H, Mason DY. Immunohistological analysis of human lymphoma: correlation of histological and immunological categories. Adv Cancer Res 1984; 42: 67-147.

39. Bofill M, Janossy G, Janossa M, et al. Human B cell development. II. Subpopulations in the human fetus. $J$ Immunol 1985; 134: 1531-1538.

40. Swerdlow SH, Murray LJ, Habeshaw JA, Stansfeld AG. Lymphocytic lymphoma/B-chronic lymphocytic leukaemia - an immunohistopathological study of peripheral B lymphocyte neoplasia. Br J Cancer 1984; 50: $587-599$.

41. Swerdlow SH, Habeshaw JA, Murray LJ, Dhaliwal HS, Lister TA, Stansfeld AG. Centrocytic lymphoma: a distinct clinicopathologic and immunologic entity. A multiparameter study of 18 cases of diagnosis and relapse. Am J Pathol 1983; 113: 181-197.

42. Cossman J, Neckers ML, Hsu SM, Longo D, Jaffe ES. Low grade lymphomas: expression of developmentally regulated B-cell antigens. Am J Pathol 1984; 115: $117-124$.

43. Gobbi M, Caligaris-Cappo F, Janossy G. Normal equivalent cells of $\mathrm{B}$ cell malignancies: analysis with monoclonal antibodies. $\mathrm{Br}$ J Haematol 1983; 54: 393-403.

44. Hsu SM, Jaffe ES. Phenotypic expression of Blymphocytes. I. Identification with monoclonal antibodies in normal lymphoid tissues. Am J Pathol 1984; 114: $387-395$.

45. Murray LJ, Swerdlow SH, Habeshaw JA. Distribution of B lymphocyte subsets in normal lymphoid tissue. Clin Exp Immunol 1984; 56: 399-406.

46. Ritz J, Nadler LM, Bhan AK, Notis-McConarty J, Pesando JM, Schlossman SF. Expression of common acute lymphoblastic leukemia antigen (CALLA) by lymphomas of B cell and T cell lineage. Blood 1981; 58: $648-652$.

47. Swerdlow SH, Murray LJ, Habeshaw JA, Stansfeld AG. B- and T-cell subsets in follicular centroblastic/ centrocytic (cleaved follicular center cell) lymphoma: an immunohistologic analysis of 26 lymph nodes and three spleens. Hum Pathol 1985; 16: 339352.

48. Williamson JMS, Grigor I, Smith MEF, et al. Cluster differentiation antigen expression, proliferative activity and clinical stage in centroblastic lymphomas. $J$ Pathol 1986; 150: 51-59.

49. Durie BGM, Grogan TM. Calla-positive myeloma: an aggressive subtype with poor survival. Blood 1985; 66: $229-232$.

50. Harris NL, Bhan AK. B cell neoplasms of the lymphocyte, lymphoplasmacytoid and plasma cell types. Immunohistologic analysis and clinical correlation. Hum Pathol 1985; 16: 829-837.

51. Iida K, Nadler LM, Nussenweig V. Identification of the membrane receptor on the complement fragment C3d by means of a monoclonal antibody. J Exp Med 1983; 158: 1021-1033.
52. Tedder TF, Clement LT, Cooper MD. Expression of $\mathrm{C} 3 \mathrm{~d}$ receptors during human $\mathrm{B}$ cell differentiation: immunofluorescence analysis with the HB-5 monoclonal antibody. J Immunol 1984; 133: 678-683.

53. Stashenko P, Nadler LM, Hardy R, Schlossman SF. Expression of cell surface markers after human B cell activation. Proc Natl Acad Sci USA 1981; 78: 3848-3852.

54. Dorkan B, Moblenhauer G, Pezzuho A, et al. HD39 (B3) a B lineage-restricted antigen whose cell surface expression is limited to resting and activated human $B$ lymphocytes. $J$ Immunol 1985; 136: 4470-4479.

55. Clark EA, Holly RD, Yolcochi T, Ledbetter JA. Antigens expressed on mitogen activated $\mathrm{B}$ lymphocytes (Abstract). First International Workshop on Human Leukocyte Differentiation Antigens, 1982.

56. Thorley-Lawson DA, Nadler LM, Bhan AK, Schooley RT. B-LAST-2 (EBVCS), an early cell surface marker of human B cell activation is superinduced by Epstein-Barr virus. J Immunol 1985; 134: 3007-3012.

57. Walker L, Guy G, Brown G, Rowe M, Milner AE, Gordon GJ. Control of human B lymphocyte replication. I. Characterisation of novel activation states that precede entry of GO B cells into cycle. Immunology 1986; 58: 583-590.

58. Habeshaw JA, Lister TA, Stansfeld AG, Greaves MF. Correlation of transferrin receptor expression with histological class and outcome in non-Hodgkin's lymphoma. Lancet 1983; i: 498-501.

59. Pileri S, Gobbi M, Rivano MT, Martinelli G. Immunohistological study of transferrin receptor expression in non-Hodgkin's lymphoma. $\mathrm{Br} J$ Haematol 1984; 58: 501-508.

60. Korsmeyer SJ, Greene WC, Cossman J, et al. Rearrangement and expression of immunoglobulin genes and expression of Tac antigen in hairy cell leukemia. Proc Natl Acad Sci USA 1983; 80: 4522-4526.

61. Anderson KC, Boyd AW, Fisher DC, Leske D, Schlossman SF, Nadler LM. Hairy cell leukemia: a tumor of pre-plasma cells. Blood 1985; 65: 620-629.

62. Lantz O, Grillot-Courvalin C, Schmitt C, Fernand JP, Brouet JC. Interleukin-2 induced proliferation of leukemic B cells. J Exp Med 1985; 161: 1225-1230.

63. Hivroz C, Grillot-Courvalin C, Brouet JC, Seligmann M. Heterogeneity of responsiveness of chronic lymphocytic leukaemic B cells to B cell growth factor or interleukin 2. Eur J Immunol 1986; 16: 1001-1004.

64. Krajewski AS, Guy K, Dewar AE, Cossar D. Immunohistochemical analysis of human MHC class II antigens in B cell non-Hodgkin's lymphoma. $J$ Pathol 1985; 145: 185-194.

65. Guy K, Krajewski AS, Dewar AW. Expression of MHC class II antigen in human B cell leukaemia and non-Hodgkin's lymphoma. $B r J$ Cancer 1986; 53: 161-173. 
66. Smith MEF, Holgate CS, Williamson JMS, Grigor I, Quirke P, Bird CC. Major histocompatibility complex class II antigen expression in B and T cell nonHodgkin's lymphoma. J Clin Pathol 1987; 40: 34-41.
67. Kehrl JL, Muraguchi A, Fauci AS. The modulation of membrane Ia on human B lymphocytes. Cell Immunol 1985; 92: 391-403. 


\title{
PROGNOSTIC SIGNIFICANCE OF ACTIVATION AND DIFFERENTIATION ANTIGEN EXPRESSION IN B-CELL NON-HODGKIN'S LYMPHOMA
}

\author{
D. M. SALTER*, A. S. KRAJEWSKI*, T. SHEEHAN $\dagger$, G. TURNER $\ddagger$, R. J. G. CUTHBERT $\dagger$ AND A. MCLEAN* \\ *Department of Pathology, Medical School, University of Edinburgh; $\uparrow$ Department of Haematology, Royal Infirmary \\ of Edinburgh; $\ddagger$ Department of Haematology, Western General Hospital, Edinburgh, U.K. \\ Received 6 March 1989 \\ Revised 9 May 1989
}

\begin{abstract}
SUMMARY
Immunophenotyping shows heterogeneity of expression of activation and differentiation antigens in B-cell nonHodgkin's lymphoma (NHL). To investigate whether antigen expression correlates with clinical behaviour we have studied the clinical presentation and follow-up of a series of 111 B-cell lymphomas previously phenotyped for a panel of antigens including CD groups 5, 9, 10,21, 23, 25, 30,38,4F2 antigen, and transferrin receptor. CD antigens 5, 10, and 23 were expressed significantly more often by low grade lymphomas whereas CD38, 4F2 antigen, and transferrin receptor were more often expressed by high grade lymphomas. There was a significant correlation with survival and age, stage at presentation, histological grade, and expression of $4 \mathrm{~F} 2$ antigen and transferrin receptor but not with the other antigens studied. $4 \mathrm{~F} 2$ antigen and transferrin receptor may identify a poor prognostic group of cases in low grade lymphoma but we conclude that phenotyping B-cell NHL for many of the antigens expressed at various stages of B-cell differentiation and activation does not provide clinically useful information in addition to that obtained from standard histological classifications.
\end{abstract}

KEY WORDS-Immunophenotyping, survival, B-cell non-Hodgkin's lymphoma.

\section{INTRODUCTION}

Classifications of non-Hodgkin's lymphoma (NHL) such as the Kiel Classification ${ }^{1}$ and Working Formulation (WF) ${ }^{2}$ identify different morphologic categories which may be separated into major prognostic groupings. Immunophenotyping aids categorization of NHL into T- and B-cell groups. Extended phenotyping (i.e., detailed analysis of the expression of a number of activation and differentiation antigens using a large panel of antibodies) has shown phenotypic heterogeneity within morphologically similar groups. ${ }^{3-5}$ Previous studies of antigen expression have shown a correlation with survival in NHL although only a limited number of markers have been used. Transferrin receptor and $4 \mathrm{~F} 2$ expression is associated with poor survival; ${ }^{6,7}$

Addressee for correspondence: Dr D. M. Salter, Department of Pathology, University Medical School, Teviot Place, Edinburgh EH8 9AG, U.K.
MT2 expression in colorectal lymphomas is believed to be of prognostic value ${ }^{8}$ and CD23 expression has been associated with prolonged disease-free survival. ${ }^{9}$

To determine whether extended phenotyping provides additional clinically useful information we have studied the clinical presentation and follow-up of a series of B-cell NHL which have been phenotyped for expression of a large panel of antigens. These antigens are expressed at different stages of B-cell maturation, activation, and entry into cell cycle and their expression may be expected to be associated with clinical behaviour.

\section{MATERIALS AND METHODS}

\section{Cases and clinical data}

Clinical follow-up was obtained from case notes of 111 cases of B-cell NHL diagnosed in 
Table I-Antibodies used for phenotyping cases of NHL

\begin{tabular}{|c|c|c|c|}
\hline Antibody & $\begin{array}{l}\text { Mol. wt of antigen } \\
\text { (kD)/CD number }\end{array}$ & Source & Ref. \\
\hline \multicolumn{4}{|l|}{ Anti-immunoglobulin } \\
\hline Anti-kappa & & Dakopatts & \\
\hline Anti-kappa-FITC/anti-kappa-TRIC & & Kallestad & \\
\hline Anti-lambda & & Dakopatts & \\
\hline Anti-lambda-FITC/anti-lambda-TRIC & & Kallestad & \\
\hline Anti-IgM/DA6127/anti-IgM-FITC & & Dakopatts/K. Guy/Kallestad & \\
\hline Anti-IgD-FITC & & Kallestad & \\
\hline Anti-IgD/anti-IgG-FITC & & Dakopatts/Kallestad & \\
\hline Anti-IgA/anti-IgA-FITC & & Dakopatts/Kallestad & \\
\hline \multicolumn{4}{|l|}{ - Pan B cell } \\
\hline HD37 & $40 / \mathrm{CD} 19$ & Dakopatts & 11 \\
\hline B1 & $35 / \mathrm{CD} 20$ & Coulter & 12 \\
\hline Dako-B & $135 / \mathrm{CD} 22$ & Dakopatts & 13 \\
\hline F8-11-13 & $220 / \mathrm{CD} 45 \mathrm{R}$ & J. Fabre & 14 \\
\hline \multicolumn{4}{|l|}{ 'Restricted B cell' } \\
\hline Leu 1 & $65 / \mathrm{CD} 5$ & $\mathrm{BD}$ & 15 \\
\hline FMC 8 & $24 / \mathrm{CD} 9$ & H. Zola & 16 \\
\hline Dako Calla & $100 / \mathrm{CD} 10$ & Dakopatts & 17 \\
\hline OKT10 & $45 / \mathrm{CD} 38$ & Ortho & 18 \\
\hline \multicolumn{4}{|l|}{ 'Activation-associated } \\
\hline S/RFB6 & $140 / \mathrm{CD} 21$ & SAPU & 19 \\
\hline MHM6/101B7 & $45 / \mathrm{CD} 23$ & J. Gordon/Dakopatts & 11,20 \\
\hline Dako-IL2-R & $55 / \mathrm{CD} 25$ & Dakopatts & 21 \\
\hline Dako-Kil & $116126 / \mathrm{CD} 30$ & Dakopatts & 22 \\
\hline OKT9 & 90/NA (Trf-R) & Ortho & 23 \\
\hline $4 \mathrm{~F} 2$ & $40,80 / \mathrm{NA}$ & K. Guy & 24 \\
\hline \multicolumn{4}{|l|}{ MHC class II } \\
\hline L243 & DR & S. Howie (ATCC) & 25 \\
\hline B7/21 & DP & I. S. Trowbridge & 26 \\
\hline Leu $10 /$ Tu 22 & $\mathrm{DQ}$ & BD/A. Ziegler & 27,28 \\
\hline
\end{tabular}

$\mathrm{BD}=$ Becton Dickenson $\mathrm{NA}=$ not allocated $\mathrm{SAPU}=$ Scottish Antibody Production Unit $; \mathrm{Tr}-\mathrm{R}=$ transferrin receptor $; \mathrm{ATCC}=$ American Tissue Culture Collection.

the Immunopathology Laboratory, Edinburgh University Pathology Department during the period July 1982 to December 1986. Biopsies were obtained from hospitals in the Lothian Region, Borders, and Fife. These cases were part of a series of 145 B-cell NHL which had been previously phenotyped, ${ }^{3}$ clinical data being unobtainable on 34 .

\section{Histology and phenotyping}

Cases were classified by the Kiel Classification and Working Formulation following review by
D.M.S. and A.S.K. Detailed results of the immunohistochemical techniques used and results of immunophenotyping have been reported previously. ${ }^{3,10} \mathrm{~A}$ list of the antibodies used and specificity is given in Table I. Correlation between antigen expression, histology, and clinical behaviour was only undertaken for markers in the 'restricted B cell' and 'activation-associated' groups. Expression of these antigens varies with stage of differentiation, entry into the cell cycle, and activation of normal B cells. $^{13,16,19,20,29-37}$ CD23 and CD25 are growthfactor receptors. ${ }^{38,39}$ Their expression is potentially 
PHENOTYPE AND SURVIVAL IN B-CELL NHL

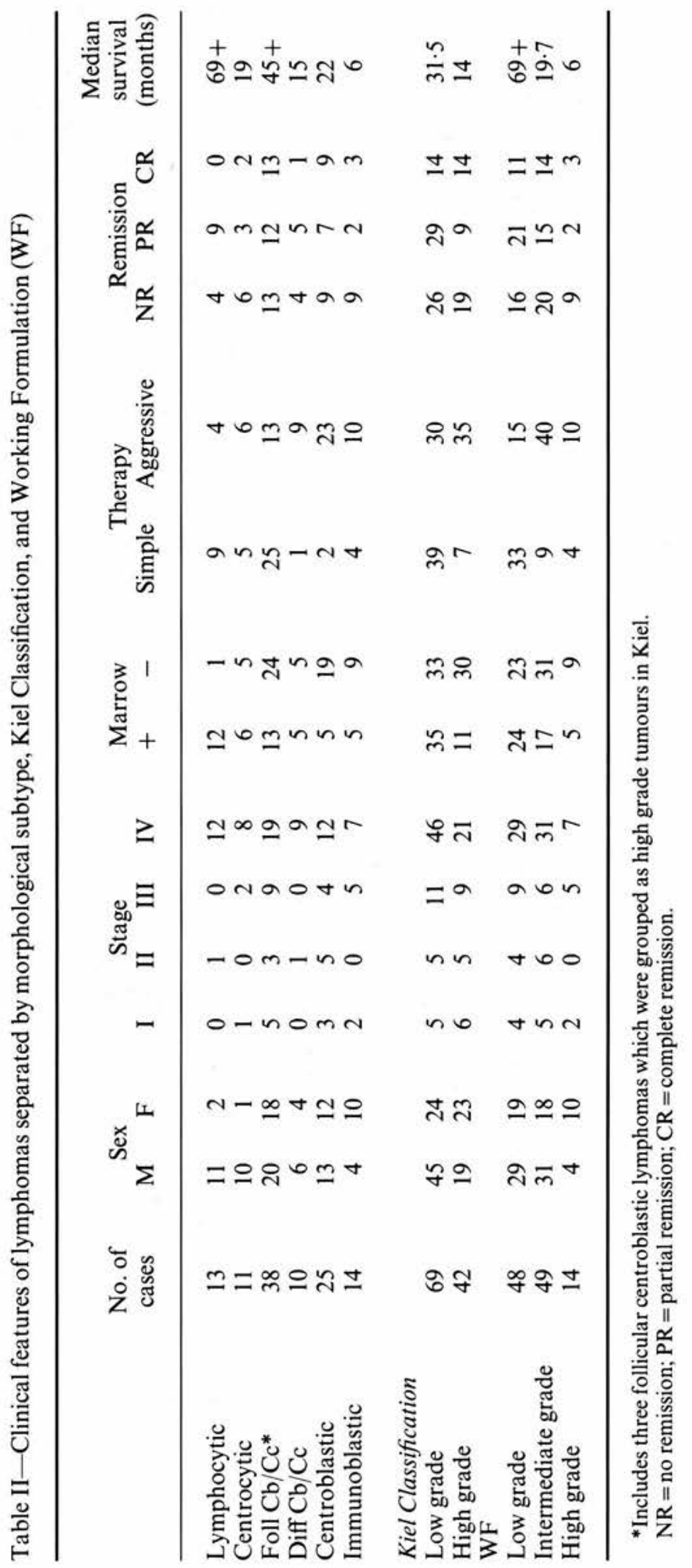


Table III-Antigen expression. Cases were classified as being positive if more than 30 per cent of cells showed immunoreactivity

\begin{tabular}{|c|c|c|c|c|c|c|c|c|c|c|}
\hline & \multirow[b]{2}{*}{ CD5 } & \multirow[b]{2}{*}{ CD9 } & \multirow[b]{2}{*}{ CD10 } & \multicolumn{4}{|c|}{ No. positive/No. cases tested } & \multirow[b]{2}{*}{ CD38 } & \multirow[b]{2}{*}{ Trf-R } & \multirow[b]{2}{*}{$4 \mathrm{~F} 2$} \\
\hline & & & & CD21 & CD23 & CD25 & CD30 & & & \\
\hline Lymphocytic & $13 / 13$ & $3 / 13$ & $0 / 13$ & $6 / 6$ & $5 / 6$ & $5 / 13$ & $0 / 2$ & $0 / 13$ & $4 / 13$ & $9 / 13$ \\
\hline Centrocytic & $11 / 11$ & $3 / 11$ & $0 / 10$ & $4 / 4$ & $0 / 4$ & $1 / 11$ & $0 / 1$ & $2 / 11$ & $6 / 11$ & $8 / 11$ \\
\hline Foll $\mathrm{Cb} / \mathrm{Cc} *$ & $1 / 38$ & $26 / 36$ & $21 / 35$ & $14 / 17$ & $10 / 19$ & $3 / 38$ & $0 / 17$ & $11 / 37$ & $32 / 38$ & $31 / 38$ \\
\hline Diff $\mathrm{Cb} / \mathrm{Cc}$ & $0 / 9$ & $2 / 10$ & $2 / 10$ & $3 / 4$ & $2 / 6$ & $2 / 9$ & N.T. & $0 / 10$ & $7 / 10$ & $10 / 10$ \\
\hline Centroblastic & $1 / 25$ & $8 / 25$ & $4 / 21$ & $9 / 14$ & $0 / 15$ & $7 / 24$ & $2 / 15$ & $11 / 24$ & $25 / 25$ & $24 / 25$ \\
\hline Immunoblastic & $0 / 14$ & $3 / 14$ & $1 / 12$ & $3 / 7$ & $1 / 9$ & $4 / 14$ & $1 / 9$ & $7 / 14$ & $14 / 14$ & $13 / 13$ \\
\hline \multicolumn{11}{|l|}{ Kiel Classification } \\
\hline Low grade & $25 / 67$ & $32 / 67$ & $23 / 65$ & $25 / 29$ & $17 / 35$ & $10 / 68$ & $0 / 19$ & $12 / 68$ & $46 / 69$ & $55 / 69$ \\
\hline High grade & $1 / 42$ & $13 / 42$ & $5 / 36$ & $14 / 23$ & $1 / 24$ & $12 / 41$ & $3 / 25$ & $19 / 41$ & $42 / 42$ & $40 / 41$ \\
\hline \multicolumn{11}{|l|}{$W F$} \\
\hline Low grade & $14 / 48$ & $27 / 46$ & $21 / 45$ & $18 / 21$ & $15 / 25$ & $7 / 48$ & $0 / 18$ & $10 / 47$ & $33 / 48$ & $37 / 48$ \\
\hline Intermediate grade & $12 / 48$ & $15 / 49$ & $6 / 44$ & $18 / 24$ & $2 / 25$ & $11 / 47$ & $2 / 17$ & $14 / 48$ & $41 / 49$ & $45 / 49$ \\
\hline High grade & $0 / 14$ & $3 / 14$ & $1 / 12$ & $3 / 7$ & $1 / 9$ & $4 / 14$ & $1 / 9$ & $7 / 14$ & $14 / 14$ & $13 / 13$ \\
\hline
\end{tabular}

*Includes three follicular centroblastic lymphomas which were grouped as high grade tumours in Kiel.

associated with uncontrolled proliferation and aggressive clinical behaviour. The antigens in these two groups also showed variable expression in our initial immunophenotype analysis; strongly positive and weakly positive/negative subsets could readily be identified for comparison. The 'pan B cell' and MHC class II antigens were expressed by the large majority of lymphomas, and correlations between positive and negative subsets could not be made.

In our previous study, antigen expression was assessed in a semi-quantitative manner with strongly ( $>70$ per cent cells staining), moderately (30-70 per cent), and weakly ( $5-30$ per cent) positive or negative groups being identified. For statistical analysis in this study groups were separated into moderate to strongly positive $(>30$ per cent positive) and weakly positive/negative subsets $(<30$ per cent positive).

\section{Statistical analysis}

The non-parametric chi-square test was used. Survival data were analysed by the algorithm of Lee and Desu; ${ }^{40}$ multivariate regression analysis was done using the Cox proportional hazards regression model. $^{41}$

\section{RESULTS}

\section{Histology and clinical features}

A total of 111 cases were studied. The histological classification and clinical features are summarized in Table II.

The series included 64 males and 47 females, age range 15-88 (mean 59 years). The majority of cases showed disseminated disease at presentation (11 stage 1,10 stage II, 20 stage III, and 67 stage IV, three not staged). Sixty-three of 109 cases showed bone marrow involvement.

Cases were treated by a number of different therapeutic regimes. These have been grouped as simple or aggressive. Simple therapies were those not intended to induce remission and included radiotherapy and/or simple drug regimes (chlorambucil \pm prednisolone \pm vincristine). Aggressive therapy included drug regimes designed to achieve complete remission $(\mathrm{CHOP} \pm$ bleomycin, BACOD, MOPP, MVPP, CHIVPP M-PEEC, MCHOP \pm bleomycin). Forty-six cases were given simple therapy and 69 cases aggressive therapy. Kiel highgrade tumours were more often treated aggressively (35 of 42) than were low grade tumours (30 of 69). There was a strong correlation with type of therapy and induction of complete remission $(P<0.00001)$, 
Table IV-Median survival of cases when separated by clinical features and histological grade

\begin{tabular}{|c|c|c|c|}
\hline Clinical data & $\begin{array}{l}\text { No. } \\
\text { of } \\
\text { cases }\end{array}$ & $\begin{array}{r}\text { Median } \\
\text { survival } \\
\text { (months) }\end{array}$ & Significance \\
\hline \multicolumn{4}{|l|}{ Age } \\
\hline$<60$ years & 51 & $50 \cdot 3$ & $P<0.001$ \\
\hline$>60$ years & 60 & $17 \cdot 0$ & \\
\hline \multicolumn{4}{|l|}{ Stage } \\
\hline I & 11 & $50 \cdot 0+$ & $P<0.012$ \\
\hline II & 10 & $62 \cdot 0+$ & \\
\hline III & 20 & $12 \cdot 9$ & \\
\hline IV & 67 & $22 \cdot 8$ & \\
\hline \multicolumn{4}{|l|}{ Clinical } \\
\hline NR & 44 & $9 \cdot 0$ & $P<0.00001$ \\
\hline PR & 38 & $25 \cdot 1$ & \\
\hline CR & 28 & $62 \cdot 0+$ & \\
\hline \multicolumn{4}{|l|}{ Sex } \\
\hline Male & 64 & $30 \cdot 5$ & NS \\
\hline Female & 47 & $23 \cdot 3$ & \\
\hline \multicolumn{4}{|l|}{ Bone marrow } \\
\hline Negative & 63 & $33 \cdot 6$ & NS \\
\hline Positive & 46 & $23 \cdot 5$ & \\
\hline \multicolumn{4}{|l|}{ Histology } \\
\hline \multicolumn{4}{|l|}{ Kiel Classification } \\
\hline High grade & 42 & 14 & $P<<0.015$ \\
\hline Low grade & 69 & $31 \cdot 5$ & \\
\hline \multicolumn{4}{|l|}{ Working } \\
\hline \multicolumn{4}{|l|}{ Formulation } \\
\hline High grade & 14 & 6 & $P<0.0001$ \\
\hline Intermediate grade & 49 & $19 \cdot 7$ & \\
\hline Low grade & 48 & $69+$ & \\
\hline
\end{tabular}

$\mathrm{NS}=$ Not significant; $\mathrm{NR}=$ no remission $; \mathrm{PR}=$ partial remission; $\mathrm{CR}=$ complete remission.

but none between grade of lymphoma and induction of remission.

\section{Immunophenotype analysis}

The results of immunophenotyping are summarized in Table III. More detailed analysis of these cases has been published previously. ${ }^{3}$ Low grade lymphomas expressed CD5 $(P<0 \cdot 0001)$, CD10 $(P<0.05)$, and CD23 $(P<0.001)$ significantly more often than high grade tumours. CD38 $(P<0.01)$, transferrin receptor $(P<0.0001)$, and $4 \mathrm{~F} 2(P<0.05)$ were more frequently expressed by high grade lesions.
There was no association between antigen expression and clinical findings including stage, bone marrow involvement, or response to therapy.

\section{Survival analysis}

The results are summarized in Tables IV and V.

(a) Clinical data-A number of clinical parameters were associated with better survival (Table IV). These included age less than $60(P<0.001)$, stage at presentation $(P<0.03)$, and response to therapy $(P<0.00001)$. There was no association between survival and sex or bone marrow involvement.

(b) Histology-Histological grading showed significant correlation with survival (Table IV) for both Kiel Classification $(P<0.015)$ (Fig. 1) and WF (overall $P<0.0001$; low vs. intermediate $P<0.002$; low vs. high $P<0.0001$; intermediate vs. high $P<0.025)$ (Fig. 2).

(c) Immunophenotype-Survival was correlated with expression of individual markers for (i) all cases; (ii) cases within histological grades, WF and $\mathrm{Kiel}$; and (iii) cases given aggressive therapy. The results are summarized in Table V. There were significant associations between expression of $4 \mathrm{~F} 2$ $(P<0.01)$ (Fig. 4) and transferrin receptor (TrfR) $(P<0.015)$ (Fig. 3) and survival with all cases included. Expression of $4 \mathrm{~F} 2$ by low grade tumours was associated with a shortened survival in Kiel $(P<0 \cdot 05)$, whereas Trf-R expression and survival in low grade lymphomas reached significant levels with WF $(P<0.05)$ only. As almost all high grade lymphomas expressed 4F2 and Trf-R, it was not possible to undertake separate analysis of this group. There was no significant association with survival and the other antigens studied before or after histological grading. There was no association between survival and antigen expression in the group of NHLs given 'aggressive' therapy.

(d) Multivariate analysis-The association between both $4 \mathrm{~F} 2$ and Trf-R and survival was independant of age, Kiel Classification, and stage $(P<0 \cdot 05)$, but not WF. When 4F2 and Trf-R were included together Trf-R was not independent of $4 \mathrm{~F} 2$ as a prognostic marker.

\section{DISCUSSION}

A large number of antibodies are available for immunophenotyping lympho-proliferative lesions. 


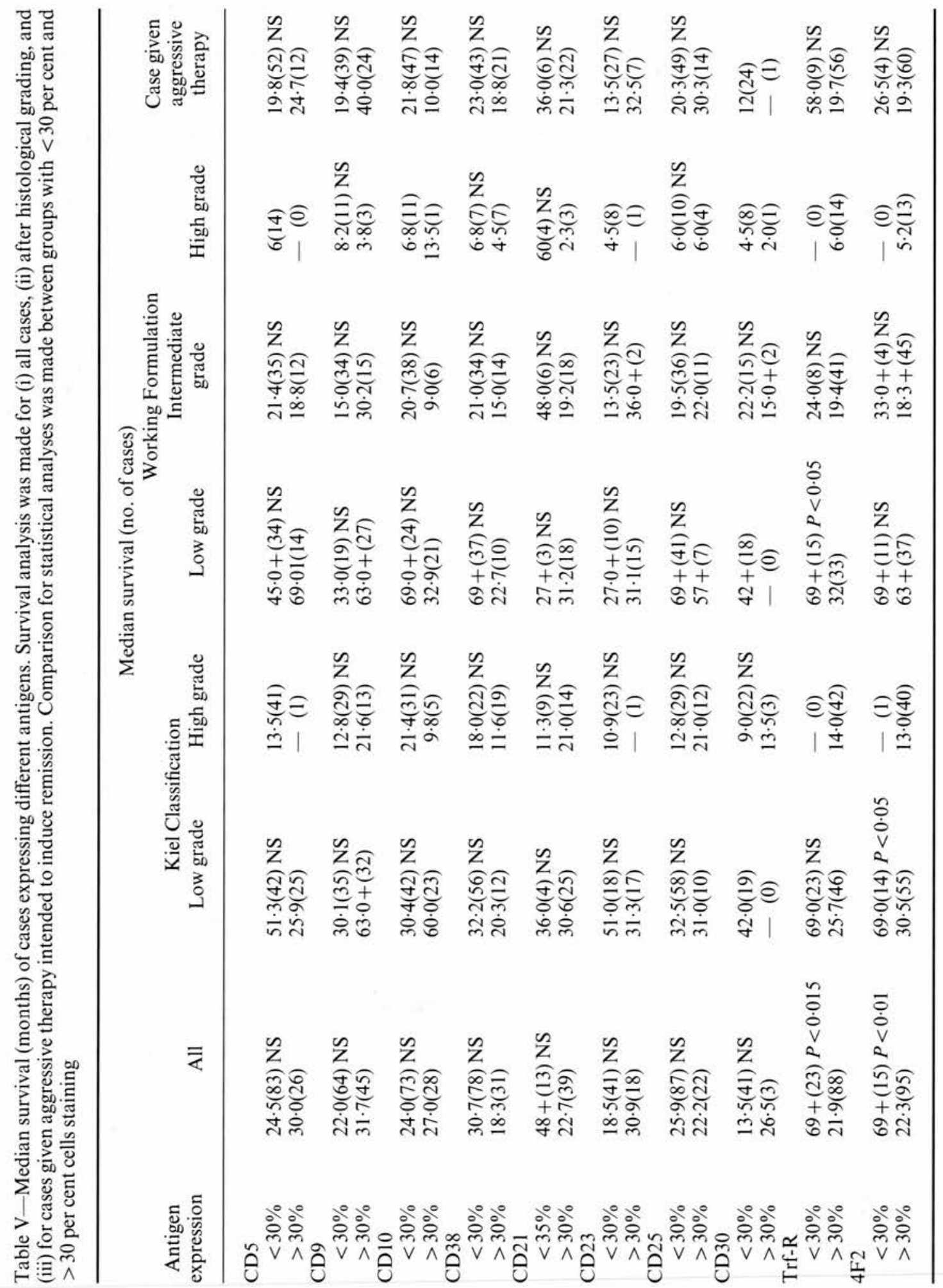




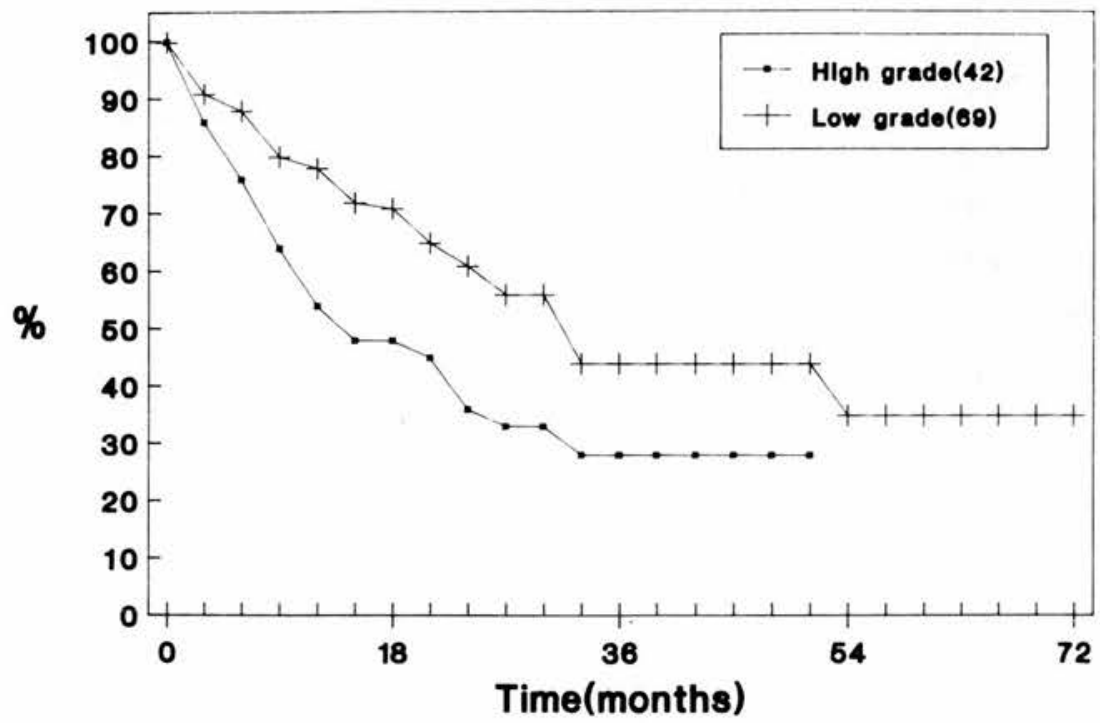

Fig. 1-Survival of cases of B-cell NHL grouped by Kiel Classification $(P<0.015)$

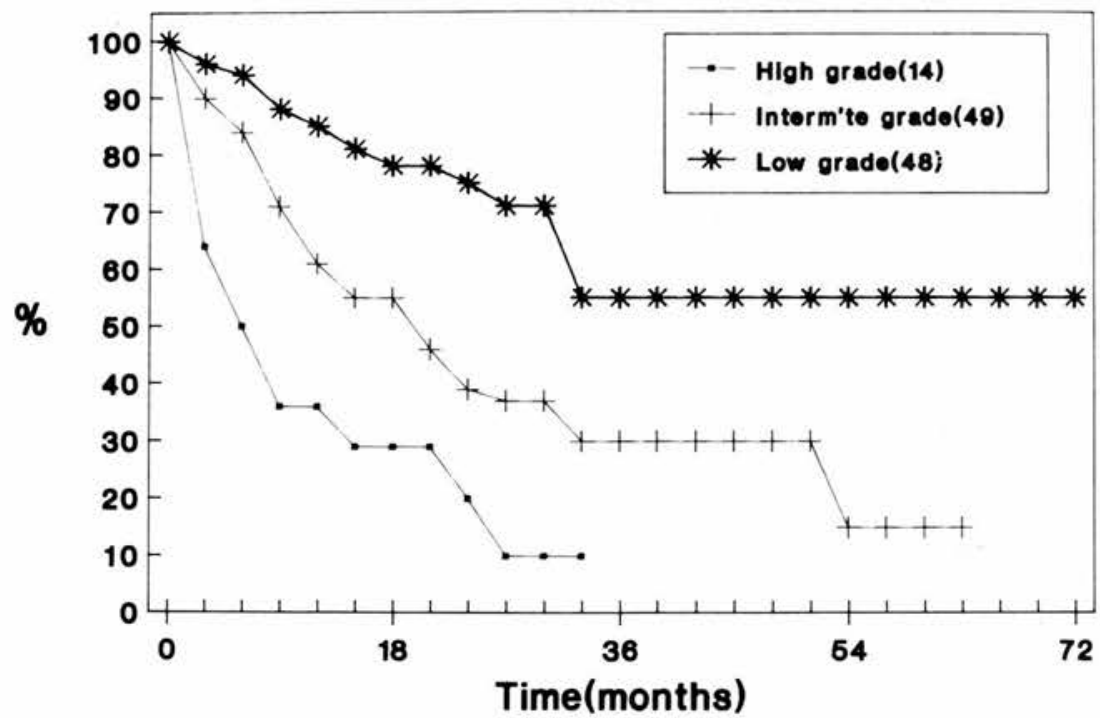

Fig. 2-Survival of cases of B-cell NHL grouped by Working Formulation (overall $P<0.0001$, HG vs. IG $P<0.025$, HG vs. LG $P<0.0001$, IG vs. LG $P<0.002$ )

Immunophenotyping is useful in clinical practice for distinguishing between lymphoid and nonlymphoid neoplasms, and reactive and neoplastic lymphoid proliferation, and for determining Tor B-cell lineage of NHL. When a large panel of antibodies is used for phenotyping B-cell NHL, relatively few consistent features of antigen expression are seen; e.g., CD5 is expressed by lymphocytic and centrocytic NHL and rarely by other B-cell tumours. $^{3,5}$ Phenotypic heterogeneity of histologically similar lymphomas suggests that extensive immunophenotyping is not of primary benefit in the classification of these lesions, and it is now our practice to limit the immunophenotyping undertaken for diagnostic purposes. ${ }^{3}$

Previous studies have shown a correlation with antigen expression and clinical behaviour. 4F2, which recognizes a disulphide-linked glycoprotein 


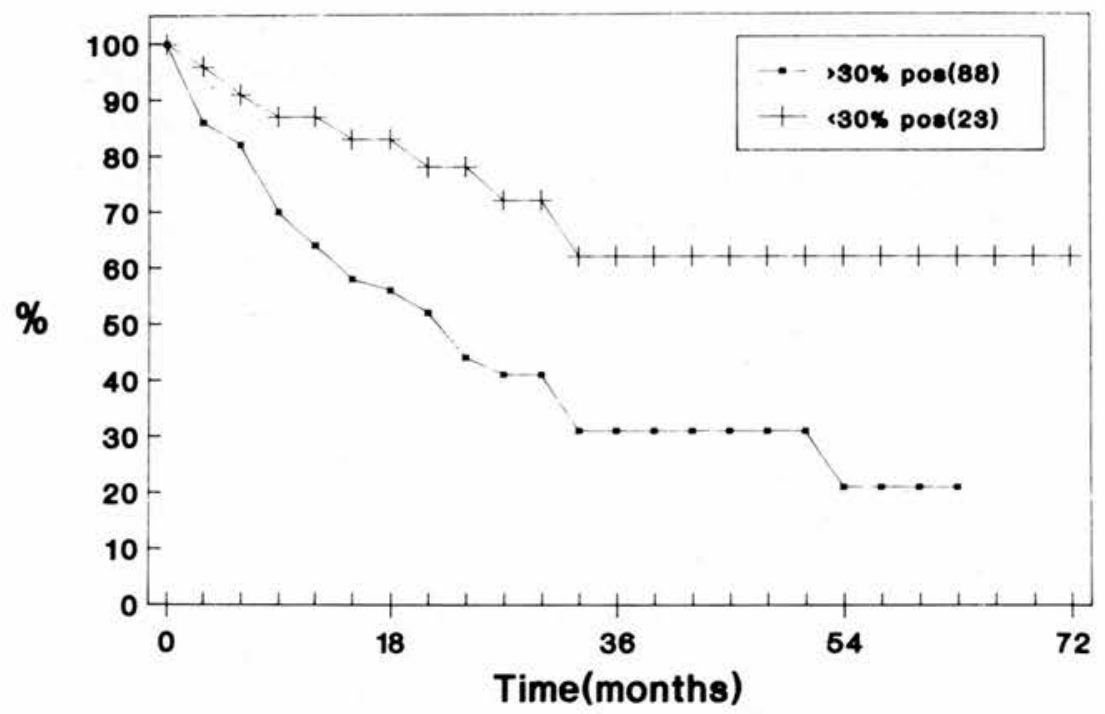

Fig. 3-Survival of cases of B-cell NHL grouped by expression of transferrin receptor $(P<0.015)$

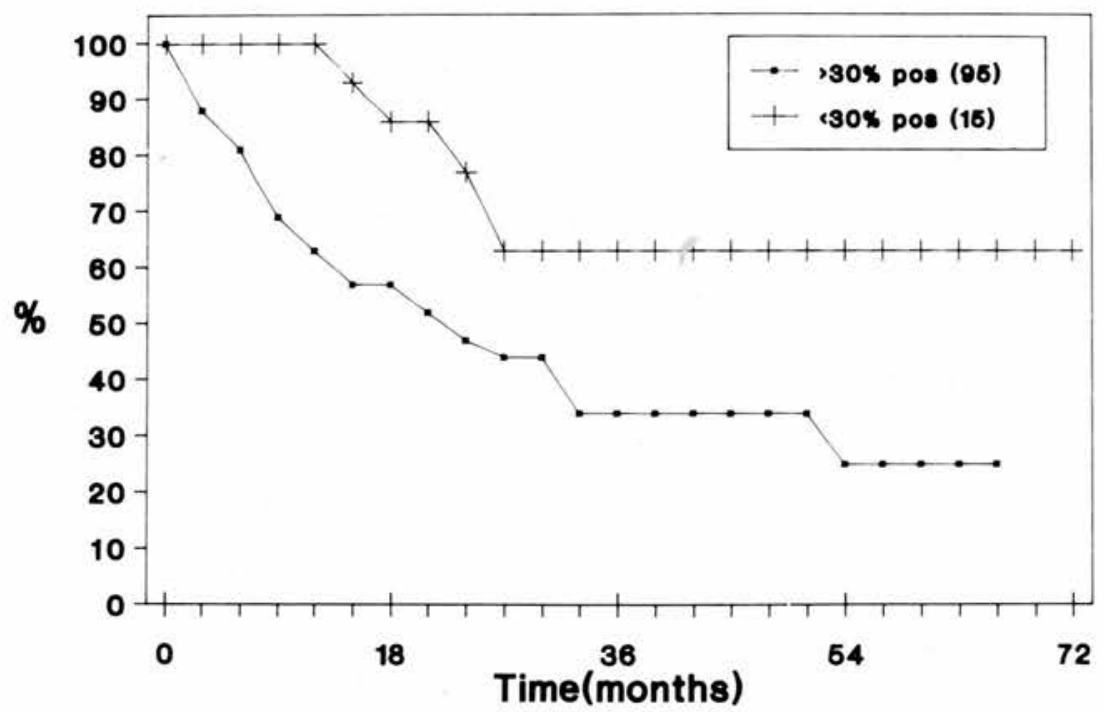

Fig. 4-Survival of cases of B-cell NHL grouped by expression of 4F2 $(P<0.01)$

of unknown function expressed from early Gl on proliferating lymphoid cells, ${ }^{42}$ and transferrin receptor expression is associated with poor prognosis in NHL. ${ }^{6,72}$ Our investigations confirm that strong transferrin receptor and $4 \mathrm{~F} 2$ antigen expression is associated with poorer prognosis ${ }^{43}$ but we could find no association with survival and expression of other activation and differentiation associated antigens studied. Both $4 \mathrm{~F} 2$ antigen and transferrin receptor are expressed more frequently by histologically high-grade tumours whose overall prognosis is known to be poor. Expression of these antigens can therefore in part be predicted by histology, but multivariate analysis shows that the association with survival is independent of age, stage, and Kiel histological grade. Expression of 4F2 antigen was associated with poorer survival of patients with low grade tumours in the Kiel Classification, whereas expression of Trf-R was associated with a worse prognosis with WF low-grade tumours. 
These markers may therefore be useful for predicting clinically poor prognostic cases in low grade lymphomas.

Other membrane associated antigens have been shown to have prognostic significance. CD10 myelomas behave aggressively, ${ }^{44}$ but in our series of B-NHLs there was no significant correlation between expression of this antigen and survival. This is probably partly because of the large number of low-grade follicular lymphomas we see expressing CD10 and the few cases of lymphoblastic lymphoma (often CD10-positive ${ }^{45}$ ) in our series.

CD23 expression has been associated with prolonged relapse-free survival in NHL. ${ }^{9}$ This is not unexpected as it is expressed predominantly by low grade lesions; however, we were unable to confirm an association between CD23 and survival. Schuurman et al. ${ }^{9}$ correlated the expression of a panel of markers similar to that used here (including CD groups $9,10,21,23,25$, and transferrin receptor) with relapse-free survival in cases of NHL given therapy intended to achieve complete remission. This form of treatment was given to only 65 of our cases. When these were analysed separately, we were still unable to show an association between survival and CD23 expression or other markers. This may in part be a reflection of the larger proportion of low grade lymphomas given aggressive therapy in the study of Schuurman et al. ${ }^{9}$

While immunophenotyping of NHL has allowed greater understanding of the biology of this group of neoplasms and is an invaluable research tool, the clinical application and usefulness of many of the antibodies used for phenotyping lymphoid cells are in doubt. A limited panel of antibodies which aids identification of lymphoid neoplasms and helps ascertain lineage of these tumours is probably all that is necessary for routine clinical use at present. New markers need to be developed which will differentiate between good and poor prognosis cases in histological grades, allowing the pathologist to make more accurate predications of behaviour of NHL. Our results suggest that 4F2 and Trf-R may identify poor prognostic cases of histologically lowgrade NHL. Immunostaining for the proliferation marker Ki 67 may allow similar discrimination. ${ }^{46}$ The number of different chemotherapeutic regimes given to a series of NHLs in a retrospective study such as this creates some problems in assessment of associations between phenotype and clinical behaviour but when potentially useful markers such as $4 \mathrm{~F} 2$, TrF-R and $\mathrm{Ki} 67$ have been identified it may be appropriate for immunophenotype as well as histological grade to be taken into consideration in prospective trials of the efficacy of different treatment modalities.

\section{ACKNOWLEDGEMENTS}

We are grateful to the Consultant Haematologists and Clinical Oncologists of Lothian, Fife, and Borders for allowing access to the notes of cases studied and Miss Celia MacIntyre of the Medical Statistics Unit of Edinburgh University for help with the multivariate analysis. We thank Miss Seona Macintosh for typing the manuscript. This work was in part funded by a grant from the Melville Trust.

\section{REFERENCES}

1. Lennert K. Malignant Lymphomas other than Hodgkin's Disease. Berlin: Springer, 1978.

2. Rosenberg SA. (Chairman). National Cancer Institute sponsored study of classifications of non-Hodgkin's lymphomas: summary and description of a working formulation for clinical usage. Cancer 1982; 49: $2112-2135$.

3. Salter DM, Krajewski AS, Cunningham S. Activation and differentiation antigen expression in B-cell non-Hodgkin's lymphoma. $J$ Pathol 1988; 154: 209-222.

4. Krajewski AS, Myskow M, Cachia P, Salter DM, Sheehan T, Dewar AE. T-cell lymphoma: morphology, immunophenotype and clinical features. Histopathology 1988; 13: 19-41.

5. Schuurman HJ, Van Baarlen J, Huppes W, Lam BW, Verdonck LF, Van Unnik JAM. Immunophenotyping of non-Hodgkin's lymphoma: lack of correlation between immunophenotype and cell morphology. Am J Pathol 1987; 129: 140-151.

6. Habeshaw JA, Lister TA, Stansfeld AG, Greaves MF. Correlation of transferrin receptor expression with histological class and outcome in non-Hodgkin's lymphoma. Lancet 1983; i: 498-501.

7. Holte H, Davies CDL, Kvaloy S, et al. The activation antigen $4 \mathrm{~F} 2$ predicts patient survival in low grade B-cell lymphomas. Int J Cancer 1987; 39: 590-594.

8. Shepherd NA, Hall PA, Coates PJ, Levison DA. Primary colorectal lymphoma: a histopathological and immunohistochemical study with clinical correlation. Histopathology 1988; 12: 235-252.

9. Schuurman HJ, Huppes W, Verdonck LF, Baarlen JV, Van Unnik JAM. Immunophenotyping of non-Hodgkin's lymphoma: correlation with relapse-free survival. Am J Pathol 1988; 131: 102-111.

10. Salter DM, Krajewski AS, Dewar AE. Immunohistochemical staining of non-Hodgkin's lymphoma with monoclonal antibodies specific for the leucocyte common antigen. J Pathol 1985; 146: 345-353.

11. Mason DY, Ladyman H, Gatter KC. Immunohistochemical analysis of monoclonal anti-B cell antibodies. In: Reinherz EL, Haynes BF, Nadler LM, Bernstein ID, eds. Leucocyte Typing II. Vol 2. Human B Lymphocytes. New York: Springer, 1986; 245.

12. Nadler LM, Stashenko P, Ritz J, Hardy R, Pesando JM, Schlossman SF. A unique cell surface antigen identifying lymphoid malignancies of B cell origin. J Clin Invest 1981; 67: 134-140.

13. Stein H, Gerdes J, Mason DY. The normal and malignant germinal center. Clin Hematol 1982; 11: 531-559.

14. Dalchau R, Fabre JW. Identification with a monoclonal antibody of a predominantly B lymphocyte specific determinant of the human leucocyte common antigen. J Exp Med 1981; 153: 755-765.

15. Royston J, Jarida JA, Baird SM. Human T-cell antigens defined by monoclonal antibodies to the 65000 dalton antigen of T-cells (T65) is also found on chronic lymphocytic leukemia cells bearing surface immunoglobulin. J Immunol 1980; 125: 725-731.

16. Brooks DA, Bradley J, Zola H. A differentiation antigen expressed selectively by a proportion of human blood cells, detection with a monoclonal antibody. Pathology 1982; 14: 5-11. 
17. Newman RA, Sutherland R, Greaves MF. The biochemical characterisation of a cell surface antigen associated with acute lymphoblastic leukemia and lymphocyte precursors. J Immunol 1981; 126: 2024 2030.

18. Anderson KC, Park ER, Batese MP, et al. Antigens on plasma cells identified by monoclonal antibodies. J Immunol 1983; 130: 1132-1138.

19. Boyd AW, Anderson KC, Freedman AS, et al. Studies of in vitro activation of human B lymphocytes. I. Phenotypic and functional characterisation of the B-cell population responding to anti-Ig antibody. J Immunol 1985; 134: 1516-1523.

20. Rowe M, Hildreth JEK, Rickman AB, Epstein MA. Monoclonal antibodies to Epstein-Barr virus-induced transformation-associated cell surface antigens. Binding patterns and effects upon virus specific T-cell cytotoxicity. Int J Cancer 1982; 15: 373-381.

21. Uchiyama $T$, Broder $S$, Waldmann TA. A monoclonal antibody (anti-Tac) reactive with activated and functionally mature human $\mathrm{T}$ cells. I. Production of anti-Tac monoclonal antibody and destination of Tac (+) cells. J Immunol 1981; 126: 1393-1397.

22. Schwab U, Stein H, Gerdes J, et al. Production of a monoclonal antibody specific for Hodgkin and Sternberg-Reed cells of Hodgkin's disease and a subset of normal lymphoid cells. Nature 1982; 299: 65-67.

23. Trowbridge IS, Omery MB. Human cell surface glycoprotein related to cell proliferation is the receptor for transferrin. Proc Natl Acad Sci USA 1981: 78: 3039-3043.

24. Haynes BF, Hemler ME, Mann DL, et al. Characterisation of a monoclonal antibody (4F2) that binds to human monocytes and to a subset of activated lymphocytes. J Immunol 1981; 126; 1409-1414.

25. Lampour LA, Levy R. Two populations of Ia-like molecules on a human B-cell line. J Immunol 1980; 125: 293-299.

26. Watson AJ, Demars R, Trowbridge IS, Bach FH. Detection of a novel class II antigen. Nature 1983; 304: 358-361.

27. Brodsky FM. A mature approach to human class II histocompatability antigens: reaction of four monoclonal antibodies with the products of nine haplotypes. Immunogenetics 1984; 19: 179-184.

28. Pawelec OP, Shaw S, Ziegler, A, Muller C, Wernet P. Differential inhibition of HLA-D- or SB-directed secondary lymphoproliferative responses with monoclonal antibodies detecting human Ia-like determinants. J Immunol 1982; 129: 1070-1075.

29. Bhan AK, Nadler LM, Stashenko P, McCluskey RT, Schlossman SF Stages of B-cell differentiation in human lymphoid tissue. J Exp Med 1981; 154: 737-749.

30. Campana D, Janossy G, Bofill M, et al. Human B-cell development. I. Phenotypic differences in B lymphocyte in the bone marrow and peripheral lymphoid tissue. $J$ Immunol 1985; 134: 1524-1529.

31. Waldmann TA, Goldman CK, Robb RJ, et al. Expression of interleukin-2 receptors on activated human B-cells. J Exp Med 1984; 160: 1450.-1466.
32. Stein M, Mason DY, Gerdes J, et al. The expression of the Hodgkin's disease associated antigen $\mathrm{Kil}$ in the reactive and neoplastic lymphoid tissue. Evidence that Reed-Sternberg cells and histiocytic malignancies are derived from activated lymphoid cells. Blood 1985; 66: 848-858.

33. Tedder TF, Clement LT, Cooper MD. Expression of C3d receptors during human B-cell differentiation: immunofluoresence analysis with the HB-5 monoclonal antibody. J Immunol 1984; 133: 678-683.

34. Stashenko P, Nadler LM, Hardy R, Schlossman SF. Expression of cell surface markers after human B-cell activation. Proc Natl Acad Sci USA 1981; 78: 3848-3852.

35. Dorkan B, Moblenhauer G, Pezzuho A, et al. HD39 (B3) a B lineagerestricted antigen whose cell surface expression is limited to resting and activated human B lymphocytes. J Immunol 1985; 136: 44704479 .

36. Thorley-Lawson DA, Nadler LM, Bhan AK, Schooley RT. B-LAST2 (EBVCS), an early cell surface marker of human B-cell activation is super-induced by Epstein-Barr virus. J Immunol 1985; 134: 3007 3012 .

37. Walker L, Guy G, Brown G, Rowe M, Milner AE, Gordon GJ. Control of human B lymphocyte replication. I. Characterisation of novel activation states that precede entry of GO B-cells into cycle. Immunology 1986; 58: 583-590.

38. Gordon J, Webbs AJ, Walker L. Evidence for an association between CD23 and the receptor for a low molecular weight B cell growth factor. Eur J Immunol 1986; 16: 1627-1630.

39. Jung LKL, Hara T, Fu SM. Detection and functional studies of p60-65 (Tac antigen) on activated human B-cells. J Exp Med 1984; 160: $1597-1602$.

40. Lee E, Desu M. A computer program for comparing $\mathrm{K}$ samples with right-censored data. Computer. Programs Biomed 2: 315-321.

41. Cox DR. Regression models and life tables (with discussion) J R Stat Soc B 1972; 34: 187-220.

42. Kehrl J, Muraguchi A, Fauchi AS. Differential expression of cell activation markers after stimulation of resting B lymphocytes. $J$ Immunol 1984; 132: 2857-2861.

43. Pileri S, Gobbie M, Rivano MT, Martinelli G. Immunohistological study of transferrin receptor expression in non-Hodgkin's lymphoma. Br J Haematol 1984; 58: 501-508.

44. Durie BGM, Grogan TM. Calla-positive myeloma: an aggressive subtype with poor survival. Blood 1985; 66: 229-232.

45. Ritz J, Nadler LM, Bhan AK, Notis-McConarty J, Pesando JM, Schlossman SF. Expression of common acute lymphoblastic leukemia antigen (CALLA) by lymphomas of B cell and T cell lineage. Blood 1981; 58: 648-652

46. Hall PA, Richards MA, Gregory WM, D'Ardenne AJ, Lister TA, Stansfeld AG. The prognostic value of $\mathrm{Ki} 67$ immunostaining in nonHodgkin's lymphoma. J Pathol 1988; 154: 223-236. 